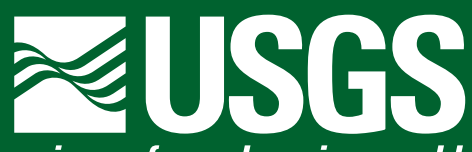

science for a changing world

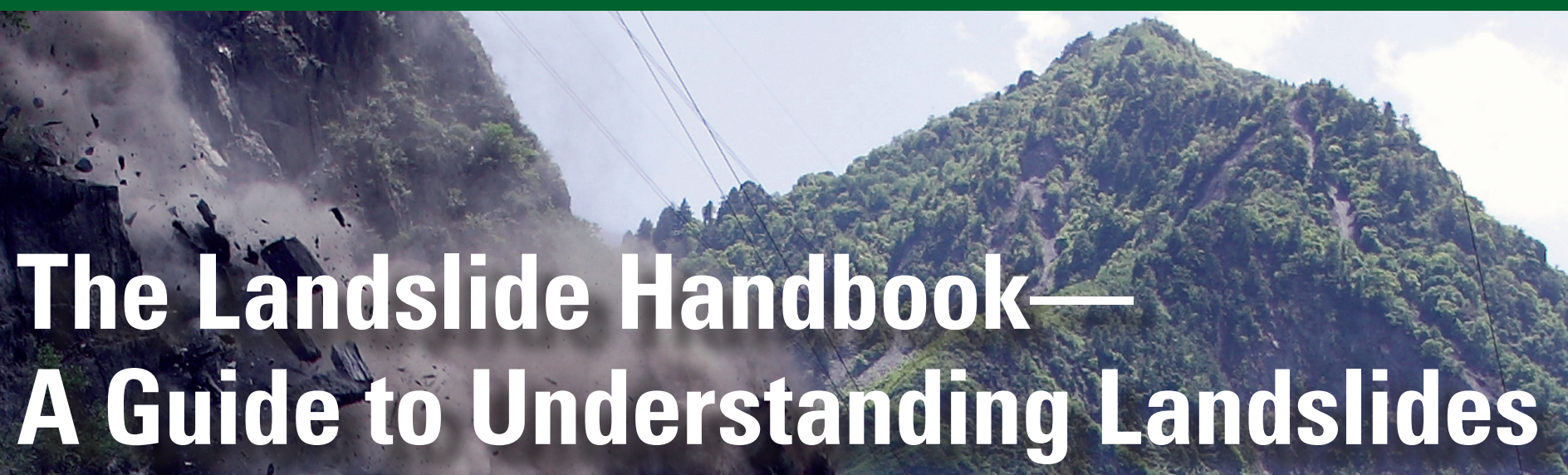

(8)

at 1

trit

w.

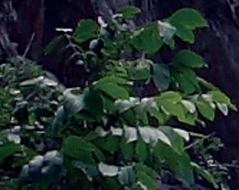

5

a 50

(4)

andys

$1+20$

Circular 1325
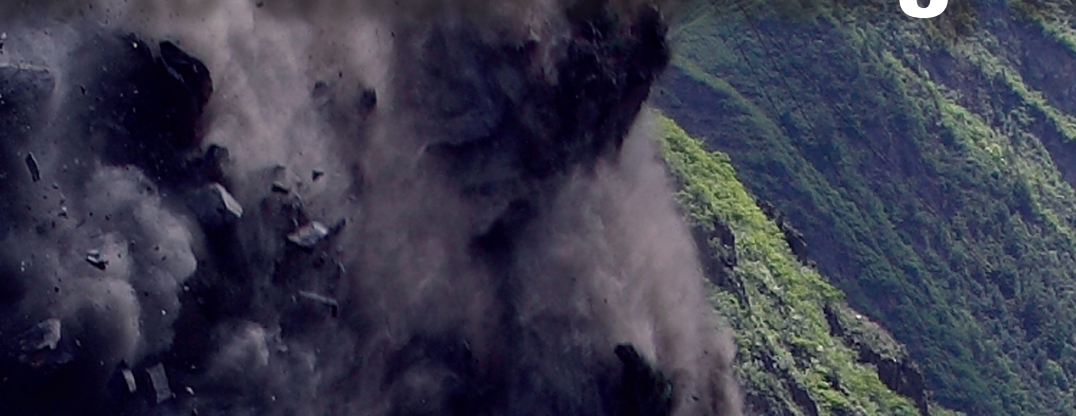

U.S. Department of the interior
U.S. Geological Survey -

\title{
$2)$
}


Cover: The threat of landslides like this have made the long drive to Wenchuan a risky affair for rescuers and aid delivery teams as they tried to reach the epicenter of the Wenchuan, China, earthquake of May 12, 2008. This photograph shows a landslide that sealed the entrance and exit to Wenchuan on May 23, 2008. (Photograph by Chua Chin Hon, Straits Times, Singapore.) 


\section{The Landslide Handbook - A Guide to Understanding Landslides}

By Lynn M. Highland, United States Geological Survey, and

Peter Bobrowsky, Geological Survey of Canada

Circular 1325 


\section{U.S. Department of the Interior DIRK KEMPTHORNE, Secretary}

\section{U.S. Geological Survey \\ Mark D. Myers, Director}

\section{U.S. Geological Survey, Reston, Virginia: 2008}

For product and ordering information:

World Wide Web: http://www.usgs.gov/pubprod

Telephone: 1-888-ASK-USGS

For more information on the USGS--the Federal source for science about the Earth, its natural and living resources, natural hazards, and the environment:

World Wide Web: http://www.usgs.gov

Telephone: 1-888-ASK-USGS

Any use of trade, product, or firm names is for descriptive purposes only and does not imply endorsement by the U.S. Government.

Although this report is in the public domain, permission must be secured from the individual copyright owners to reproduce any copyrighted materials contained within this report.

Suggested citation:

Highland, L.M., and Bobrowsky, Peter, 2008, The landslide handbook-A guide to understanding landslides: Reston, Virginia, U.S. Geological Survey Circular 1325, 129 p. 


\section{Acknowledgments}

The authors thank the International Consortium on Landslides for sponsoring this project and the many reviewers who spent much of their time and effort on the careful review of this book. Thanks also to those who gave permission to use their previously published text, photographs and graphics and to those authors of landslide research and information whose painstaking work was crucial to its completion. We thank the Geological Survey of Canada, and especially Jan Aylsworth for her valuable review and suggestions. In addition, we acknowledge the U.S. Geological Survey, especially Paula Gori who supported the entire handbook process and provided advice and encouragement. This is Geological Survey of Canada Contribution Number 20080377. 


\section{Contents}

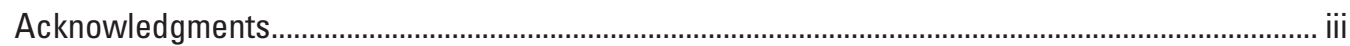

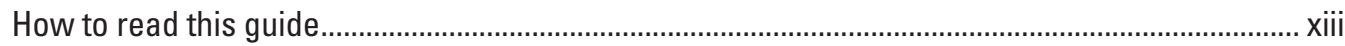

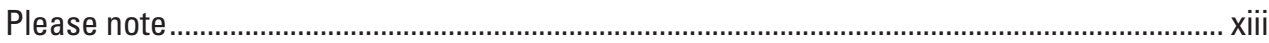

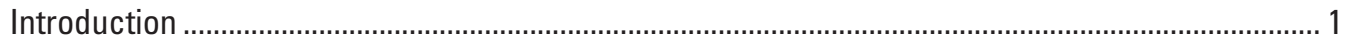

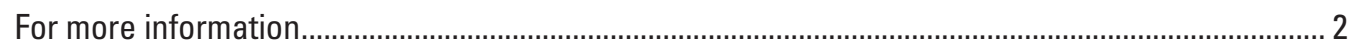

Section I. Basic Information About Landslides.................................................................... 3

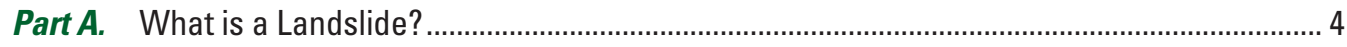

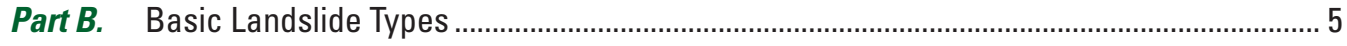

Falls

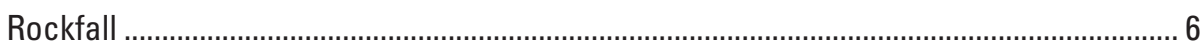

Occurrence and relative size/range..................................................................... 6

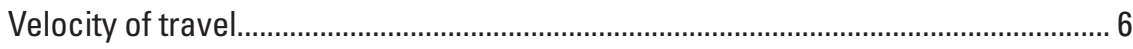

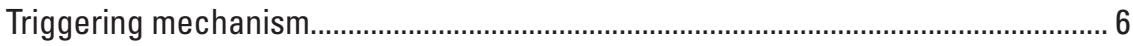

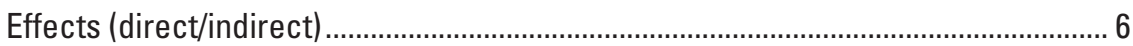

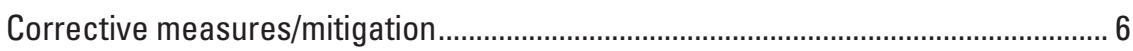

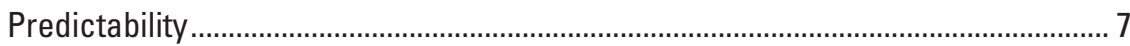

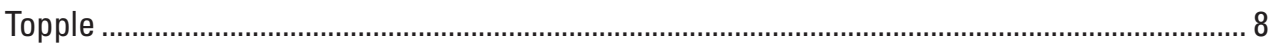

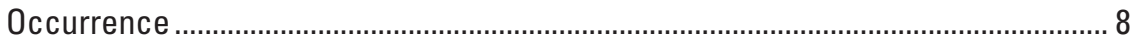

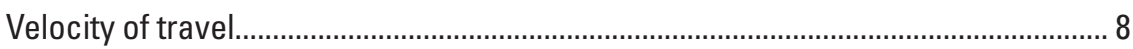

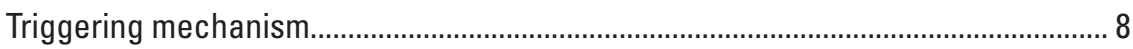

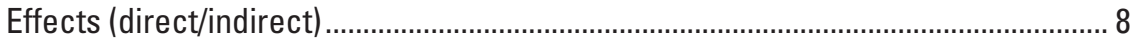

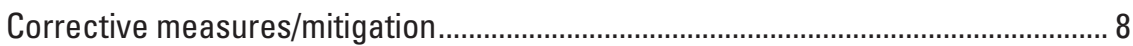

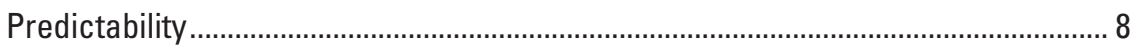

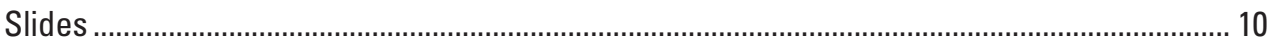

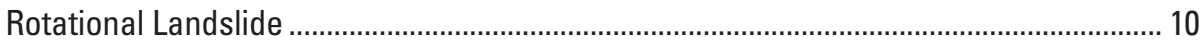

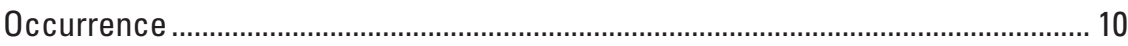

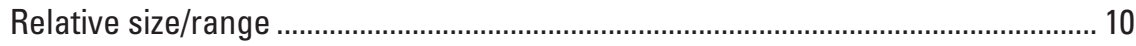

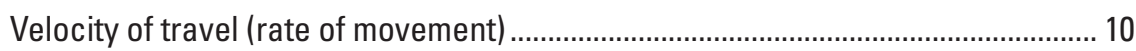

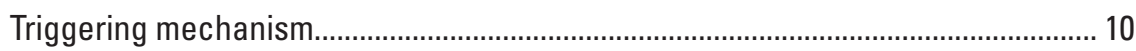

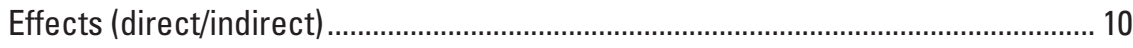

Mitigation measures ........................................................................................... 10

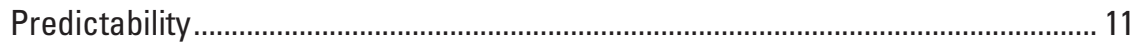

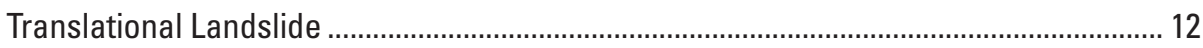

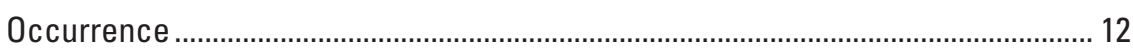

Relative size/range ......................................................................................... 12

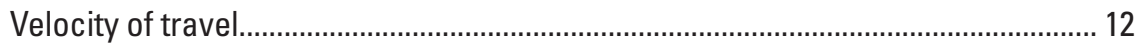

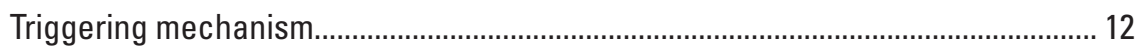

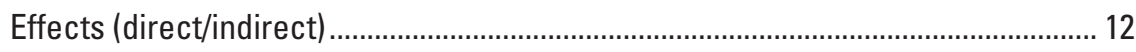

Mitigation measures ....................................................................................... 12

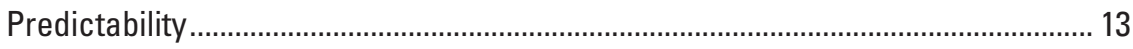

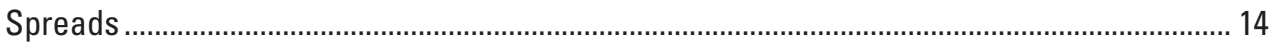

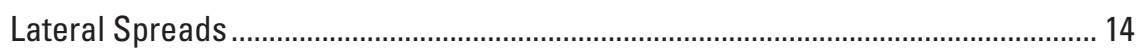

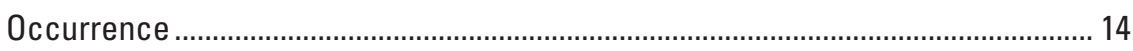

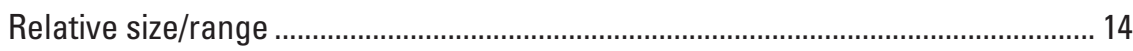




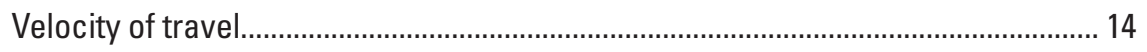

Triggering mechanism...................................................................................... 14

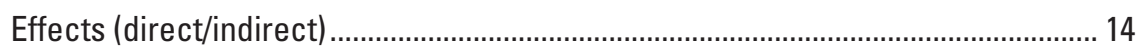

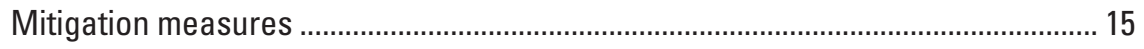

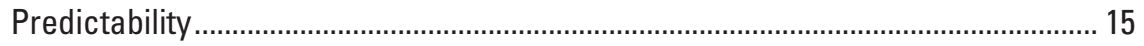

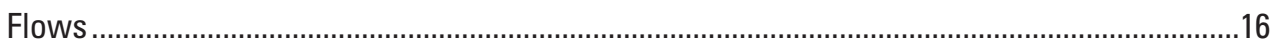

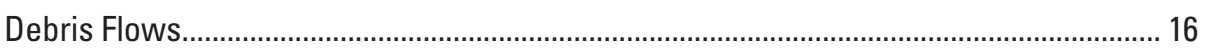

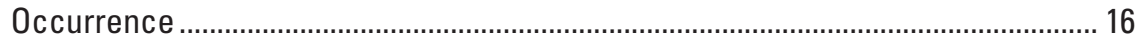

Relative size/range ............................................................................................. 16

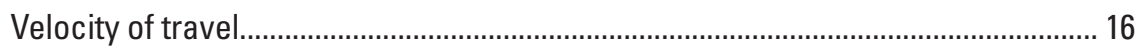

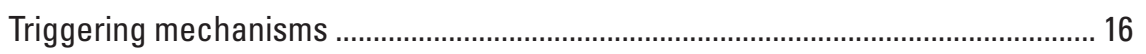

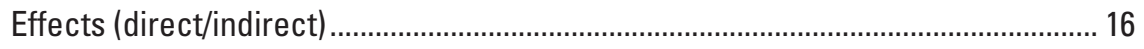

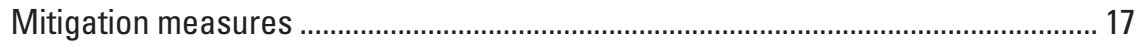

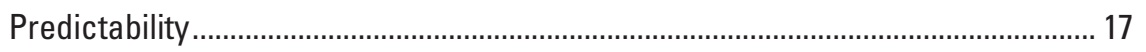

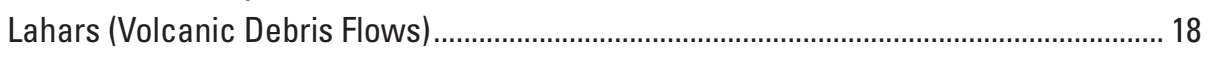

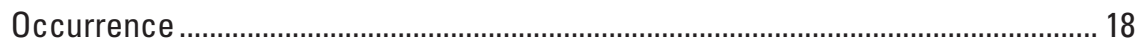

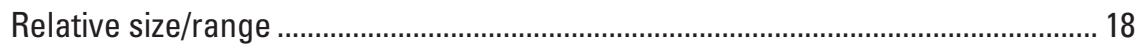

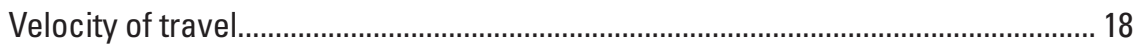

Triggering mechanism....................................................................................... 18

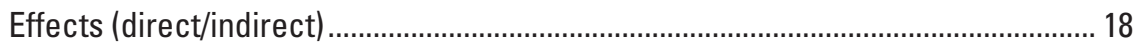

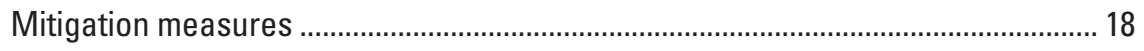

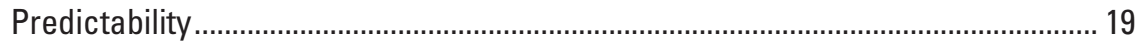

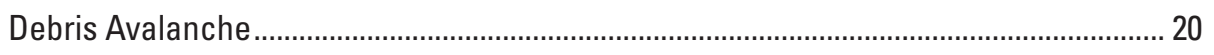

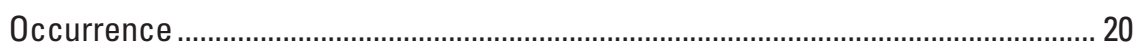

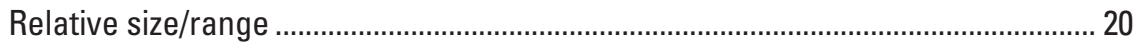

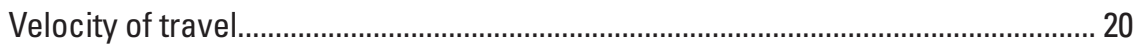

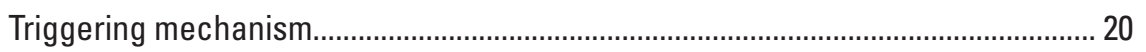

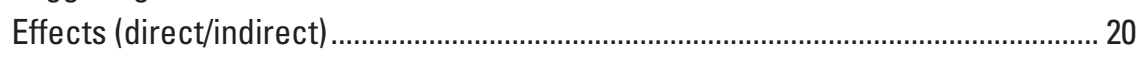

Corrective measures/mitigation........................................................................ 20

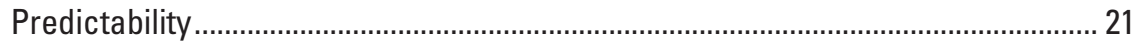

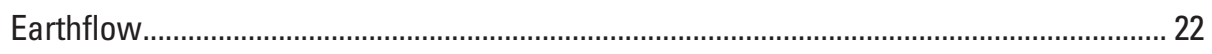

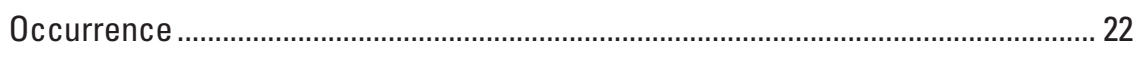

Relative (size/range) ....................................................................................... 22

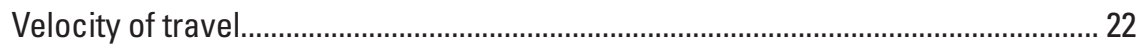

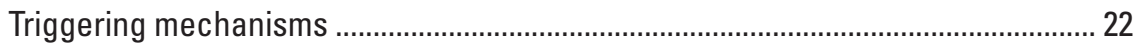

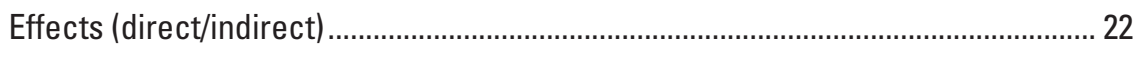

Corrective measures/mitigation.......................................................................... 22

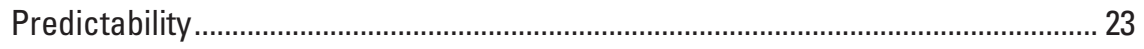

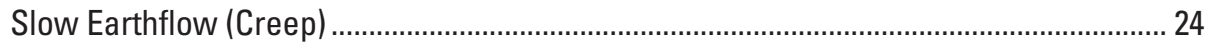

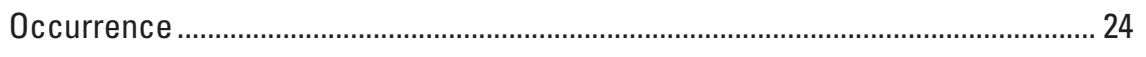

Relative size/range ........................................................................................... 24

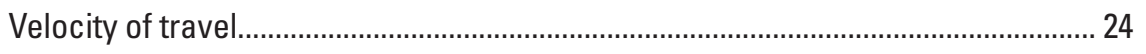

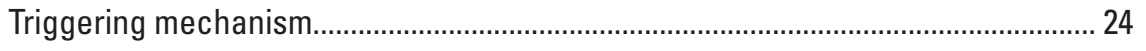

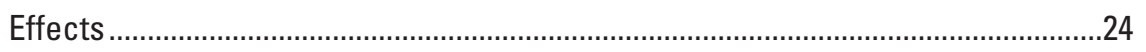

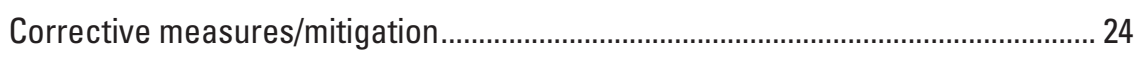

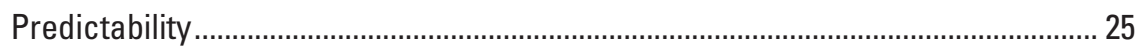




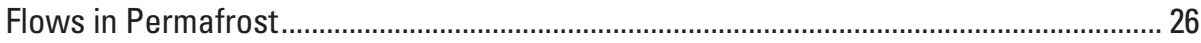

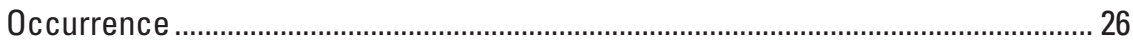

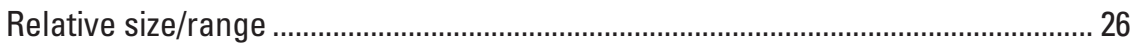

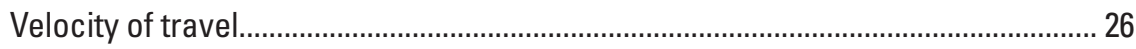

Triggering mechanisms .................................................................................... 26

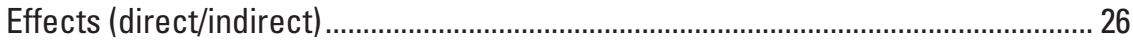

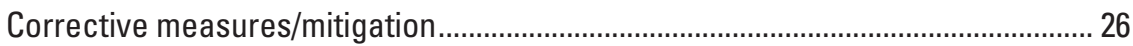

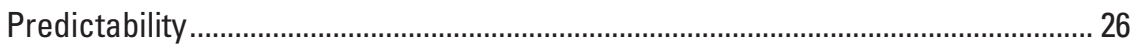

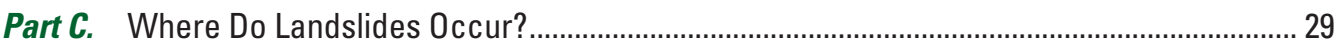

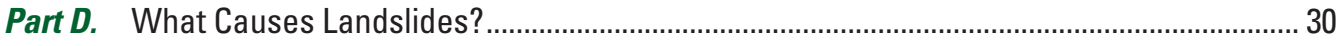

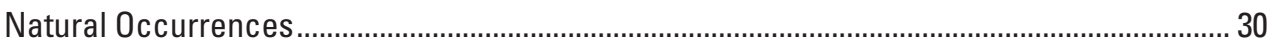

Landslides and Water............................................................................................... 30

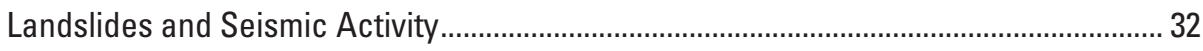

Landslides and Volcanic Activity .................................................................................. 33

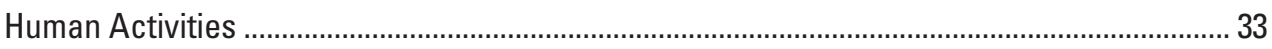

Part $\boldsymbol{E}$. What are the Effects and Consequences of Landslides? ................................................... 34

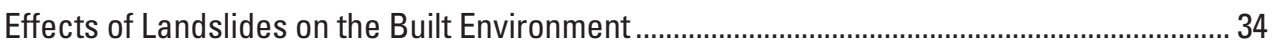

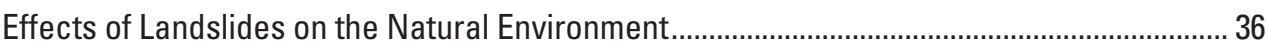

Part F. Interrelationship of Landslides with Other Natural Hazards-

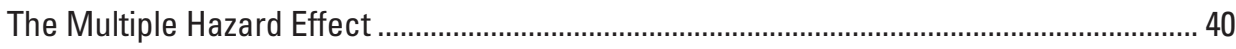

Section II. Evaluating and Communicating Landslide Hazard ....................................................... 43

Part A. Evaluating Landslide Hazards ..................................................................................... 44

Observation and (or) inspection by local experts and (or) municipal officials,

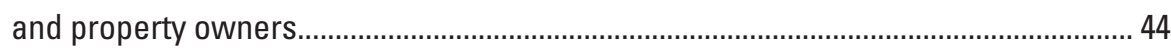

Features that might indicate landslide movement............................................................ 44

Technological Tools for Evaluation of Landslides-Mapping, Remote Sensing, and Monitoring.......................................................................................................... 46

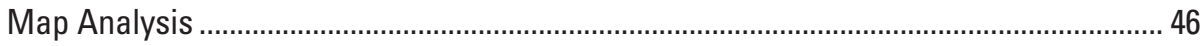

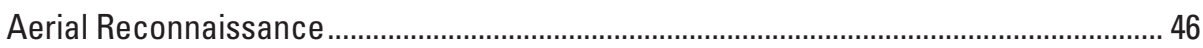

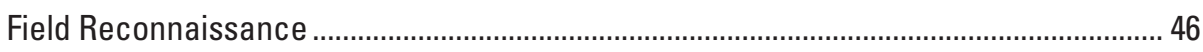

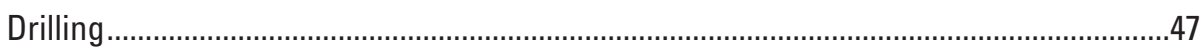

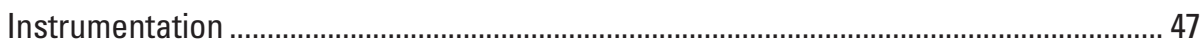

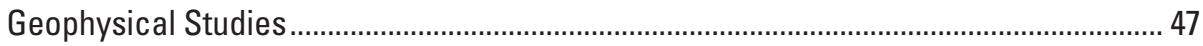

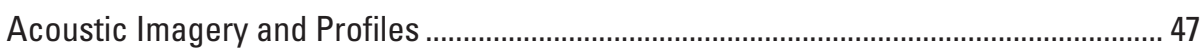

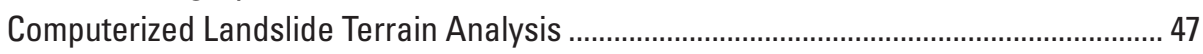

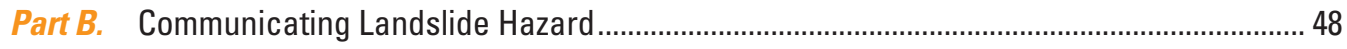

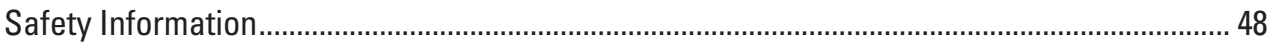

Building and Construction Information .................................................................................... 48

Suggested Local Government Outreach for Landslide Hazard .................................................. 49

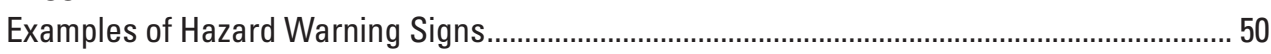

Section III. Mitigation Concepts and Approaches ………………………………................ 51

Part A. Overview of Mitigation Methods for Various Types of Landslide Hazards........................ 52

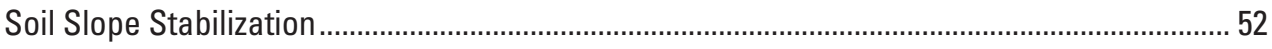

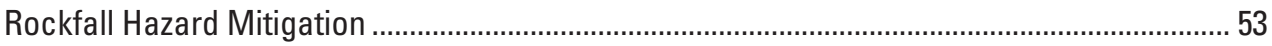

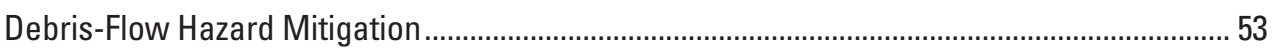

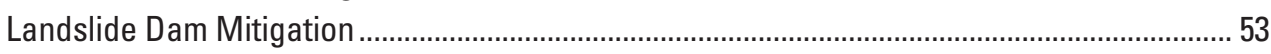

Methods of Biotechnical Landslide Mitigation........................................................................ 55 
Part B. Simple Mitigation Techniques for Home and Businesses, Managers, and Citizens ........ 56

Part C. List of Works Consulted/Cited/Quoted and for Further Reading ....................................... 57

Appendix A. Basic Information about Landslides ................................................................... 59

Part 1. Glossary of Landslide Terms …………………….................................................... 60

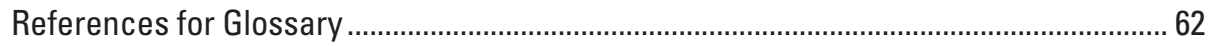

Sources of information on nomenclature ...................................................................... 63

Part 2. Parts of a Landslide —Description of Features/Glossary ................................................. 63

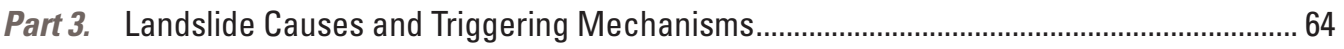

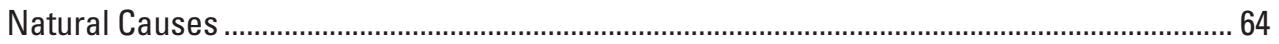

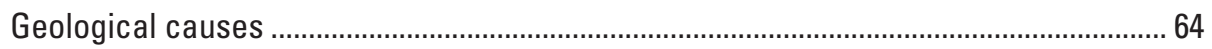

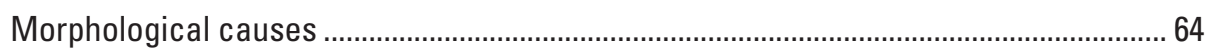

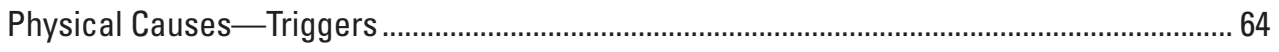

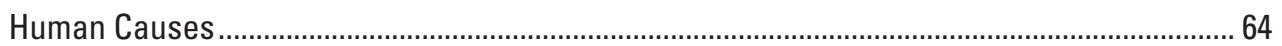

Appendix B. Introduction to Landslide Evaluation Tools-Mapping, Remote Sensing, and

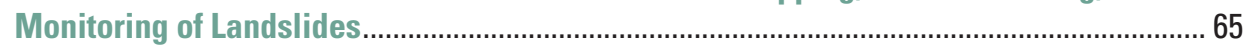

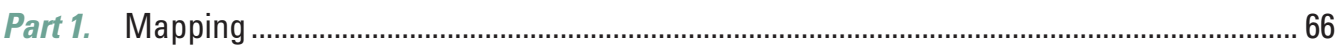

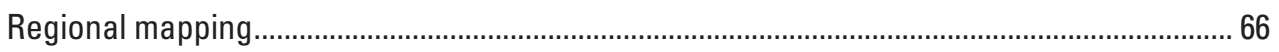

Community-level mapping .............................................................................................. 66

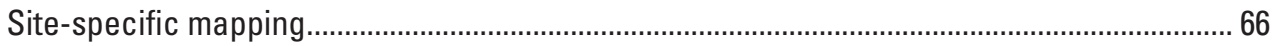

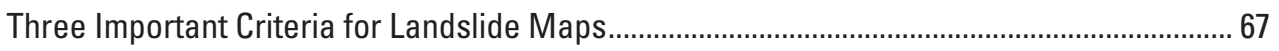

Landslide inventory maps......................................................................................... 67

Landslide susceptibility maps ....................................................................................... 68

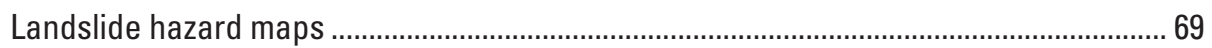

Part 2. Remote Sensing and Other Tools that Show Features of Landslide Activity ...................... 70

Part 3. Real-Time Monitoring of Landslides and Landslide Instrumentation .................................. 74

Appendix C. Introduction to Landslide Stabilization and Mitigation ........................................... 75

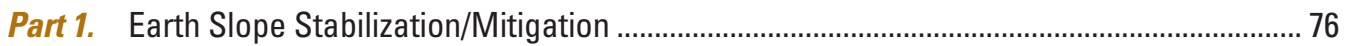

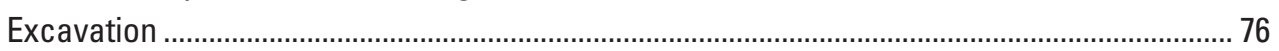

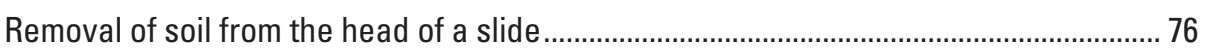

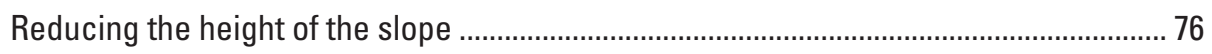

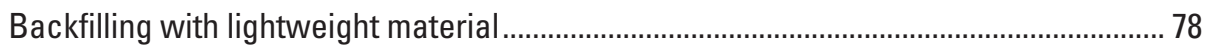

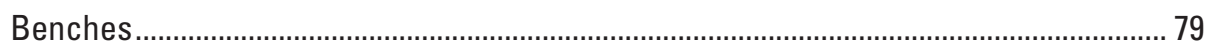

Flattening or reducing slope angle, or other slope modification ................................... 79

When not to excavate a slide mass.............................................................................. 79

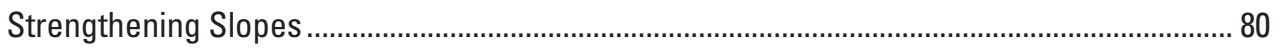

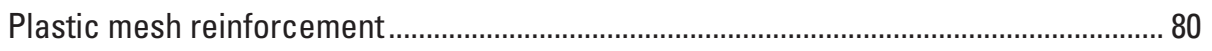

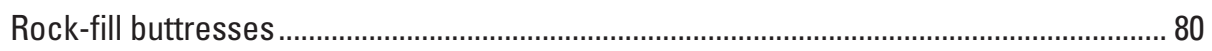

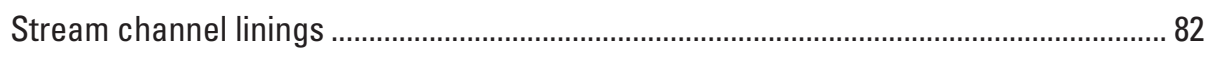

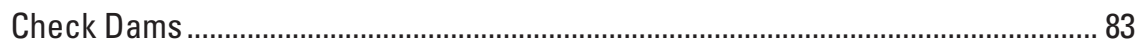

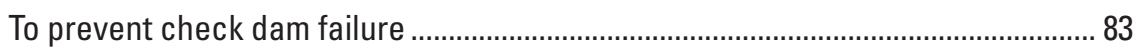

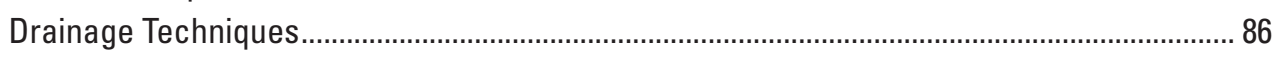

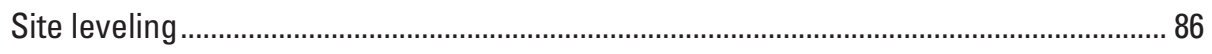

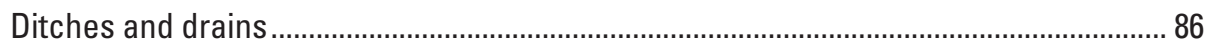

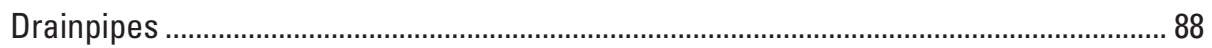

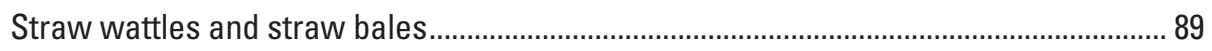

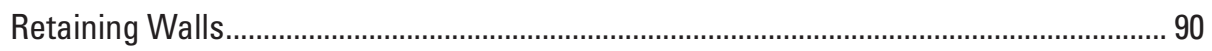




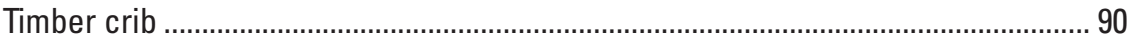

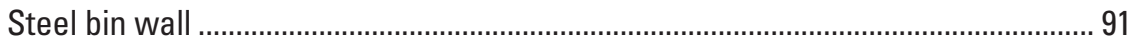

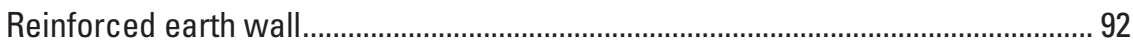

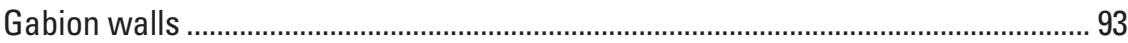

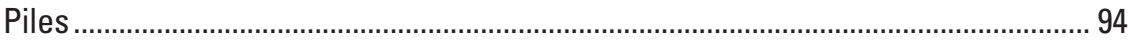

Slope Stabilization Using Vegetation................................................................................ 95

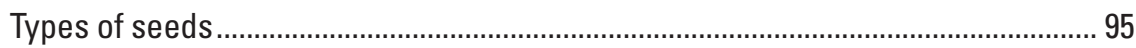

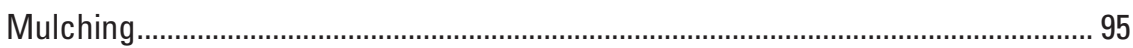

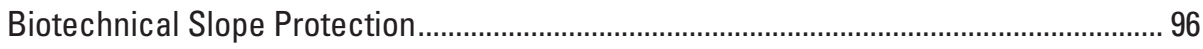

Part 2. Rock Slope Stabilization/Mitigation Techniques ................................................................. 99

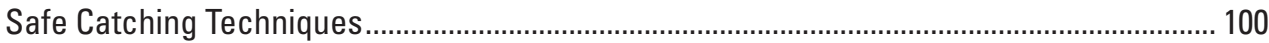

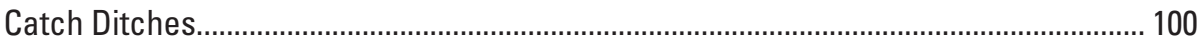

Cable, Mesh, Fencing, and Rock Curtains.................................................................. 100

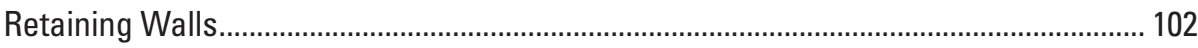

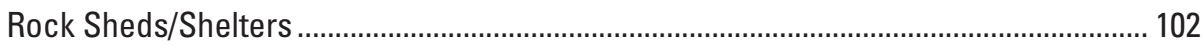

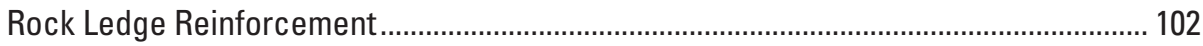

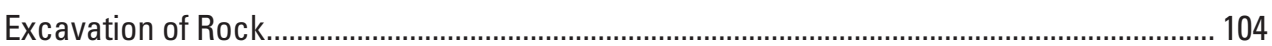

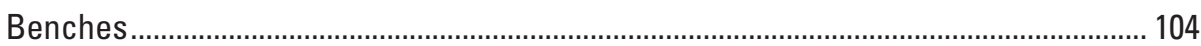

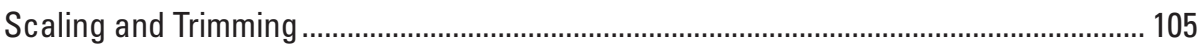

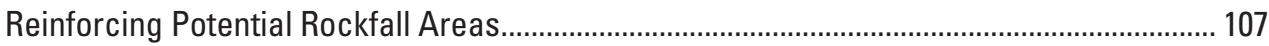

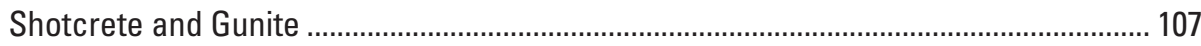

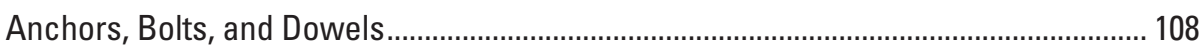

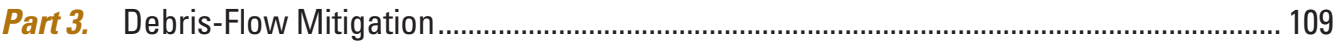

Strengthening Slopes for Erosion/Debris Flows................................................................. 109

Strengthening the soil to resist erosion ...................................................................... 110

Proper planting of vegetation on slopes can prevent erosion ......................................... 110

Keeping slopes free from fuel for wildfires ................................................................. 110

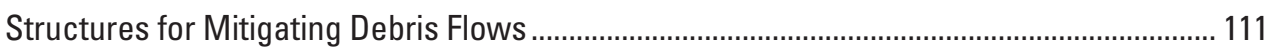

Debris-flow basins .......................................................................................................... 111

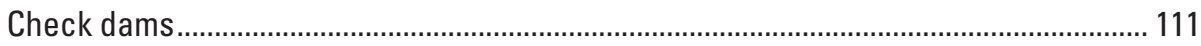

Debris-flow retaining walls .............................................................................................. 112

Box Debris-Flow Mitigation for the Homeowner ........................................................... 113

Box Basic Things to Remember Concerning Mitigation and Response to

Debris-Flow and Other Landslide Hazards/Emergency Response ............. 122

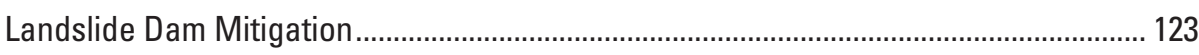

Diversion of inflow water before it reaches the lake formed by

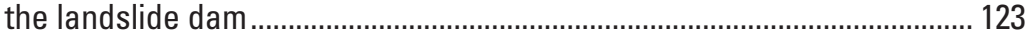

Temporary drainage from the impoundment by pumps or siphons......................... 123

Construction of an erosion-resistant spillway............................................................ 124

Drainage tunnel through an abutment...................................................................... 124

Appendix D. Sample Safety Information for Landslides/Debris Flows ..................................... 127

What Can You Do If You Live Near Steep Hills? ....................................................................... 128

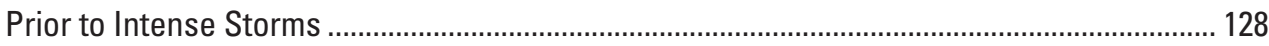

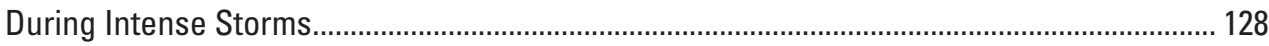

What to do if you suspect imminent landslide danger ........................................................ 128

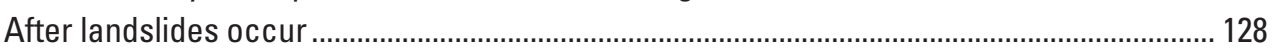

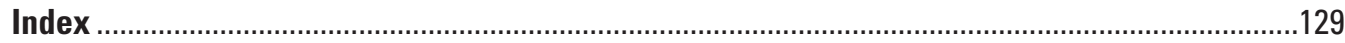




\section{Figures}

1. This landslide occurred at La Conchita, California, USA, in 2005 .....................................

2. A simple illustration of a rotational landslide that has evolved into an earthflow ............5

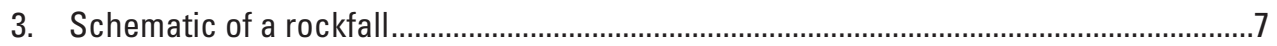

4. A rockfall/slide that occurred in Clear Creek Canyon, Colorado, USA, in 2005 ................7

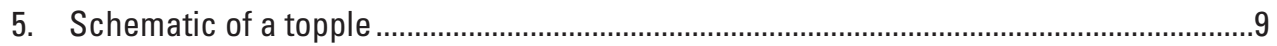

6. Photograph of block toppling at Fort St. John, British Columbia, Canada ..........................

7. Schematic of a rotational landslide .................................................................................11

8. Photograph of a rotational landslide which occurred in New Zealand ..........................11

9. Schematic of a translational landslide..........................................................................13

10. A translational landslide that occurred in 2001 in the Beatton River Valley, British

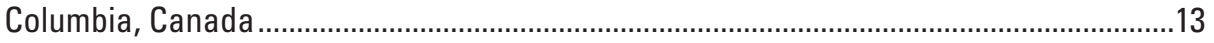

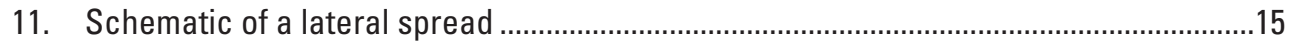

12. Photograph of lateral spread damage to a roadway as a result of the 1989 Loma

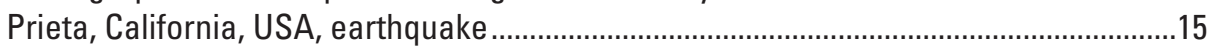

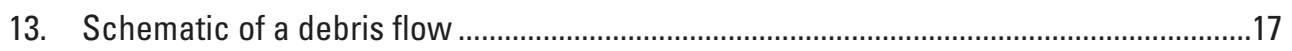

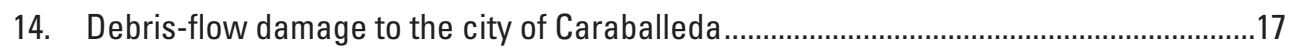

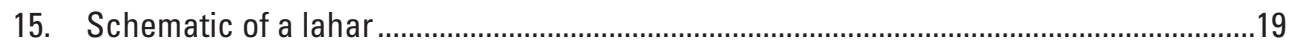

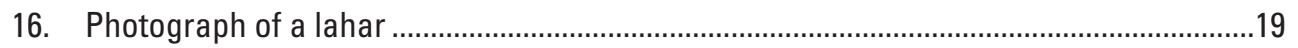

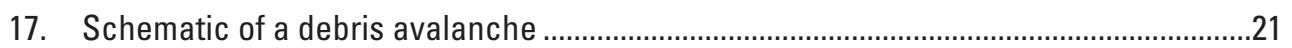

18. A debris avalanche that buried the village of Guinsaugon, Southern Leyte,

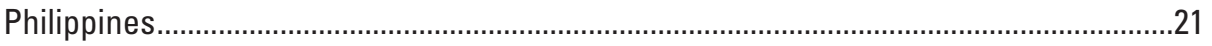

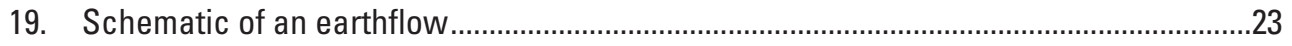

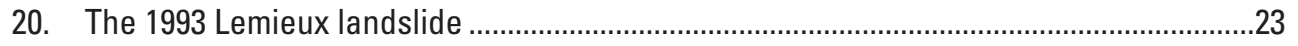

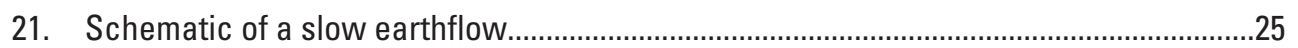

22. The effects of creep, in an area near East Sussex, United Kingdom .............................25

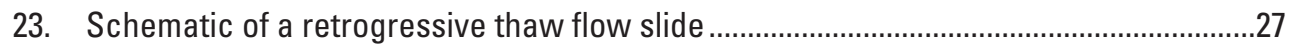

24. Photograph of a retrogressive thaw flow in the Northwest Territories, Canada.............28

25. Photograph showing lateral spreading damage .........................................................29

26. Photograph showing the Mameyes, Puerto Rico, landslide, 1985 ....................................31

27. Earthquake-induced landslide damage to a house built on artificial fill ..........................32

28. Photograph showing the side of Casita Volcano in Nicaragua, Central America............33

29. A landslide on the Pan American Highway in El Salvador, Central America ...................35

30. The active volcano, Mount Shasta in California, USA ……...........................................37

31. View looking downstream at the confluence of the Río Malo .........................................38

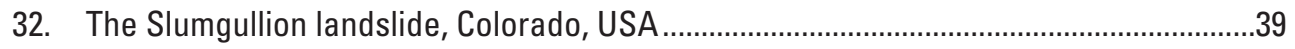

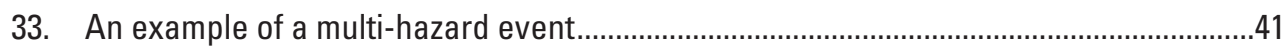

34. The 1999 multi-hazard event in Tanaguarena, in coastal Venezuela, South America ....42

35. Photograph showing the aftereffects of a multi-hazard event........................................42

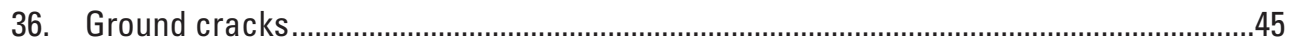

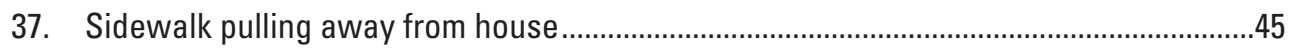

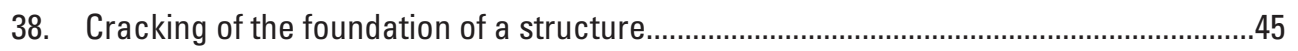

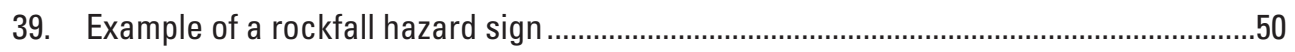

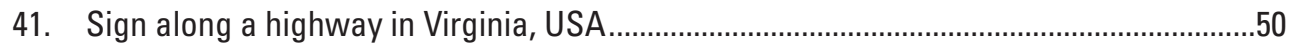

40. A notice for cliff hazards, city of Wanneroo, Australia ....................................................50 


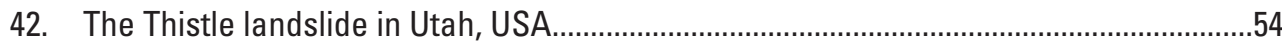

43. Extensive damage in the mountainous terrain of Beichuan County ................................55

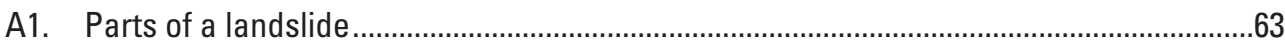

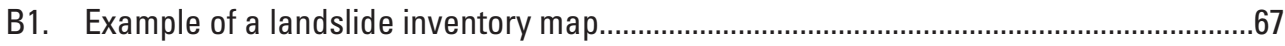

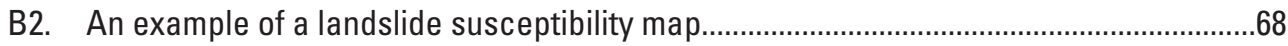

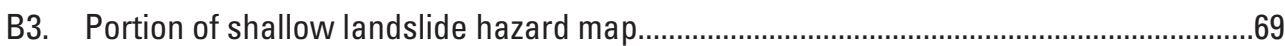

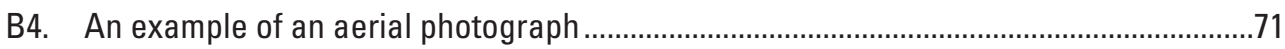

B5. Schematic showing satellite passes over an area of the Earth's surface .......................71

B6. Interferogram from InSAR imaging process ................................................................

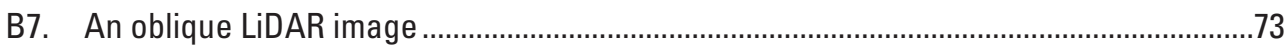

B8. Measuring landslide movement using an extensometer..................................................

B9. Testing a solar-powered radiotelemetry system ..........................................................74

B10. Example of a network for measurement and transmission of real-time

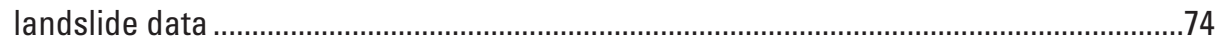

C1. Illustration of the differences in stability resulting in excavation at the head and toe surfaces of a slope...

C2. Illustration of the difference in stability of loading either the head or

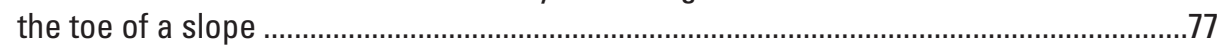

C3. Illustration of the importance of water in the stability of a slope......................................77

C4. Schematic and photograph of a lightweight backfill........................................................78

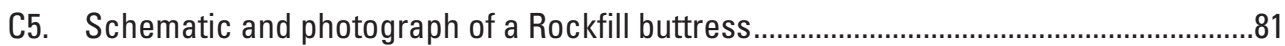

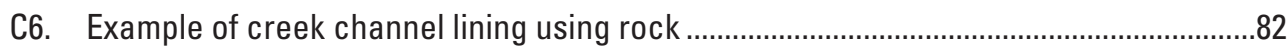

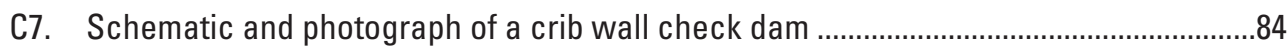

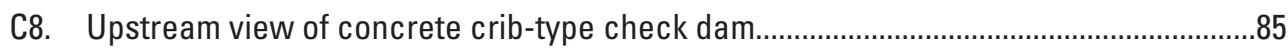

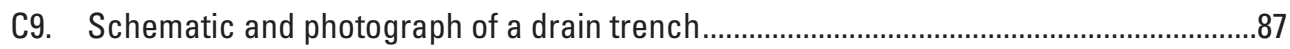

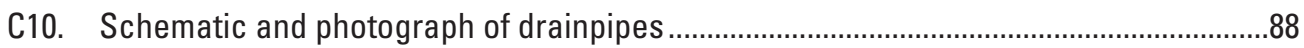

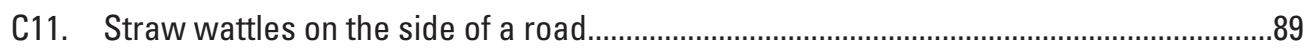

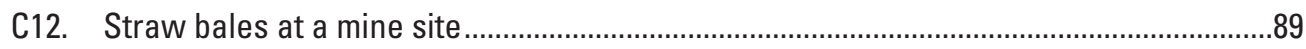

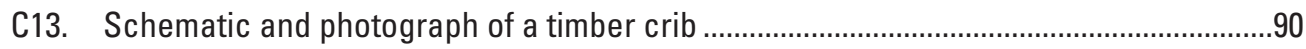

C14. Schematic and photograph of a steel bin wall ...........................................................

C15. Schematic and photograph of a reinforced earth wall ..................................................92

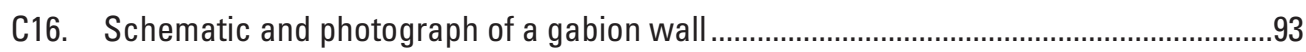

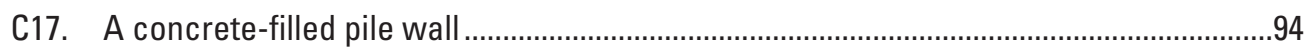

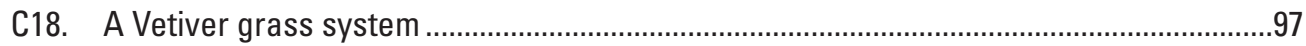

C19. Worldwide distribution of active Vetiver grass programs ...........................................98

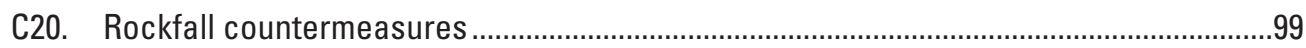

C21. Example of wire mesh placed over a rocky slope.......................................................

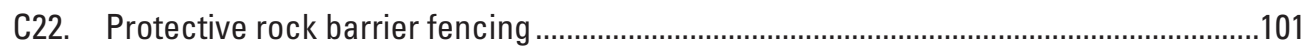

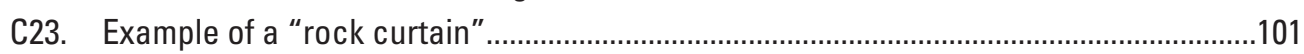

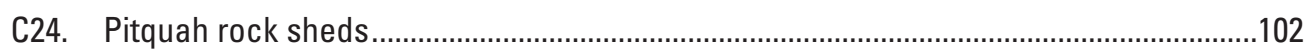

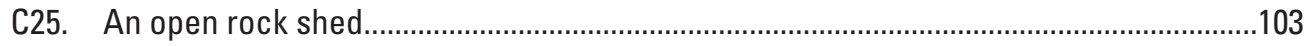

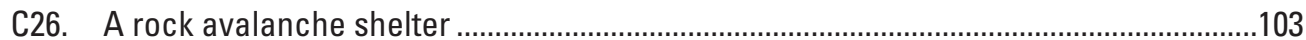

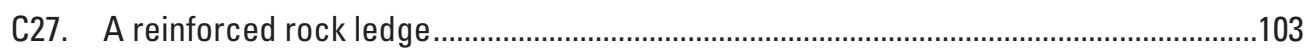

C28. Schematic and photograph of rock benches...........................................................104

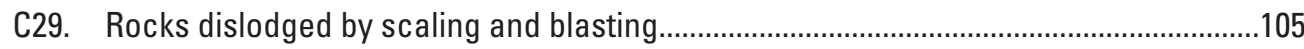

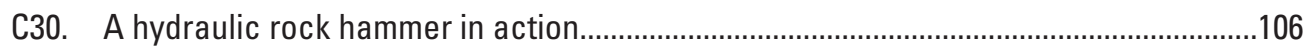




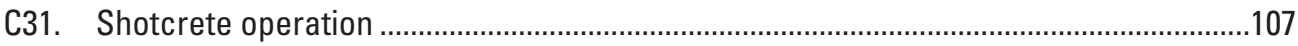

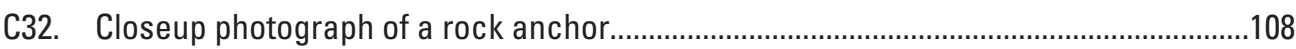

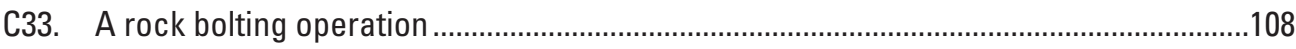

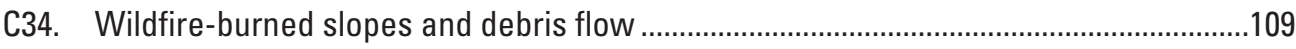

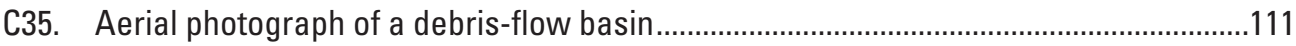

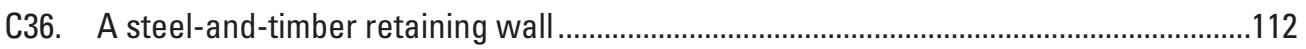

C37. A debris-flow retaining wall................................................................................112

C38. Schematic of an unprotected home ....................................................................113

C39. Schematic example of a house with protective structures in place .............................113

C40. Schematic of typical materials for helping to reduce damage from flood/

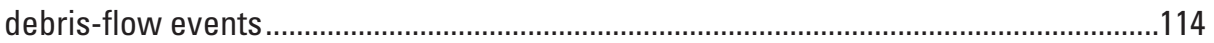

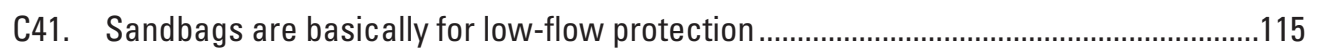

C42. Schematic of a typical placement of sandbags for home protection.............................116

C43. Sandbags help in directing debris away from buildings..............................................116

C44. Controlling debris or stormflows in streets with sandbags ..........................................117

C45. Directing flows between buildings by using sandbags..............................................117

C46. Sliding glass door sealing ..........................................................................................118

C47. Typical window and door protection..........................................................................119

C48. Nailing up plywood or lumber for window and door protection....................................119

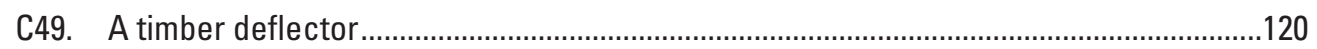

C50. Closeup schematic of a timber deflector installation technique...................................120

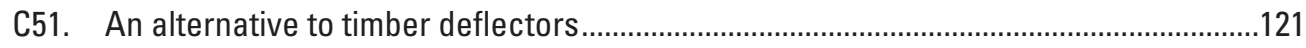

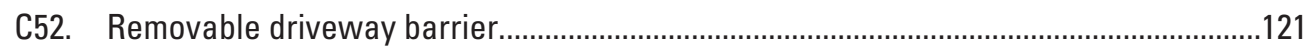

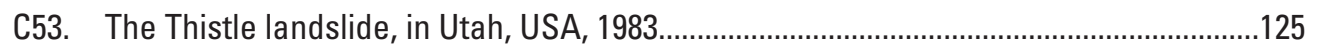

C54. Closeup view of mitigation measures taken to reduce the impact of the

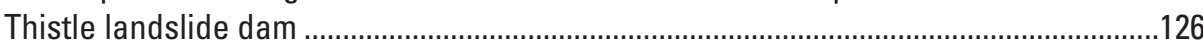

C55. Photograph with annotations showing the reactivation and enlargement of the Thistle landslide dam 


\section{How to read this guide}

This guide consists of three primary sections with a series of extensive appendixes and an index. This style provides the most flexibility for users with considerable differences of interest and level of detail. Much of the detailed and expanded explanatory information can be found in the appendixes, including a Glossary of Landslide Terms. References are provided for more information.

\section{Please note}

- For ease of reading, references are numbered at the end of sections and are not embedded within the text. The user may also contact either the United States Geological Survey or the Geological Survey of Canada for further guidance and assistance.

- Web sites are used as references for this book; however, Web site addresses (URLs) can change over time, and the Internet links given in this publication may become inactive or erroneous. It is suggested that users consult a Web-based keyword search engine if links are no longer accessible. 


\title{
The Landslide Handbook - A Guide to Understanding Landslides
}

\author{
By Lynn M. Highland, United States Geological Survey, and \\ Peter Bobrowsky, Geological Survey of Canada
}

\section{Introduction}

This handbook is intended to be a resource for people affected by landslides to acquire further knowledge, especially about the conditions that are unique to their neighborhoods and communities. Considerable literature and research are available concerning landslides, but unfortunately little of it is synthesized and integrated to address the geographically unique geologic and climatic conditions around the globe. Landslides occur throughout the world, under all climatic conditions and terrains, cost billions in monetary losses, and are responsible for thousands of deaths and injuries each year. Often, they cause long-term economic disruption, population displacement, and negative effects on the natural environment.

Outdated land-use policies may not always reflect the best planning for use of land that is vulnerable to landslides. The reasons for poor or nonexistent land-use policies that minimize the perceived or actual danger and damage potential from geologic hazards are many and encompass the political, cultural, and financial complexities and intricacies of communities. Landslides often are characterized as local problems, but their effects and costs frequently cross local jurisdictions and may become State or Provincial or national problems.

Growing populations may be limited in their geographic expansion, except to occupy unstable, steep, or remote areas. Often, stabilizing landslide-scarred areas is too costly, and some inhabitants have no other places to relocate. Fortunately, simple, "low-tech" precautions and actions can be adopted to at least ensure an individual's immediate safety, and this handbook gives a brief overview of many of these options. We strongly suggest that, where possible, the assistance of professional engineers/geologists or those experienced in the successful mitigation of unstable slopes be consulted before actions are taken. This handbook helps homeowners, community and emergency managers, and decisionmakers to take the positive step of encouraging awareness of available options and recourse in regard to landslide hazard. 
We provide a list of references, available in print or on the World Wide Web (Internet), that can be used for further knowledge about landslides. We recommend this handbook to managers and decisionmakers in communities in the hope that the information will be disseminated by such officials to other members of those communities. In response to the differing levels of literacy around the globe, we have emphasized visual information through the use of photographs and graphics. We plan to translate the handbook into additional languages as funding permits to further facilitate its use.

We welcome comments and critiques and have provided our contact information and the names and addresses of our respective agencies.

\title{
For more information
}

For questions on the content of this book or other inquiries regarding landslide issues, please be aware that the U.S. Geological Survey (USGS) National Landslide Information Center (NLIC), in Golden, Colorado, USA, is available as a resource to answer questions, help with interpretations, or otherwise support users of this book in providing additional information. Please contact the center by telephone, email, or written inquiry.

\author{
United States Geological Survey \\ Landslide Program and National Landslide Information Center \\ Mail Stop 966, Box 25046, Denver Federal Center \\ Denver, Colorado, 80225 USA \\ Web address: http://landslides.usgs.gov/ \\ Telephone: 1-800-654-4966, or 1-303-273-8586 \\ Highland@usgs.gov \\ Geological Survey of Canada \\ Landslides and Geotechnic Section \\ 601 Booth Street \\ Ottawa, Ontario, Canada KIA 0E8 \\ Web address: http://gsc.nrcan.gc.ca/landslides/index_e.php \\ Telephone: 1-613-947-0333 \\ pbobrows@nrcan-rncan.gc.ca
}




\section{Section I.}

\section{Basic Information About Landslides}




\section{Part A. What is a Landslide?}

Geologists, engineers, and other professionals often rely on unique and slightly differing definitions of landslides. This diversity in definitions reflects the complex nature of the many disciplines associated with studying landslide phenomena. For our purposes, landslide is a general term used to describe the downslope movement of soil, rock, and organic materials under the effects of gravity and also the landform that results from such movement (please see figure 1 for an example of one type of landslide).

Varying classifications of landslides are associated with specific mechanics of slope failure and the properties and characteristics of failure types; these will be discussed briefly herein.

There are a number of other phrases/terms that are used interchangeably with the term "landslide" including mass movement, slope failure, and so on. One commonly hears such terms applied to all types and sizes of landslides.

Regardless of the exact definition used or the type of landslide under discussion, understanding the basic parts of a typical landslide is helpful. Figure 2 shows the position and the most common terms used to describe the unique parts of a landslide. These terms and other relevant words are defined in the Glossary of Landslide Terms included in Appendix A.

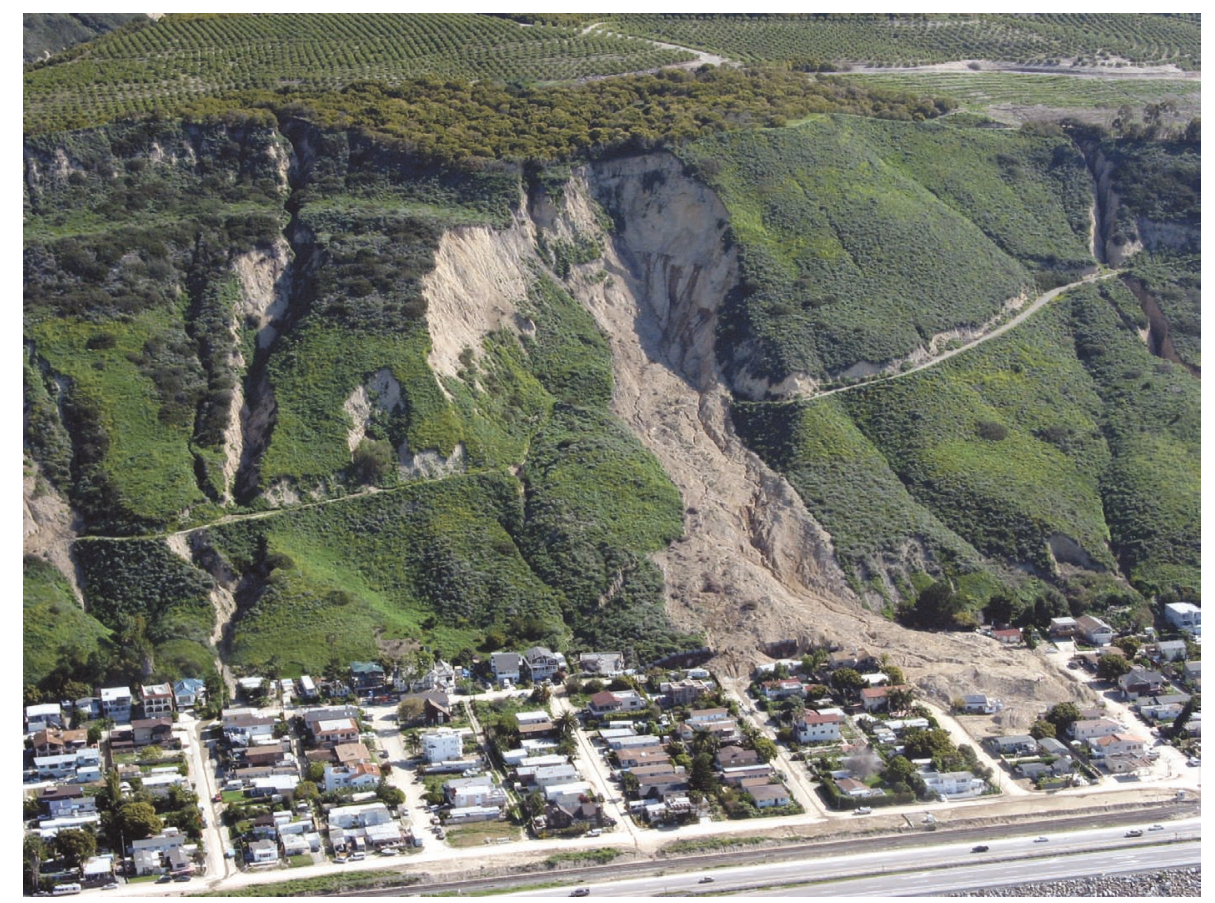

Figure 1. This landslide occurred at La Conchita, California, USA, in 2005. Ten people were killed. (Photograph by Mark Reid, U.S. Geological Survey.) 


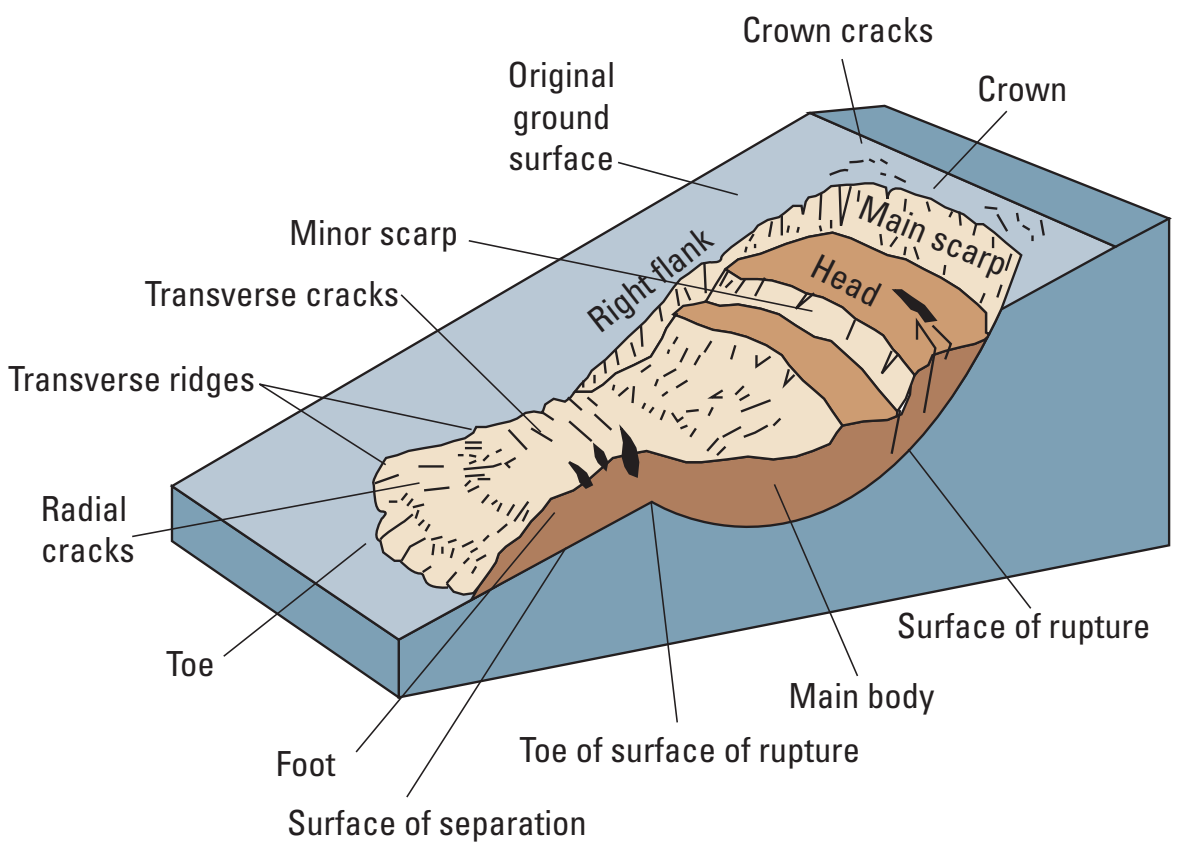

Figure 2. A simple illustration of a rotational landslide that has evolved into an earthflow. Image illustrates commonly used labels for the parts of a landslide (from Varnes, 1978, Reference 43).

\section{Part B. Basic Landslide Types}

A landslide is a downslope movement of rock or soil, or both, occurring on the surface of rupture-either curved (rotational slide) or planar (translational slide) rupture-in which much of the material often moves as a coherent or semicoherent mass with little internal deformation. It should be noted that, in some cases, landslides may also involve other types of movement, either at the inception of the failure or later, if properties change as the displaced material moves downslope.

This section provides descriptions and illustrations of the various types of landslides. Understanding the characteristics of the specific type of landslide hazard in your area is vitally important to consider when planning or adopting appropriate mitigative action to lessen the risk of loss and damage. The type of landslide will determine the potential speed of movement, likely volume of displacement, distance of run-out, as well as the possible effects of the landslide and the appropriate mitigative measures to be considered.

Landslides can be classified into different types on the basis of the type of movement and the type of material involved (please see References 9 and 39). In brief, material in a landslide mass is either rock or soil (or both); the latter is described as earth if mainly composed of sand-sized or finer particles and debris if composed of coarser fragments. The type of movement describes the actual internal mechanics of how the landslide mass is displaced: fall, topple, slide, spread, or flow. Thus, landslides are described using two terms that refer respectively to material and movement (that is, rockfall, debris flow, and so forth). Landslides may also form a complex failure encompassing more than one type of movement (that is, rock slide-debris flow).

For the purposes of this handbook we treat "type of movement" as synonymous with "landslide type." Each type of movement can be further subdivided according to specific properties and characteristics, and the main subcategories of each type are described elsewhere. Less common subcategories are not discussed in this handbook but are referred to in the source reference.

Direct citations and identification of sources and references for text are avoided in the body of this handbook, but all source materials are duly recognized and given in the accompanying reference lists. 


\section{Falls}

A fall begins with the detachment of soil or rock, or both, from a steep slope along a surface on which little or no shear displacement has occurred. The material subsequently descends mainly by falling, bouncing, or rolling.

\section{Rockfall}

Falls are abrupt, downward movements of rock or earth, or both, that detach from steep slopes or cliffs. The falling material usually strikes the lower slope at angles less than the angle of fall, causing bouncing. The falling mass may break on impact, may begin rolling on steeper slopes, and may continue until the terrain flattens.

\section{Occurrence and relative size/range}

Common worldwide on steep or vertical slopes-also in coastal areas, and along rocky banks of rivers and streams. The volume of material in a fall can vary substantially, from individual rocks or clumps of soil to massive blocks thousands of cubic meters in size.

\section{Velocity of travel}

Very rapid to extremely rapid, free-fall; bouncing and rolling of detached soil, rock, and boulders. The rolling velocity depends on slope steepness.

\section{Triggering mechanism}

Undercutting of slope by natural processes such as streams and rivers or differential weathering (such as the freeze/thaw cycle), human activities such as excavation during road building and (or) maintenance, and earthquake shaking or other intense vibration.

\section{Effects (direct/indirect)}

Falling material can be life-threatening. Falls can damage property beneath the fall-line of large rocks. Boulders can bounce or roll great distances and damage structures or kill people. Damage to roads and railroads is particularly high: rockfalls can cause deaths in vehicles hit by rocks and can block highways and railroads.

\section{Corrective measures/mitigation}

Rock curtains or other slope covers, protective covers over roadways, retaining walls to prevent rolling or bouncing, explosive blasting of hazardous target areas to remove the source, removal of rocks or other materials from highways and railroads can be used. Rock bolts or other similar types of anchoring used to stabilize cliffs, as well as scaling, can lessen the hazard. Warning signs are recommended in hazardous areas

For further reading: References 9, 39, 43, and 45 for awareness. Stopping or parking under hazardous cliffs should be warned against. 


\section{Predictability}

Mapping of hazardous rockfall areas has been completed in a few areas around the world. Rock-bounce calculations and estimation methods for delineating the perimeter of rockall zones have also been determined and the information widely published. Indicators of imminent rockfall include terrain with overhanging rock or fractured or jointed rock along steep slopes, particularly in areas subject to frequent freeze-thaw cycles. Also, cut faces in gravel pits may be particularly subject to falls. Figures 3 and 4 show a schematic and an image of rockfall.

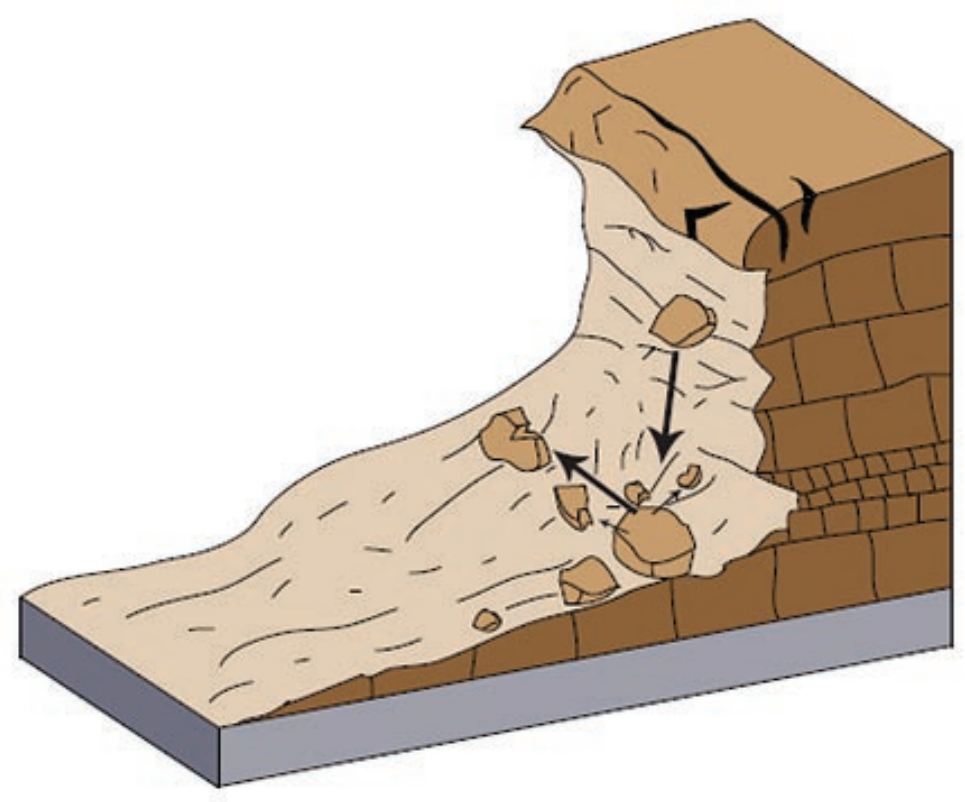

Figure 3. Schematic of a rockfall. (Schematic modified from Reference 9.)

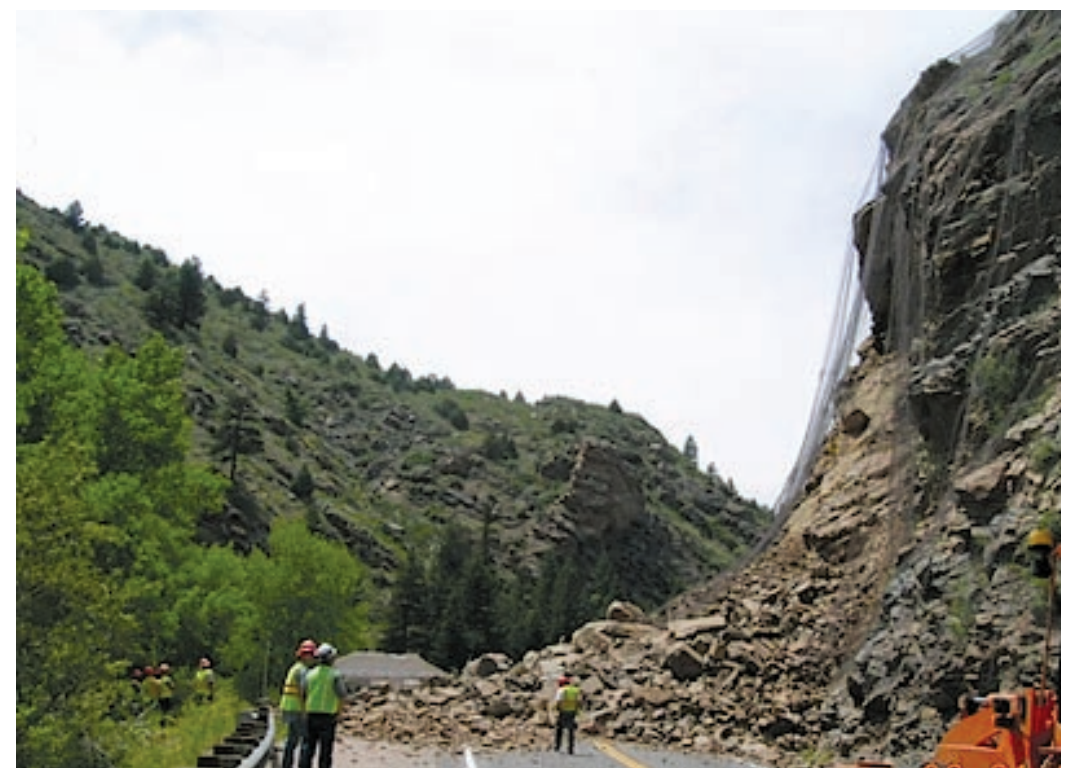

Figure 4. A rockfall/slide that occurred in Clear Creek Canyon, Colorado, USA, in 2005, closing the canyon to traffic for a number of weeks. The photograph also shows an example of a rock curtain, a barrier commonly applied over hazardous rock faces (right center of photograph). (Photograph by Colorado Geological Survey.) 


\section{Topple}

A topple is recognized as the forward rotation out of a slope of a mass of soil or rock around a point or axis below the center of gravity of the displaced mass. Toppling is sometimes driven by gravity exerted by the weight of material upslope from the displaced mass. Sometimes toppling is due to water or ice in cracks in the mass. Topples can consist of rock, debris (coarse material), or earth materials (finegrained material). Topples can be complex and composite.

\section{Occurrence}

Known to occur globally, often prevalent in columnar-jointed volcanic terrain, as well as along stream and river courses where the banks are steep.

\section{Velocity of travel}

Extremely slow to extremely rapid, sometimes accelerating throughout the movement depending on distance of travel.

\section{Triggering mechanism}

Sometimes driven by gravity exerted by material located upslope from the displaced mass and sometimes by water or ice occurring in cracks within the mass; also, vibration, undercutting, differential weathering, excavation, or stream erosion.

\section{Effects (direct/indirect)}

Can be extremely destructive, especially when failure is sudden and (or) the velocity is rapid.

\section{Corrective measures/mitigation}

In rock there are many options for the stabilization of topple-prone areas. Some examples for reinforcement of these slopes include rock bolts and mechanical and other types of anchors. Seepage is also a contributing factor to rock instability, and drainage should be considered and addressed as a corrective means.

\section{Predictability}

For further reading: References 9, 39, 43, and 45
Not generally mapped for susceptibility; some inventory of occurrence exists for certain areas. Monitoring of topple-prone areas is useful; for example, the use of tiltmeters. Tiltmeters are used to record changes in slope inclination near cracks and areas of greatest vertical movements. Warning systems based on movement measured by tiltmeters could be effective. Figures 5 and 6 show a schematic and an image of topple. 


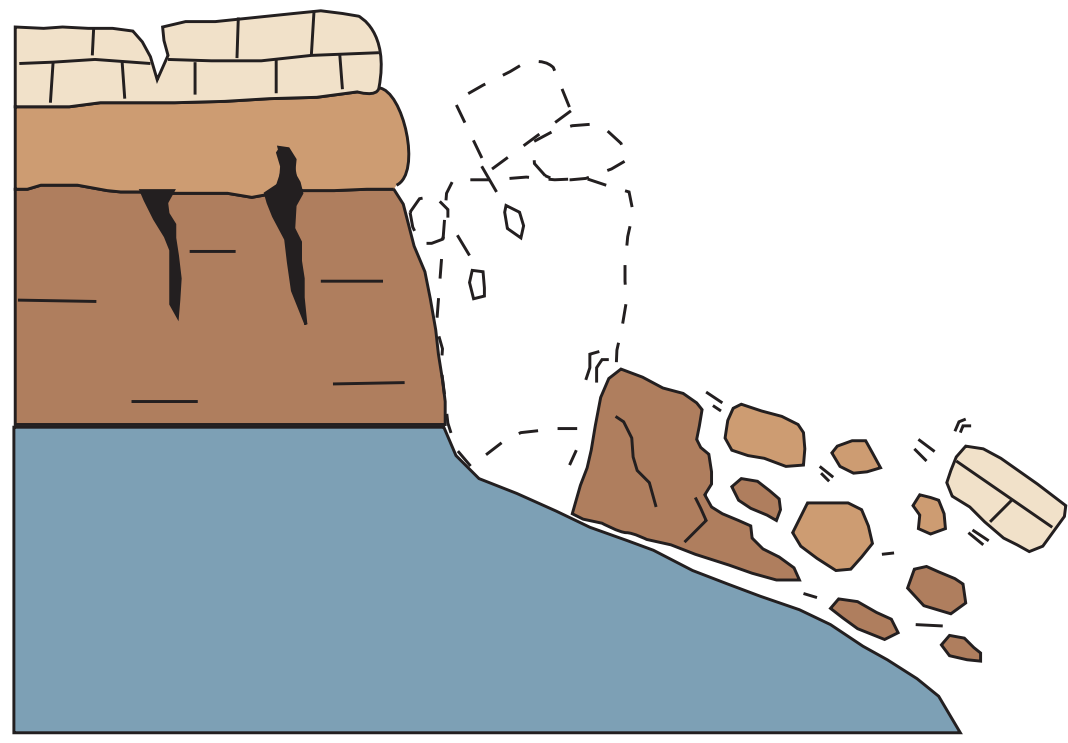

Figure 5. Schematic of a topple. (Schematic from Reference 9.)

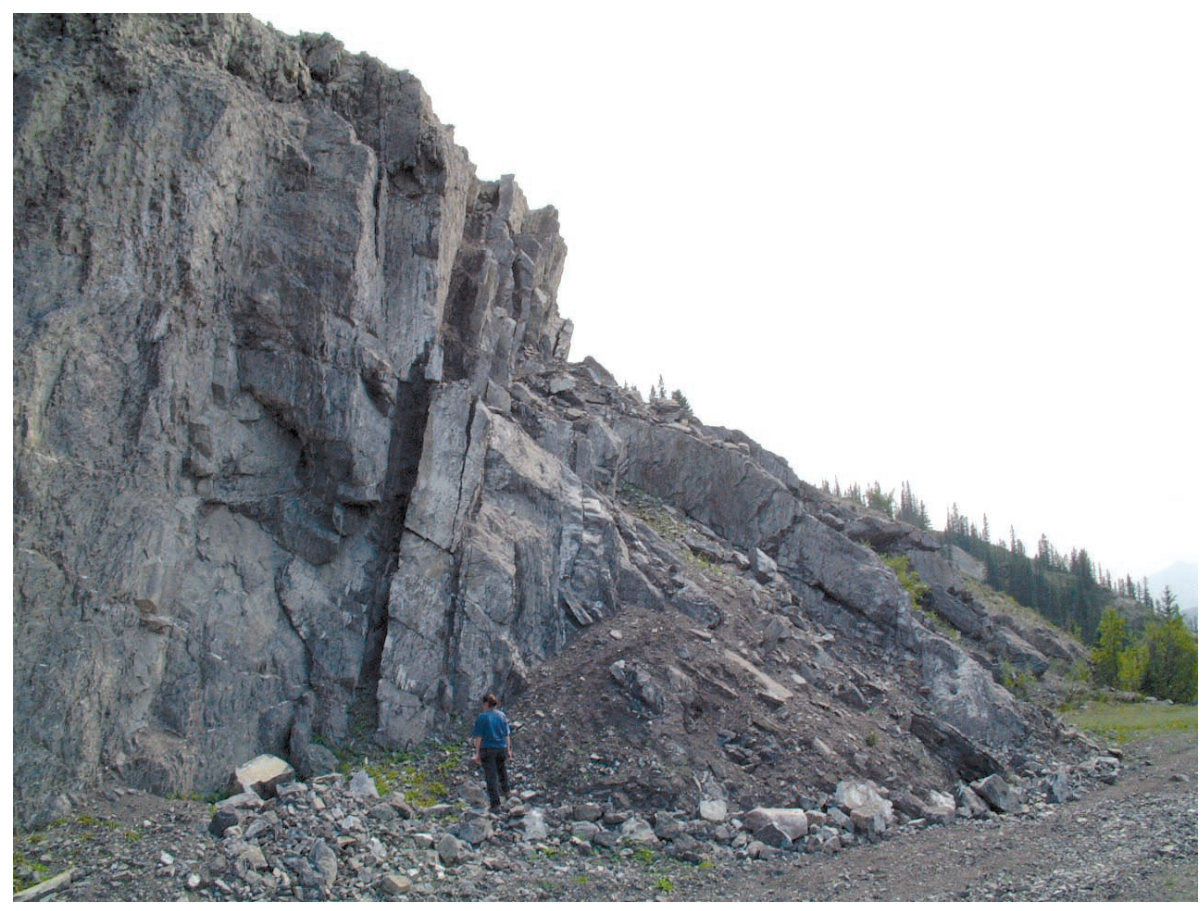

Figure 6. Photograph of block toppling at Fort St. John, British Columbia, Canada. (Photograph by G. Bianchi Fasani.) 


\section{Slides}

A slide is a downslope movement of a soil or rock mass occurring on surfaces of rupture or on relatively thin zones of intense shear strain. Movement does not initially occur simultaneously over the whole of what eventually becomes the surface of rupture; the volume of displacing material enlarges from an area of local failure.

\section{Rotational Landslide}

A landslide on which the surface of rupture is curved upward (spoon-shaped) and the slide movement is more or less rotational about an axis that is parallel to the contour of the slope. The displaced mass may, under certain circumstances, move as a relatively coherent mass along the rupture surface with little internal deformation. The head of the displaced material may move almost vertically downward, and the upper surface of the displaced material may tilt backwards toward the scarp. If the slide is rotational and has several parallel curved planes of movement, it is called a slump.

\section{Occurrence}

Because rotational slides occur most frequently in homogeneous materials, they are the most common landslide occurring in "fill" materials.

\section{Relative size/range}

Associated with slopes ranging from about 20 to 40 degrees. In soils, the surface of rupture generally has a depth-to-length ratio between 0.3 to 0.1 .

\section{Velocity of travel (rate of movement)}

Extremely slow (less than 0.3 meter or 1 foot every 5 years) to moderately fast (1.5 meters or 5 feet per month) to rapid.

\section{Triggering mechanism}

Intense and (or) sustained rainfall or rapid snowmelt can lead to the saturation of slopes and increased groundwater levels within the mass; rapid drops in river level following floods, ground-water levels rising as a result of filling reservoirs, or the rise in level of streams, lakes, and rivers, which cause erosion at the base of slopes. These types of slides can also be earthquake-induced.

\section{Effects (direct/indirect)}

Can be extremely damaging to structures, roads, and lifelines but are not usually life-threatening if movement is slow. Structures situated on the moving mass also can be severely damaged as the mass tilts and deforms. The large volume of material that is displaced is difficult to permanently stabilize. Such failures can dam rivers, causing flooding.

\section{Mitigation measures}

Instrumental monitoring to detect movement and the rate of movement can be implemented. Disrupted drainage pathways should be restored or reengineered to prevent future water buildup in the slide mass. Proper grading and engineering of slopes, where possible, will reduce the hazard considerably. Construction of retaining walls at the toe may be effective to slow or deflect the moving soil; however, the slide may overtop such retaining structures despite good construction. 


\section{Predictability}

Historical slides can be reactivated; cracks at tops (heads) of slopes are good indicators of the initiation of failure. Figures 7 and 8 show a schematic and an image of a rotational landslide.
For further reading:

References 9, 39, 43, and 45

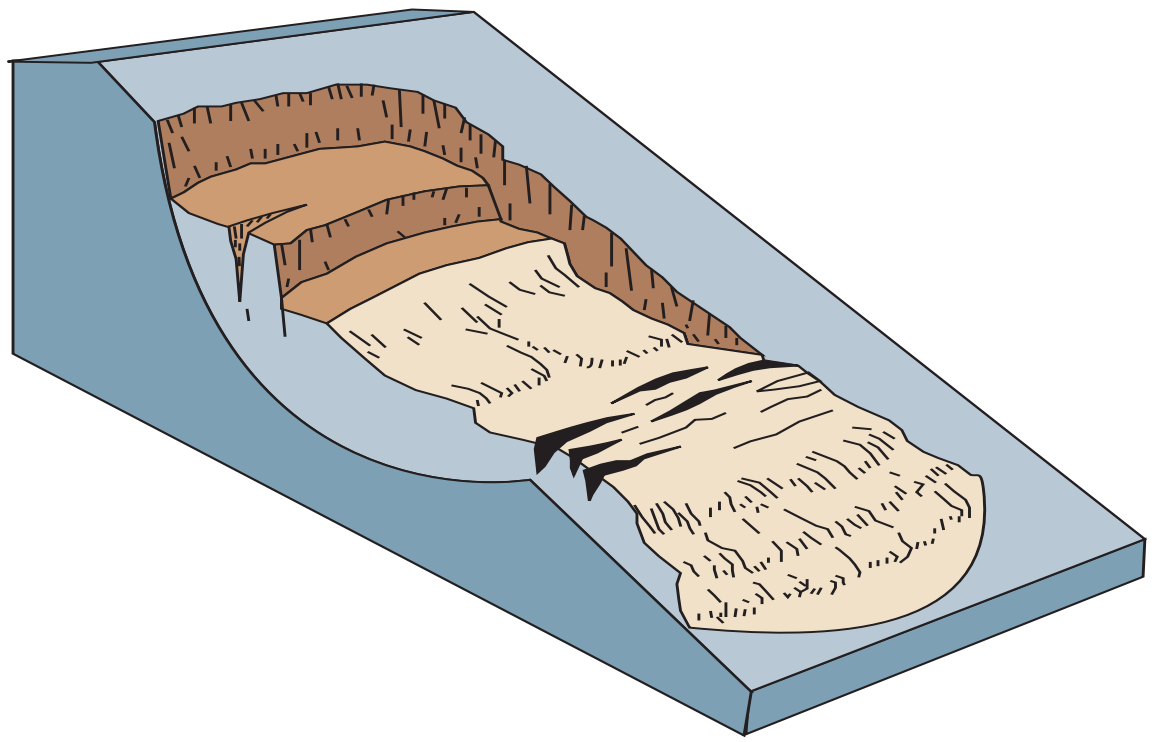

Figure 7. Schematic of a rotational landslide. (Schematic modified from Reference 9.)

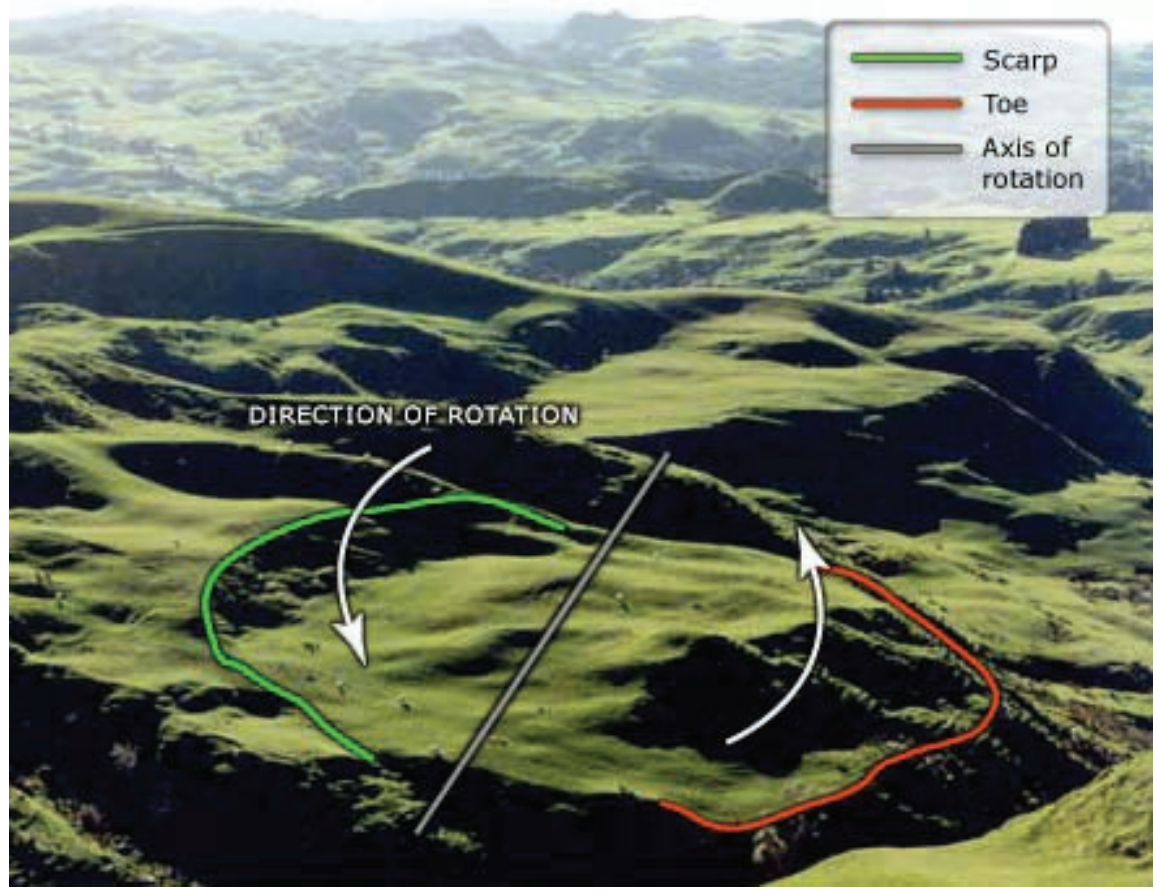

Figure 8. Photograph of a rotational landslide which occurred in New Zealand. The green curve at center left is the scarp (the area where the ground has failed). The hummocky ground at bottom right (in shadow) is the toe of the landslide (red line). This is called a rotational landslide as the earth has moved from left to right on a curved sliding surface. The direction and axis of rotation are also depicted. (Photograph by Michael J. Crozier, Encyclopedia of New Zealand, updated September 21, 2007.) 


\section{Translational Landslide}

The mass in a translational landslide moves out, or down and outward, along a relatively planar surface with little rotational movement or backward tilting. This type of slide may progress over considerable distances if the surface of rupture is sufficiently inclined, in contrast to rotational slides, which tend to restore the slide equilibrium. The material in the slide may range from loose, unconsolidated soils to extensive slabs of rock, or both. Translational slides commonly fail along geologic discontinuities such as faults, joints, bedding surfaces, or the contact between rock and soil. In northern environments the slide may also move along the permafrost layer.

\section{Occurrence}

One of the most common types of landslides, worldwide. They are found globally in all types of environments and conditions.

\section{Relative size/range}

Generally shallower than rotational slides. The surface of rupture has a distance-to-length ratio of less than 0.1 and can range from small (residential lot size) failures to very large, regional landslides that are kilometers wide.

\section{Velocity of travel}

Movement may initially be slow ( 5 feet per month or 1.5 meters per month) but many are moderate in velocity ( 5 feet per day or 1.5 meters per day) to extremely rapid. With increased velocity, the landslide mass of translational failures may disintegrate and develop into a debris flow.

\section{Triggering mechanism}

Primarily intense rainfall, rise in ground water within the slide due to rainfall, snowmelt, flooding, or other inundation of water resulting from irrigation, or leakage from pipes or human-related disturbances such as undercutting. These types of landslides can be earthquake-induced.

\section{Effects (direct/indirect)}

Translational slides may initially be slow, damaging property and (or) lifelines; in some cases they can gain speed and become life-threatening. They also can dam rivers, causing flooding.

\section{Mitigation measures}

Adequate drainage is necessary to prevent sliding or, in the case of an existing failure, to prevent a reactivation of the movement. Common corrective measures include leveling, proper grading and drainage, and retaining walls. More sophisticated remedies in rock include anchors, bolts, and dowels, which in all situations are best implemented by professionals. Translational slides on moderate to steep slopes are very difficult to stabilize permanently. 


\section{Predictability}

High probability of occurring repetitively in areas where they have occurred in the past, including areas subject to frequent strong earthquakes. Widening cracks at the head or toe bulge may be an indicator of For further reading: imminent failure. Figures 9 and 10 show a schematic and an image of a translational landslide.

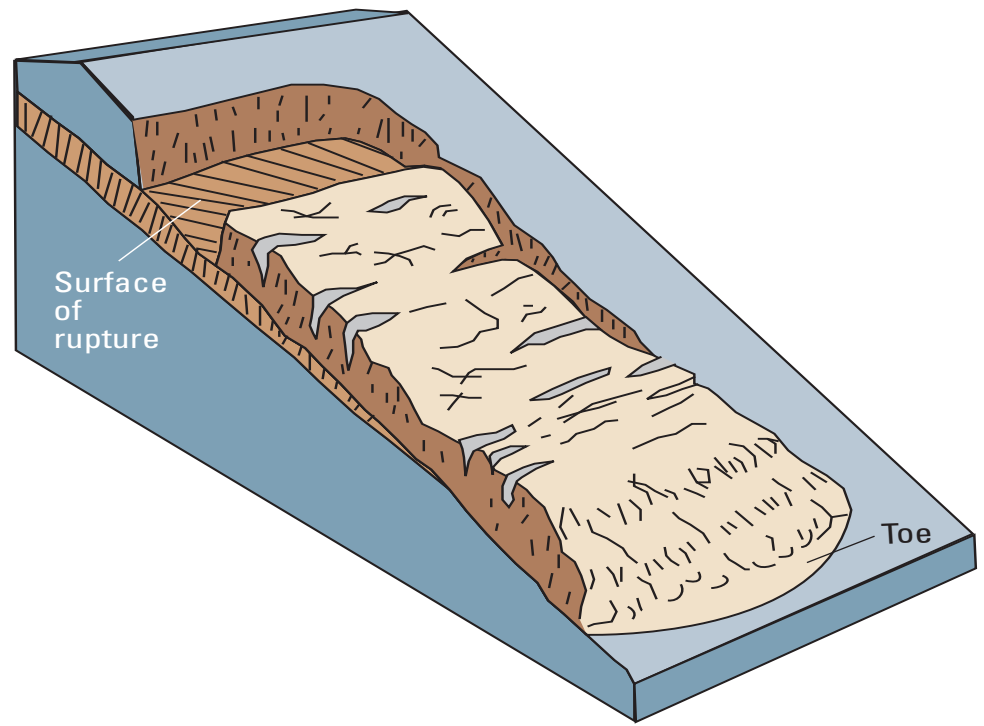

Figure 9. Schematic of a translational landslide. (Schematic modified from Reference 9.)

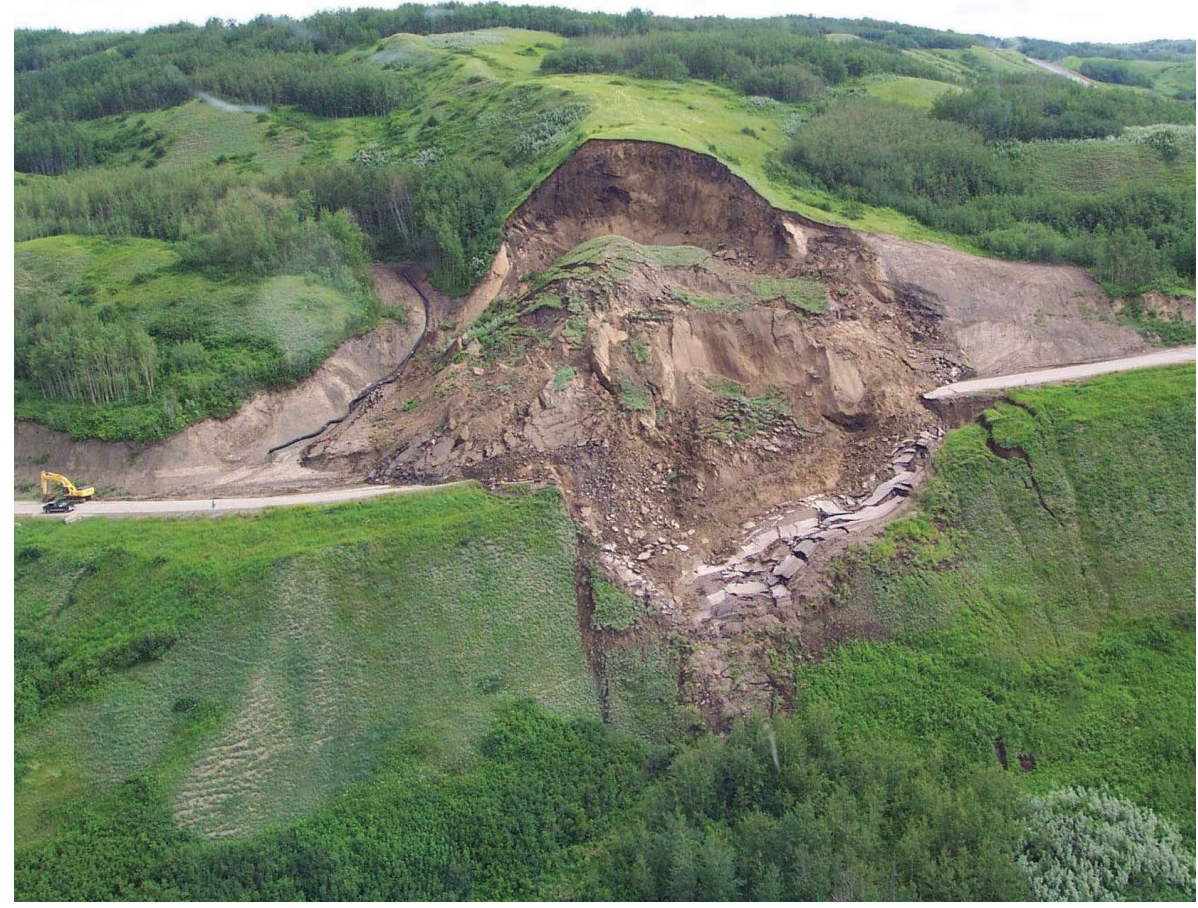

Figure 10. A translational landslide that occurred in 2001 in the Beatton River Valley, British Columbia, Canada. (Photograph by Réjean Couture, Canada Geological Survey.) 


\section{Spreads}

An extension of a cohesive soil or rock mass combined with the general subsidence of the fractured mass of cohesive material into softer underlying material. Spreads may result from liquefaction or flow (and extrusion) of the softer underlying material. Types of spreads include block spreads, liquefaction spreads, and lateral spreads.

\section{Lateral Spreads}

Lateral spreads usually occur on very gentle slopes or essentially flat terrain, especially where a stronger upper layer of rock or soil undergoes extension and moves above an underlying softer, weaker layer. Such failures commonly are accompanied by some general subsidence into the weaker underlying unit. In rock spreads, solid ground extends and fractures, pulling away slowly from stable ground and moving over the weaker layer without necessarily forming a recognizable surface of rupture. The softer, weaker unit may, under certain conditions, squeeze upward into fractures that divide the extending layer into blocks. In earth spreads, the upper stable layer extends along a weaker underlying unit that has flowed following liquefaction or plastic deformation. If the weaker unit is relatively thick, the overriding fractured blocks may subside into it, translate, rotate, disintegrate, liquefy, or even flow.

\section{Occurrence}

Worldwide and known to occur where there are liquefiable soils.

Common, but not restricted, to areas of seismic activity.

\section{Relative size/range}

The area affected may start small in size and have a few cracks that may spread quickly, affecting areas of hundreds of meters in width.

\section{Velocity of travel}

May be slow to moderate and sometimes rapid after certain triggering mechanisms, such as an earthquake. Ground may then slowly spread over time from a few millimeters per day to tens of square meters per day.

\section{Triggering mechanism}

Triggers that destabilize the weak layer include:

- Liquefaction of lower weak layer by earthquake shaking

- Natural or anthropogenic overloading of the ground above an unstable slope

- Saturation of underlying weaker layer due to precipitation, snowmelt, and (or) ground-water changes

- Liquefaction of underlying sensitive marine clay following an erosional disturbance at base of a riverbank/slope

- Plastic deformation of unstable material at depth (for example, salt)

\section{Effects (direct/indirect)}

Can cause extensive property damage to buildings, roads, railroads, and lifelines. Can spread slowly or quickly, depending on the extent of water saturation of the various soil layers. Lateral spreads may be a precursor to earthflows. 


\section{Mitigation measures}

Liquefaction-potential maps exist for some places but are not widely available. Areas with potentially liquefiable soils can be avoided as construction sites, particularly in regions that are known to experience frequent earthquakes. If high ground-water levels are involved, sites can be drained or other water-diversion efforts can be added.

\section{Predictability}

High probability of recurring in areas that have experienced previous problems. Most prevalent in areas that have an extreme earthquake hazard as well as liquefiable soils. Lateral spreads are also associated with susceptible marine clays and are a common problem throughout the St. Lawrence Lowlands of eastern Canada. Figures 11 and 12 show a schematic and an image of a lateral spread.

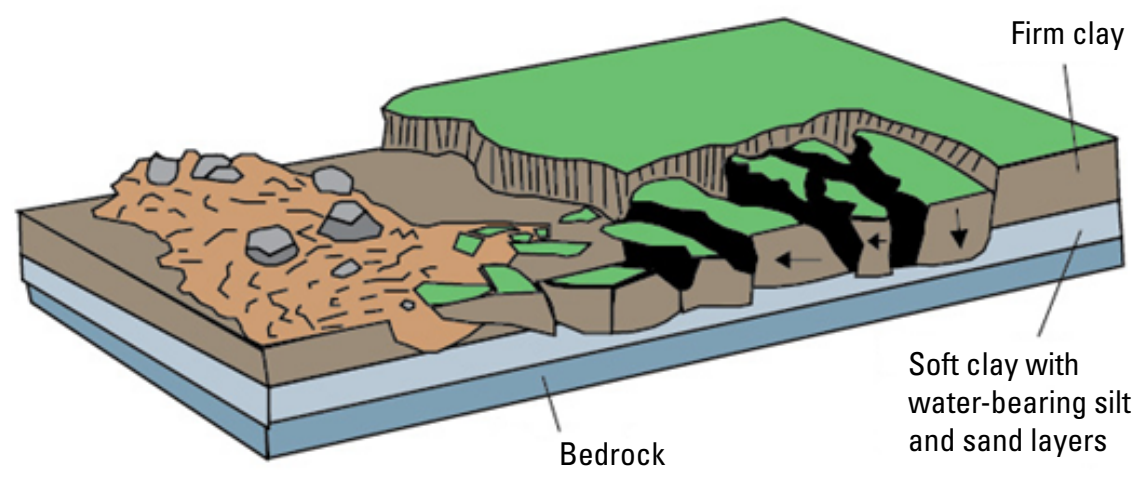

Figure 11. Schematic of a lateral spread. A liquefiable layer underlies the surface layer. (Schematic modified from Reference 9.)

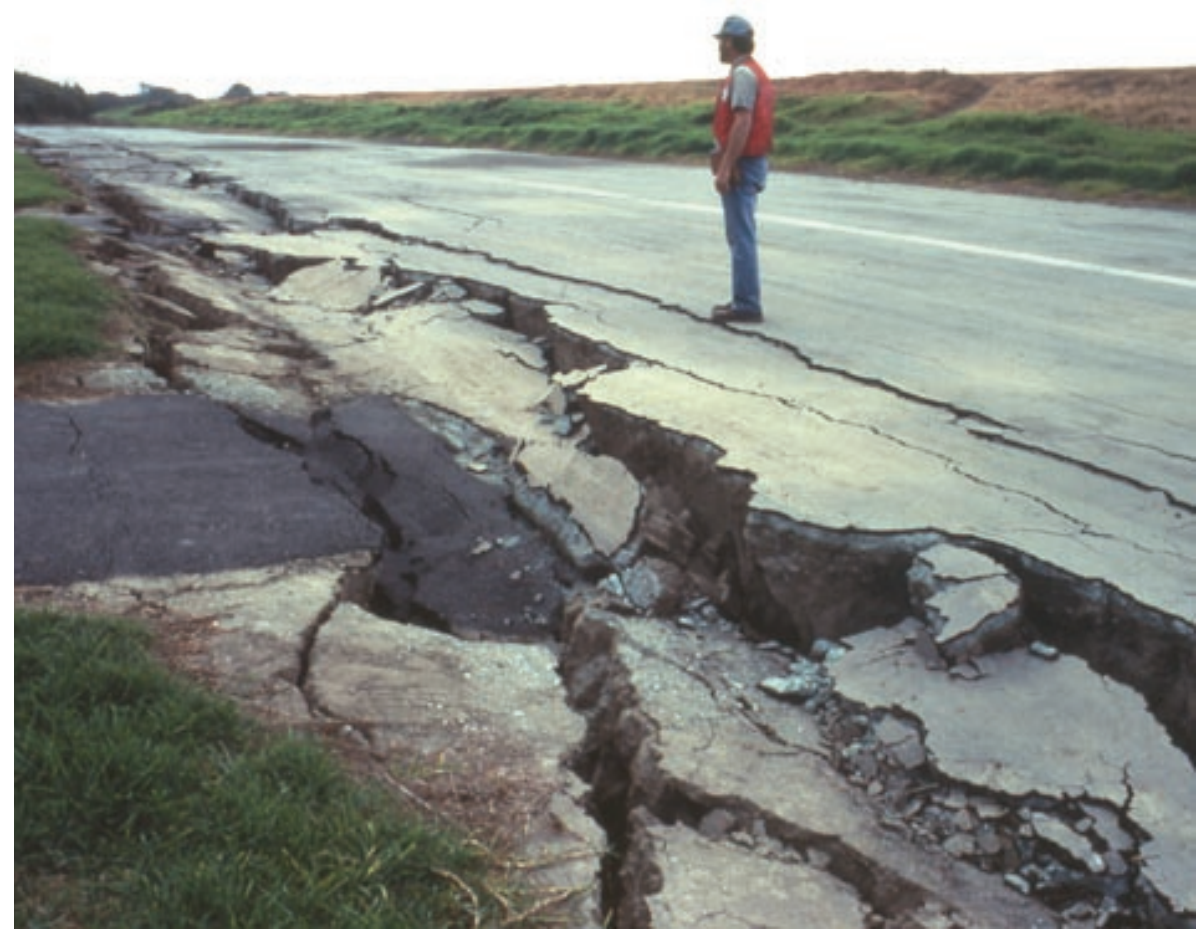

Figure 12. Photograph of lateral spread damage to a roadway as a result of the 1989 Loma Prieta, California, USA, earthquake. (Photograph by Steve Ellen, U.S. Geological Survey.) 


\section{Flows}

A flow is a spatially continuous movement in which the surfaces of shear are short-lived, closely spaced, and usually not preserved. The component velocities in the displacing mass of a flow resemble those in a viscous liquid. Often, there is a gradation of change from slides to flows, depending on the water content, mobility, and evolution of the movement.

\section{Debris Flows}

A form of rapid mass movement in which loose soil, rock and sometimes organic matter combine with water to form a slurry that flows downslope. They have been informally and inappropriately called "mudslides" due to the large quantity of fine material that may be present in the flow. Occasionally, as a rotational or translational slide gains velocity and the internal mass loses cohesion or gains water, it may evolve into a debris flow. Dry flows can sometimes occur in cohesionless sand (sand flows). Debris flows can be deadly as they can be extremely rapid and may occur without any warning.

\section{Occurrence}

Debris flows occur around the world and are prevalent in steep gullies and canyons; they can be intensified when occurring on slopes or in gullies that have been denuded of vegetation due to wildfires or forest logging. They are common in volcanic areas with weak soil.

\section{Relative size/range}

These types of flows can be thin and watery or thick with sediment and debris and are usually confined to the dimensions of the steep gullies that facilitate their downward movement. Generally the movement is relatively shallow and the runout is both long and narrow, sometimes extending for kilometers in steep terrain. The debris and mud usually terminate at the base of the slopes and create fanlike, triangular deposits called debris fans, which may also be unstable.

\section{Velocity of travel}

Can be rapid to extremely rapid ( 35 miles per hour or $56 \mathrm{~km}$ per hour) depending on consistency and slope angle.

\section{Triggering mechanisms}

Debris flows are commonly caused by intense surface-water flow, due to heavy precipitation or rapid snowmelt, that erodes and mobilizes loose soil or rock on steep slopes. Debris flows also commonly mobilize from other types of landslides that occur on steep slopes, are nearly saturated, and consist of a large proportion of silt- and sand-sized material.

\section{Effects (direct/indirect)}

Debris flows can be lethal because of their rapid onset, high speed of movement, and the fact that they can incorporate large boulders and other pieces of debris. They can move objects as large as houses in their downslope flow or can fill structures with a rapid accumulation of sediment and organic matter. They can affect the quality of water by depositing large amounts of silt and debris. 


\section{Mitigation measures}

Flows usually cannot be prevented; thus, homes should not be built in steep-walled gullies that have a history of debris flows or are otherwise susceptible due to wildfires, soil type, or other related factors. New flows can be directed away from structures by means of deflection, debris-flow basins can be built to contain flow, and warning systems can be put in place in areas where it is known at what rainfall thresholds debris flows are triggered. Evacuation, avoidance, and (or) relocation are the best methods to prevent injury and life loss.

\section{Predictability}

Maps of potential debris-flow hazards exist for some areas. Debris flows can be frequent in any area of steep slopes and heavy rainfall, either seasonally or intermittently, and especially in areas that have been recently burned or the vegetation removed by other means. Figures 13 and 14 show a schematic and an image of a debris flow.

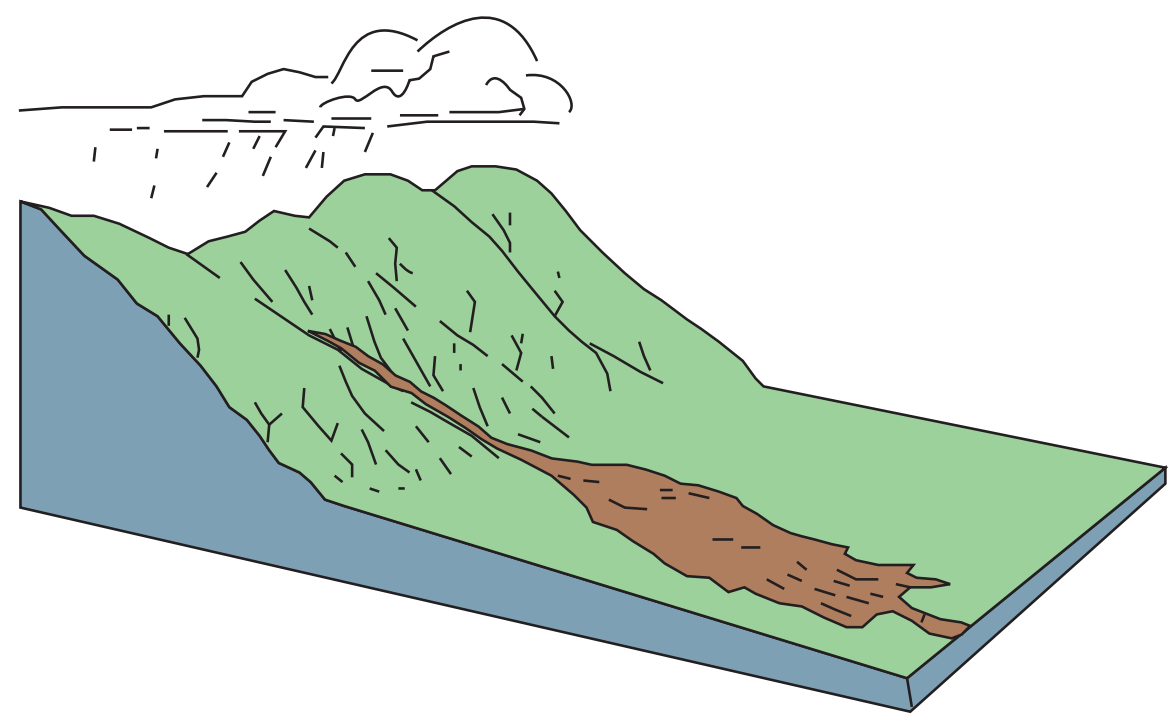

Figure 13. Schematic of a debris flow. (Schematic modified from Reference 9.)

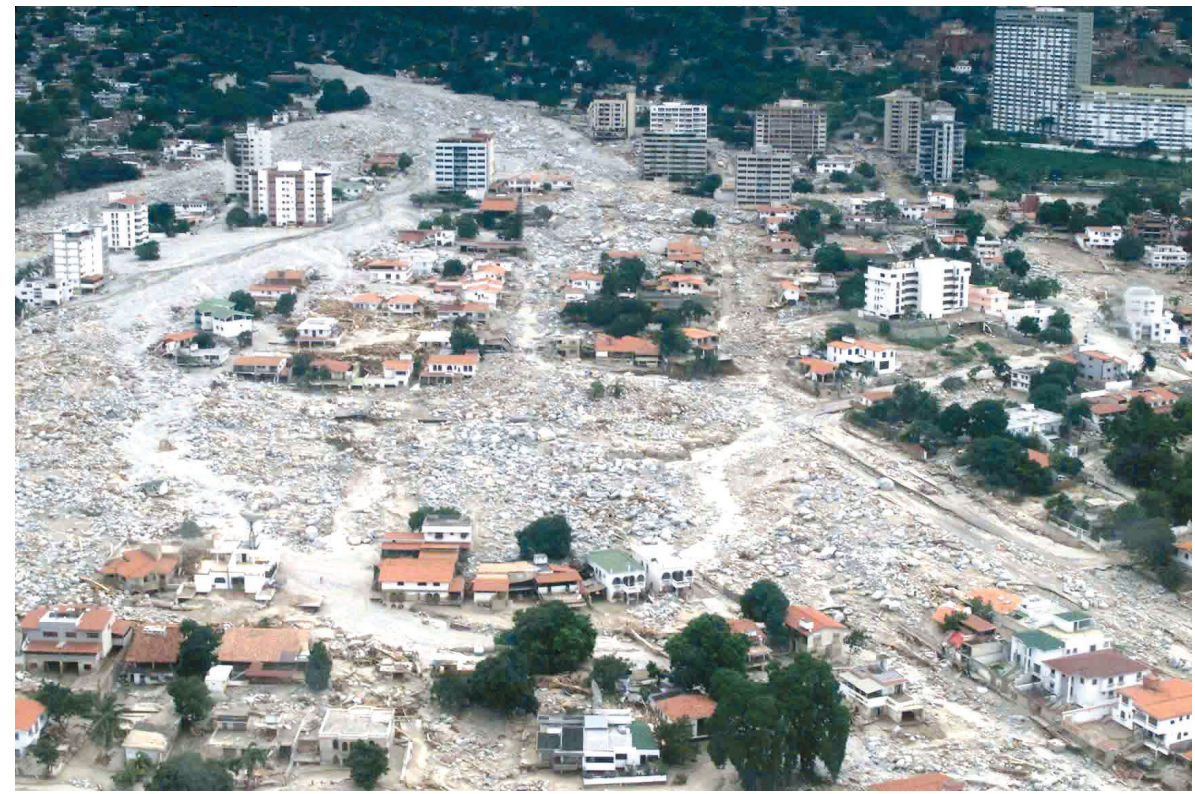

For further reading:

References 9, 39, 43, and 45
Figure 14. Debris-flow damage to the city of Caraballeda, located at the base of the Cordillera de la Costan, on the north coast of Venezuela. In December 1999, this area was hit by Venezuela's worst natural disaster of the 20th century; several days of torrential rain triggered flows of mud, boulders, water, and trees that killed as many as 30,000 people. (Photograph by L.M. Smith, Waterways Experiment Station, U.S. Army Corps of Engineers.) 


\section{Lahars (Volcanic Debris Flows)}

The word "lahar" is an Indonesian term. Lahars are also known as volcanic mudflows. These are flows that originate on the slopes of volcanoes and are a type of debris flow. A lahar mobilizes the loose accumulations of tephra (the airborne solids erupted from the volcano) and related debris.

\section{Occurrence}

Found in nearly all volcanic areas of the world.

\section{Relative size/range}

Lahars can be hundreds of square kilometers or miles in area and can become larger as they gain speed and accumulate debris as they travel downslope; or, they can be small in volume and affect limited areas of the volcano and then dissipate downslope.

\section{Velocity of travel}

Lahars can be very rapid (more than 35 miles per hour or 50 kilometers per hour) especially if they mix with a source of water such as melting snowfields or glaciers. If they are viscous and thick with debris and less water, the movement will be slow to moderately slow.

\section{Triggering mechanism}

Water is the primary triggering mechanism, and it can originate from crater lakes, condensation of erupted steam on volcano particles, or the melting of snow and ice at the top of high volcanoes. Some of the largest and most deadly lahars have originated from eruptions or volcanic venting which suddenly melts surrounding snow and ice and causes rapid liquefaction and flow down steep volcanic slopes at catastrophic speeds.

\section{Effects (direct/indirect)}

Effects can be extremely large and devastating, especially when triggered by a volcanic eruption and consequent rapid melting of any snow and ice- the flow can bury human settlements located on the volcano slopes. Some large flows can also dam rivers, causing flooding upstream. Subsequent breaching of these weakly cemented dams can cause catastrophic flooding downstream. This type of landslide often results in large numbers of human casualties.

\section{Mitigation measures}

No corrective measures are known that can be taken to prevent damage from lahars except for avoidance by not building or locating in their paths or on the slopes of volcanoes. Warning systems and subsequent evacuation work in some instances may save lives. However, warning systems require active monitoring, and a reliable evacuation method is essential. 


\section{Predictability}

Susceptibility maps based on past occurrences of lahars can be constructed, as well as runout estimations of potential flows. Such maps are not readily available for most hazardous areas. Figures 15 and 16 show a schematic and an image of a lahar.

For further reading:

References 9, 39, 43, and 45

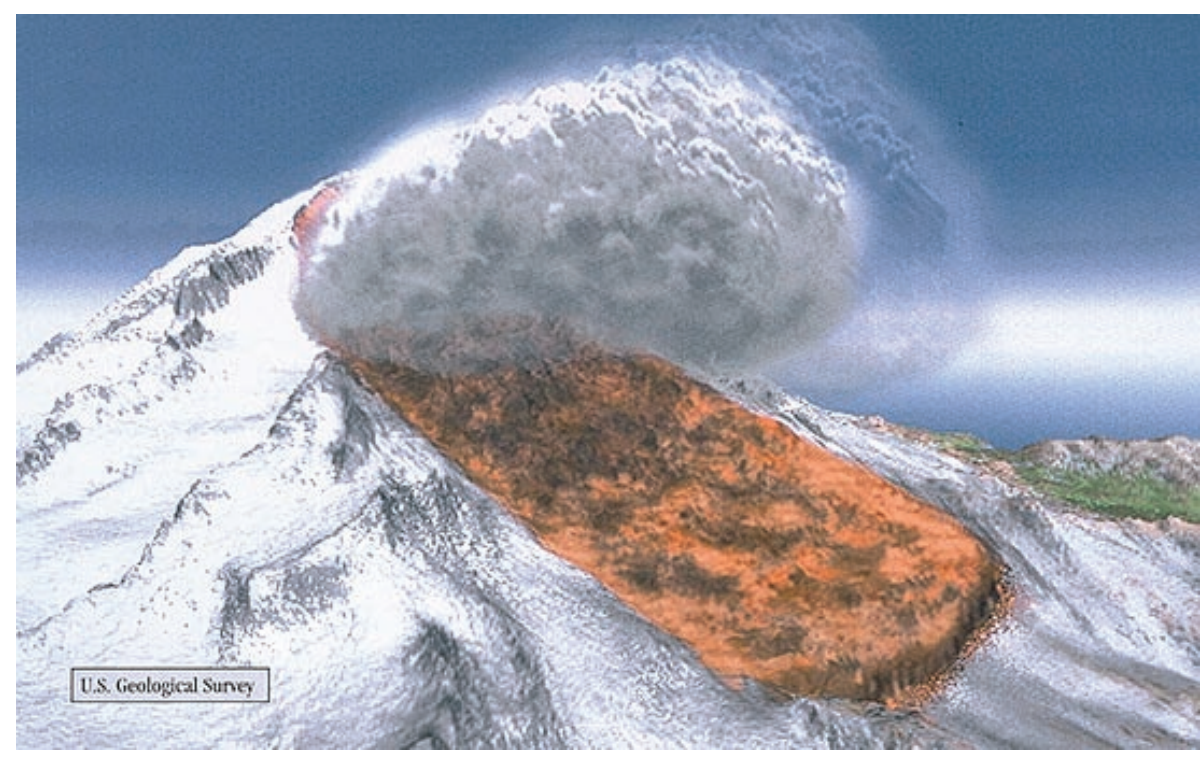

Figure 15. Schematic of a lahar. (Graphic by U.S. Geological Survey.)

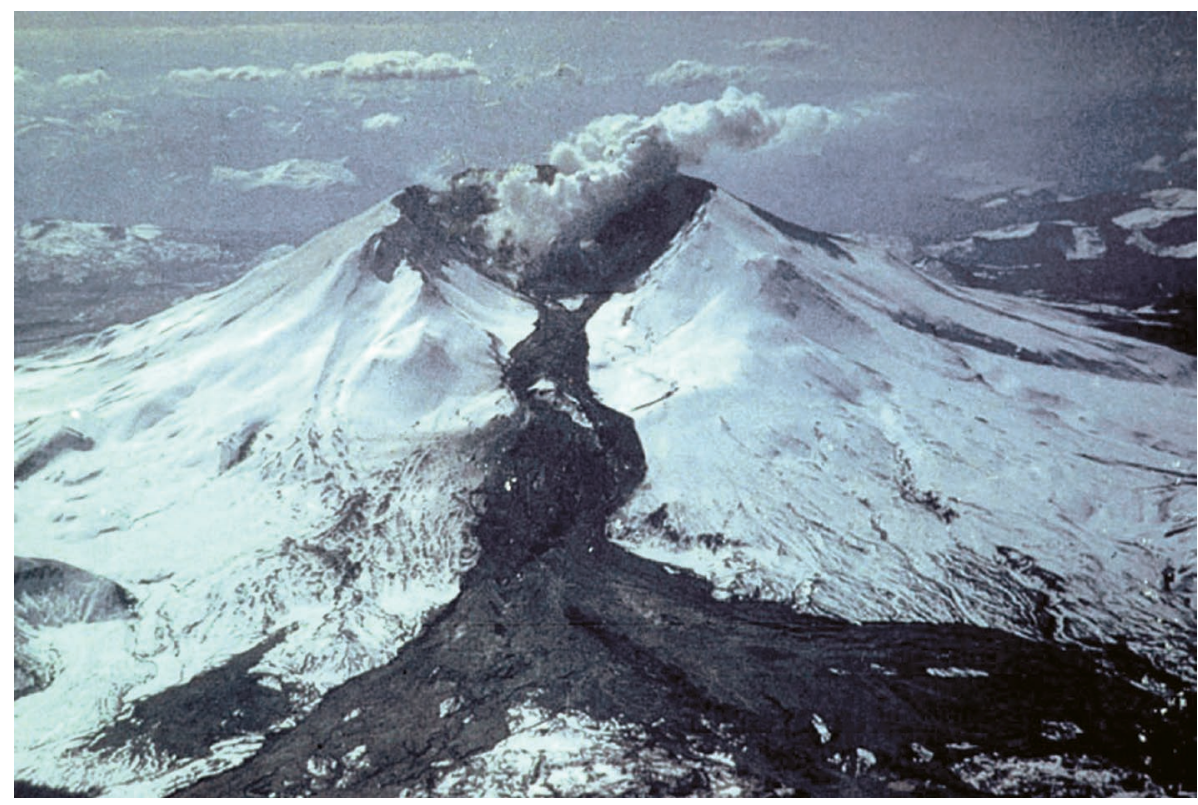

Figure 16. Photograph of a lahar caused by the 1982 eruption of Mount St. Helens in Washington, USA. (Photograph by Tom Casadevall, U.S. Geological Survey.) 


\section{Debris Avalanche}

Debris avalanches are essentially large, extremely rapid, often open-slope flows formed when an unstable slope collapses and the resulting fragmented debris is rapidly transported away from the slope. In some cases, snow and ice will contribute to the movement if sufficient water is present, and the flow may become a debris flow and (or) a lahar.

\section{Occurrence}

Occur worldwide in steep terrain environments. Also common on very steep volcanoes where they may follow drainage courses.

\section{Relative size/range}

Some large avalanches have been known to transport material blocks as large as 3 kilometers in size, several kilometers from their source.

\section{Velocity of travel}

Rapid to extremely rapid; such debris avalanches can travel close to $100 \mathrm{~meters} / \mathrm{sec}$.

\section{Triggering mechanism}

In general, the two types of debris avalanches are those that are "cold" and those that are "hot." A cold debris avalanche usually results from a slope becoming unstable, such as during collapse of weathered slopes in steep terrain or through the disintegration of bedrock during a slide-type landslide as it moves downslope at high velocity. At that point, the mass can then transform into a debris avalanche. A hot debris avalanche is one that results from volcanic activity including volcanic earthquakes or the injection of magma, which causes slope instability.

\section{Effects (direct/indirect)}

Debris avalanches may travel several kilometers before stopping, or they may transform into more water-rich lahars or debris flows that travel many tens of kilometers farther downstream. Such failures may inundate towns and villages and impair stream quality. They move very fast and thus may prove deadly because there is little chance for warning and response.

\section{Corrective measures/mitigation}

Avoidance of construction in valleys on volcanoes or steep mountain slopes and real-time warning systems may lessen damages. However, warning systems may prove difficult due to the speed at which debris avalanches occur - there may not be enough time after the initiation of the event for people to evacuate. Debris avalanches cannot be stopped or prevented by engineering means because the associated triggering mechanisms are not preventable. 


\section{Predictability}

If evidence of prior debris avalanches exists in an area, and if such evidence can be dated, a probabilistic recurrence period might be established. During volcanic eruptions, chances are greater for a debris avalanche to occur, so appropriate cautionary actions could be adopted.

Figures 17 and 18 show a schematic and an image of a debris avalanche.

For further reading: References 9, 39, 43, and 45

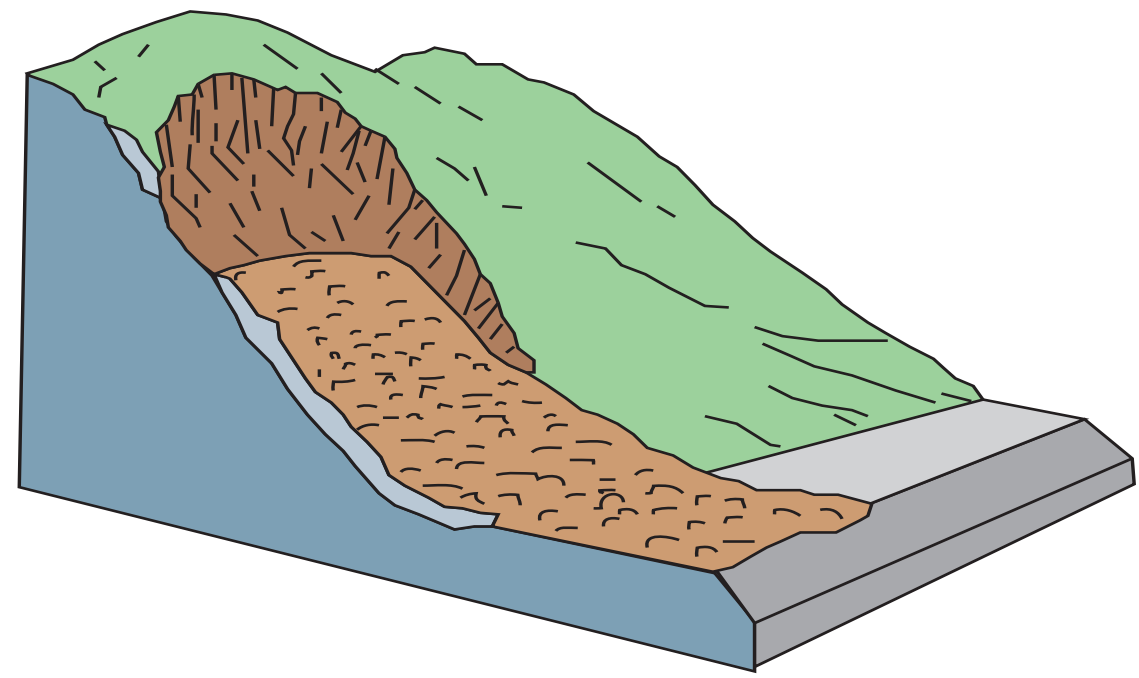

Figure 17. Schematic of a debris avalanche. (Schematic modified from Reference 9.)

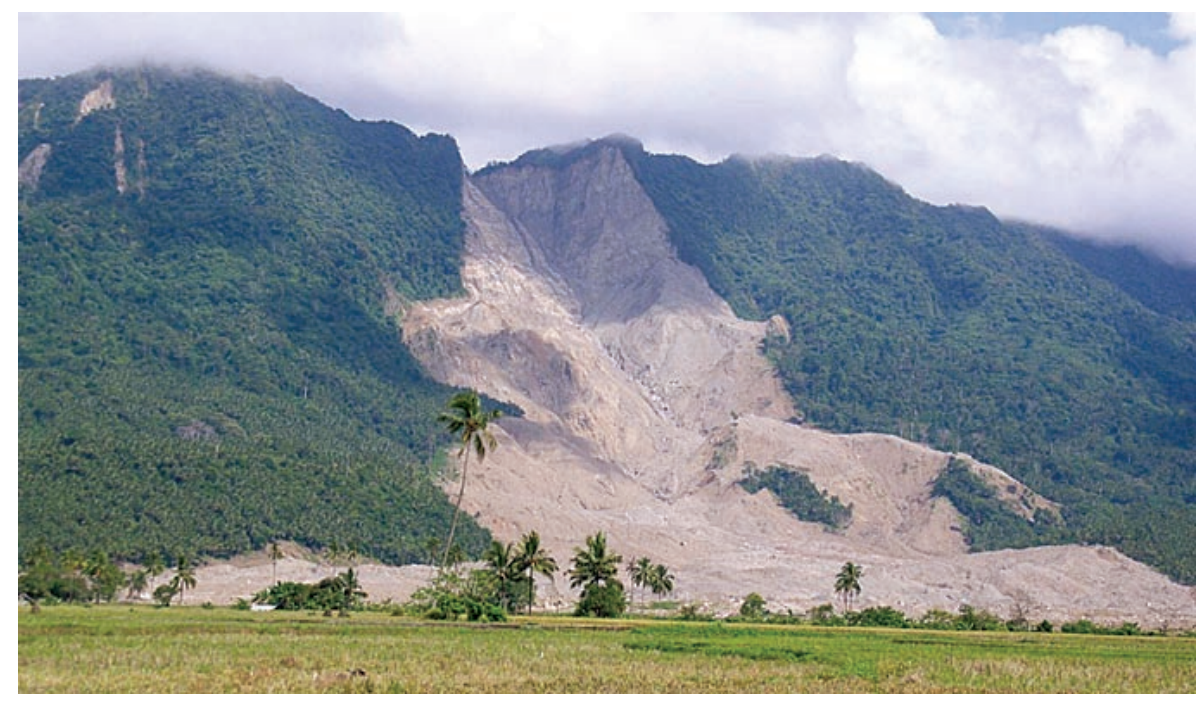

Figure 18. A debris avalanche that buried the village of Guinsaugon, Southern Leyte, Philippines, in February 2006. (Photograph by University of Tokyo Geotechnical Team.) Please see figure 30 for an image of another debris avalanche. 


\section{Earthflow}

Earthflows can occur on gentle to moderate slopes, generally in fine-grained soil, commonly clay or silt, but also in very weathered, clay-bearing bedrock. The mass in an earthflow moves as a plastic or viscous flow with strong internal deformation. Susceptible marine clay (quick clay) when disturbed is very vulnerable and may lose all shear strength with a change in its natural moisture content and suddenly liquefy, potentially destroying large areas and flowing for several kilometers. Size commonly increases through headscarp retrogression. Slides or lateral spreads may also evolve downslope into earthflows. Earthflows can range from very slow (creep) to rapid and catastrophic. Very slow flows and specialized forms of earthflow restricted to northern permafrost environments are discussed elsewhere.

\section{Occurrence}

Earthflows occur worldwide in regions underlain by fine-grained soil or very weathered bedrock. Catastrophic rapid earthflows are common in the susceptible marine clays of the St. Lawrence Lowlands of North America, coastal Alaska and British Columbia, and in Scandinavia.

\section{Relative (size/range)}

Flows can range from small events of 100 square meters in size to large events encompassing several square kilometers in area. Earthflows in susceptible marine clays may runout for several kilometers. Depth of the failure ranges from shallow to many tens of meters.

\section{Velocity of travel}

Slow to very rapid.

\section{Triggering mechanisms}

Triggers include saturation of soil due to prolonged or intense rainfall or snowmelt, sudden lowering of adjacent water surfaces causing rapid drawdown of the ground-water table, stream erosion at the bottom of a slope, excavation and construction activities, excessive loading on a slope, earthquakes, or human-induced vibration.

\section{Effects (direct/indirect)}

Rapid, retrogressive earthflows in susceptible marine clay may devastate large areas of flat land lying above the slope and also may runout for considerable distances, potentially resulting in human fatalities, destruction of buildings and linear infrastructure, and damming of rivers with resultant flooding upstream and water siltation problems downstream. Slower earthflows may damage properties and sever linear infrastructure.

\section{Corrective measures/mitigation}

Improved drainage is an important corrective measure, as is grading of slopes and protecting the base of the slope from erosion or excavation. Shear strength of clay can be measured, and potential pressure can be monitored in suspect slopes. However, the best mitigation is to avoid development activities near such slopes. 


\section{Predictability}

Evidence of past earthflows is the best indication of vulnerability. Distribution of clay likely to liquefy can in some cases be mapped and has been mapped in many parts of eastern North America. Cracks opening near the top of the slope may indicate potential failure. Figures 19 and 20 show a schematic and an image of an earthflow.

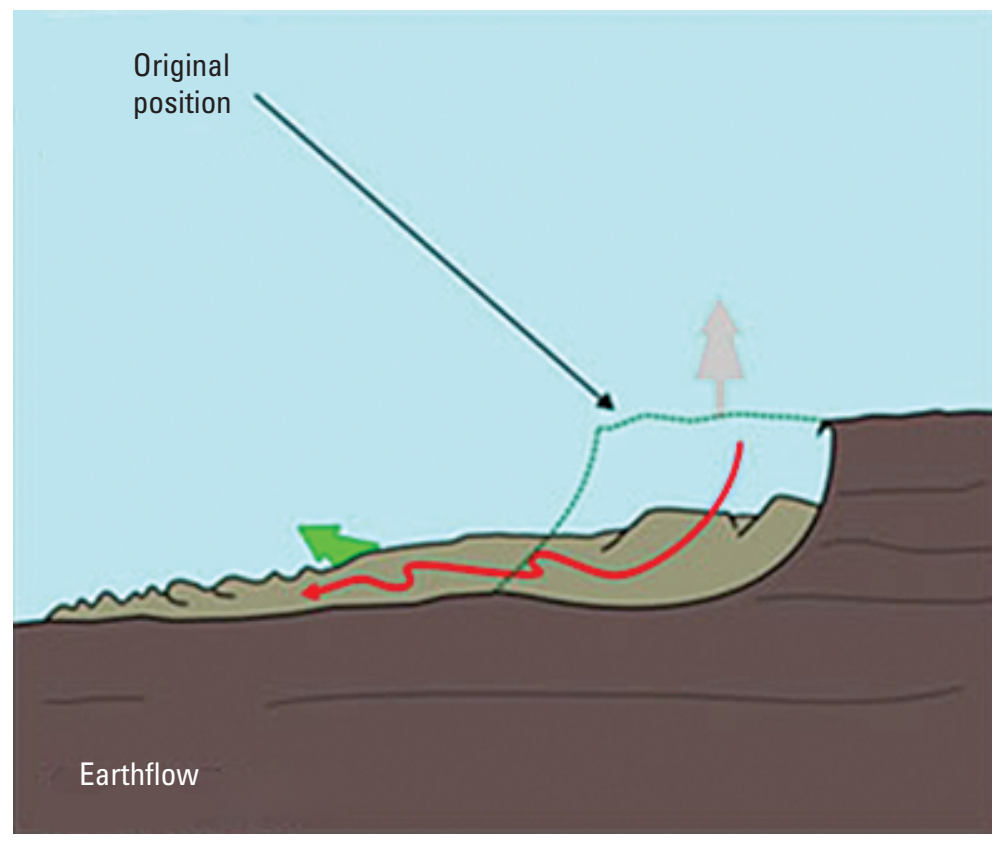

Figure 19. Schematic of an earthflow. (Schematic from Geological Survey of Canada.)

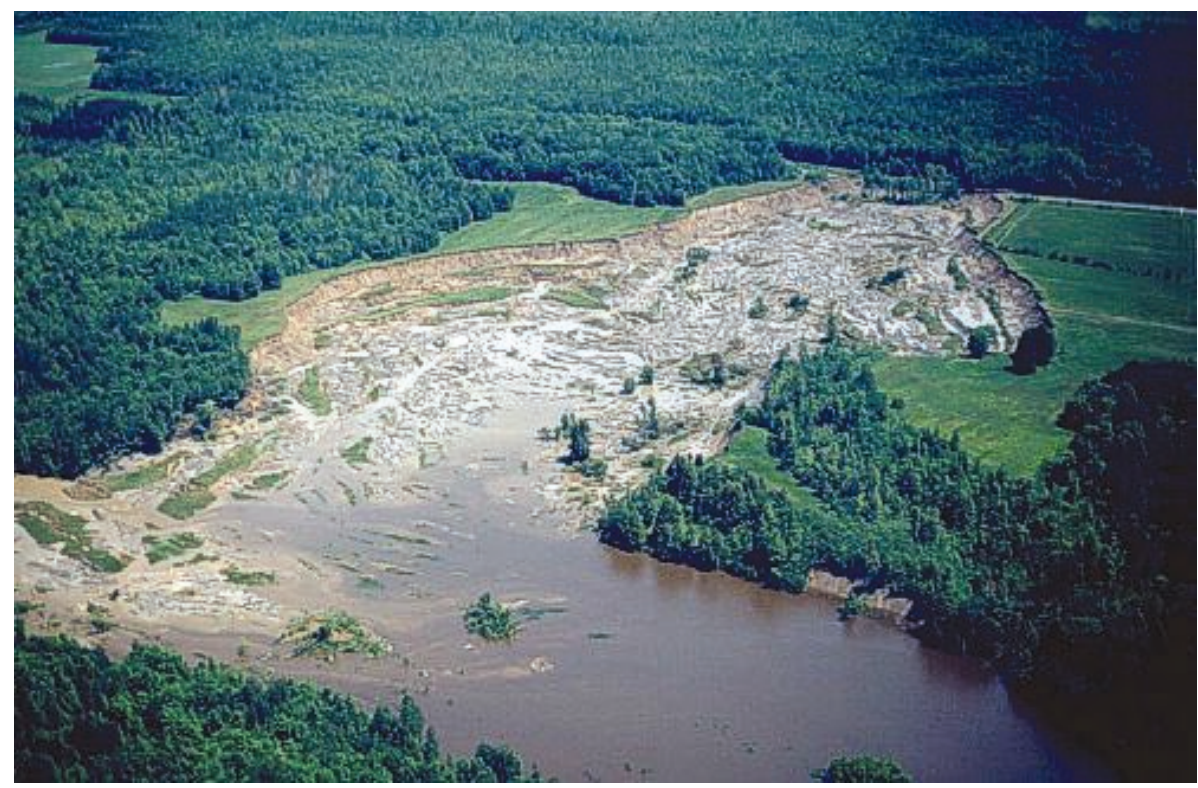

Figure 20. The 1993 Lemieux landslide — a rapid earthflow in sensitive marine clay near Ottawa, Canada. The headscarp retrogressed 680 meters into level ground above the riverbank. About 2.8 million tons of clay and silt liquefied and flowed into the South Nation River valley, damming the river. (Photograph by G.R. Brooks, Geological Survey of Canada.) 


\section{Slow Earthflow (Creep)}

Creep is the informal name for a slow earthflow and consists of the imperceptibly slow, steady downward movement of slope-forming soil or rock. Movement is caused by internal shear stress sufficient to cause deformation but insufficient to cause failure. Generally, the three types of creep are: (1) seasonal, where movement is within the depth of soil affected by seasonal changes in soil moisture and temperature; (2) continuous, where shear stress continuously exceeds the strength of the material; and (3) progressive, where slopes are reaching the point of failure for other types of mass movements.

\section{Occurrence}

Creep is widespread around the world and is probably the most common type of landslide, often preceding more rapid and damaging types of landslides. Solifluction, a specialized form of creep common to permafrost environments, occurs in the upper layer of ice-rich, fine-grained soils during the annual thaw of this layer.

\section{Relative size/range}

Creep can be very regional in nature (tens of square kilometers) or simply confined to small areas. It is difficult to discern the boundaries of creep since the event itself is so slow and surface features representing perceptible deformation may be lacking.

\section{Velocity of travel}

Very slow to extremely slow. Usually less than 1 meter ( 0.3 foot) per decade.

\section{Triggering mechanism}

For seasonal creep, rainfall and snowmelt are typical triggers, whereas for other types of creep there could be numerous causes, such as chemical or physical weathering, leaking pipes, poor drainage, destabilizing types of construction, and so on.

\section{Effects}

Because it is hard to detect in some places because of the slowness of movement, creep is sometimes not recognized when assessing the suitability of a building site. Creep can slowly pull apart pipelines, buildings, highways, fences, and so forth, and can lead to more drastic ground failures that are more destructive and faster moving.

\section{Corrective measures/mitigation}

The most common mitigation for creep is to ensure proper drainage of water, especially for the seasonal type of creep. Slope modification such as flattening or removing all or part of the landslide mass, can be attempted, as well as the construction of retaining walls. 


\section{Predictability}

Indicated by curved tree trunks, bent fences and (or) retaining walls, tilted poles or fences, and small soil ripples or ridges on the surface. Rates of creep can be measured by inclinometers installed in boreholes or by detailed surface measurements. Figures 21 and 22 show a schematic and an image of creep.

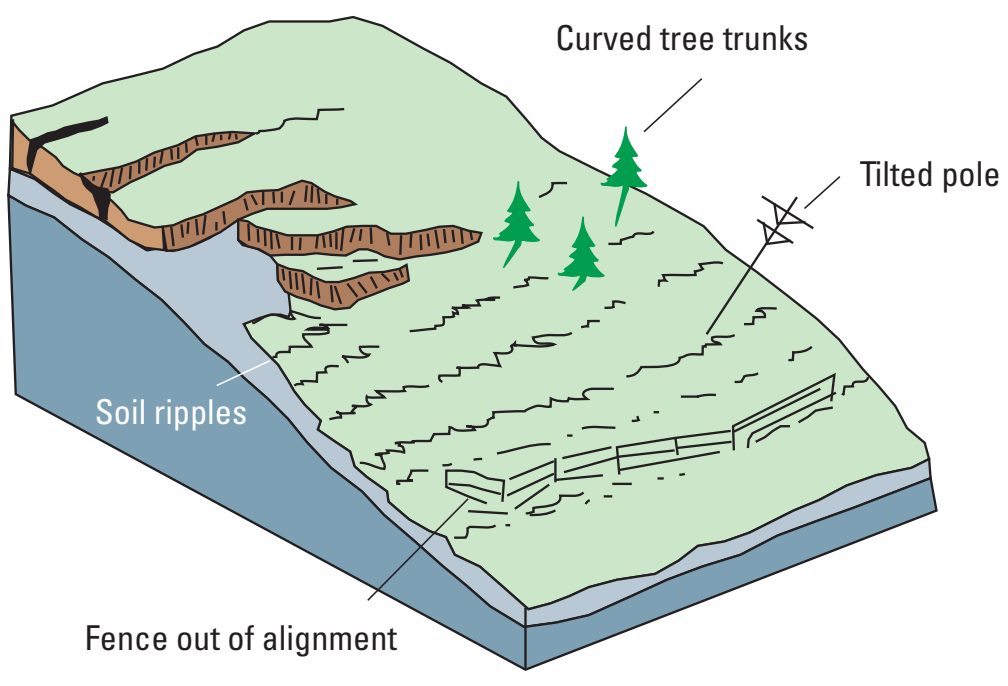

Figure 21. Schematic of a slow earthflow, often called creep. (Schematic modified from Reference 9.)

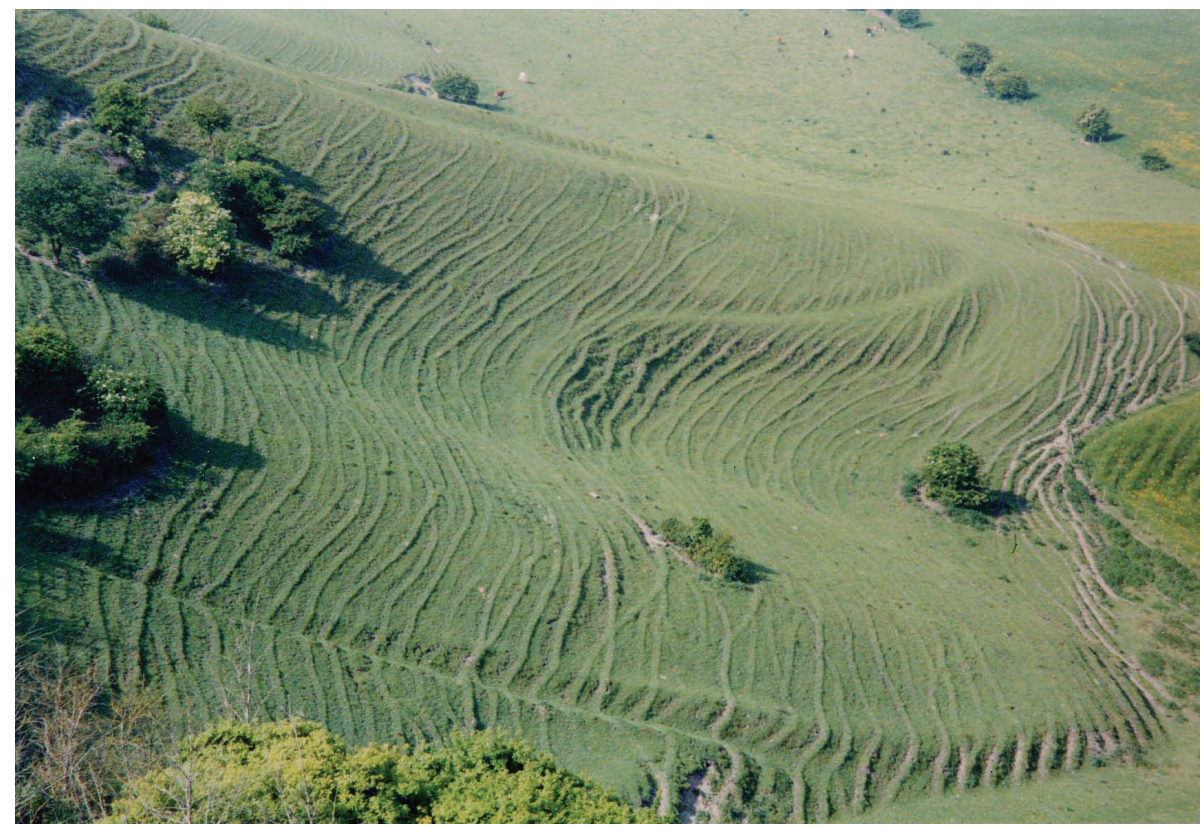

Figure 22. This photograph shows the effects of creep, in an area near East Sussex, United Kingdom, called the Chalk Grasslands. Steep slopes of thin soil over marine chalk deposits, develop a ribbed pattern of grass-covered horizontal steps that are 0.3 to 0.6 meter ( 1 to 2 feet) high. Although subsequently made more distinct by cattle and sheep walking along them, these terraces (commonly known as sheep tracks) were formed by the gradual, creeping movement of soil downhill. (Photograph by Ian Alexander.)
For further reading:

References 9, 39, 43, and 45 


\section{Flows in Permafrost}

Failures in permafrost conditions involve the movement of fine-grained, previously ice-rich soil and can occur on gentle slopes. Seasonal thaw of the upper meter of frozen ground melts ground ice and results in oversaturation of the soil, which in turn loses shear strength and initiates flows. Solifluction, a form of cold environment creep, involves very slow deformation of the surface and forms shallow lobes elongated downslope. Active layer detachments, also known as skinflows, involve rapid flow of a shallow layer of saturated soil and vegetation, forming long, narrow flows moving on the surface but over the underlying permanently frozen soil. This type of movement may expose buried ice lenses, which when thawed may develop into retrogressive thaw flows or possibly debris flows. Retrogressive thaw flows are larger features with a bimodal shape of a steep headwall and low-angle tongue of saturated soil. This type of feature will continue to expand through headscarp retrogression until displaced vegetation buries and insulates the ice-rich scarp.

\section{Occurrence}

Flows are common in ice-rich permafrost soils in northern latitudes and high altitudes (cold environments).

\section{Relative size/range}

Flows are generally small but can increase in size through headscarp retrogression. They may evolve into a larger debris flow.

\section{Velocity of travel}

Very slow (solifluction); slow (retrogressive thaw flow); rapid (active layer detachment).

\section{Triggering mechanisms}

Above-average summer temperatures, frost wedges, wildfire, and anthropogenic disturbances to insulating peat layer. Such landslides are particularly likely in warming climates.

\section{Effects (direct/indirect)}

Damage to pipelines and roads and other structures can be severe.

\section{Corrective measures/mitigation}

Infrastructure designs that have minimal effect on the surface peat layer or temperature of the active layer and avoidance, when possible, of icerich soils when planning roads and other infrastructure, can reduce risk. Ice content of the upper soil can be readily tested.

\section{Predictability}

For further reading: References 2, 9, 39, 43, and 45
If ice-rich soil thaws, it will flow. In some areas, ice content has been mapped; in other areas, ice content can be estimated on the basis of specific mapped units shown on surficial geology maps. Figures 23 and 24 show a schematic and an image of permafrost-related flow. 


\section{A. Original slope}

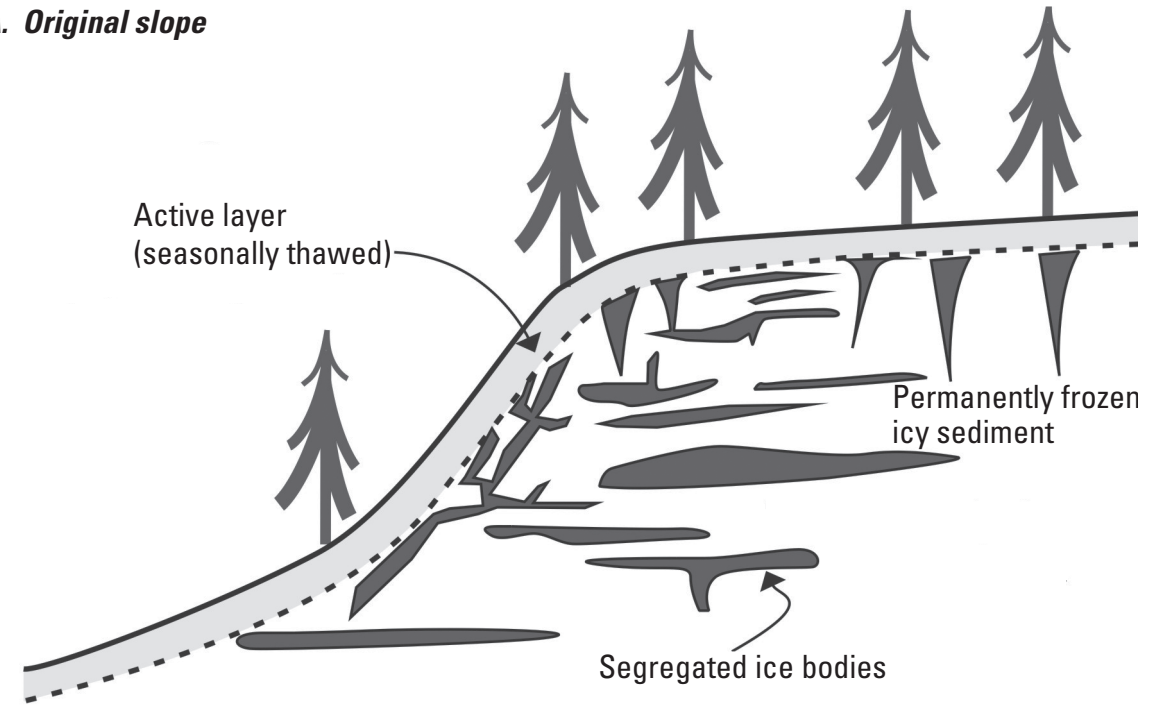

\section{B. Retrogressive thaw flow in progress}

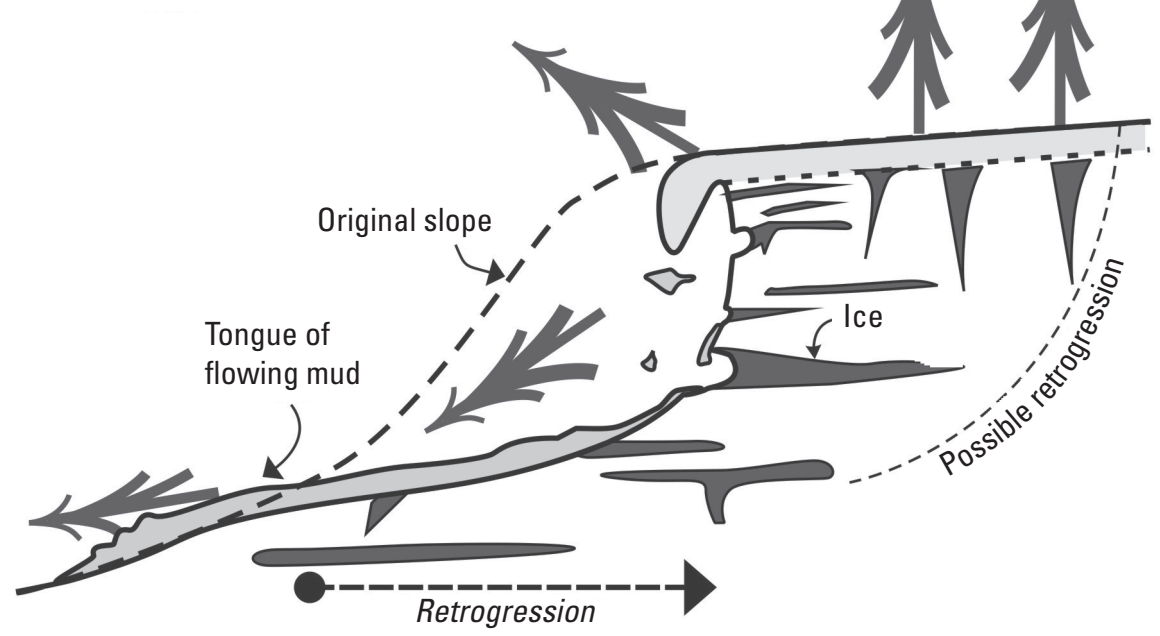

Figure 23. Schematic of a retrogressive thaw flow slide. (Schematic by Jan Aylsworth, Geological Survey of Canada.)

A note about complex landslides:

These are landslides that feature components of two or more of the basic types of landslides and can occur either simultaneously or at different times during the onset of slope failure. 


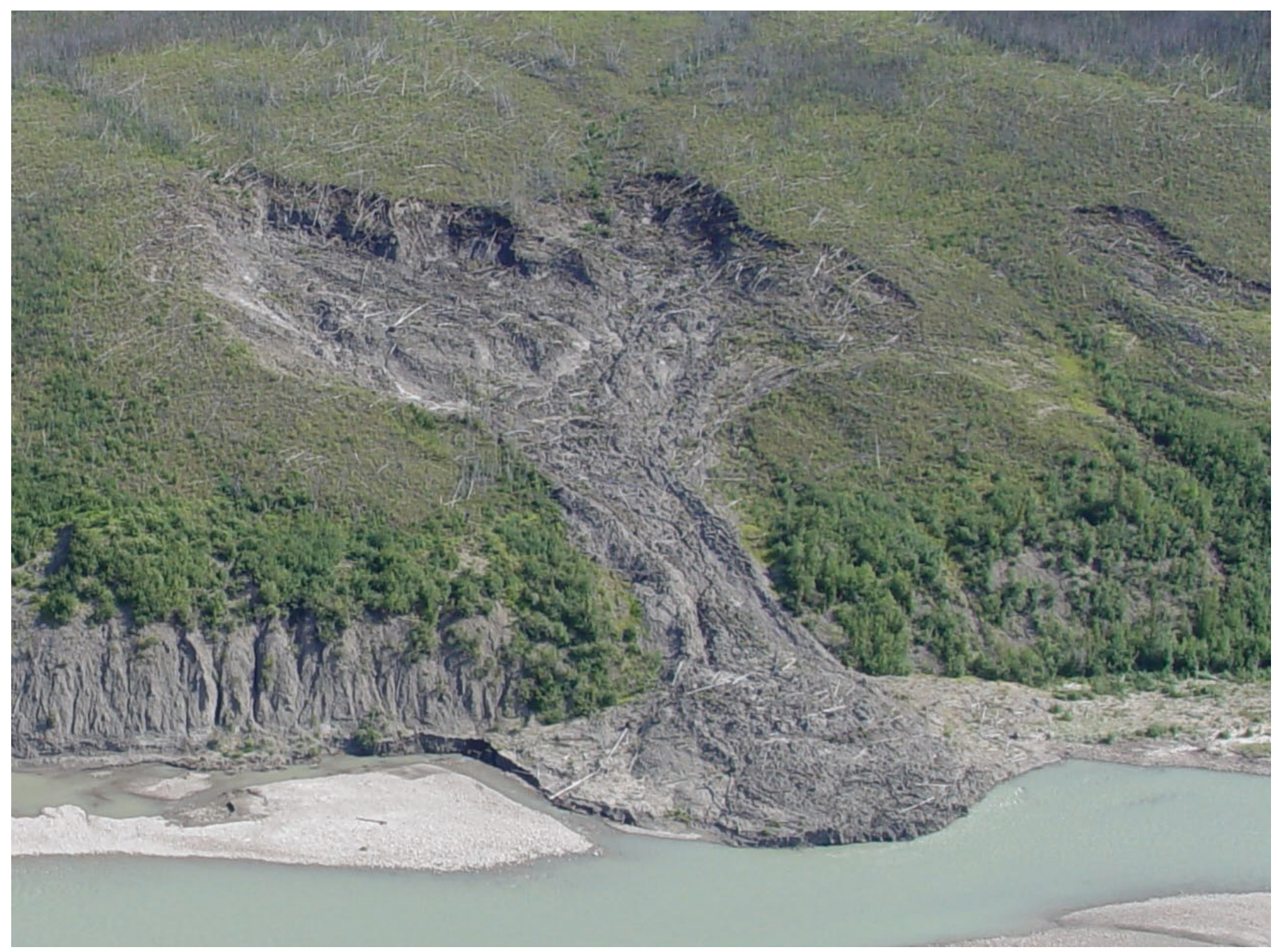

Figure 24. Photograph of a retrogressive thaw flow in the Northwest Territories, Canada. Wildfire has likely contributed to the size of the flow by means of damage to an insulating moss layer, resulting in the thickening of the active layer, which is thawing permafrost. (Photograph by Marten Geertsema, Ministry of Forests, British Columbia, Canada.) 


\section{Part C. Where Do Landslides Occur?}

A surprising fact to many people is that landslides can occur virtually anywhere in the world. The traditional viewpoint that landslides are restricted to extremely steep slopes and inhospitable terrain does not accurately reflect the real nature of the problem. Most countries in the world have been affected in some manner by landslides. The reason for such wide geographic coverage has much to do with the many different triggering mechanisms for landslides.

Excessive precipitation, earthquakes, volcanoes, forest fires and other mechanisms, and more recently, certain dangerous human activities are just some of the key causes that can trigger landslides. See "Part D. What Causes Landslides?" for more information on triggering mechanisms. Figure 25 shows an example of lateral spreading, a type of ground failure often associated with earthquakes.

Similarly, landslides are known to occur both on land and under water; they can occur in bedrock or on soils; cultivated land, barren slopes and natural forests are all subject to landslides. Both extremely dry areas and very humid areas can be affected by slope failures, and most important, steep slopes are not a necessary prerequisite for landslides to occur. In some cases, gentle slopes as shallow as 1-2 degrees have been observed to fail.

Bearing in mind that landslides can happen virtually anywhere around the world, we do, however, recognize certain patterns in their occurrence. At the national scale in countries such as Canada and the United States, the association of hilly terrain such as the Rocky Mountains with certain types of landslides is clear. Other geographic trends in landslide distribution can be linked to natural patterns of climate and weather, wildfires, and stream/river courses or human patterns involving the clearing of vegetation, modification to slopes, and other urban and rural practices. In each of these cases, it is important to recognize that landslide types vary in relation to the local and regional conditions.

Debris torrents require channels and ravines to occur, whereas rockfalls will happen only where steep, exposed faces of bedrock or boulder-rich deposits are present. Geology itself figures prominently in the occurrence of many landslides. The correlation of seismic and volcanic activity to landslides is of paramount importance, so specialists often approach the evaluation of hazards from a multi-hazard perspective, which by definition takes into account most of the factors discussed previously.

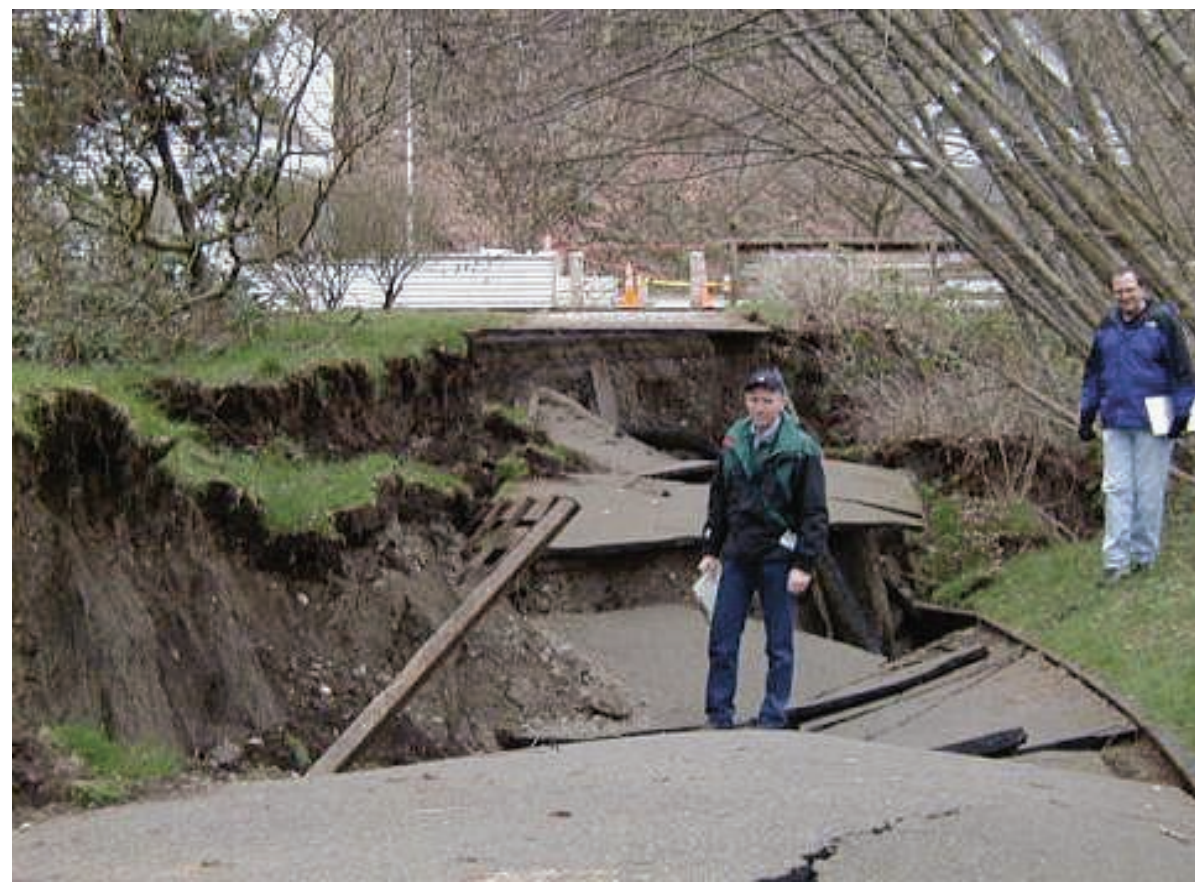

For further reading: Reference 2

For further reading:

References 8, 16, 19, 25, 30, and 45
Figure 25. Lateral spreading damage. Photograph shows the Puget Sound area in Washington, USA, after the 2001 Nisqually earthquake. (Photograph courtesy of the Seattle Times.) 


\section{Part D. What Causes Landslides?}

There are two primary categories of causes of landslides: natural and humancaused. Sometimes, landslides are caused, or made worse, by a combination of the two factors.

\section{Natural Occurrences}

This category has three major triggering mechanisms that can occur either singly or in combination - (1) water, (2) seismic activity, and (3) volcanic activity. Effects of all of these causes vary widely and depend on factors such as steepness of slope, morphology or shape of terrain, soil type, underlying geology, and whether there are people or structures on the affected areas. Effects of landslides will be discussed in more detail in Part E.

\section{Landslides and Water}

Slope saturation by water is a primary cause of landslides. Saturation can occur in the form of intense rainfall, snowmelt, changes in ground-water levels, and surfacewater level changes along coastlines, earth dams, and in the banks of lakes, reservoirs, canals, and rivers. Landslides and flooding are closely associated because both are related to precipitation, runoff, and the saturation of ground by water. Flooding may cause landslides by undercutting banks of streams and rivers and by saturation of slopes by surface water (overland flow). In addition, debris flows and mudflows usually occur in small, steep stream channels and commonly are mistaken for floods; in fact, these two events often occur simultaneously in the same area. Conversely, landslides also can cause flooding when sliding rock and debris block stream channels and other waterways, allowing large volumes of water to back up behind such dams. This causes backwater flooding and, if the dam fails, subsequent downstream flooding. Moreover, solid landslide debris can "bulk" or add volume and density to otherwise normal streamflow or cause channel blockages and diversions, creating flood conditions or localized erosion. Landslides also can cause tsunamis (seiches), overtopping of reservoirs, and (or) reduced capacity of reservoirs to store water. Steep wildfire-burned slopes often are landslide-prone due to a combination of the burning and resultant denudation of vegetation on slopes, a change in soil chemistry due to burning, and a subsequent saturation of slopes by water from various sources, such as rainfall. Debris flows are the most common type of landslide on burned slopes (for a description and images of a debris flow, see "Part B. Basic Landslide Types" in Section I). Wildfires, of course, may be the result of natural or human causes. Figure 26 shows a devastating landslide caused by rainfall, and possibly made worse by a leaking water pipe, which added even more water to the soil. 


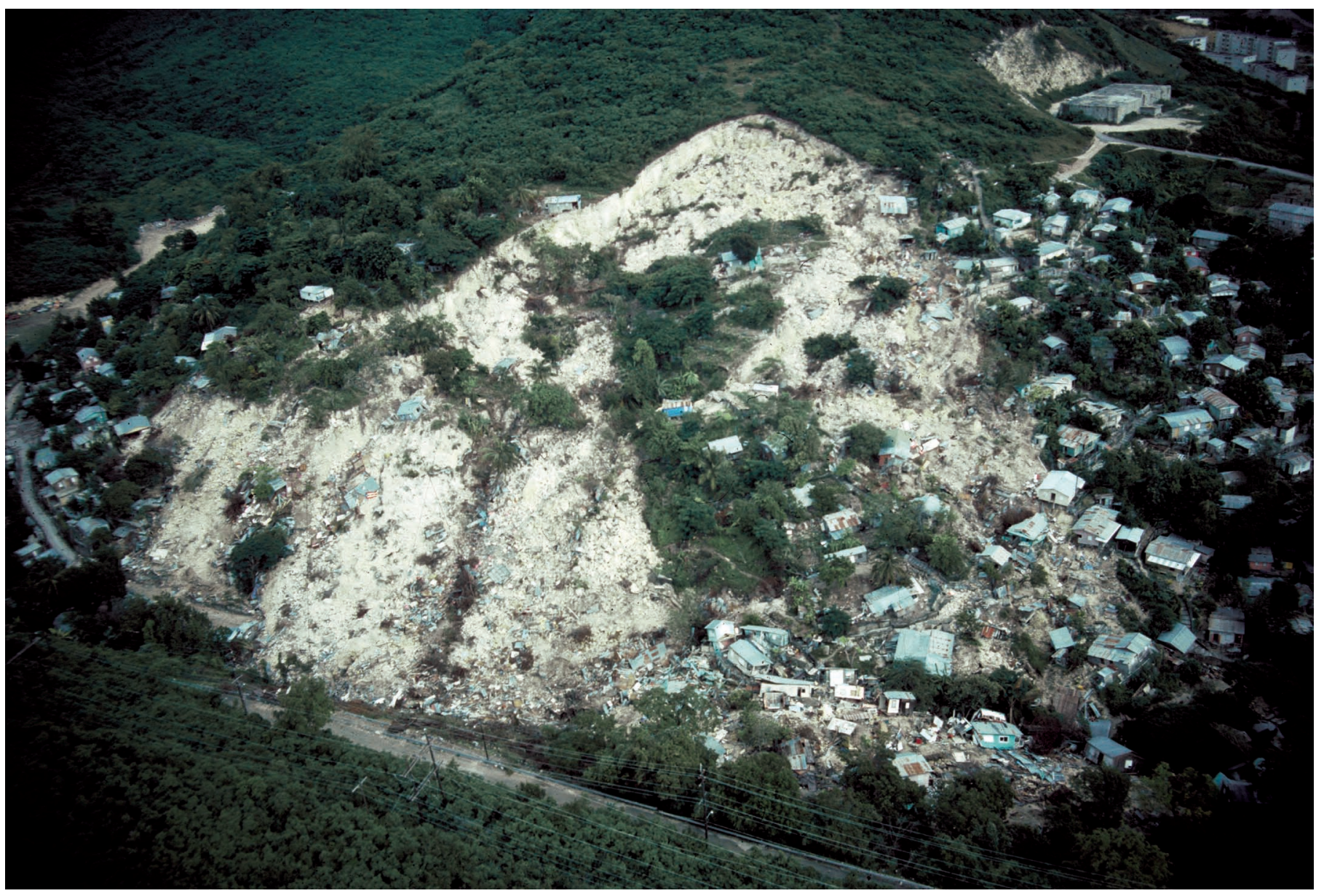

Figure 26. The Mameyes, Puerto Rico, landslide, 1985. This landslide destroyed 120 houses and killed at least 129 people. The catastrophic slide was triggered by a tropical storm that produced extremely heavy rainfall. Contributing factors could also have included sewage saturating the ground in the densely populated area, and a leaking water pipe at the top of the landslide. (Photograph by Randall Jibson, U.S. Geological Survey.) 
Figures 32, 42, C53, C54, and C55 show examples of large landslide dams that still exist

\section{Landslides and Seismic Activity}

Many mountainous areas that are vulnerable to landslides have also experienced at least moderate rates of earthquake activity in recorded times. Earthquakes in steep landslide-prone areas greatly increase the likelihood that landslides will occur, due to ground shaking alone, liquefaction of susceptible sediments, or shaking-caused dilation of soil materials, which allows rapid infiltration of water. For instance, the 1964 Great Alaska earthquake in the United States caused widespread landsliding and other ground failure, which led to most of the monetary loss attributed to the earthquake. Other areas in North America, such as the State of California, the Puget Sound region in Washington, and the St. Lawrence lowlands of eastern Canada, have experienced landslides, lateral spreading, and other types of ground failure classified as landslides, due to moderate to large earthquakes. Rockfalls and rock topples can also be caused by loosening of rocks or rocky formations as a result of earthquake ground shaking. Figure 27 shows damage from a landslide that was triggered by an earthquake. There is also a great danger of landslide dams forming in streams and rivers below steep slopes, a result of rock and earth being shaken down by the earthquake. These landslide dams often completely or partially block the flow of water, causing water to back up behind the landslide dam, flooding areas upriver. As these dams are often unstable, they may erode either quickly or over a period of time and fail catastrophically, unleashing the backed up water as a rapid deluge below the dam. This deluge is capable of causing a great deal of damage downriver.

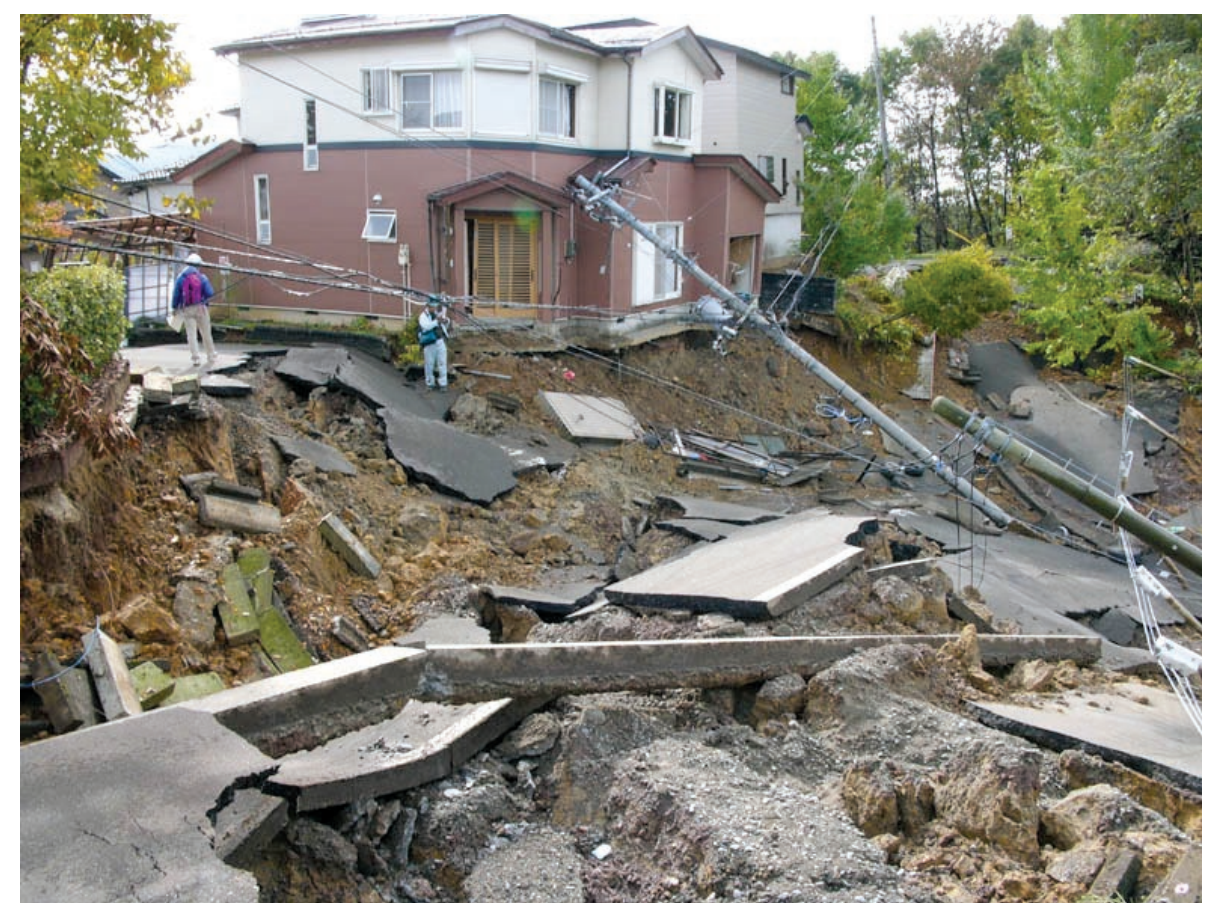

Figure 27. Earthquake-induced landslide damage to a house built on artificial fill, after the 2004 Niigata Prefecture earthquake in Japan. (Photograph by Professor Kamai, Kyoto University, Japan.) 


\section{Landslides and Volcanic Activity}

Landslides due to volcanic activity represent some of the most devastating types of failures. Volcanic lava may melt snow rapidly, which can form a deluge of rock, soil, ash, and water that accelerates rapidly on the steep slopes of volcanoes, devastating anything in its path. These volcanic debris flows (also known as lahars, an Indonesian term) can reach great distances after they leave the flanks of the volcano and can damage structures in flat areas surrounding the volcanoes. Volcanic edifices are young, unconsolidated, and geologically weak structures that in many cases can collapse and cause rockslides, landslides, and debris avalanches. Many islands of volcanic origin experience periodic failure of their perimeter areas (due to the weak volcanic surface deposits), and masses of soil and rock slide into the ocean or other water bodies, such as inlets. Such collapses may create massive sub-marine landslides that may also rapidly displace water, subsequently creating deadly tsunamis that can travel and do damage at great distances, as well as locally. Figure 28 shows a collapse of the side of a volcano and the resulting devastation.

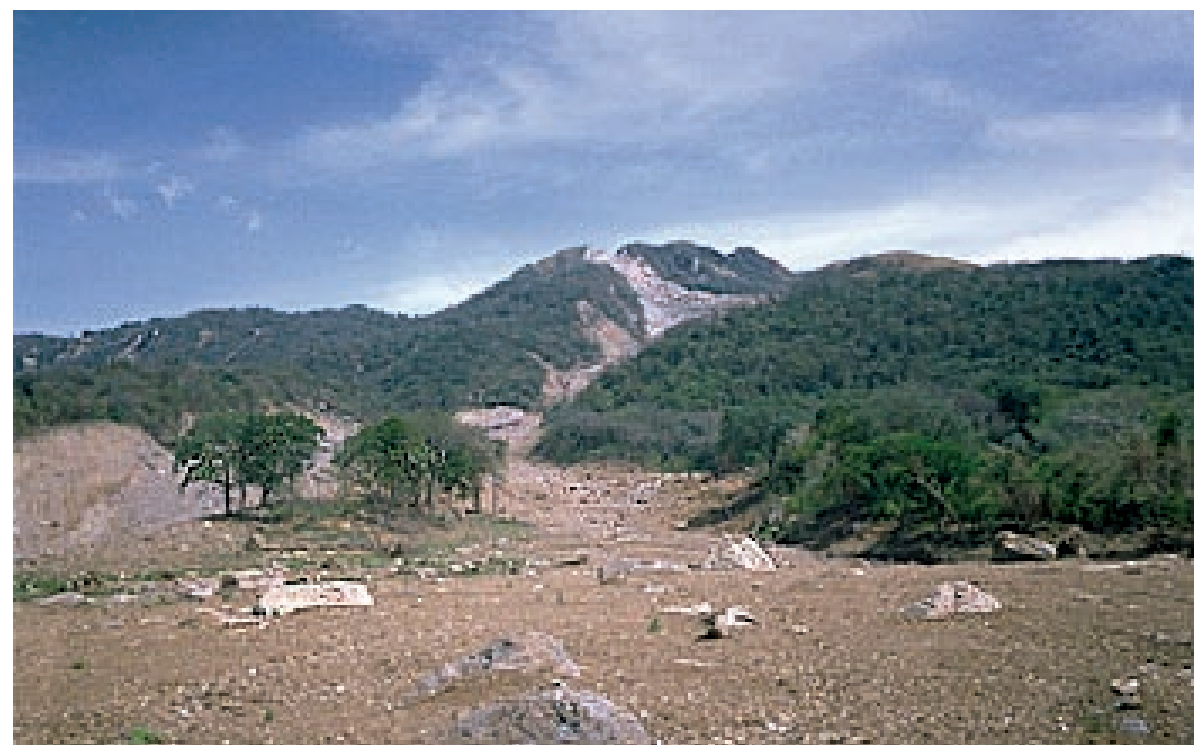

Figure 28. The side of Casita Volcano in Nicaragua, Central America, collapsed on October 30, 1998, the day of peak rainfall as Hurricane Mitch moved across Central America. This lahar killed more than 2,000 people as it swept over the towns of El Porvenir and Rolando Rodriguez. (Photograph by K.M. Smith, U.S. Geological Survey.)

\section{Human Activities}

Populations expanding onto new land and creating neighborhoods, towns, and cities is the primary means by which humans contribute to the occurrence of landslides. Disturbing or changing drainage patterns, destabilizing slopes, and removing vegetation are common human-induced factors that may initiate landslides. Other examples include oversteepening of slopes by undercutting the bottom and loading the top of a slope to exceed the bearing strength of the soil or other component material. However, landslides may also occur in once-stable areas due to other human activities such as irrigation, lawn watering, draining of reservoirs (or creating them), leaking pipes, and improper excavating or grading on slopes. New construction on landslide-prone land can be improved through proper engineering (for example, grading, excavating) by first identifying the site's susceptibility to slope failures and by creating appropriate landslide zoning.

See Appendix A for an expanded, detailed list of causes/triggering mechanisms of landslides.

For further reading:

References 16, 19, 32, 38, 39, 43, and 45 


\section{Part $E$. What are the Effects and Consequences of Landslides?}

Landslide effects occur in two basic environments: the built environment and the natural environment. Sometimes there is intersection between the two; for example agricultural lands and forest lands that are logged.

\section{Effects of Landslides on the Built Environment}

Landslides affect manmade structures whether they are directly on or near a landslide. Residential dwellings built on unstable slopes may experience partial damage to complete destruction as landslides destabilize or destroy foundations, walls, surrounding property, and above-ground and underground utilities. Landslides can affect residential areas either on a large regional basis (in which many dwell-

Note: In many areas of the world that provide private disaster insurance, damage from landslides is not covered in these insurance policies, and the costs of damages must be borne by the individual homeowner. ings are affected) or on an individual site basis (where only one structure or part of a structure is affected). Also, landslide damage to one individual property's lifelines (such as trunk sewer, water, or electrical lines and common-use roads) can affect the lifelines and access routes of other surrounding properties. Commercial structures are affected by landslides in much the same way residential structures are affected. In such a case, consequences may be great if the commercial structure is a commonuse structure, such as a food market, which may experience an interruption in business due to landslide damage to the actual structure and (or) damage to its access roadways.

Fast-moving landslides such as debris flows are the most destructive type of landslide to structures, as they often occur without precursors or warnings, move too quickly for any mitigation measures to be enacted, and due to velocity and material are often very powerful and destructive. Fast-moving landslides can completely destroy a structure, whereas a slower moving landslide may only slightly damage it, and its slow pace may allow mitigation measures to be enacted. However, left unchecked, even slow landslides can completely destroy structures over time. Debris avalanches and lahars in steep areas can quickly destroy or damage the structures and lifelines of cities, towns, and (or) neighborhoods due to the fact that they are an extremely fast-moving, powerful force. The nature of landslide movement and the fact that they may continue moving after days, weeks, or months preclude rebuilding on the affected area, unless mitigative measures are taken; even then, such efforts are not always a guarantee of stability.

One of the greatest potential consequences from landslides is to the transportation industry, and this commonly affects large numbers of people around the world. Cut and fill failures along roadways and railways, as well as collapse of roads from underlying weak and slide-prone soils and fill, are common problems. Rockfalls may injure or kill motorists and pedestrians and damage structures. All types of landslides can lead to temporary or long-term closing of crucial routes for commerce, tourism, and emergency activities due to road or rail blockage by dirt, debris, and (or) rocks (fig. 29). Even slow creep can affect linear infrastructure, creating maintenance problems. Figure 29 shows a landslide blocking a major highway. Blockages of highways by landslides occur very commonly around the world, and many can simply be bulldozed or shoveled away. Others, such as the one shown in figure 29, will require major excavation and at least temporary diversion of traffic or even closure of the road.

As world populations continue to expand, they are increasingly vulnerable to landslide hazards. People tend to move on to new lands that might have been deemed too hazardous in the past but are now the only areas that remain for a growing population. Poor or nonexistent land-use policies allow building and other construction to take place on land that might better be left to agriculture, open-space parks, or uses other than for dwellings or other buildings and structures. Communities often are not prepared to regulate unsafe building practices and may not have the legitimate political means or the expertise to do so. 


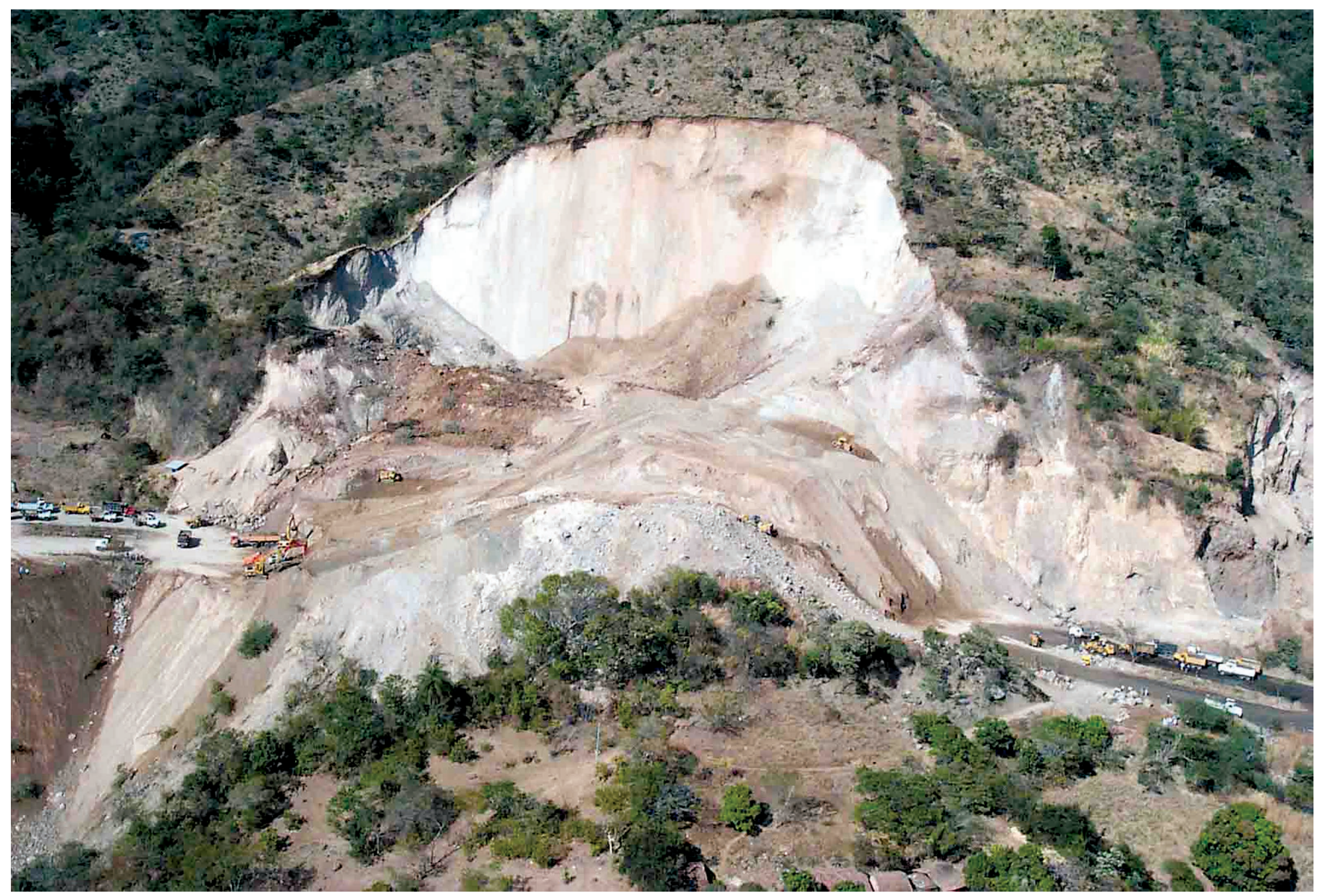

Figure 29. A landslide on the Pan American Highway in El Salvador, Central America, near the town of San Vicente, in 2001. (Photograph by Ed Harp, U.S. Geological Survey.) 


\section{Effects of Landslides on the Natural Environment}

Landslides have effects on the natural environment:

- The morphology of the Earth's surface-mountain and valley systems, both on the continents and beneath the oceans; mountain and valley morphologies are most significantly affected by downslope movement of large landslide masses;

- The forests and grasslands that cover much of the continents; and

- The native wildlife that exists on the Earth's surface and in its rivers, lakes, and seas.

Figures 30, 31, and 32 show the very large areal extent of some landslides and how they may change the face of the terrain, affecting rivers, farmland, and forests.

Forest, grasslands, and wildlife often are negatively affected by landslides, with forest and fish habitats being most easily damaged, temporarily or even rarely, destroyed. However, because landslides are relatively local events, flora and fauna can recover with time. In addition, recent ecological studies have shown that, under certain conditions, in the medium-to-long term, landslides can actually benefit fish and wildlife habitats, either directly or by improving the habitat for organisms that the fish and wildlife rely on for food.

The following list identifies some examples of landslides that commonly occur in the natural environment:

- Submarine landslide is a general term used to describe the downslope mass movement of geologic materials from shallower to deeper regions of the ocean. Such events may produce major effects to the depth of shorelines, ultimately affecting boat dockings and navigation. These types of landslides can occur in rivers, lakes, and oceans. Large submarine landslides triggered by earthquakes have caused deadly tsunamis, such as the 1929 Grand Banks (off the coast of Newfoundland, Canada) tsunamis.

- Coastal cliff retreat, or cliff erosion, is another common effect of landslides on the natural environment. Rock-and-soil falls, slides, and avalanches are the common types of landslides affecting coastal areas; however, topples and flows also are known to occur. Falling rocks from eroding cliffs can be especially dangerous to anyone occupying areas at the base of cliffs, or on the beaches near the cliffs. Large amounts of landslide material can also be destructive to aquatic life, such as fish and kelp, and the rapid deposition of sediments in water bodies often changes the water quality around vulnerable shorelines.

- Landslide dams can naturally occur when a large landslide blocks the flow of a river, causing a lake to form behind the blockage. Most of these dams are short-lived as the water will eventually erode the dam. If the landslide dam is not destroyed by natural erosional processes or modified by humans, it creates a new landform - a lake. Lakes created by landslide dams can last a long time, or they may suddenly be released and cause massive flooding downstream. There are many ways that people can lessen the potential dangers of landslide dams, and some of these methods are discussed in the safety and mitigation sections of this volume. Figure 32 shows the Slumgullion landslide one of the largest landslides in the world - the landslide dam it has formed is so large and wide, that it has lasted 700 years. Figures C53, C54, and C55 (in Appendix C) also show aspects of another large landslide dam.

See Appendix C for more information on mitigating the effects of landslide dams. 


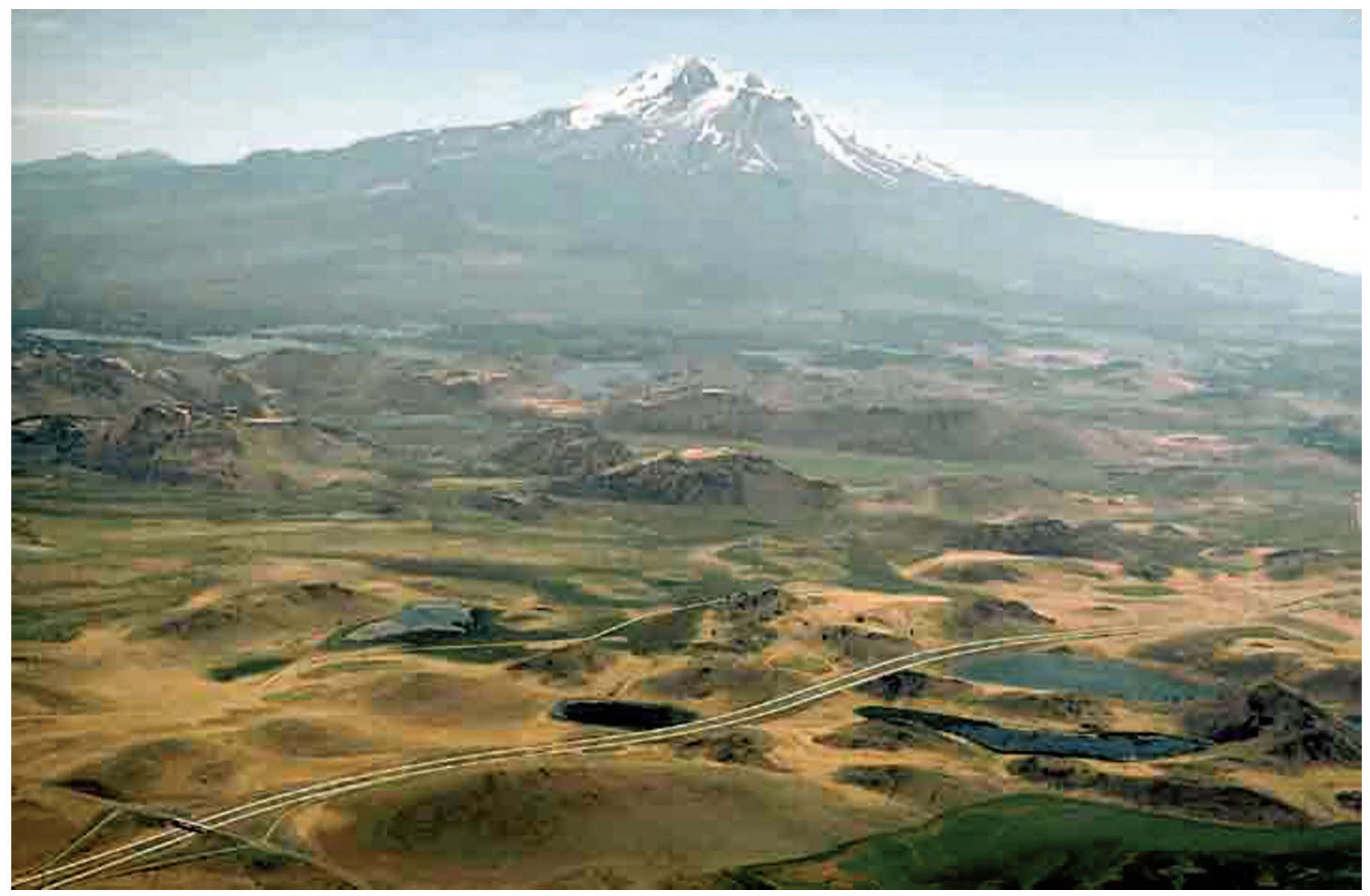

Figure 30. The active volcano, Mount Shasta in California, USA. Note the landforms in the foreground, caused by a debris avalanche that occurred about 300,000 years ago. The debris avalanche traveled great distances from the volcano and produced lasting landform effects that can still be seen today. (Photograph by R. Crandall, U.S. Geological Survey.) 


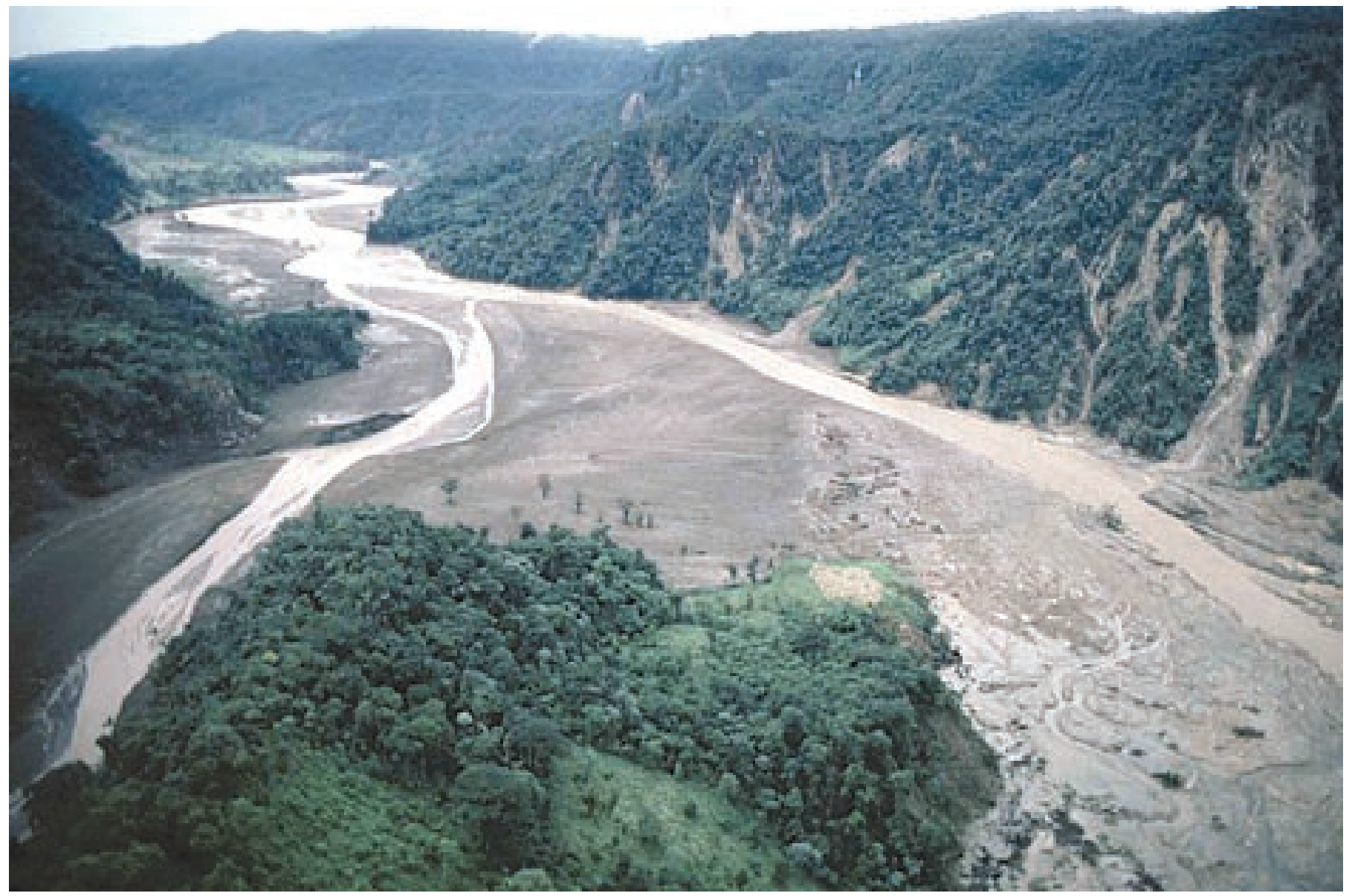

Figure 31. View looking downstream at the confluence of the Río Malo (flowing from lower left) and the Río Coca, northeastern Ecuador, in South America. Both river channels have been filled with sediment left behind by debris flows triggered by the 1987 Reventador earthquakes. Slopes in the area had been saturated by heavy rains in recent days before the earthquake. Debris/earth slides, debris avalanches, debris/mudflows, and resulting floods destroyed about 40 kilometers of the Trans-Ecuadorian oil pipeline and the only highway from Quito. (Photograph by R.L. Schuster, U.S. Geological Survey; information from Reference 32.) 


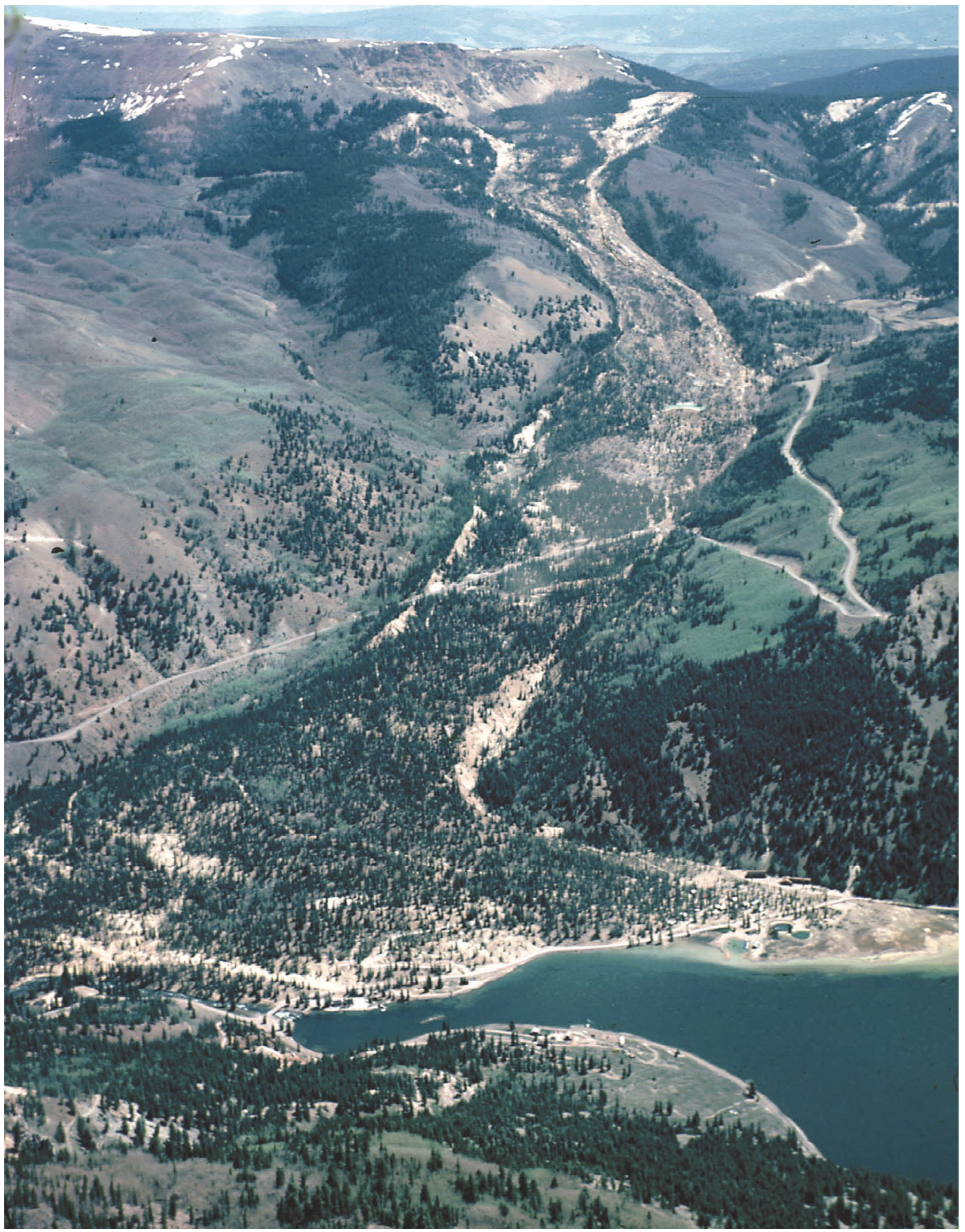

Figure 32. The Slumgullion landslide, Colorado, USA. This landslide (formally referred to also as an earthflow) dammed the Lake Fork of the Gunnison River, which flooded the valley and formed Lake Cristobal. (Photograph by Jeff Coe, U.S. Geological Survey.) 


\section{Part $F$ Interrelationship of Landslides with Other Natural Hazards-The Multiple Hazard Effect}

Natural hazards such as floods, earthquakes, volcanic eruptions, and landslides can occur simultaneously, or one or more of these hazards can trigger one or more of the others. Landslides are often the result of earthquakes, floods, and volcanic activity and may in turn cause subsequent hazards; for example, an earthquake-induced landslide can cause a deadly tsunami if sufficient landslide material slides into a body of water to displace a large volume of water. Another example would be a volcanic eruption-induced or earthquake-induced landslide that blocks a river, causing water to back up behind the mass and flood the upstream area. Should the dam fail, the impounded water will be suddenly unleashed to cause flooding downstream. This flooding can then add to riverbank and coastal erosion and destabilization through rapid saturation of slopes and undercutting of cliffs and banks. It is therefore imperative, when evaluating an area's vulnerability to landslides, to examine all other possible natural hazards. At this time, few maps exist that show multiplehazard susceptibilities; for most areas, if hazards are mapped at all, only a single hazard is mapped.

Figures 33-35 show multi-hazard events involving landslides.

For further reading:

References 17, 20, 35, 39, 43, and 45 


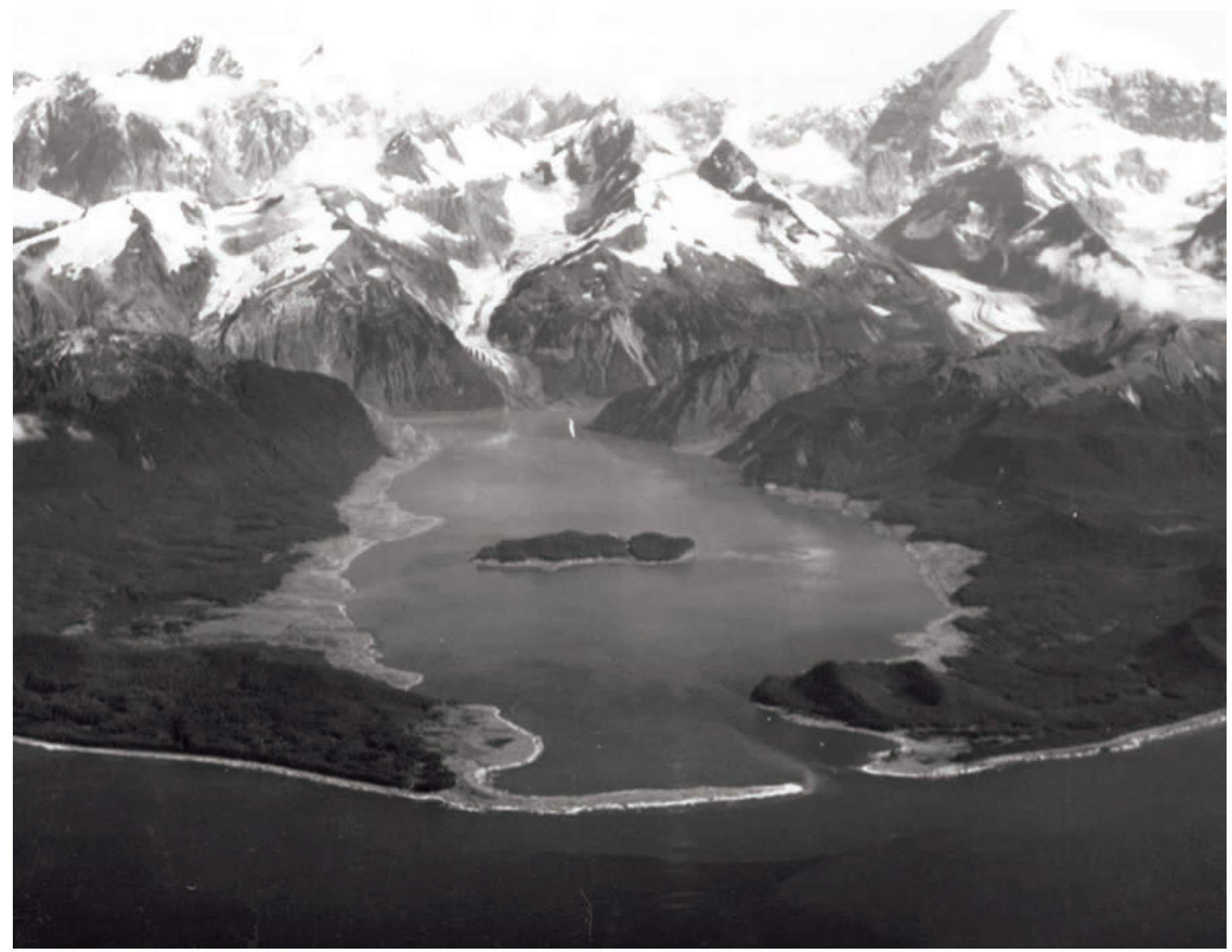

Figure 33. An example of a multi-hazard event. Photograph shows an aerial view of Lituya Bay, Alaska, USA. On July 9, 1958, an earthquake occurred which caused a landslide to enter the bay. The landslide in turn, caused a tsunami wave that had a run-up of 174 meters on the opposite shore, and a 30-meter wave passed beyond Lituya Bay. It is the largest landslide-generated wave ever documented. Note the extent of the nonforested areas of land lining the shore of the bay, which marks the approximate reach of the tsunami wave. (Photograph by D.J. Miller, U.S. Geological Survey.) 


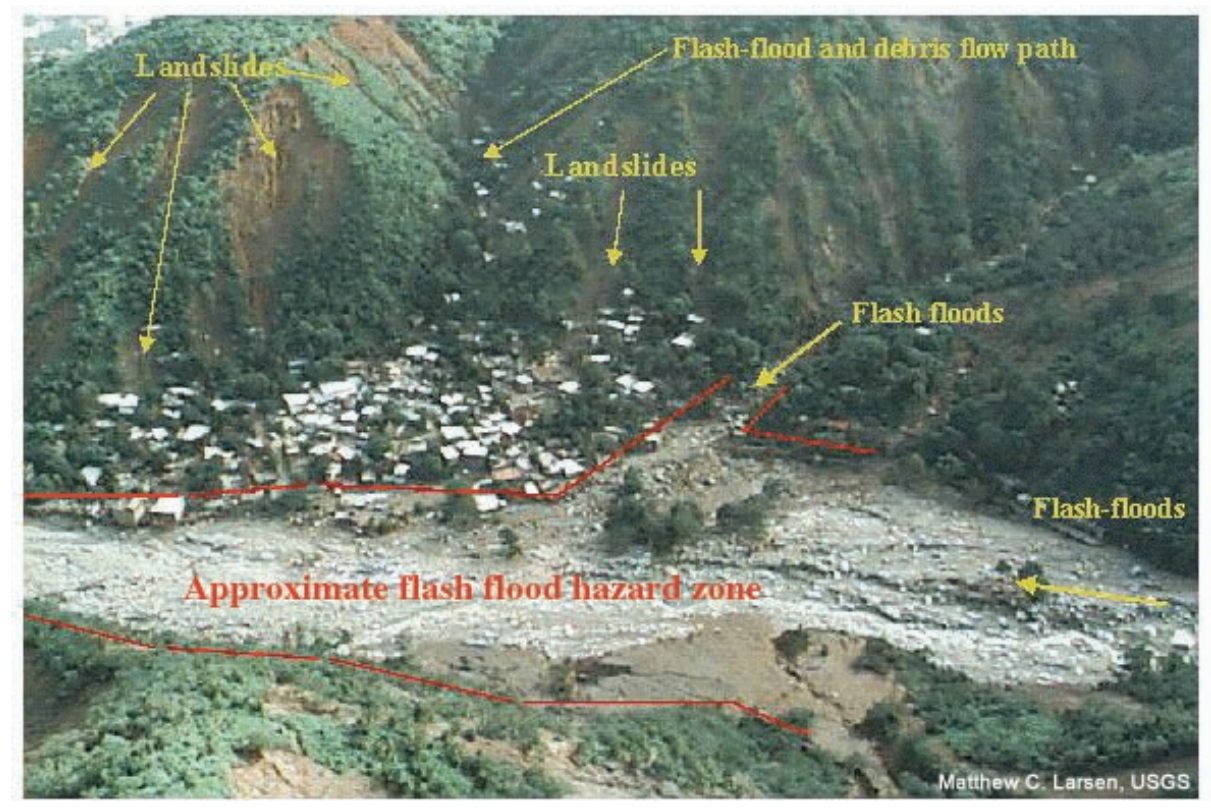

Figure 34. The 1999 multi-hazard event in Tanaguarena, in coastal Venezuela, South America. The floods and landslides were triggered by heavy rains. (Photograph by Matthew Larsen, U.S. Geological Survey.)

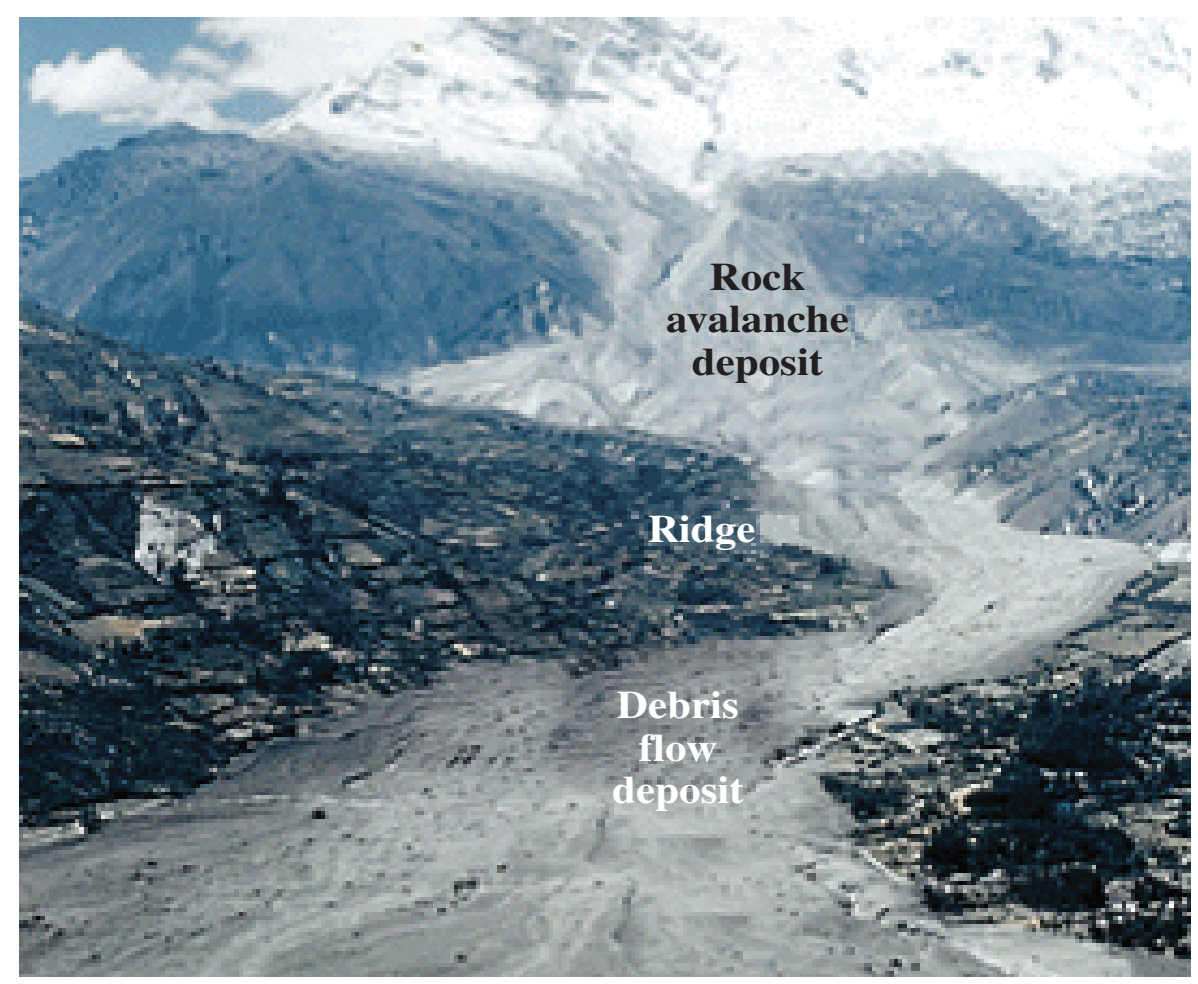

Figure 35. This is a photograph showing the aftereffects of a multi-hazard event. It is an aerial view showing part of the Andes Mountains and Nevado Huascaran, the highest peak in Peru, South America. A massive avalanche of ice and rock debris, triggered by the May 31, 1970, earthquake, buried the towns of Yungay and Ranrahirca, killing more than 20,000 people, about 40 percent of the total death toll of 67,000 . The avalanche started with a sliding mass of glacial ice and rock about 1,000 meters (3,000 feet) wide and 1.6 kilometers (one mile) long that swept downslope about 5.4 kilometers ( 3.3 miles) to Yungay at average speed of more than 160 kilometers per hour. The ice picked up morainal material of water, mud, and rocks. (Photograph by Servicio Aerofotográfico National, graphics by George Plafker, U.S. Geological Survey.) Photograph and information from the U.S. Geological Survey Photographic Archives: http://libraryphoto.cr.usgs.gov/ 


\section{Section II.}

\section{Evaluating and Communicating Landslide Hazard}

Worldwide, information about landslides varies in its quantity and complexity and ranges in quality from detailed inventories of past landslides and resultant susceptibility and hazard maps to no information at all. People in some regions of the world have collective memories of past landslide events and know where slopes are unstable and (or) dangerous, and as a result, intuitively know where it is advantageous to build or not build. However, many areas are not readily obvious as to potential landslide hazard, and ground failure does not occur on any kind of regular basis. Also, some triggering mechanisms occur sporadically and have a gradual and cumulative effect and are not readily obvious. 
For further reading:

References 1, 3, 4, 19, 20, 21, 25, 26, $36,39,42$, and 44

\section{Part A. Evaluating Landslide Hazards}

There are many different means of assessing landslide hazard for an area; it is always advisable to consult with an expert for the most accurate assessment, although this is not always possible. Two types of landslide hazard evaluation, direct observation and the use of technological tools, are discussed here.

\section{Observation and (or) inspection by local experts and (or) municipal officials, and property owners.}

The following simple guide may assist individuals in observing and assessing a potential landslide hazard. It is important to note that some of these features can also be due to causes other than landslides, such as swelling soils.

\section{Features that might indicate landslide movement:}

- Springs, seeps, and wet or saturated ground in previously dry areas on or below slopes.

- Ground cracks—cracks in snow, ice, soil, or rock on or at the head of slopes.

- Sidewalks or slabs pulling away from structures if near a slope; soil pulling away from foundations.

- Offset fence lines, which were once straight or configured differently (see photograph in figure 22).

- Unusual bulges or elevation changes in the ground, pavements, paths, or sidewalks.

- Tilting telephone poles, trees, retaining walls, fences.

- Excessive tilting or cracking of concrete floors and foundations.

- Broken water lines and other underground utilities.

- Rapid increase or decrease in stream-water levels, possibly accompanied by increased turbidity (soil content clouding the water).

- Sticking doors and windows and visible open spaces, indicating walls and frames are shifting and deforming.

- Creaking, snapping, or popping noises from a house, building, or grove of trees (for example, roots snapping or breaking).

- Sunken or down-dropped roads or paths.

Note to Managers: It is important that governing bodies provide a means of keeping records, preferably in written format, about the occurrences of landslides, with photographs and (or) diagrams where possible. For areas of the world that do not already have laws or regulations that require disclosure of landslide hazards to property owners, it is important for villages, municipalities, or cities to establish some source of authority for hazard information. This need not be sophisticated or expensive but will provide a means to sustain landslide knowledge through time. Although some information may be politically sensitive, such as landowner rights, it is important that landslide information be made available, in some manner, to the general population. 


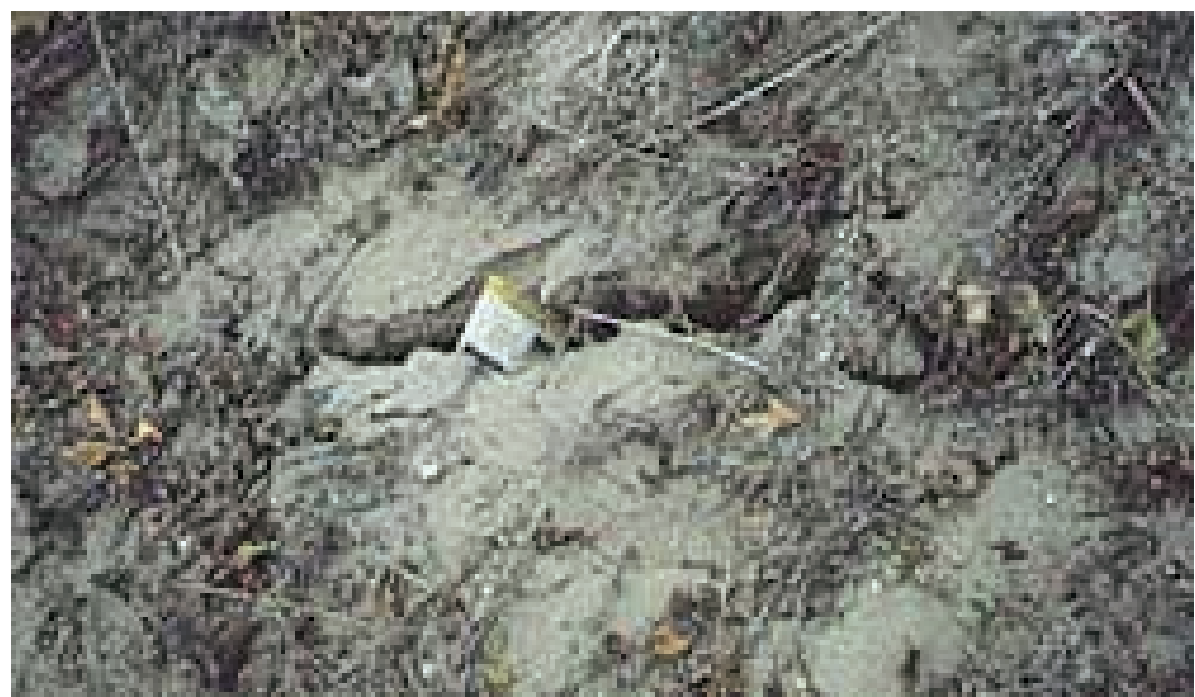

Figure 36. Ground cracks. (Phtograph courtesy of Utah Geological Survey.)

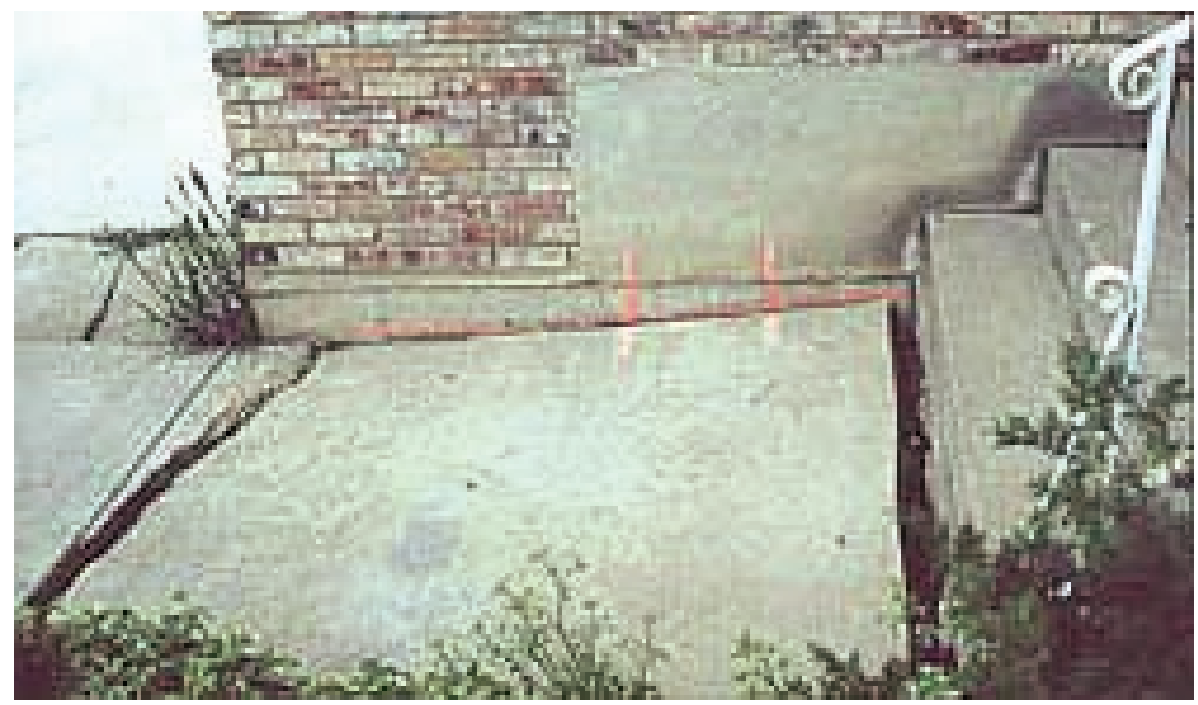

Figure 37. Sidewalk pulling away from house. (Photograph courtesy of Utah Geological Survey.)

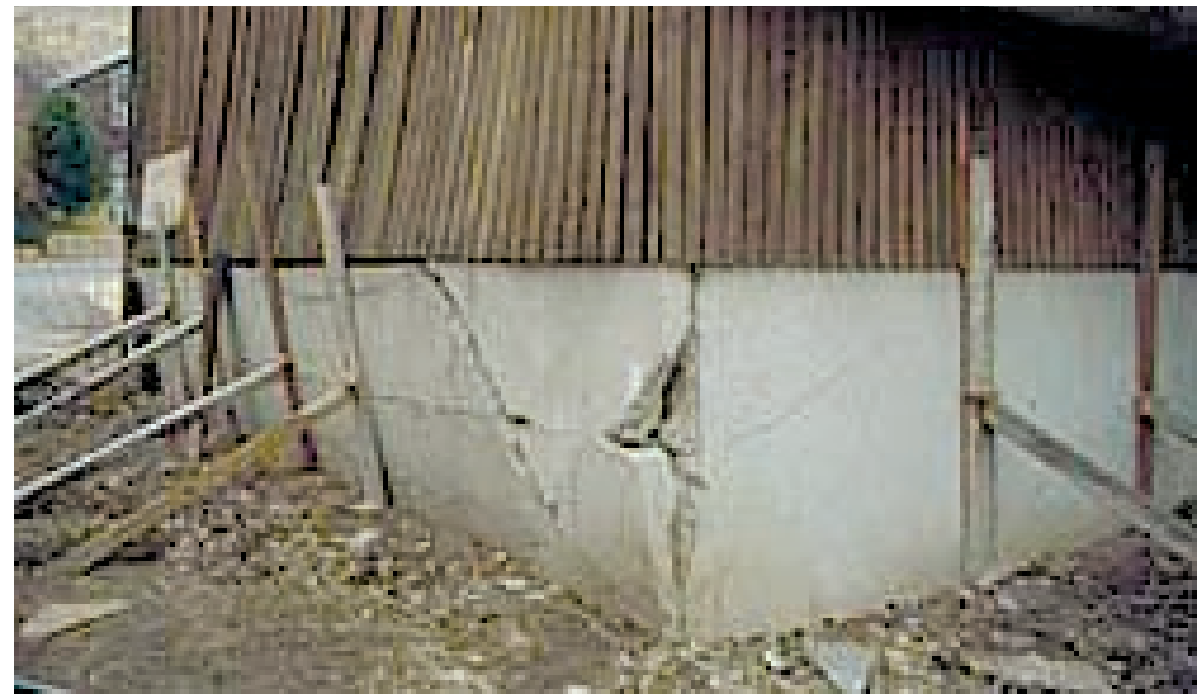

Figure 38. Cracking of the foundation of a structure. (Photograph courtesy of Utah Geological Survey.) 


\section{Technological Tools for Evaluation of Landslides- Mapping, Remote Sensing, and Monitoring}

One of the guiding principles of geology is that the past is the key to the future. In evaluating landslide hazards this means that future slope failures could occur as a result of the same geologic, geomorphic, and hydrologic situations that led to past and present failures. Based on this assumption, it is possible to estimate the types, frequency of occurrence, extent, and consequences of slope failures that may occur in the future. However, the absence of past events in a specific area does not preclude future failures. Human-induced conditions, such as changes in the natural topography or hydrologic conditions, can create or increase an area's susceptibility to slope failure.

In order to predict landslide hazards in an area, the conditions and processes that promote instability must be identified and their relative contributions to slope failure estimated, if possible. Useful conclusions concerning increased probability of landsliding can be drawn by combining geological analyses with knowledge of short- and long-term meteorological conditions. Current technology enables persons monitoring earth movements to define those areas most susceptible to landsliding and to issue warnings and "alerts" covering time spans of hours to days when meteorological conditions or thresholds known to increase or initiate certain types of landslides are met.

\section{Map Analysis}

Map analysis is usually one of the first steps in a landslide investigation. Necessary maps include bedrock and surficial geology, topography, soils, and if available, geomorphology maps. Using knowledge of geologic materials and processes, a trained person can obtain a general idea of landslide susceptibility from such maps. Appendix B at the end of this report contains a section on the various types of maps used in landslide analysis.

\section{Aerial Reconnaissance}

Analysis of aerial photography is a quick and valuable technique for identifying landslides, because it provides a three-dimensional overview of the terrain and indicates human activities as well as much geologic information to a trained person. In addition, the availability of many types of aerial imagery (satellite, infrared, radar, and so forth) makes aerial reconnaissance very versatile although cost-prohibitive in some cases.

\section{Field Reconnaissance}

Many of the more subtle signs of slope movement cannot be identified on maps or photographs. Indeed, if an area is heavily forested or has been urbanized, even major features may not be evident. Furthermore, landslide features change over time on an active slide. Thus, field reconnaissance is always mandatory to verify or detect landslide features, and to critically evaluate the potential instability of vulnerable slopes. It identifies areas with past landslides (which could indicate future likelihood of landslides) by using field mapping and laboratory testing of terrain through the sampling of soil and rock. Mapping and laboratory testing for example, may identify vulnerable clays or other susceptible soils and show where they exist and their size and extent. 


\section{Drilling}

At most sites, drilling is necessary to determine the type of earth materials involved in the slide, the depth to the slip surface, and thus the thickness and geometry of the landslide mass, the water-table level, and the degree of disruption of the landslide materials. It also can provide suitable samples for age-dating and testing the engineering properties of landslide materials. Finally, drilling is needed for installation of some monitoring instruments and hydrologic observation wells. Note that drilling for information on stratigraphy, geology, water-table levels and for installation of instruments, for example, is also done for areas that have never had a landslide but for which the possibility exists.

\section{Instrumentation}

Sophisticated methods such as electronic distance measurement (EDM), instruments such as inclinometers, extensometers, strain meters, and piezometers (see Glossary for definitions of these instruments), and simple techniques, such as establishing control points by using stakes can all be used to determine the mechanics of landslide movement and to monitor and warn against impending slope failure.

\section{Geophysical Studies}

Geophysical techniques (measurement of soil's electrical conductivity/ resistivity, or measurement of induced seismic behavior) can be used to determine some subsurface characteristics such as the depth to bedrock, stratigraphic layers, zones of saturation, and sometimes the ground-water table. It can also be used to determine texture, porosity, and degree of consolidation of subsurface materials and the geometry of the units involved. In most instances, such surface survey methods can best be used to supplement drilling information, spatially extending and interpolating data between boreholes. They can also offer an alternative if drilling is impossible. Downhole geophysical methods (nuclear, electrical, thermal, seismic) also can be applied to derive detailed measurements in a borehole. Monitoring of natural acoustic emissions from moving soil or rock has also been used in landslide studies.

\section{Acoustic Imagery and Profiles}

Profiles of lakebeds, river bottoms, and the sea floor can be obtained using acoustic techniques such as side-scan sonar and subbottom seismic profiling. Surveying of controlled grids, with accurate navigation, can yield three-dimensional perspectives of subaqueous geologic phenomena. Modern, high-resolution techniques are used routinely in offshore shelf areas to map geologic hazards for offshore engineering.

\section{Computerized Landslide Terrain Analysis}

In recent years, computer modeling of landslides has been used to determine the volume of landslide masses and changes in surface expression and cross section over time. This information is useful in calculating the potential for stream blockage, cost of landslide removal (based on volume), and type and mechanism of movement. Very promising methods are being developed that use digital elevation models (DEMs) to evaluate areas quickly for their susceptibility to landslide/debris-flow events. Computers also are being used to perform complex stability analyses. Software programs for these studies are readily available for personal computers.

For further reading: References 4, 15, 18, 24, 25, 39, and 46 


\section{Part $B$. Communicating Landslide Hazard}

The successful translation of natural hazard information into a form useful for nontechnical users conveys the following three elements in one form or another:

- Likelihood of the occurrence of an event of a size and in a location that would cause casualties, damage, or disruption to an existing standard of safety.

- Expected location and extent of the effects of the event on the ground, structures or socioeconomic activity.

- Estimated severity of the effects on the ground, structures, or socioeconomic activity.

These elements are needed because engineers, planners, and decisionmakers usually will not be concerned with a potential hazard if its likelihood is rare, its location is unknown, or its severity is slight.

Unfortunately, these three pieces of information can come in different forms with many different names, some quantitative and precise, others qualitative and general. For a product to qualify as useful hazard information, the nontechnical user must be able to perceive likelihood, location, and severity of the hazard so that they become aware of the danger, can convey the risk to others, and can use the translated information directly to reduce a threat.

\section{Safety Information}

Safety is no doubt the first order of business for managers and municipal officials. People living in areas prone to fast-moving, deadly debris flows need information on the likelihood of the hazard; for example, when it is most dangerous to be in the path of potential debris flows (such as during heavy rainstorms) and at what point to evacuate and (or) cease walking or driving in a hazardous area. Safety information about slow-moving landslides is equally important as these types of landslides can damage and (or) break electrical and gas lines, creating an additional hazard of fire, electrocution, and gas fumes.

\section{Building and Construction Information}

This information is also valuable to communities, so that some of the causes of landslides might be avoided. This information is discussed in Section III, "Mitigation Concepts and Approaches."

Safety, education, and building information can be made available to community residents in various ways. A list of building codes, building inspection processes, and potential areas where destabilization may cause landslide problems can be made available through the following: 


\section{Suggested Local Government Outreach for Landslide Hazard}

- Newspaper bulletins/advertisements.

- Public-service brochures distributed door-to-door or displayed in public places.

- Community meeting discussions.

- Posters in public buildings and (or) marketplaces with as much visual information as possible.

- Media announcements through radio, television, loudspeakers, or other means.

- Public lectures by experts or other officials.

- Signs posted in immediate areas of hazards, informing people of the kind of hazard and warning them to be cautious. An example of this would be a sign warning of rockfall hazards along well-used footpaths.

- In areas where literacy rates are low, oral communications with graphics, photographs, and illustrations of hazards can be extremely effective. Pictures may take the place of a thousand words!

- Telephone book-In areas where phone service is widespread or accessible, municipal listings for engineering, emergency planning, and police or fire departments.

- Where possible a municipal Internet Web site is a useful source of safety information and contact phone numbers and emails for emergency personnel and engineering and (or) planning departments.

- Determine local landslide hazard problems through a working committee and (or) secure professional advice. State/Provincial or Federal geological surveys, university geology or engineering departments, and private geotechnical companies are sources of advice. Provide for a mapping program where possible, either within local government or contracted with professionals.

- Conduct public education and information programs through community meetings, city council, or other councils.

- Adopt and enforce appropriate land-use policies - discuss with landowners, developers, buyers, and sellers. One option is to require disclosure of geological hazards during property sales to ensure that the new buyer is aware of any problems.

- Monitor changes in unstable slopes and take appropriate actions (see "Mitigation" section of this handbook).

- Construct street and drainage projects that meet local safety needs and ordinances.

- Pursue public grant programs, government programs for infrastructure, and public works improvement projects.

- Be informed about insurance programs available and liability issues and know where local government responsibility lies for public safety and well-being.

- Have an emergency response plan for the community. Consult with neighboring towns and (or) communities that have plans and have used them in an emergency. Evaluate their effectiveness for your own situation. 
For further reading:

References 1, 6, 19, 21, 23, 24, 26, 36 , and 41

\section{Examples of Hazard Warning Signs}

The following figures (figs. 39, 40, and 41) show examples of some simple warning signs that can be placed in hazardous areas. This information can also be used in emergency management policies for municipalities and (or) communities.

Please see Appendix B for samples of basic safety information for debris flow and other landslide hazards that are suitable for posting and distributing in public places.

Figure 39. Example of a rockfall hazard sign.

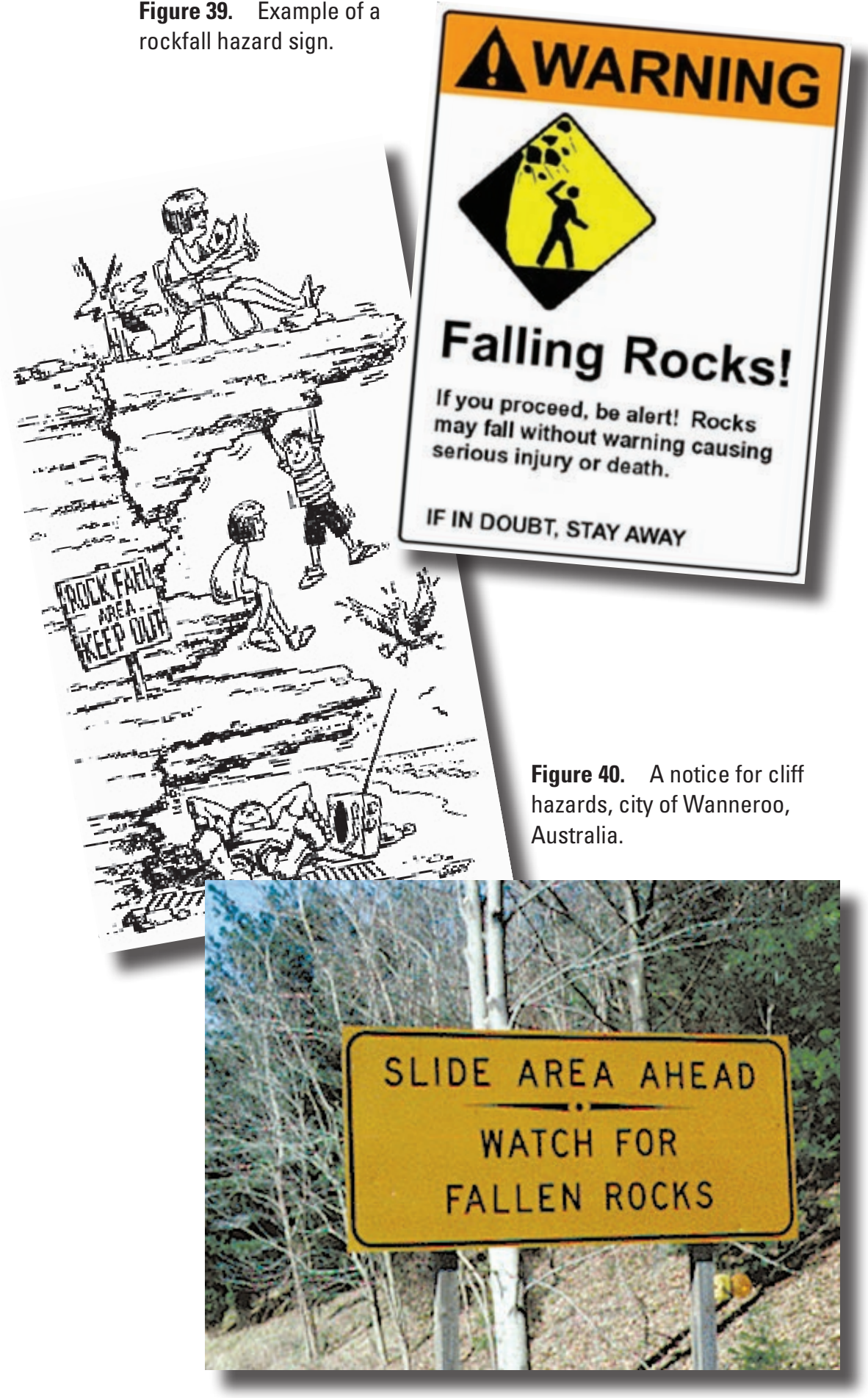

Figure 41. Sign along a highway in Virginia, USA. 


\section{Section III.}

\section{Mitigation Concepts and Approaches}

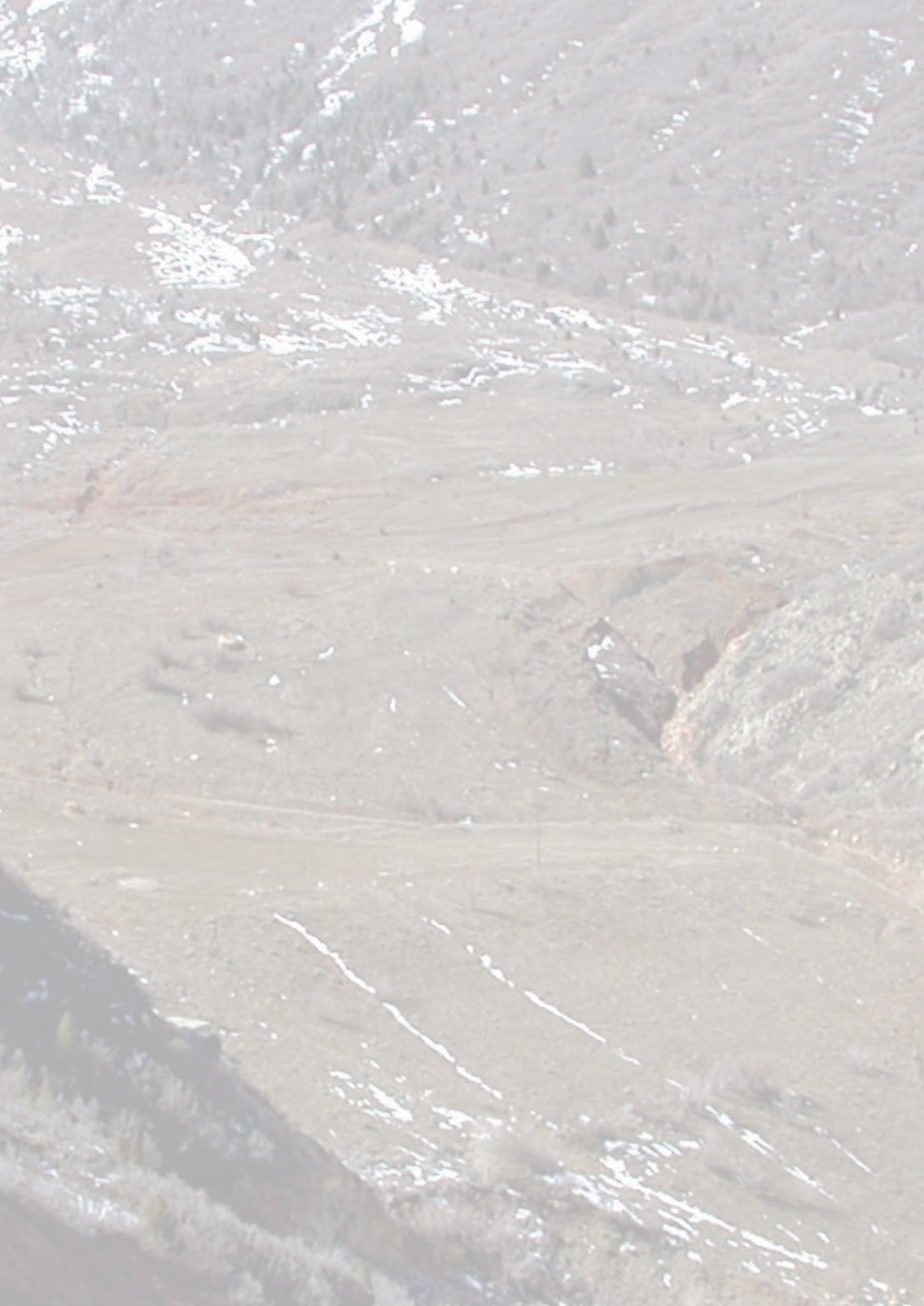

Vulnerability to landslide hazards is a function of a site's location (topography, geology, drainage), type of activity, and frequency of past landslides. The effects of landslides on people and structures can be lessened by total avoidance of landslide hazard areas or by restricting, prohibiting, or imposing conditions on hazard-zone activity. Local governments can accomplish this through landuse policies and regulations. Individuals can reduce their exposure to hazards by educating themselves on the past hazard history of a desired site and by making inquiries to planning and engineering departments of local governments. They could also hire the professional services of a geotechnical engineer, a civil engineer, or an engineering geologist who can properly evaluate the hazard potential of a site, built or unbuilt. 


\section{Part A. Overview of Mitigation Methods for Various Types of Landslide Hazards}

Seeking the advice of professionals is always advised where possible, but managers and homeowners should be educated about mitigation in order to make informed decisions concerning construction and land use. A few of these measures are discussed in this section. More detailed information on landslide mitigation is available in Appendix C and in Turner and Schuster (1996) (Reference 39).

The simplest means of dealing with landslide hazards is to avoid construction on steep slopes and existing landslides; however, this is not always practical. Regulating land use and development to ensure that construction does not reduce slope stability is another approach. Avoidance and regulation rely on landslide maps and the underlying definitions of landslide areas to reduce hazard (Appendix B). In cases where landslides affect existing structures or cannot be avoided, physical controls can be used. In some cases, monitoring and warning systems (Appendix B) allow residents to evacuate temporarily during times when the probability of landslide activity is high.

\section{Soil Slope Stabilization}

Stability increases when ground water is prevented from rising in the slide mass by

- directing surface water away from the landslide,

- draining ground water away from the landslide to reduce the potential for a rise in ground-water level,

- covering the landslide with an impermeable membrane, and (or)

- minimizing surface irrigation. Slope stability is also increased when weight or retaining structures are placed at the toe of the landslide or when mass (weight) is removed from the head of the slope.

Planting or encouraging natural growth of vegetation can also be an effective means of slope stabilization - this is further discussed in the section on biotechnical mitigation methods and Appendix C.

An example of one means of slope stabilization is the use of retaining walls. Retaining walls are structures built to support a soil mass permanently. They also are used whenever space requirements make it impractical to slope the side of an excavation, or to prevent sloughing of loose hillslope soils onto roads or property. Retaining walls are also used to prevent or minimize toe erosion by river scour or to retard creep. They cannot, however, be used to stop landslides from occurring. Several basic types of wall are timber crib, steel bin, pile, cantilever, sheet pile, plastic mesh, and reinforced earth. Each of these types has advantages in certain situations, but cost is usually what determines which is type is adopted. More information about retaining walls is given in Appendix C.

See Appendix C for more information on stabilization methods. 


\section{Rockfall Hazard Mitigation}

Rockfall is common in areas of the world with steep rock slopes and cliffs. Commonly, these are mountainous or plateau areas, whether in coastal areas or among isolated rock formations. Rockfall causes extraordinary amounts of monetary damage and death, the former mostly by impeded transportation and commerce due to blocked highways and waterways and the latter as direct casualties from falling rocks. Diverting paths and highways around rockfall areas is sometimes implemented but is not always practical. Many communities post danger signs around areas of high rockfall hazard. Some methods of rockfall hazard mitigation include catch ditches, benches, scaling and trimming, cable and mesh, shotcrete, anchors, bolts, dowels, and controlled blasting.

See Appendix $\mathrm{C}$ for more information on mitigation means for preventing and diverting rockfall.

\section{Debris-Flow Hazard Mitigation}

Due to the speed and intensity of most debris flows, they are very hard to stop once they have started. However, methods are available to contain and deflect debris flows primarily through the use of retaining walls and debris-flow basins. Other mitigation methods include modifying slopes (preventing them from being vulnerable to debris-flow initiation through the use of erosion control), revegetation, and the prevention of wildfires, which are known to intensify debris flows on steep slopes.

See Appendix C for more information on methods for debris-flow hazard mitigation.

\section{Landslide Dam Mitigation}

Many problems arise when landslides dam waterways. Dams caused by landslides are a common problem in many areas of the world. Landslides can occur on the valley walls of streams and rivers. If enough displaced material (rock, soil, and (or) debris) fills the waterway, the landslide will act as a natural dam, blocking the flow of the river and creating flooding upstream. As these natural dams are frequently composed of loose, unconsolidated material, they commonly are inherently weak and are soon overtopped and fail due to erosion. When breaching happens quickly, the backed-up water rushes down the waterway, potentially causing catastrophic downstream flooding. An example of a landslide dam is the 600-meter-high Usoi landslide dam in Tajikistan, one of the largest landslide dams in the world. A large earthquake-induced landslide dammed the Murghab River, creating Lake Sarez. The dam poses a hazard for people living downstream. Also, future seismic action may cause more landslides to slide into the dammed lake, causing a seiche (a tsunami-like wave in a closed water basin), which may weaken and (or) overtop the landslide dam. Figure 42 shows a landslide dam caused by the sliding of saturated slopes, and figure 43 shows a landslide dam caused by an earthquake.

See Appendix C for more details on mitigation methods for landslide dams. 


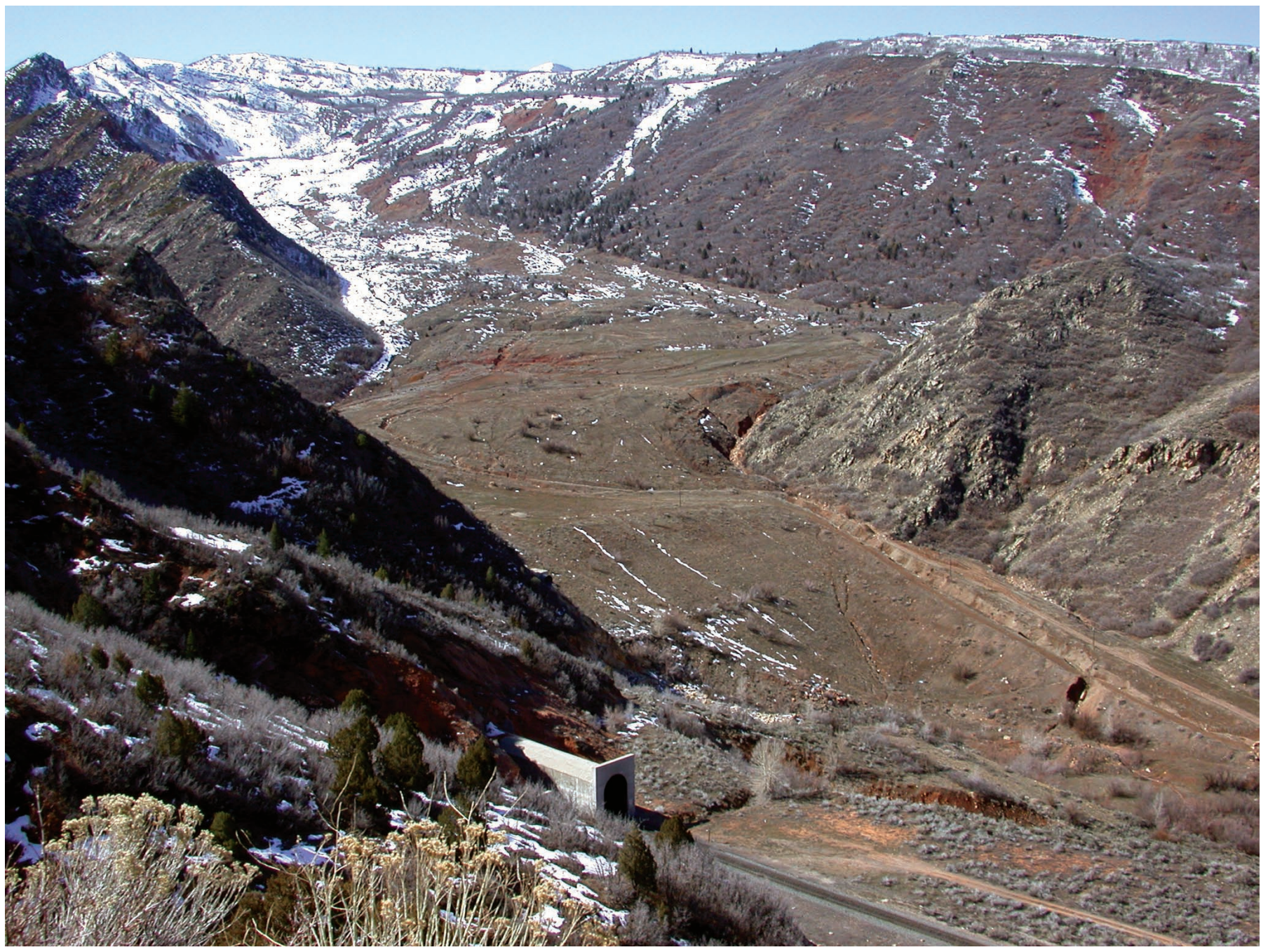

Figure 42. The Thistle landslide in Utah, USA. This 1983 landslide dammed the Spanish Fork River, backing up water that flooded the town of Thistle. Many landslide dams are much smaller than the one shown here and potentially can be overtopped by backed-up water, or eroded through. Some are much larger, and roads and railroad lines that are blocked or damaged must be diverted around the landslide mass. The concrete tunnel at the lower part of the bottom photograph shows where the rail line was rerouted around the Thistle slide and excavated through an adjacent mountain. 

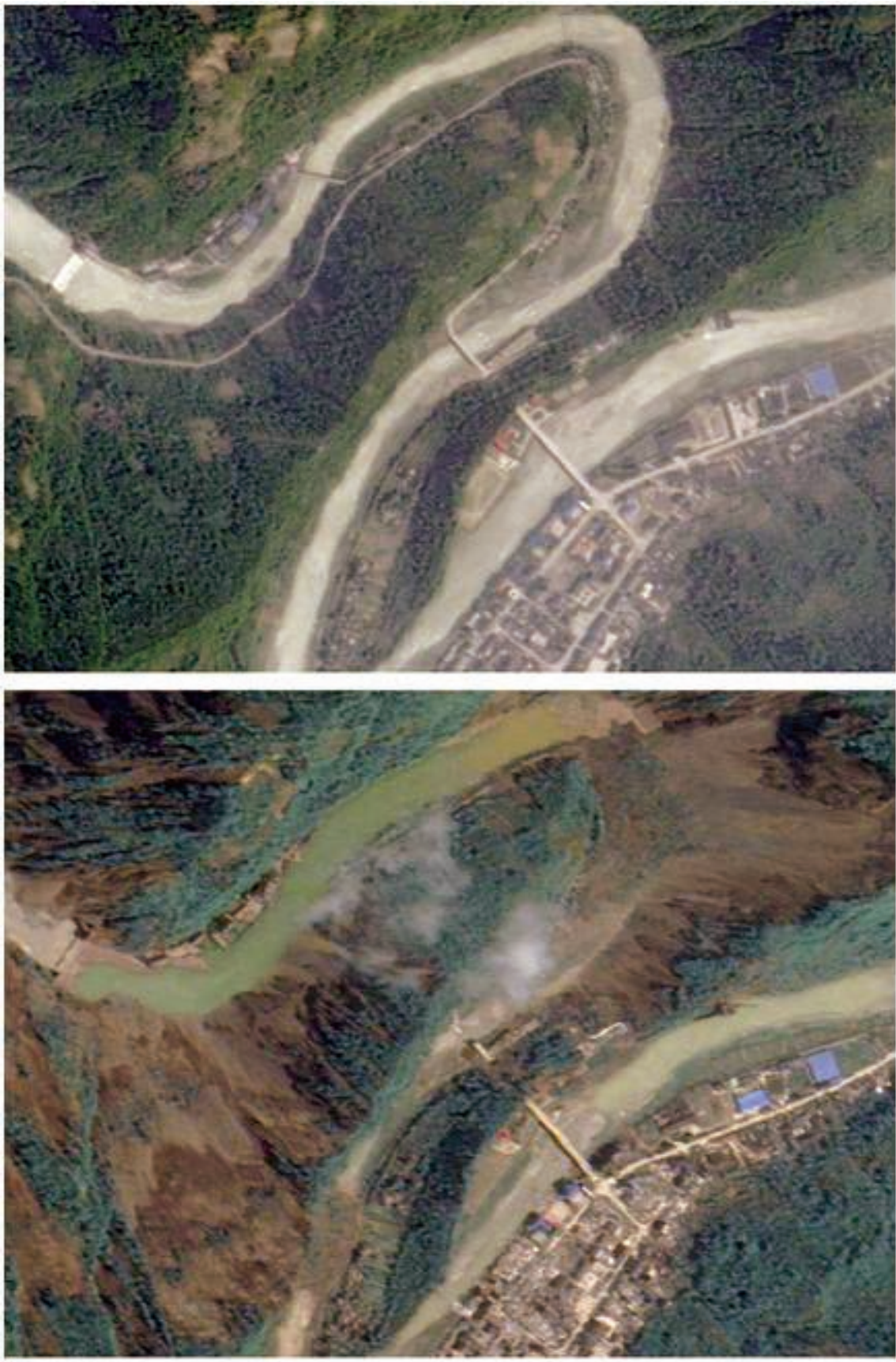

\section{Methods of Biotechnical Landslide Mitigation}

This type of slope protection is used to reduce the adverse environmental consequences of landslide-mitigation measures. When used for landslide remediation or mitigation, conventional earth-retaining structures made of steel or concrete usually are not visually pleasing or environmentally friendly. These traditional "hard" remedial measures are increasingly being supplanted by vegetated composite soil/structure bodies that are environmentally more friendly; that is, a process that has come to be known as biotechnical slope protection. Common biotechnical systems include nets of various materials anchored by soil nails that hold in place soil seeded with grass. Research has been done on using plants to stabilize soil to prevent excessive erosion and also to mitigate the effect of landslides. One of the most promising types of plants is Vetiver, a type of grass that works very well to stabilize slopes against erosion in many different environments. See Appendix $\mathrm{C}$ for more information on Vetiver grass uses and its geographical suitability.

See Appendix C for more information on mitigation techniques.
Figure 43. The great earthquake that struck China on May 12, 2008, caused extensive damage in the mountainous terrain of Beichuan County. In many cases, landslides in steep valleys formed landslide dams, creating new lakes in a period of hours. This pair of highresolution, photo-like images from Taiwan's Formosat-2 satellite on May 14, 2006 (top), and May 14, 2008 (bottom), before and after the earthquake, show the large landslide that blocked the Jiangjian River, forming a dangerous landslide-dammed lake. 
For further reading:

References 4, 8, 11, 19, 20, 28, 30, 31,32 , and 37

\section{Part B. Simple Mitigation Techniques for Home and Businesses, Managers, and Citizens}

There are simple and low-technology means for homeowners and others to implement methods and techniques that are effective and lessen the effects of landslides. First, it is always best to consult a professional, such as a geotechnical engineer or a civil engineer, as they have had the training and experience to solve instability problems; a local company or professional may be the best, as they may be familiar with the geology, soil types, and geography of the area in question. This is not always the case, but it is a basis for making inquiries. When there are local jurisdictions such as county and (or) city municipal offices, individuals within these institutions may be professional geologists, planners, and (or) building experts who can answer questions, provide maps, and explain building regulations and inspection procedures. Access to these types of officials varies widely around the world, and local situations may be handled differently. When consulting a professional is not possible, some steps can be taken in the meantime, as detailed in Appendixes C and D.

See Appendixes $\mathrm{C}$ and $\mathrm{D}$ for detailed information on mitigation techniques for property owners, citizens, and managers. 


\section{Part C. List of Works Consulted/Cited/Quoted and for Further Reading}

1. Advisory Committee on the International Decade for Natural Hazard Reduction,Commission on Engineering and Technical Systems, 1987, Confronting natural disasters, an International Decade for Natural Hazard Reduction, National Research Council: U.S. National Academy of Sciences, Washington, D.C.

2. Aylsworth, J.M., Duk-Rodkin, A., Robertson, T., and Traynor, J.A., 2000, Landslides, in the physical environment of the Mackenzie Valley, Northwest Territories-A baseline for the assessment of environmental change, Dyke, L.D., and Brooks, G.R., eds.: Geological Survey of Canada, Bulletin no. 547, p. 41-48.

3. Barrows, Alan, and Smith, Ted, 2004, Hazards from "mudslides," debris avalanches and debris flows in hillside and wildfire areas: California Geological Survey Note 33. Online: http://www.consrv.ca.gov/cgs/ information/publications/cgs_notes/ note_33/index.htm

4. Blake, T.F., Holingsworth, R.A., and J.P. Stewart, eds., 2002, Recommended procedures for implementation of guidelines for analyzing and mitigating landslide hazards in California: Department of Mining and Geology special publication 117 American Society of Civil Engineers (ASCE), Los Angeles Section Geotechnical Group, published by Southern California Earthquake Center (SCEC). Online: http://www.scec.org/resources/catalog/ LandslideProceduresJune02.pdf

5. California Department of Conservation, Division of Mines and Geology, 1997, Factors affecting landslides in forested terrain, Note 50. Online: http:// www.consrv.ca.gov/cgs/information/ publications/cgs_notes/note_50/ Documents/note50.pdf

6. Case, William F., (no date) LandslidesWhat they are, why they occur: Utah Geological Survey, Utah Department of Natural Resources, Public Information Series 74. Online: http://geology.utah. gov/online/pdf/pi-74.pdf
7. Case, William F., 2003, Debris-flow hazards: Utah Geological Survey, Public Information Series 70. Online: http://geology.utah.gov/online/pi-70/ debrisflow.htm

8. Case, William F., 2000, Rock-fall hazards: Utah Geological Survey, Public Information Series 69. Online: http:// geology.utah.gov/online/pdf/pi-69.pdf

9. Cruden, D.M, and Varnes, D.J., 1996, Landslide types and processes, in Turner, A. Keith, and Schuster, Robert L. eds. Landslides-Investigation and mitigation: Transportation Research Board, Special report no. 247, National Research Council, National Academy Press, Washington, D.C., p. 36-75.

10. Cruden, D.M., 1993, The multilingual landslide glossary: Richmond., British Columbia, Canada, Bitech Publishers, for the UNESCO Working Party on World Landslide Inventory, 1993.

11. Chatwin, S.C., Howes, D.E., Schwab, J.W., and Swanston, D.N., 1994, A guide for management of landslideprone terrain in the Pacific Northwest, second edition: Ministry of Forests, 31 Bastion Square, Victoria, British Columbia V8W3E7, 220 p. Online: http://www.for.gov.bc.ca/hfd/pubs/docs/ Lmh/Lmh18.htm

12. Creath, W.B., 1996. Homebuyers' guide to geologic hazards-An AIPG issues and answers publication: Department of Natural Resources, Denver, Colorado Geological Survey, Miscellaneous Publication (MI) no. 58, 30 p.

13. Fleming, Robert W., and Taylor, Fred A., 1980, Estimating the costs of landslide damage in the United States: U.S. Geological Survey Circular 832, 21p.

14. Gray, D.H., and Sotir, R.B., 1996, Biotechnical and soil bioengineering slope stabilization-A practical guide for erosion control: New York, John Wiley, $378 \mathrm{p}$.

15. Haugerud, Ralph A., Harding, David J., Johnson, Samuel Y., Harless, Jerry L., Weaver, Craig S., and Brian L. Sherrod, 2003, High-resolution LiDAR topography of the Puget Lowland, Washington-A Bonanza for earth science: GSA Today, Geological Society of America, p. 4-10.
16. Highland, Lynn, 2004, Landslide types and processes: U.S. Geological Survey Fact Sheet FS-2004-3072. Online: http://pubs.usgs.gov/fs/2004/3072/

17. Jackson, Julia A., ed., 1997, Glossary of geology, fourth edition: American Geophysical Institute, Alexandria, Virginia, USA, 769 p.

18. Jibson, Randall W., Harp, Edwin L., and Michael, John A., 1998, A method for producing digital probabilistic seismic landslide hazard maps-An example from the Los Angeles, California, area: U.S. Geological Survey Open-File Report 98-113, 17 p. Online: http:// pubs.usgs.gov/of/1998/ofr-98-113/

19. Jochim, Candice, Rogers, William P., Truby, John O., Wold, Jr., Robert L., Weber, George, and Brown, Sally P., 1988, Colorado landslide hazard mitigation plan: Department of Natural Resources, Colorado Geological Survey, Denver, Colo., USA.

20. Los Angeles County Department of Public Works, Board of Supervisors, 1993, Homeowner's guide for flood, debris, and erosion control: Alhambra, California, in English and Spanish. Online: http://dpw.lacounty.gov/wmd/ Homeowners/index.cfm

21. McInnes, Robin, 2000, Managing ground instability in urban areas, a guide to best practice, Centre for the Coastal Environment, Isle of Wight Council: United Kingdom, Cross Publishing, Walpen Manor, Chale, Isle of Wight.

22. National Research Council, 1993 , Vetiver grass-A thin green line against erosion: National Academy Press, Washington, D.C. Online: http://www.vetiver.org

23. Nichols, Donald R., and Catherine C. Campbell, eds., 1971, Environmental planning and geology: U.S. Department of Housing and Urban Development, U.S. Department of the Interior, U.S. Government Printing Office. 
24. Norheim, Robert A., Queija, Vivian R., and Haugerud, Ralph A., 2002, Comparison of LiDAR and InSAR DEMs with dense ground control: Proceedings, Environmental Systems Research Institute 2002 User Conference. Online: http://gis.esri.com/library/userconf/ proc02/pap0442/p0442.htm

25. Nuhfer, Edward B., Proctor, Richard J., and Moser, Paul H., 1993. The citizen's guide to geologic hazards: The American Institute of Professional Geologists, $134 \mathrm{p}$.

26. Olshansky, Robert B., 1996, Planning for hillside development: American Planning Association (APA), Planning Advisory Service Report no. 466, 50 p.

27. Pelletier, B.R., ed., 2000, Environmental atlas of the Beaufort coastlands, supplement to the Marine Science Atlas of the Beaufort Sea: Geological Survey of Canada, Natural Resources Canada. Online: http://gsc.nrcan.gc.ca/beaufort/ index_e.php

28. Reid, Mark, and Ellis, William L., 1999, Real-time monitoring of active landslides: U.S. Geological Survey Fact Sheet FS-091-99. Online: http://pubs.usgs.gov/fs/fs-091-99/

29. Rickenmann, Dieter, and Cheng-lung Chen, eds., 2003, Debris-flow hazards Mitigation-Mechanics, prediction, and assessment: Millpress, Rotterdam, The Netherlands.

30. Schuster, Robert L., and Highland, Lynn M., 2004, Impact of landslides and innovative landslide-mitigation measures on the natural environment: International Conference on Slope Engineering, Hong Kong, China, December 8-10, 2003, keynote address, Proceedings 29.

31. Schuster, R.L., 2004, Risk-reduction measures for landslide dams, in Security of natural and artificial rockslide dams: Extended Abstracts Volume, NATO Advanced research Workshop on Landslide Dams, Bishkek, Kyrgyzstan, June 8-13, p.170-176 [theme keynote paper].

32. Schuster, Robert L., and Highland, Lynn M., 2001, Socioeconomic effects of landslides in the western hemisphere: U.S. Geological Survey Open-File Report 2001-0276. Online: http://pubs.usgs.gov/of/2001/ ofr-01-0276/
33. Schwab, J.C., Gori, P.L., and Jeer, S., eds., 2005, Landslide hazards and planning: American Planning Association Planning Advisory Service Report no. 533/534.

34. Shelton, David C., and Prouty, Dick, 1979, Nature's building codes, geology and construction in Colorado: Department of Natural Resources, Colorado Geological Survey Bulletin 48, 72 p.

35. Soeters R., and van Westen, C.J., 1996, Slope instability recognition, analysis, and zonation, in Turner, A.K., and Schuster, R.L. eds., Landslides-Investigation and mitigation: Transportation Research Board Special Report 247, National Research Council, Washington, D.C., p. 129-177.

36. Solomon, Barry J., 2001, Using geologic hazards information to reduce risks and Losses-A guide for local governments: Utah Geological Survey, Public Information Series 75. Online: http://geology.utah.gov/online/pdf/ pi-75.pdf

37. Swanston, D., ed., 1985, Proceedings of a workshop on slope stability-Problems and solutions in forest management: USDA Forest Service General Technical Report PNW-180, Pacific Northwest Forest and Range Experimental Station, Portland, Oregon, 122 p.

38. Swanston, D.N., 1983, Assessment of mass erosion risk from forest operations in steep terrain: International Association of Forestry Research Organizations Congress, Division 3, Forest Operations and Techniques, Munich, Germany, 1982, Proceedings.

39. Turner, A. Keith, and Schuster, Robert L., 1996, Landslides - Investigation and mitigation: National Research Council, Transportation Research Board Special Report 247, National Academy Press, Washington, D.C., 673 p.

40. United States Agency for International Development, Bureau for Humanitarian Response, Office of Foreign Disaster Assistance, 1998, Field operations guide for disaster assessment and response: U.S. Government Printing Office. Online: http://www.usaid.gov/ our_work/humanitarian_assistancel disaster_assistance/resources/pdf/ fog_v3.pdf
41. U.S. Geological Survey, 2005, Monitoring ground deformation from space: U.S. Geological Survey Fact Sheet FS-2005-3025. Online: http://volcanoes.usgs.gov/insar/public_ files/InSAR_Fact_Sheet/2005-3025.pdf

42. Utah Geological Survey, 2003, Home owner's guide to recognizing and reducing landslide damage on their property: Public Information Series no. 58. Online: http://geology.utah.gov/online/ pi-58/index.htm

43. Varnes, D.J., 1978, Slope movement types and processes, in Schuster, R.L., and Krizek, R.J., eds., LandslidesAnalysis and control: Transportation Research Board Special Report 176, National Research Council, Washington, D.C., p. 11-23.

44. Weber, G., Von Schulez, W., and Czerniak, R., 1983, Flood hazard management plan for the Sheridan watershed area: Sheridan, Wyoming, Geographic Applications and Research Group, Boulder, Colorado.

45. Wieczorek, Gerald F., 1996, Landslide triggering mechanisms, in Turner, A. Keith, and Schuster, Robert L., eds., Landslides - Investigation and mitigation: Transportation Research Board, Special report no. 247, National Research Council, National Academy Press, Washington, D.C., p. 76-90.

46. Wold, Robert L., and Jochim, Candace L.,1989, Landslide loss reduction-A guide for state and local government planning: Special Publication 33, Department of Natural Resources, Colorado Geological Survey, Denver, Colo., 50 p.

47. Yoon, P.K., 1994, Important biological considerations in use of Vetiver grass hedgerows (VGHR) for slope protection and stabilisation, in Vegetation and slopes-Stabilisation, protection and ecology: Proceedings, International Conference Institution of Civil Engineers, University Museum, Oxford, September 29-30, 1994, Thomas Telford, London, p. 212-221. 


\section{Appendix A. Basic Information about Landslides}




\section{Part 1. Glossary of Landslide Terms}

Full references citations for glossary are at the end of the list.

alluvial fan An outspread, gently sloping mass of alluvium deposited by a stream, especially in an arid or semiarid region where a stream issues from a narrow canyon onto a plain or valley floor. Viewed from above, it has the shape of an open fan, the apex being at the valley mouth. (Reference 3 )

bedding surface/plane In sedimentary or stratified rocks, the division planes that separate each successive layer or bed from the one above or below. It is commonly marked by a visible change in lithology or color. (Reference 3)

bedrock The solid rock underlying gravel, sand, clay, and so forth; any solid rock exposed at the surface of the earth or overlain by unconsolidated superficial material. (Reference 3)

borehole A circular hole drilled into the earth, often to a great depth, as a prospective oil, gas, or water well or for exploratory purposes. (Reference 3)

check dams Check dams are small sediment storage dams built in the channels of steep gullies to stabilize the channel bed. A common use is to control channelized debrisflow frequency and volume. Check dams are expensive to construct and are therefore usually only built where important installations or natural habitat (such as a camp or unique spawning area) lies downslope. (Reference 2)

colluvium A general term applied to loose and incoherent deposits, usually at the foot of a slope or cliff and brought there chiefly by gravity. (Reference 2)

\section{debris basin (sometimes called catch}

basins) A large excavated basin into which a debris flow runs or is directed and where it quickly dissipates its energy and deposits its load. Abandoned gravel pits or rock quarries are often used as debris basins. (Reference 3).

delta-front landsliding Delta fronts are where deposition in deltas is most activeunderwater landsliding along coastal and delta regions due to rapid sedimentation of loosely consolidated clay, which is low in strength and high in pore-water pressures.

Digital Elevation Model (DEM) A digital elevation model (DEM) is a digital file consisting of terrain elevations for ground positions at regularly spaced horizontal intervals. (A commercial definition - new technology)
Digital Terrain Model (DTM) The term used by United States Department of Defense and other organizations to describe digital elevation data. (Reference 3)

drawdown Lowering of water levels in rivers, lakes, wells, or underground aquifers due to withdrawal of water. Drawdown may leave unsupported banks or poorly packed earth that can cause landslides. (Reference 3)

electronic distance meter (EDM) A device that emits ultrasonic waves that bounce off solid objects and return to the meter. The meter's microprocessor then converts the elapsed time into a distance measurement. Sound waves spread 1 foot wide for every 10 feet measured. There are various types available.

epicenter The point on the Earth's surface directly above the focus of an earthquake. (Reference 3)

expansive soils Types of soil that shrink or swell as the moisture content decreases or increases. Structures built on these soils may shift, crack, and break as soils shrink and subside or expand. Also known as swelling soils. (Reference 5)

extensometer An instrument for measuring small deformations, as in tests of stress. (Reference 3)

factor of safety The factor of safety, also known as Safety Factor, is used to provide a design margin over the theoretical design capacity to allow for uncertainty in the design process. The uncertainty could be any one of a number of the components of the design process including calculations and material strengths for example. Commonly, a factor of safety of less than 1, for instance, on an engineered slope indicates potential failure, where a factor of safety of greater than 1 , indicates stability. (Reference 6)

geodesic/geodetic measurements The investigation of any scientific questions connected with the shape and dimensions of the Earth. (Reference 3)

fracture Brittle deformation due to a momentary loss of cohesion or loss of resistance to differential stress and a release of stored elastic energy. Both joints and faults are fractures. (Reference 3)
Geographic Information System (GIS) A computer program and associated data bases that permit cartographic information (including geologic information) to be queried by the geographic coordinates of features. Usually the data are organized in "layers" representing different geographic entities such as hydrology, culture, topography, and so forth. A geographic information system, or GIS, permits information from different layers to be easily integrated and analyzed. (Reference 3)

geologic hazard A geologic condition, either natural or manmade, that poses a potential danger to life and property. Examples: earthquake, landslides, flooding, faulting, beach erosion, land subsidence, pollution, waste disposal, and foundation and footing failures. (Reference 3 )

geologic map A map on which is recorded the distribution, nature, and age relationships of rock units and the occurrence of structural features. (Reference 3)

geomorphology The science that treats the general configuration of the Earth's surface; specifically, the study of the classification, description, nature, origin, and development of landforms and their relationships to underlying structures, and the history of geologic changes as recorded by these surface features. (Reference 3)

geophysical studies The science of the Earth, by quantitative physical methods, with respect to its structure, composition, and development. It includes the sciences of dynamical geology and physical geography and makes use of geodesy, geology, seismology, meteorology, oceanography, magnetism, and other Earth sciences in collecting and interpreting Earth data. (Reference 3)

hydraulic Of or pertaining to fluids in motion; conveying, or acting, by water; operated or moved by means of water, as hydraulic mining. (Reference 3 )

hydrology The science that relates to the water of the Earth. (Reference 3)

inclinometer Instrument for measuring inclination to the horizontal. (Reference 3)

landslide dam An earthen dam created when a landslide blocks a stream or river. (Reference 3) 
Iahar Landslide, debris flow or mudflow, of pyroclastic material on the flank of a volcano; deposit produced by such a debris flow.

Lahars are described as wet if they are mixed with water derived from heavy rains, escaping from a crater lake, or produced by melting snow. Dry lahars may result from tremors of a cone or by accumulating material becoming unstable on a steep slope. If the material retains much heat, it is termed a hot lahar. (Reference 3)

liquefaction The transformation of saturated, loosely packed, coarse-grained soils from a solid to a liquid state. The soil grains temporarily lose contact with each other, and the particle weight is transferred to the pore water. (Reference 4)

landslide inventory maps Inventories identify areas that appear to have failed by landslide processes, including debris flows and cut-and-fill failures. (Reference 4)

landslide susceptibility map This map goes beyond an inventory map and depicts areas that have the potential for landsliding. These areas are determined by correlating some of the principal factors that contribute to landsliding, such as steep slopes, weak geologic units that lose strength when saturated, and poorly drained rock or soil, with the past distribution of landslides. (Reference 5)

landslide hazard map Hazard maps show the areal extent of threatening processes: where landslide processes have occurred in the past, where they occur now, and the likelihood in various areas that a landslide will occur in the future. (Reference 5)

landslide risk map Landslide hazards and the probability that they will occur, expressed in statistical recurrence rates; risk maps may show cost/benefit relationships, loss potential and other potential socioeconomic effects on an area and (or) community.

lithology The physical character of a rock, generally as determined at the microscopic level, or with the aid of a low-power magnifier; the microscopic study and description of rocks. (Reference 3)

loess A widespread, homogenous, commonly nonstratified, porous, friable, slightly coherent, usually highly calcareous, finegrained blanket deposit (generally less than $30 \mathrm{~m}$ thick) consisting predominantly of silt, with subordinate grain sizes ranging from amounts of clay to fine sand. (Reference 3)

mitigation Activities that reduce or eliminate the probability of occurrence of a disaster and (or) activities that dissipate or lessen the effects of emergencies or disasters when they actually occur. (Reference 5) mudslide An imprecise but popular term coined in California, USA, frequently used by the general public and the news media to describe a wide scope of events, ranging from debris-laden floods to landslides. Not technically correct. Please see "mudflow," next Glossary entry. (Reference 5)

mudflow A general term for a mass-movement landform and process characterized by a flowing mass of predominately fine-grained earth material possessing a high degree of fluidity during movement. The water content may range up to 60 percent. (Reference 3)

perched ground water Unconfined ground water separated from an underlying main body of ground water by an unsaturated zone. (Reference 3)

piezometer An instrument for measuring pressure head in a conduit, tank, or soil-it is a small diameter water well used to measure the hydraulic head of ground water in aquifers. (Reference 3)

pore-water pressure A measure of the pressure produced by the head of water in a saturated soil and transferred to the base of the soil through the pore water. This is quantifiable in the field by the measurement of free water-surface level in the soil or by direct measurement of the pressure by means of piezometers. Pore-water pressure is a key factor in failure of a steep slope soil and operates primarily by reducing the weight component of soil shear strength. (Reference 2)

pore water, or interstitial water Subsurface water in an interstice, or pore. (Reference 3)

quick clay A clay that loses nearly all its shear strength after being disturbed; a clay that shows no appreciable gain in strength after remolding. (Reference 3 )

reconnaissance geology/mapping A general, exploratory examination or survey of the main features of a region, usually preliminary to a more detailed survey. It may be made in the field or office, depending on the extent of information available. (Reference 2)

relief The difference in elevation between the high and low points of a land surface. (Reference 3)

risk The probability of occurrence or expected degree of loss, as a result of exposure to a hazard. (Reference 4)

rock mechanics The theoretical and applied science of the mechanical behavior of rocks, representing a "branch of mechanics concerned with the response of rock to the force fields of its physical environment." (Reference 3) sag pond A small body of water occupying an enclosed depression or sag formed where active or recent fault or landslide movement has impounded drainage. (Reference 3)

seepage Concentrated subsurface drainage indicated by springs, sag ponds, or moist areas on open slopes, and seepage sites along road cuts. The locations of these areas of concentrated subsurface flow should be noted on maps and profiles as potential sites of active, unstable ground. (Reference 2)

sea cliff retreat A cliff formed by wave action, causing the coastal cliff to erode and recede toward land. (Reference 3)

shear A deformation resulting from stresses that cause contiguous parts of a body to slide relative to each other in a direction parallel to their plane of contact. (Reference 3)

slurry A highly fluid mixture of water and finely divided material; for example, pulverized coal and water for movement by pipeline or of cement and water for use in grouting. (Reference 3)

soil mechanics The application of the principles of mechanics and hydraulics to engineering problems dealing with the behavior and nature of soils, sediments, and other unconsolidated accumulations; the study of the physical properties and utilization of soils, especially in relation to highway and foundation engineering. (Reference 3 )

strainmeter A seismometer that is designed to detect deformation of the ground by measuring relative displacement of two points. (Reference 3)

stress In a solid, the force per unit area, acting on any surface within it, and variously expressed as pounds or tons per square inch, or dynes or kilograms per square centimeter; also, by extension, the external pressure that creates the internal force. (Reference 3 )

sturzstroms (German language term for "fall stream") A huge mass of rapidly moving rock debris and dust, derived from the collapse of a cliff or mountainside, flowing down steep slopes and across low ground, often for several kilometers at speeds of more than $100 \mathrm{~km} / \mathrm{hr}$. Sturzstroms are the most catastrophic of all forms of mass movement. (Reference 3)

subaqueous (submarine) landslide Conditions and processes, or features and deposits, that exist or are situated in or under water. Generally used to specify a process that occurs either on land (the slide extending underwater) or that begins under water; for example, slumping, gravitational slides. (Reference 3) 
subsidence Sinking or downward settling of the Earth's surface, not restricted in rate, magnitude, or area involved. Subsidence may be caused by natural geologic processes, such as solution, compaction, or withdrawal of fluid lava from beneath a solid crust or by human activity such as subsurface mining or the pumping of oil or ground water. (Reference 3)

surficial geology Geology of surficial deposits, including soils; the term is sometimes applied to the study of bedrock at or near the Earth's surface. (Reference 3)

swelling soils These are soils or soft bedrock that increases in volume as they get wet and shrink as they dry out. They are also commonly known as bentonite, expansive, or montmorillinitic soils. (Reference 1)

tensile stress A normal stress that tends to pull apart the material on the opposite sides of the plane on which it acts. (Reference 3)

weathering The destructive process by which earth and rock materials exposed to the atmosphere undergo physical disintegration and chemical decomposition resulting in changes in color, texture, composition, or form. Processes may be physical, chemical, or biological. (Reference 4) weathering, differential When weathering across a rock face or exposure occurs at different rates mainly due to variations in the composition and resistance of the rock. This results in an uneven surface with the more resistant material protruding. (Reference 4)

weathering, mechanical The physical processes by which rocks exposed to the weather change in character, decay, and crumble into soil. Processes include temperature change (expansion and shrinkage), freeze-thaw cycle, and the burrowing activity of animals. (Reference 4)

zonation A term used generally, even vaguely, for a region of latitudinal character more or less set off from surrounding regions by some distinctive characteristic, for instance, the Earth's torrid zone, two temperate zones, and two frigid zones. For hazards, zones are geographic regions or designations that are differentiated through a variety of different criteria, for example, residential zones, zones of low hazard, zones of high hazard. (Reference 3)

\section{References for Glossary:}

1. Creath, W.B., 1996, Homebuyers' guide to geologic hazards: An AIPG issues and answers publication: Department of Natural Resources, Colorado Geological Survey, Miscellaneous Publication (MI) no. $58,30 \mathrm{p}$.

2. Chatwin, S.C., Howes, D.E., Schwab, J.W., and Swanston, D.N., 1994, A guide for management of landslideprone terrain in the Pacific Northwest, 2d edition: Research Branch, Ministry of Forests, Province of British Columbia, Victoria, British Columbia, Crown Publications.

3. Jackson, Julia A., ed., 1997, Glossary of geology, fourth edition: Prepared by the American Geological Institute, Alexandria, Virginia, USA, Doubleday.

4. Jochim, Candice L., Rogers, William P., Truby, John O., Wold, Robert L., Jr., Weber, George, and Brown, Sally P., 1988, Colorado landslide hazard mitigation plan: Department of Natural Resources, Colorado Geological Survey, Bulletin 48.

5. Shelton, David C., and Prouty, Dick, 1979, Nature's building codes, geology and construction in Colorado: Department of Natural Resources, Colorado Geological Survey Special Publication No. 48, 72 p.

6. Turner, A. Keith, and Schuster, Robert L., 1996, LandslidesInvestigation and mitigation: National Research Council, Transportation Research Board, Special Report 247, National Academy Press, Washington, D.C., 673 p. 


\section{Part 2. Parts of a Landslide-Description of Features/Glossary}

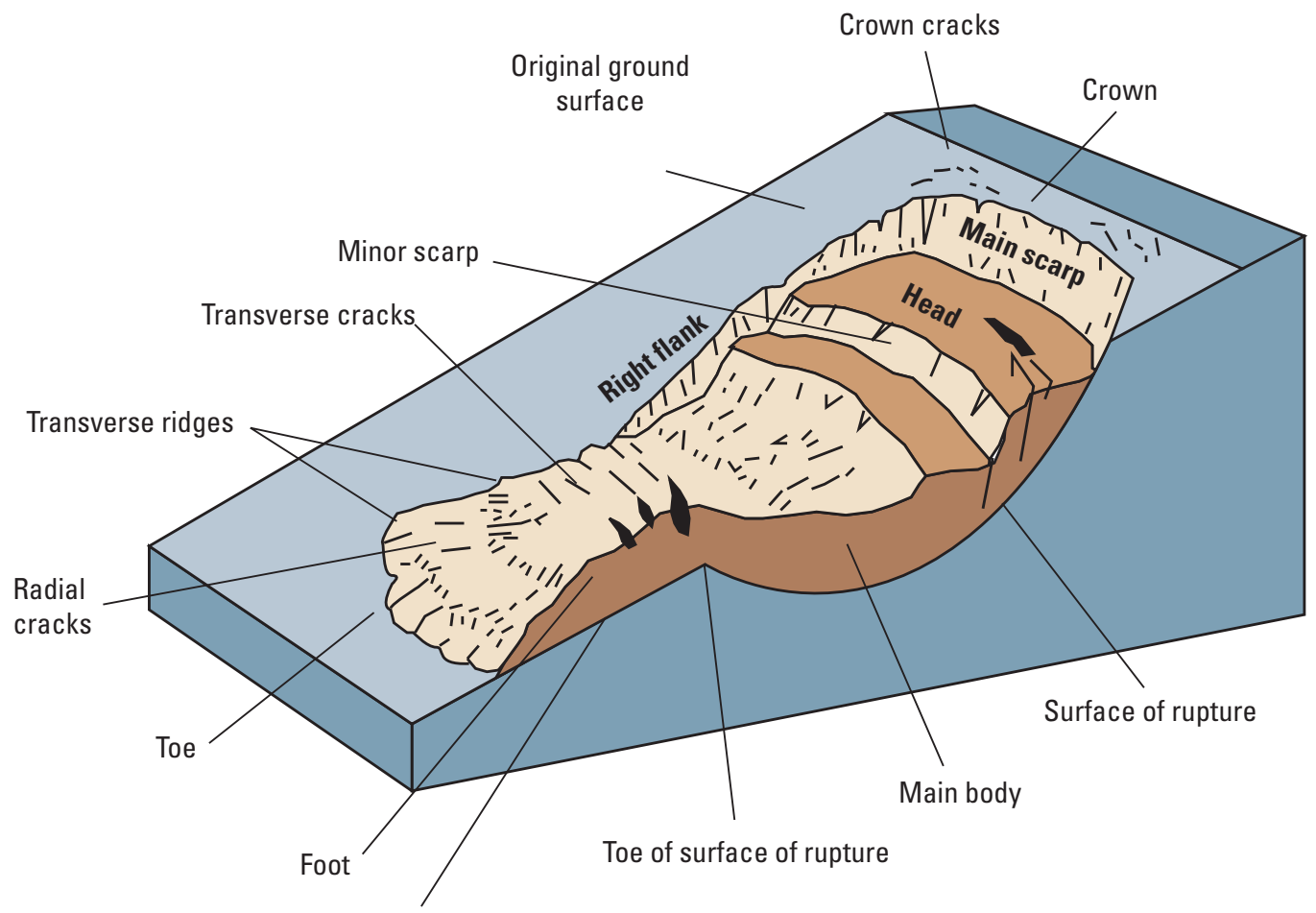

Surface of separation

Figure A1. Parts of a landslide. (Modified from Varnes, 1978, reference 43).

accumulation The volume of the displaced material, which lies above the original ground surface.

crown The practically undisplaced material still in place and adjacent to the highest parts of the main scarp.

depletion The volume bounded by the main scarp, the depleted mass and the original ground surface.

depleted mass The volume of the displaced material, which overlies the rupture surface but underlies the original ground surface.

displaced material Material displaced from its original position on the slope by movement in the landslide. It forms both the depleted mass and the accumulation.

flank The undisplaced material adjacent to the sides of the rupture surface. Compass directions are preferable in describing the flanks, but if left and right are used, they refer to the flanks as viewed from the crown.

foot The portion of the landslide that has moved beyond the toe of the surface of rupture and overlies the original ground surface.

head The upper parts of the landslide along the contact between the displaced material and the main scarp. main body The part of the displaced material of the landslide that overlies the surface of rupture between the main scarp and the toe of the surface of rupture.

main scarp A steep surface on the undisturbed ground at the upper edge of the landslide, caused by movement of the displaced material away from the undisturbed ground. It is the visible part of the surface of rupture.

minor scarp A steep surface on the displaced material of the landslide produced by differential movements within the displaced material.

original ground surface The surface of the slope that existed before the landslide took place.

surface of separation The part of the original ground surface overlain by the foot of the landslide.

surface of rupture The surface that forms (or which has formed) the lower boundary of the displaced material below the original ground surface.

tip The point of the toe farthest from the top of the landslide.

toe The lower, usually curved margin of the displaced material of a landslide, it is the most distant from the main scarp. top The highest point of contact between the displaced material and the main scarp.

toe of surface of rupture The intersection (usually buried) between the lower part of the surface of rupture of a landslide and the original ground surface.

zone of accumulation The area of the landslide within which the displaced material lies above the original ground surface.

zone of depletion The area of the landslide within which the displaced material lies below the original ground surface.

\section{Sources of information on nomenclature:}

1. Cruden, D.M., 1993, The multilingual landslide glossary: Richmond, British Columbia, Bitech Publishers, for the IUGS Working Party on World Landslide Inventory in 1993.

2. Varnes, D.J., 1978, Slope movement types and processes, in Schuster, R.L., and Krizek, R. J., eds., LandslidesAnalysis and control: Transportation Research Board Special Report 176, National Research Council, Washington, D.C., p. 11-23. 


\section{Part 3. Landslide Causes and Triggering Mechanisms}

\begin{tabular}{|l|}
\hline Physical Causes-Triggers \\
- Intense rainfall \\
- Rapid snowmelt \\
- Prolonged intense precipitation \\
- Rapid drawdown (of floods and \\
- tides) or filling \\
- Earthquake \\
- Volcanic eruption \\
- Thawing \\
- Freeze-and-thaw weathering \\
- Flooding
\end{tabular}

For further reading: References 9, 3, and 45
Natural Causes

\section{Geological causes}

- Weak materials, such as some volcanic slopes or unconsolidated marine sediments, for example

- Susceptible materials

- Weathered materials

- Sheared materials

- Jointed or fissured materials

- Adversely oriented mass discontinuity (bedding, schistosity, and so forth)

- Adversely oriented structural discontinuity (fault, unconformity, contact, and so forth)

- Contrast in permeability

- Contrast in stiffness (stiff, dense material over plastic materials)

\section{Morphological causes}

- Tectonic or volcanic uplift

- Glacial rebound

- Glacial meltwater outburst

- Fluvial erosion of slope toe

- Wave erosion of slope toe

- Glacial erosion of slope toe

- Erosion of lateral margins

- Subterranean erosion (solution, piping)

- Deposition loading slope or its crest

- Vegetation removal (by forest fire, drought)

\section{Human Causes}

- Excavation of slope or its toe

- Use of unstable earth fills, for construction

- Loading of slope or its crest, such as placing earth fill at the top of a slope

- Drawdown and filling (of reservoirs)

- Deforestation-cutting down trees/logging and (or) clearing land for crops; unstable logging roads

- Irrigation and (or) lawn watering

- Mining/mine waste containment

- Artificial vibration such as pile driving, explosions, or other strong ground vibrations

- Water leakage from utilities, such as water or sewer lines

- Diversion (planned or unplanned) of a river current or longshore current by construction of piers, dikes, weirs, and so forth 


\section{Appendix B. \\ Introduction to Landslide Evaluation Tools- Mapping, Remote Sensing, and Monitoring of Landslides}




\section{Part 1. Mapping}

Maps are a useful and convenient tool for presenting information on landslide hazards. They can present many kinds and combinations of information at different levels of detail. Hazard maps used in conjunction with land-use maps are a valuable planning tool. Commonly, there is a three-stage approach to landslide hazard mapping. The first stage is regional or reconnaissance mapping, which synthesizes available data and identifies general problem areas. This regional scale (sometimes called "small-scale") mapping is usually performed by a Provincial, State, or Federal geological survey. The next stage is community-level mapping, a more detailed surface and subsurface mapping program in complex problem areas. Finally, detailed site-specific large-scale maps are prepared. If resources are limited, it may be more prudent to bypass regional mapping and concentrate on a few known areas of concern. We discuss three types of general mapping; (1) Regional, (2) Community level, and (3) Site specific.

\section{Regional mapping}

Regional or reconnaissance mapping supplies basic data for regional planning by providing baseline information for conducting more detailed studies at the community and site-specific levels and for setting priorities for future mapping.

Such maps are usually simple inventory or susceptibility maps and are directed primarily toward the identification and delineation of regional landslide problem areas and the conditions under which they occur. They concentrate on those geologic units or environments in which additional movements are most likely. The geographical extent of regional maps can vary from a map of a State or Province to a national map, which delineates an entire country. Such mapping relies heavily on photogeology (the geologic interpretation of aerial photography), reconnaissance field mapping, and the collection and synthesis of all available pertinent geologic data. Map scales at this level are typically at scales ranging from 1:10,000 down to $1: 4,000,000$ or even smaller.

\section{Community-level mapping}

This type of mapping identifies both the three-dimensional potential of land sliding and considers its causes. Guidance concerning land use, zoning, and building, and recommendations for future site-specific investigations also are made at this stage. Investigations should include subsurface exploratory work in order to produce a map with cross sections. Map scales at this level typically vary from 1:1,000 to $1: 10,000$.

\section{Site-specific mapping}

Site-specific mapping is concerned with the identification, analysis, and solution of actual site-specific problems, often presented in the size of a residential lot. It is usually undertaken by private consultants for landowners who propose site development and typically involves a detailed drilling program with downhole logging, sampling, and laboratory analysis in order to procure the necessary information for design and construction. Map scales vary but usually are about 1:600 or $25 \mathrm{~mm}$ (1 inch) equal to $16 \mathrm{~m}$ (50 feet). 


\section{Three Important Criteria for Landslide Maps}

The three types of landslide maps most useful to planners and the general public are (1) landslide inventories, (2) landslide susceptibility maps, and (3) landslide hazard maps.

\section{Landslide inventory maps}

Inventories denote areas that are identified as having failed by landslide processes (fig. B1). The level of detail of these maps ranges from simple reconnaissance inventories that only delineate broad areas where landsliding appears to have occurred to complex inventories that depict and classify each landslide and show scarps, zones of depletion and accumulation, active and inactive slides, geological age, rate of movement, and (or) other pertinent data on depth and kind of materials involved in sliding.

Simple inventories give an overview of the areal extent of landslide occurrence and highlight areas where more detailed studies should be conducted. Detailed inventories provide a better understanding of the different landslide processes operating in an area and can be used to regulate or prevent development in landslide-prone areas and to aid the design of remedial measures. They also provide a good basis for the preparation of derivative maps, such as those indicating slope stability, for rating landslide hazard, and to identify land use. One way is to use aerial photography with selective field checking to detect landslide areas and then to present the information in map form using a coded format. The maps show any or all of the following: state of activity, certainty of identification, dominant types of slope movement, estimated thickness of landslide material, type of material, and dates or periods of activity.

In the United States, regional maps are most often prepared at a scale of 1:24,000 (1:50,000 in Canada) because high-quality U.S. Geological Survey topographic base maps at this scale are widely available and aerial photographs are commonly of a comparable scale. Other scales commonly used in the United States, for example, include 1:50,000 (county series), 1:100,000 $(30 \times 60$ minute series), and 1:250,000 $(1 \times 2$ degree series $)$.

\section{EXPLANATION}

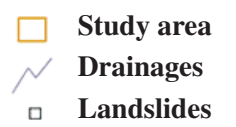

Elevation, in meters

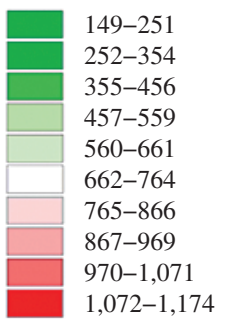

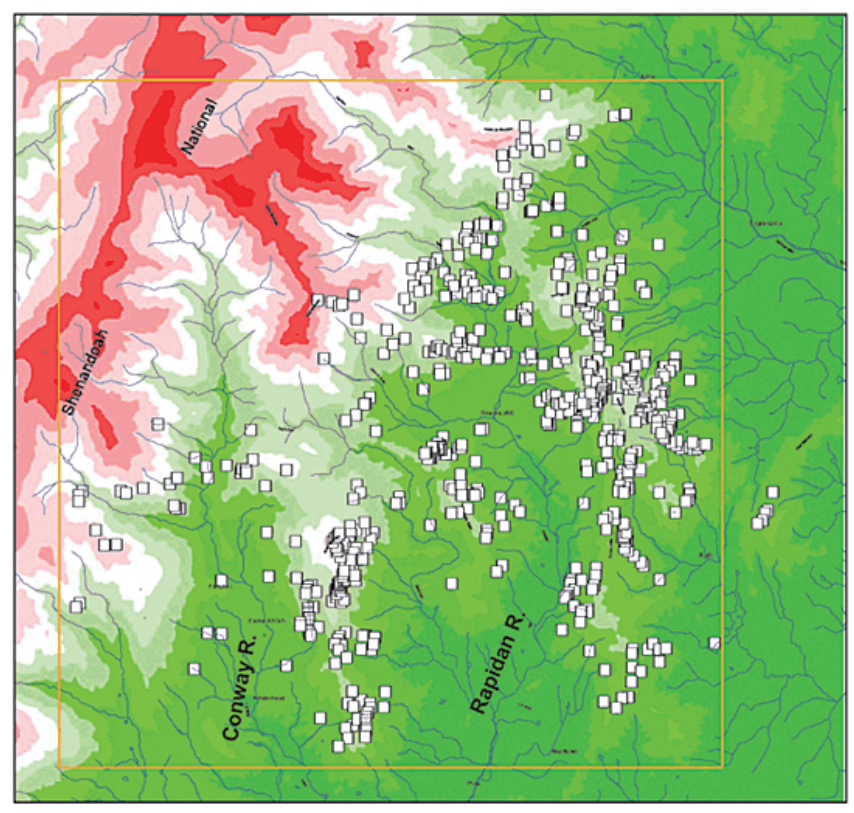

Figure B1. Example of a landslide inventory map showing the locations of past landslides and including topographical information consisting of elevation (measured in meters) and drainage courses (map from U.S. Geological Survey). 


\section{Landslide susceptibility maps}

A landslide susceptibility map goes beyond an inventory map and depicts areas that have the potential for landsliding (fig. B2). These areas are determined by correlating some of the principal factors that contribute to landsliding (such as steep slopes, weak geologic units that lose strength when saturated or disturbed, and poorly drained rock or soil) with the past distribution of landslides. These maps indicate only the relative stability of slopes; they do not make absolute predictions.

Landslide susceptibility maps can be considered derivatives of landslide inventory maps because an inventory is essential for preparing a susceptibility map. For example, overlaying a geologic map with an inventory map that shows existing landslides can identify specific landslide-prone geologic units. This information can then be extrapolated to predict other areas of potential landsliding. More complex maps may include additional information such as slope angle and drainage.

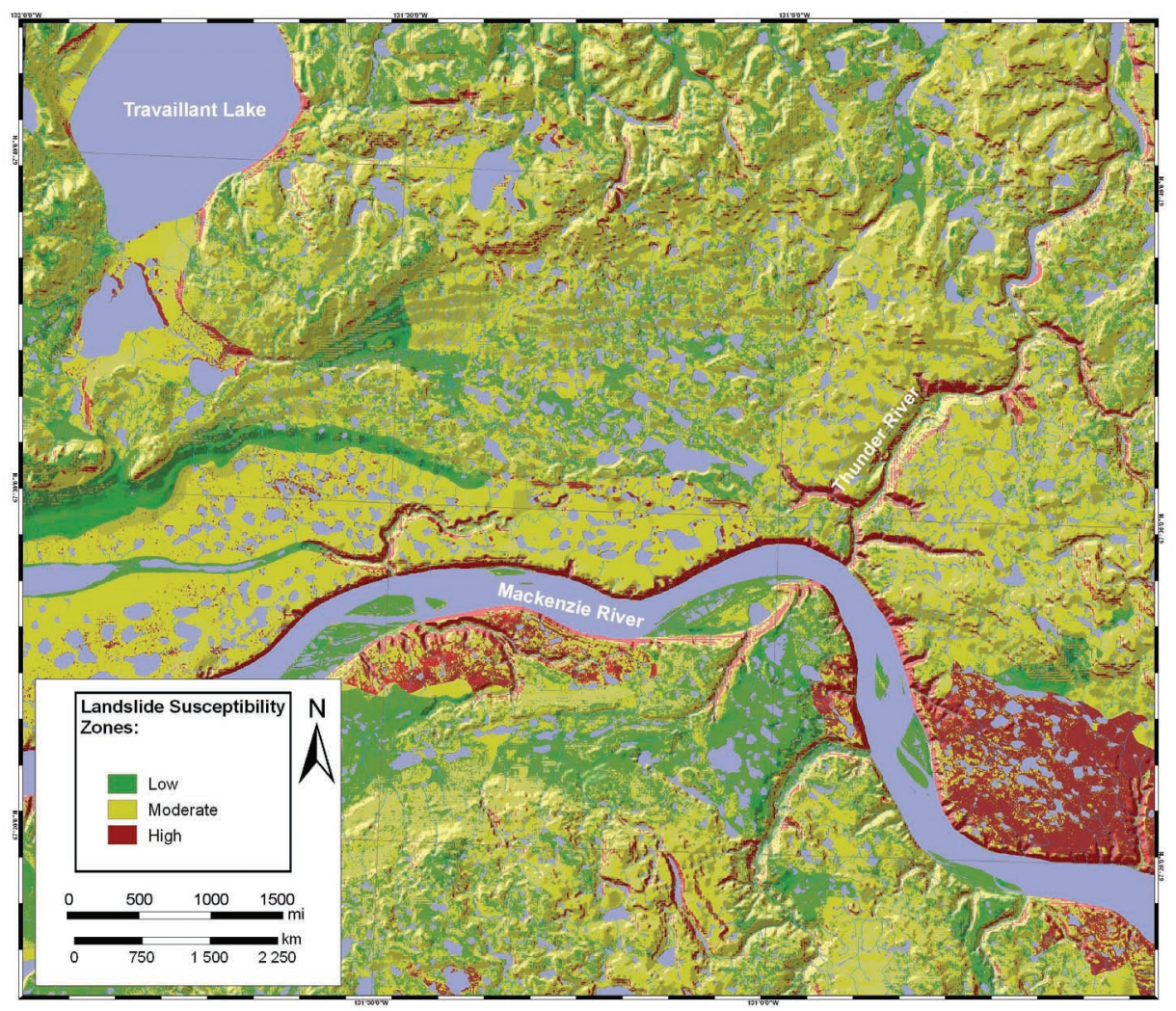

Figure B2. An example of a landslide susceptibility map. This map shows an area in Canada, the Mackenzie River Valley, Northwest Territories. Graphic by Réjean Couture, Geological Survey of Canada. 


\section{Landslide hazard maps}

Hazard maps show the areal extent of threatening processes (fig. B3): where landslide processes have occurred in the past, recent occurrences, and most important, the likelihood in various areas that a landslide will occur in the future. For a given area, hazard maps contain detailed information on the types of landslides, extent of slope subject to failure, and probable maximum extent of ground movement. These maps can be used to predict the relative degree of hazard in a landslide area. Areas may be ranked in a hierarchy such as low, moderate, and high hazard areas.

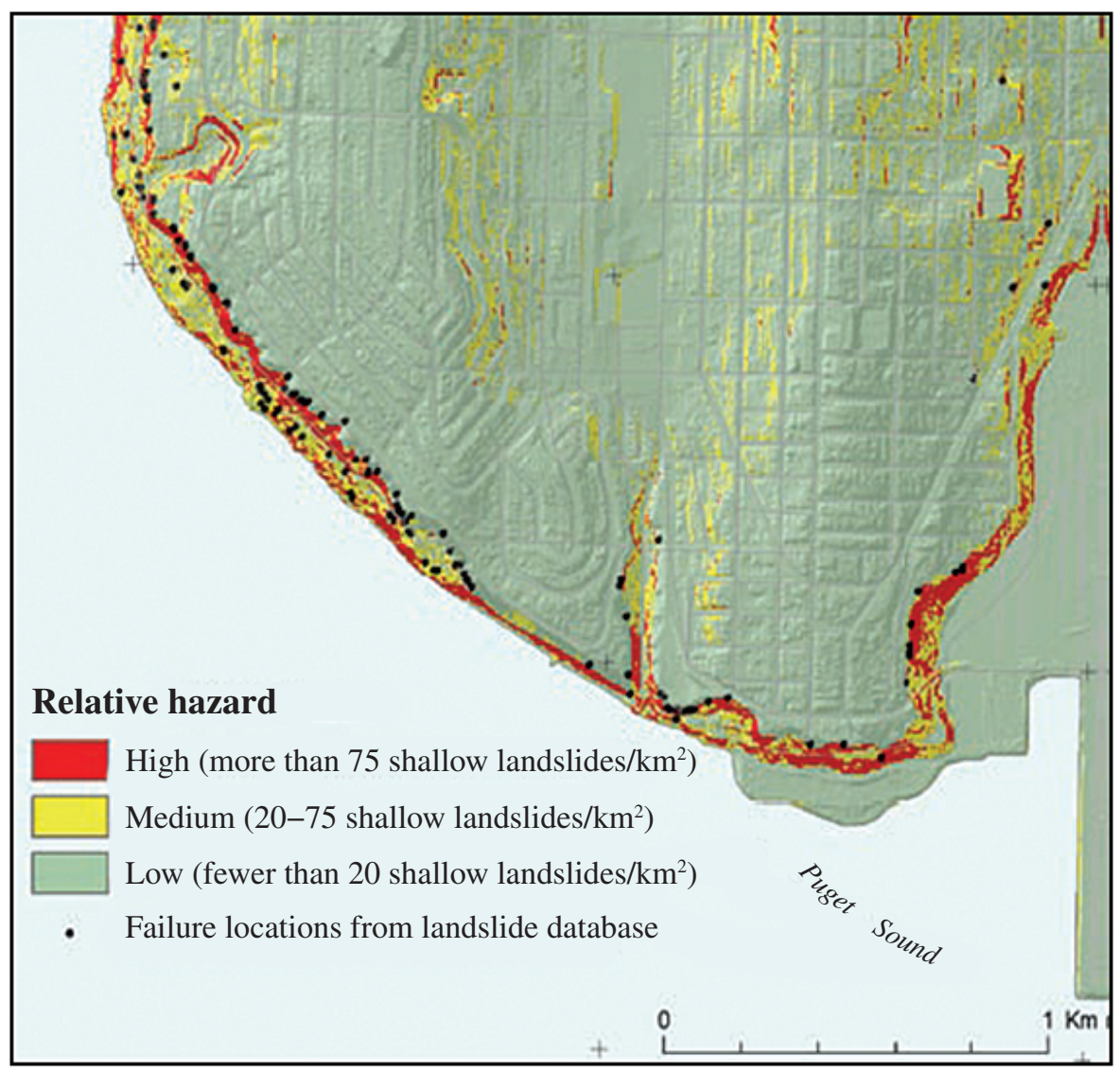

Figure B3. Portion of shallow landslide hazard map showing part of the Magnolia area of the city of Seattle, Washington, USA. ( $\mathrm{km}^{2}$ is notation for square kilometers.)
For mapping references and further reading: 4, 12, 18, 19, 21, 25, 29, 33, $34,35,41$ and 46. 


\section{Part 2. Remote Sensing and Other Tools that Show Features of Landslide Activity}

Maps and other forms of information are sometimes overlaid on each other using a GIS (Geographical Information System) so that the different types of information can be viewed all at once. In the absence of a GIS computerized system, transparencies can be made of each map and then can be overlaid together. It is important that the maps and data be at the same scale. The following list describes many types of information that might be useful in constructing layers for GIS analysis of landslide potential.

- Topographic Map Indicates slope gradient, terrain configuration, drainage pattern.

- Terrain Map Identifies material, depth, geological processes, terrain configuration, surface and subsurface drainage, slope gradient (also called surficial geology or Quaternary geology maps).

- Bedrock Map Identifies bedrock type, surface and subsurface structure, surficial cover (overburden), and age of rock over a topographic map base.

- Engineering Soil Map Identifies surficial material type, drainage, limited engineering characteristics, soils characteristics, vegetation cover.

- Forest Cover Map Identifies surface vegetation, topographic features, surface drainage pattern, and in some cases, soil drainage character.

- Research Studies May provide information on all of the above, plus quantitative data on controlling factors and possibly local stability risk assessment.

- Aerial Photography Remote Sensing (Examples shown in figs. B4 through B7.) Identification can be made of vegetation cover, topography, drainage pattern, soil drainage character, bedrock geology, surficial geology, landslide type, and relationship to other factors. Careful study of a given area of terrain with the aid of oblique aerial photographs and vertical stereo pairs can yield significant information on landslide type and frequency and the effects of management practices. A review of recent and past aerial photographs of the area should be undertaken whenever possible, as older slides may not be evident on more recent photographs. Features discernible on aerial photographs can help users identify landslide type and develop a reasonable assessment of overburden characteristics. These, in turn, provide a means for estimating the landslide hazard at a site.

- InSAR Imaging InSAR is an acronym for Interferometric Synthetic Aperture Radar. Both InSAR and LIDAR (description follows) use active sensors emitting a pulse of energy (from a satellite) and recording its return, from the ground, at the sensor. Most InSAR equipment is able to penetrate fog and rain and can be used in areas difficult to access by foot. By bouncing signals from a radar satellite off the ground, digital elevation model (DEM) maps can be produced that will show the ground terrain. Two images of the same place are taken at different times then merged, forming a map called an interferogram. The merging of the two images shows the ground displacement (if any) that would indicate any movement that has occurred between the time the two images were taken. In this way, one can determine if a hillside, for example, has moved.

Ordinary radar on a typical Earth-orbiting satellite has a very poor ground resolution of about 3 to 4 miles because of the restricted size of the antenna on the satellite. Synthetic Aperture Radar (SAR) takes advantage of the motion of the spacecraft along its orbital track to mathematically reconstruct (synthesize) an operationally larger antenna and yield high-spatialresolution imaging capability on the order of hundreds of feet. 


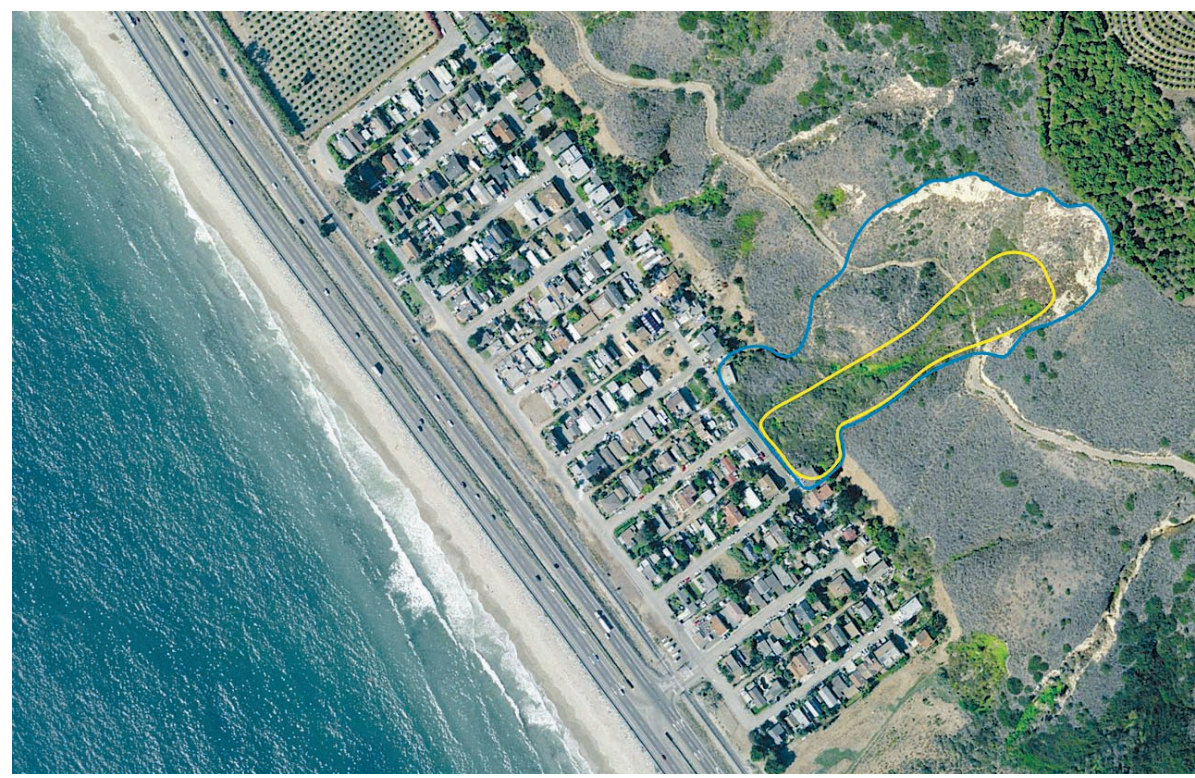

Figure B4. An example of an aerial photograph of the La Conchita landslide in California, USA, taken in 2005. Blue line delineates an older landslide, yellow a more recent landslide. (Photograph courtesy of AirPhoto USA and County of Ventura, California, and Randy Jibson, U.S. Geological Survey.)

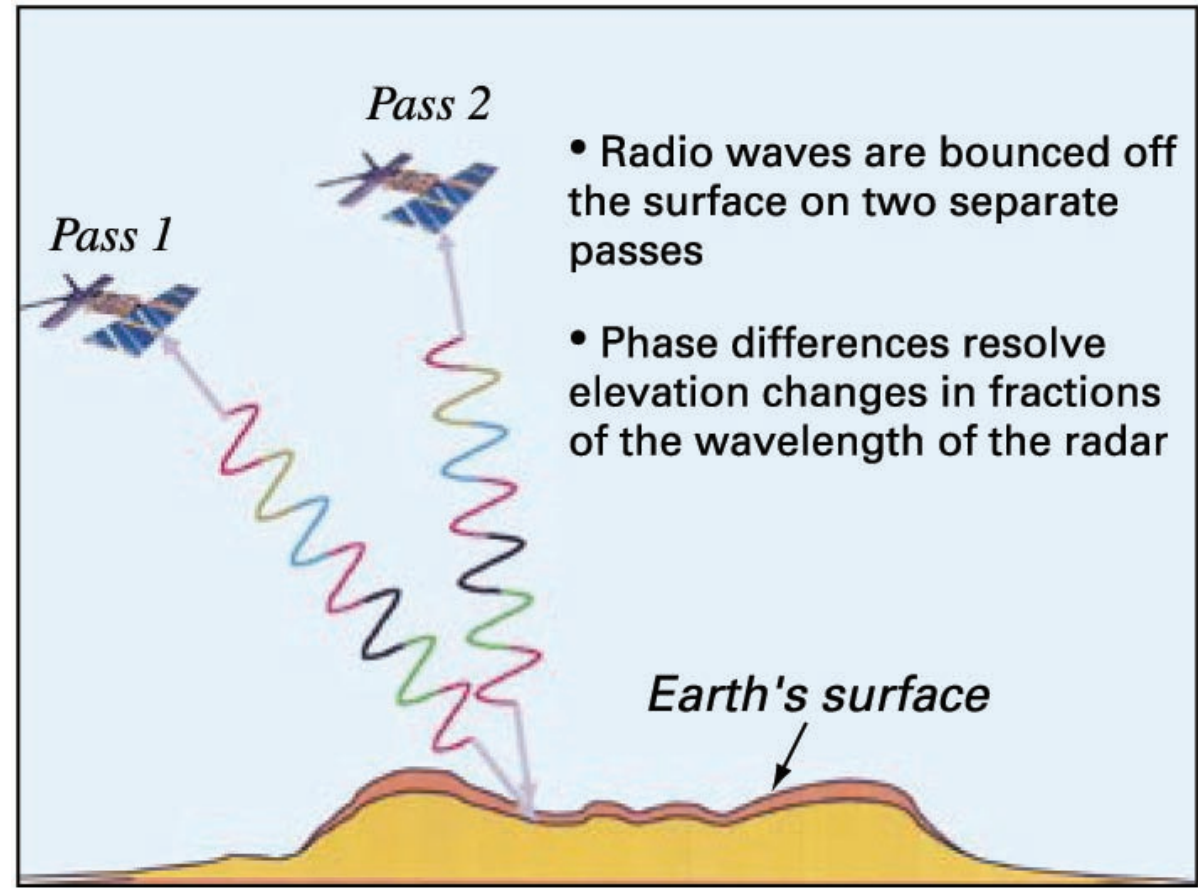

Figure B5. Schematic showing satellite passes over an area of the Earth's surface (graphic modified from Reference 41.) 


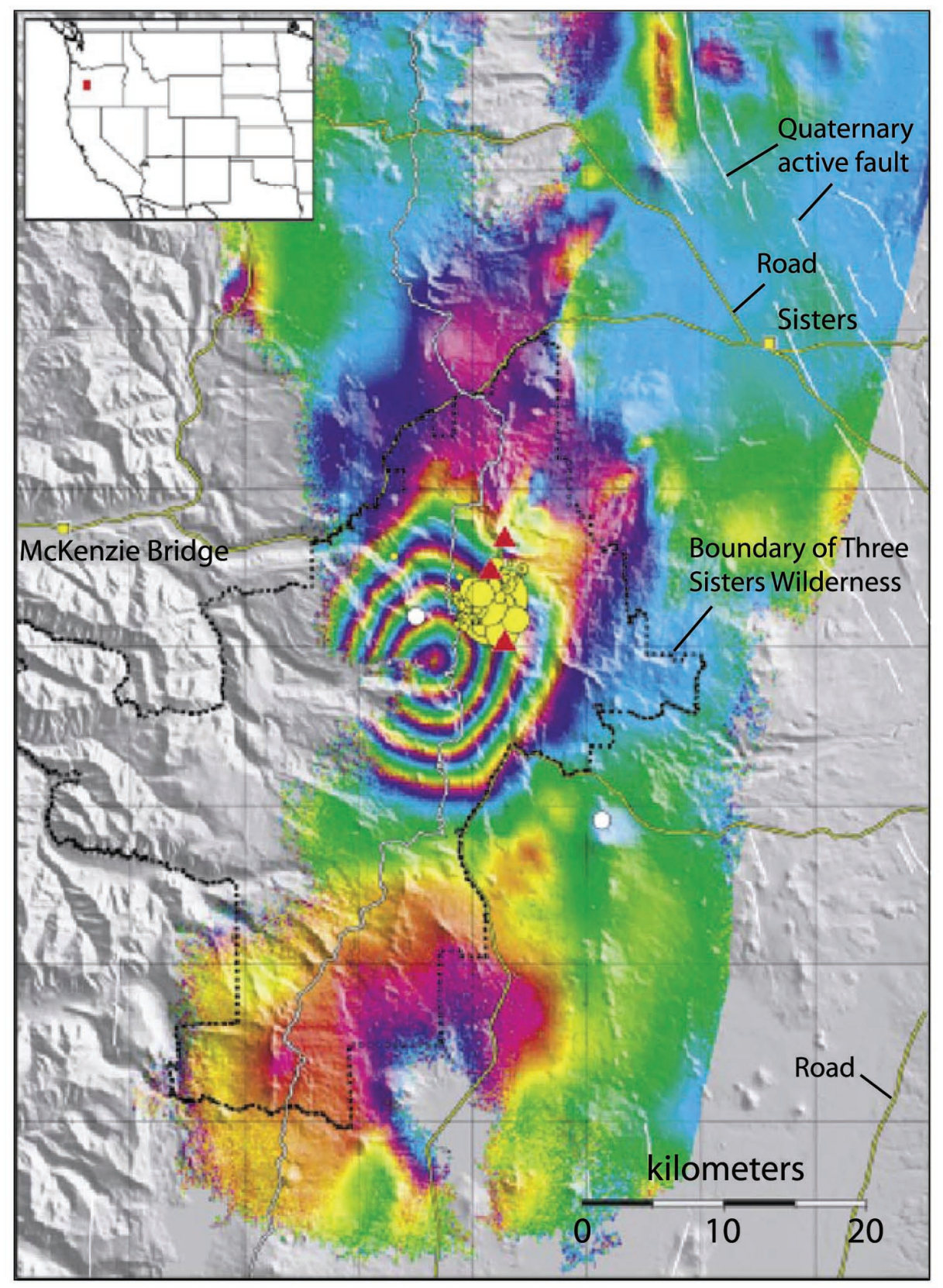

Figure B6. Interferogram from InSAR imaging process showing the area of uplift (1997-2001) at the Three Sisters volcanoes (red triangles) in the Cascade Range in central Oregon, USA (circles show locations of earthquakes). (Photograph modified from Reference 41.) 
- LiDAR Imaging LiDAR is an acronym for Light Detection and Ranging, also known as ALSM or Airborne Laser Swath Mapping. Using a narrow laser beam to probe through dense ground cover, such as trees, LiDAR can produce accurate terrain maps even where forest cover gets in the way of traditional photography. The technique produces a very accurate Digital Elevation Model map (DEM) (fig. B7). Accurate bare-earth DEMs can be produced when the imagery is acquired during the leaf-off season in areas covered by deciduous forests.

Essential elements of a LiDAR mapping system are a scanning laser rangefinder mounted in an aircraft, differential Global Positioning System (GPS) to locate the aircraft, and an internal measurement unit (IMU) to measure aircraft orientation. LiDAR is a useful topographic mapping tool for three reasons. First is accuracy, the second is productivity; measurements are made at rates of 10,000 to 80,000 laser pulses per second. Third, LiDAR is monoscopic and provides its own illumination. These characteristics overcome the major liabilities of photogrammetry in forested terrain. The maps produced by LiDAR are very clear and detailed and in many cases reveal evidence of past landslides that are virtually invisible by other means due to heavy vegetation cover. LiDAR is expensive and highly technical and is used mainly by government agencies, universities, and some private entities. One drawback is that many LiDAR systems use a near-infrared laser that does not penetrate fog or rain.

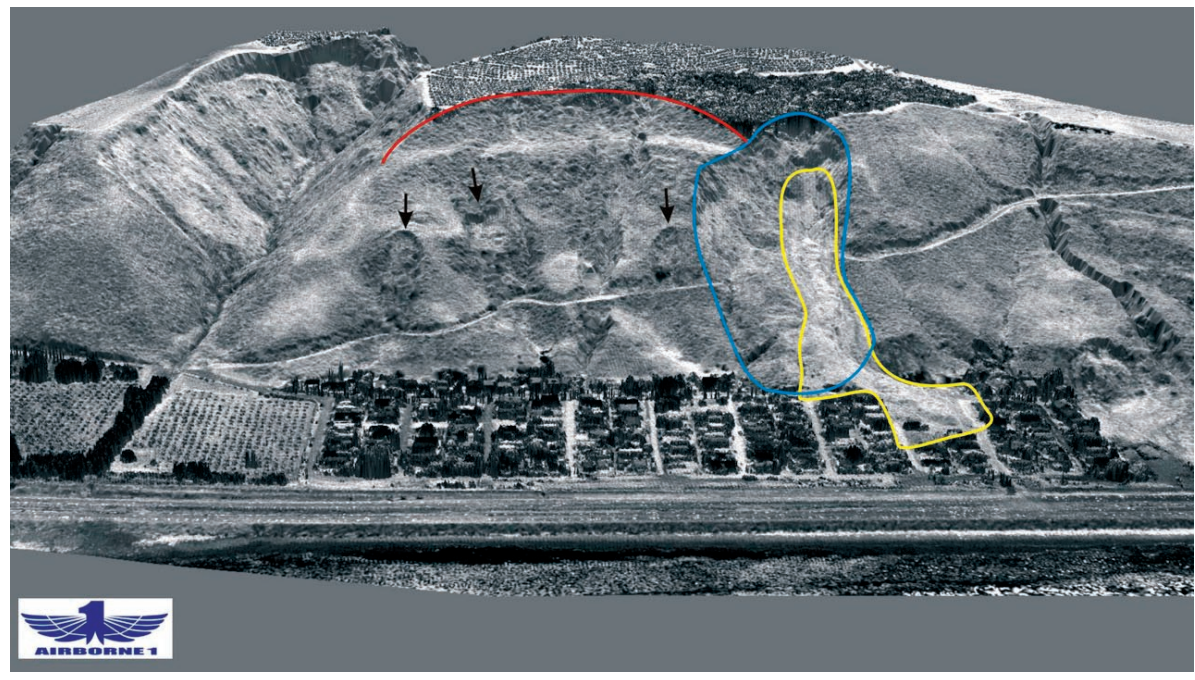

Figure B7. An oblique LiDAR image of La Conchita, California, USA, landslide, taken in 2005. Outline of 1995 (blue) and 2005 (yellow) landslides are shown; arrows show examples of other landslides in the area; red line outlines main scarp of an ancient landslide that involved the entire bluff. (Photograph by Airborne 1, El Segundo, California, USA, and Randy Jibson, U.S. Geological Survey.)
For remote sensing and other map references and further reading: $4,12,14$, $15,18,19,21,24,35,39$, and 41 
For more information: References 4 , $21,25,28,35,38,39$, and 46

\section{Part 3. Real-Time Monitoring of Landslides and Landslide Instrumentation}

The immediate detection of landslide activity that is provided by real-time systems can be crucial in saving human lives and protecting property. Traditional field observations, even if taken regularly, cannot detect changes at the moment they occur. Moreover, active landslides can be hazardous to work on, and large movements often occur during storms when visibility is poor. The continuous data provided by remote real-time monitoring permits a better understanding of dynamic landslide behavior that, in turn, enables engineers to create more effective designs to prevent or halt landslides. Landslide monitoring can be expensive, and most monitoring systems require installation by experts. The advantage is that systems that detect landslide movement can be coordinated with warning systems.
Figure B8. Measuring landslide movement using an extensometer, an instrument that can detect movement of the ground surface between stable ground and sliding ground. (Photograph by Richard LaHusen, U.S. Geological Survey.)

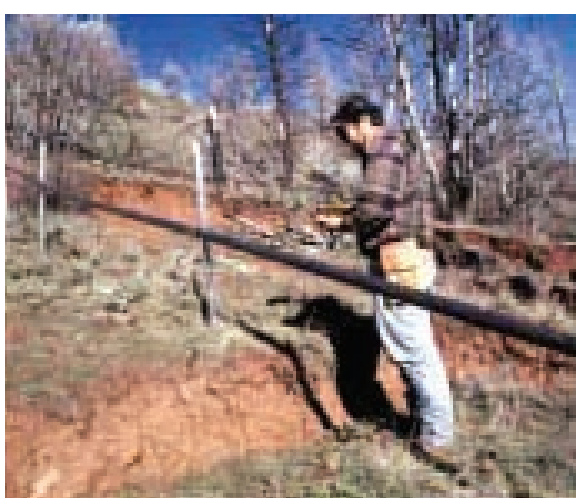

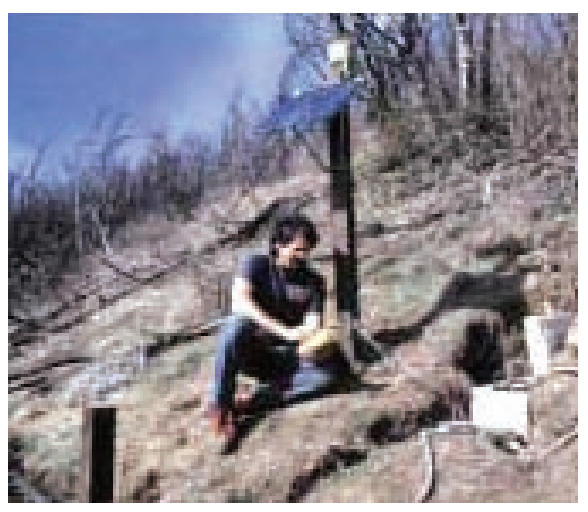

Figure B9. Testing a solar-powered radiotelemetry system for remote transmission of real-time landslide data. (Photograph by Mark Reid, U.S. Geological Survey.)

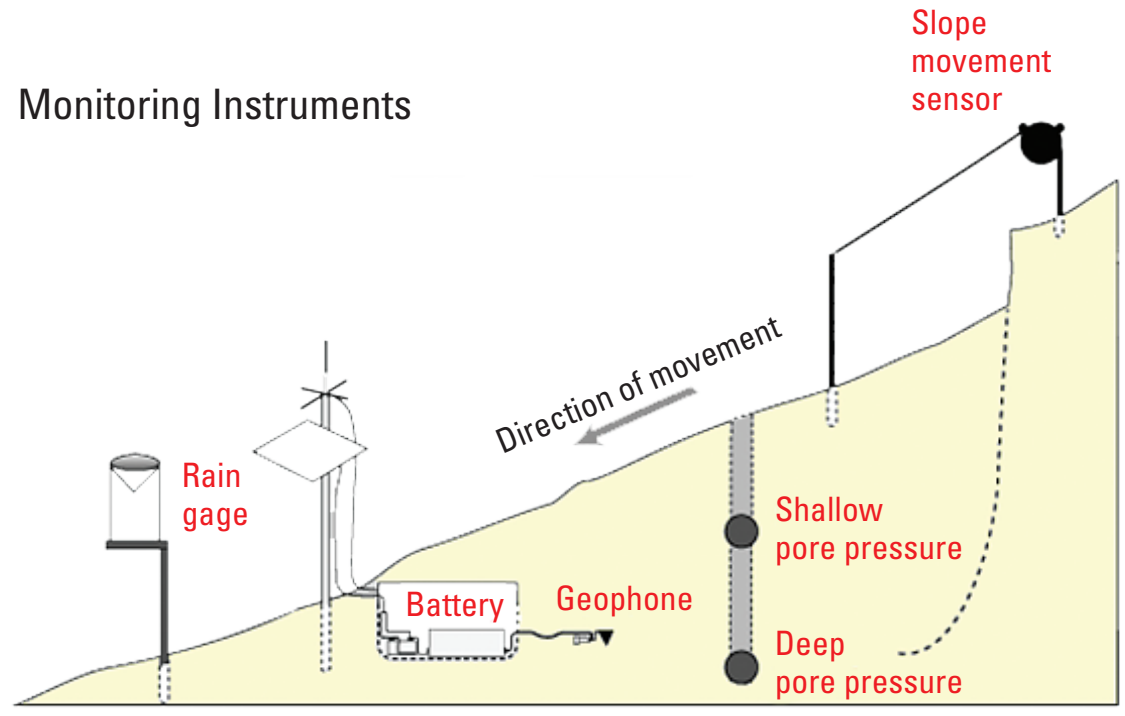

Figure B10. Example of a network for measurement and transmission of real-time landslide data. (Schematic from U.S. Geological Survey.) 


\section{Appendix C. \\ Introduction to Landslide Stabilization and Mitigation}

Note: Much of the material that follows on slope stabilization methods has been reproduced directly from "A Guide for Management of Landslide-Prone Terrain in the Pacific Northwest," published by the Research Branch of the Ministry of Forests, British Columbia, Canada. However, this volume contains a much more comprehensive overview of mitigation, and it is highly recommended by the authors for those desiring more detailed information on mitigation measures. Please see reference 11, Chatwin and others, for full publication citation. 


\section{Part 1. Earth Slope Stabilization/Mitigation}

Some of the stabilization techniques that are currently available in North America are illustrated in this discussion. We highlight simple methods that can be used safely in the absence of detailed soil or bedrock analysis or in low-risk situations. Some stabilization methods are very expensive and require significant time to implement. This is an overview of stabilization methods; many other methods are in use around the world. Professional advice is essential before, during, and after implementation (where possible), as is further literature consultation.

The stability of any slope will be improved if certain actions are carried out. To be effective, first one must identify the most important controlling process that is affecting the stability of the slope; second, one must determine the appropriate technique to be sufficiently applied to reduce the influence of that process. The mitigative prescription must be designed to fit the condition of the specific slope under study. For example, installation of drainage pipes into a slope that has very little ground water is pointless. Slope stabilization efforts take place during construction or when stability problems develop unexpectedly following construction. Most slope engineering techniques require a detailed analysis of soil properties and a sound knowledge of the underlying soil and rock mechanics.

\section{In any high-risk situation, where a landslide may endanger lives or adversely affect property, a professional landslide expert such as a geotechnical or civil engineer should always be consulted before any stabilizing work is undertaken.}

The following sections provide a general introduction to techniques that can be used to increase slope stability.

\section{Excavation}

Figures $\mathrm{C} 1, \mathrm{C} 2$, and $\mathrm{C} 3$ provide a cross-sectional view, in schematic form, of general principles for slope excavation, showing the effects and consequences of where on a slope the excavation takes place. These graphics are general in nature, and a geotechnical engineer or other professional should always be a consulted if possible.

\section{Removal of soil from the head of a slide}

This method reduces the driving force and thereby improves stability. This method is suitable only for cuts into deep soil where rotational landslides (see "Basic Landslide Types" in Section I) may occur. It is ineffective on translational failures on long, uniform or planar slopes or on flow-type landslides.

\section{Reducing the height of the slope}

Reducing the height of a cut bank reduces the driving force on the failure plane by reducing the weight of the soil mass and commonly involves the creation of an access road above the main road and the forming of a lower slope by excavation. Also, it is possible to excavate deeply and lower the main road surface if the rightof-way crosses the upper part of a landslide. This method is only moderately efficient in increasing stability, and a complete solution may involve additional modification of the land. According to Chatwin (Reference 11), it usually increases the Factor of Safety by only 10 or 15 percent. ("Factor of Safety" in its simple definition is the ratio of the maximum strength of a piece of material or a part to the probable maximum load to be applied to it.) 


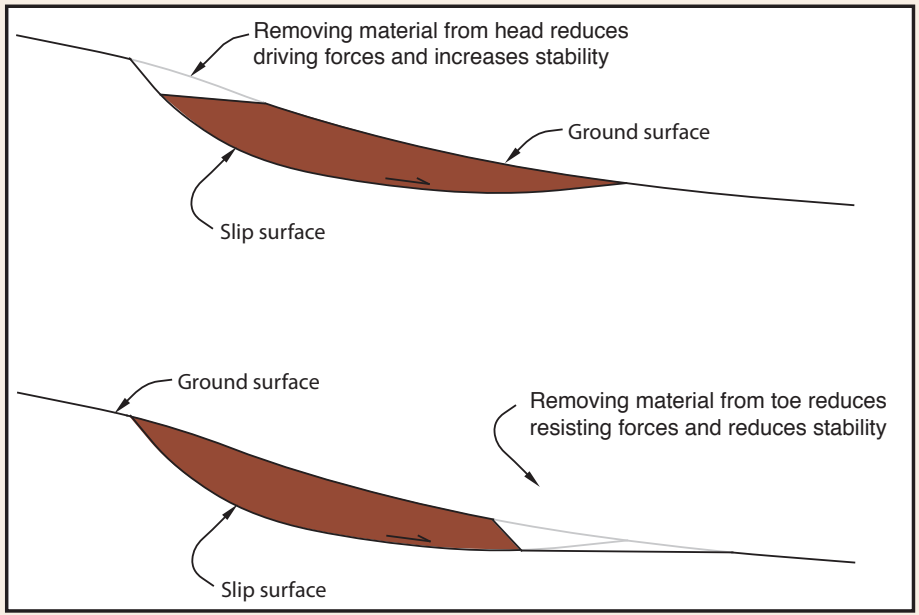

Figure C1. Illustration of the differences in stability resulting in excavation at the head and toe surfaces of a slope. (Graphic by Rex Baum, U.S. Geological Survey.)

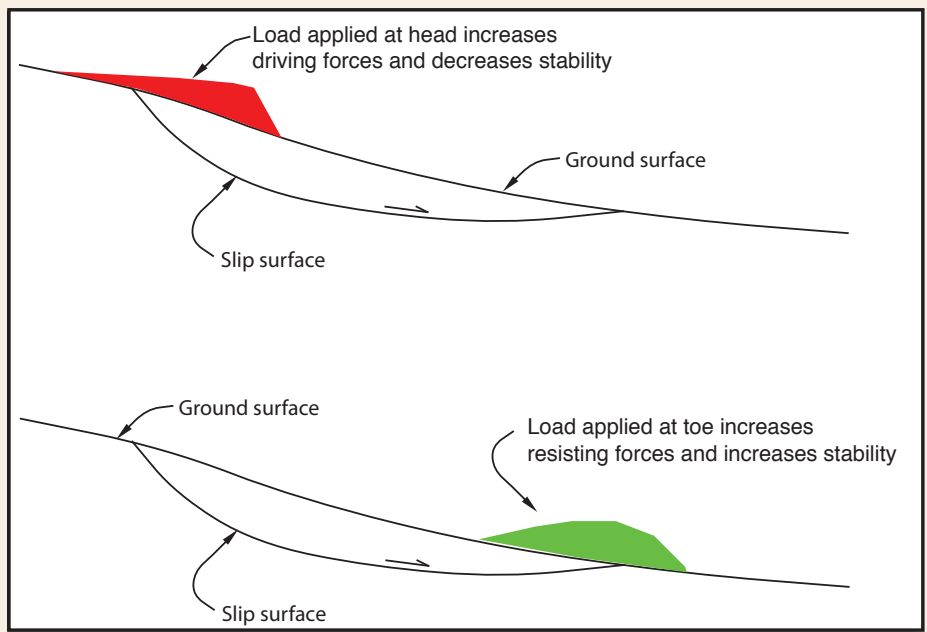

Figure C2. Illustration of the difference in stability of loading either the head or the toe of a slope. (Graphic by Rex Baum, U.S. Geological Survey.)

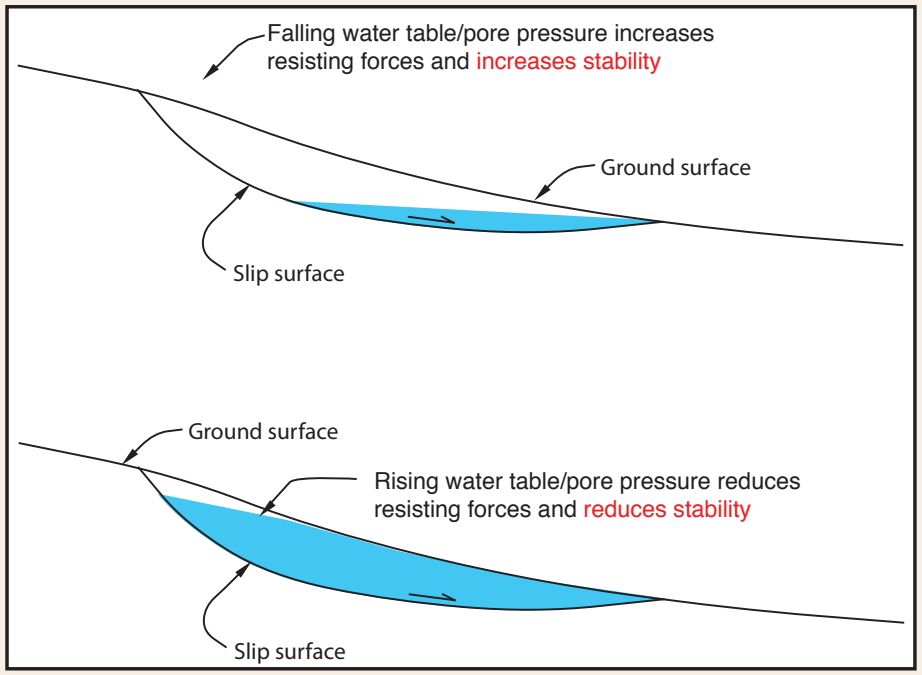

Figure C3. Illustration of the importance of water in the stability of a slope. (Graphic by Rex Baum, U.S. Geological Survey.) 


\section{Backfilling with lightweight material}

A technique related to height reduction is to excavate the upper soil and replace it with a lightweight backfill material such as woodchips or logging slash. Then, covered with a thin layer of coarse aggregate, the backfilled material can form a foundation for limited-use traffic (fig. C4).
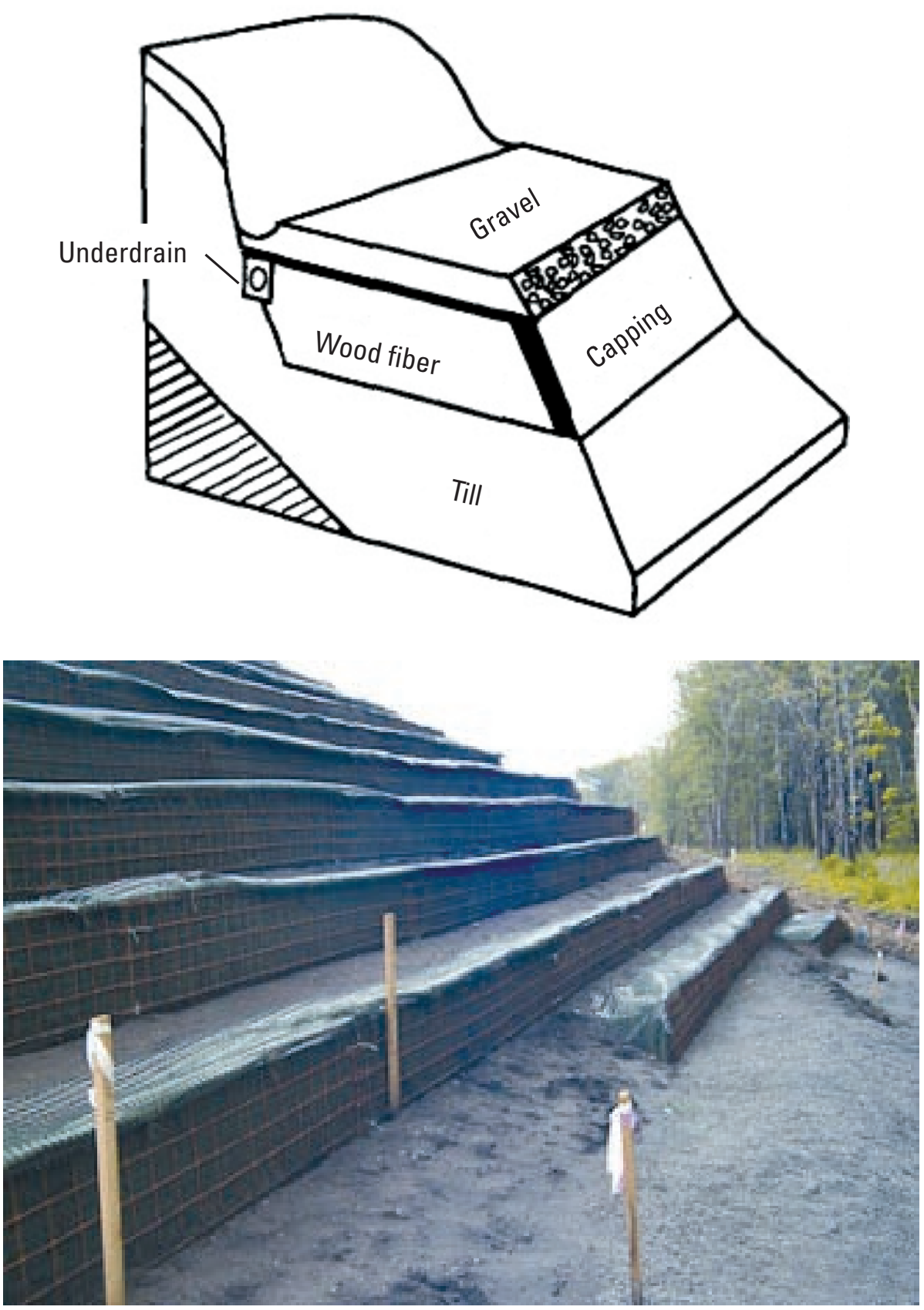

Figure C4. Schematic and photograph of a lightweight backfill. There has been an increased growth in the use of recycled tire shreds in civil engineering applications. Highway applications include using shredded tires as lightweight fill over weak soils in bridge embankments and retaining wall reinforcements or, in very cold climates, as insulation of the road base to resist frost heaves and as a high-permeability medium for edge drains. (Graphic from reference 11, photograph from U.S. Department of Transportation, Federal Highway Administration.) 


\section{Benches}

Benches are a series of "steps" cut into a deep soil or rock face for the purpose of reducing the driving forces. They are mainly effective in reducing the incidence of shallow failures but generally are not very efficient in improving the overall slope stability for which other methods are recommended. Benches are useful in providing protection structures beneath rockfall-prone cliffs, for controlling surface drainage, or for providing a work area for installing drainpipe or other structures.

Please see figure $\mathrm{C} 12$ for a photo of benches cut into a slope.

\section{Flattening or reducing slope angle, or other slope modification}

This reduces the weight of material and reduces the possibility of stream/river undercutting or construction loading.

\section{When not to excavate a slide mass}

In some situations, removing the entire slide mass is an effective and economic solution. Generally, however, it is only practical on small slumps or small rotational failures. Large-scale excavation of larger landslide areas is usually not recommended for several reasons:

- Excavation is not always effective-for large planar failures, excavation may not cause movement to stop and may allow the landslide to expand.

- Excavation may trigger a larger landslide by removing the support provided by the toe of the landslide.

- Excavation may actually destabilize the ground farther upslope by undercutting, which weakens the slope.

- In deeper soils, especially soft clays, where there are two potential failure surfaces, one deep and one shallow, excavating down to the first failure surface might trigger a sudden slippage on the deeper failure surface. A stability analysis using soil strength data is advised and most always necessary for any major excavation project in deep clay soils. 


\section{Strengthening Slopes}

\section{Plastic mesh reinforcement}

There are numerous synthetic soil reinforcement materials on the market, and one example is a reinforcement material of plastic polymer stretched to form a lightweight, high-tensile-strength grid. The grid acts similarly to reinforcing mesh in concrete, adding strength to the shear strength of the soil.

These types of materials have been used to reduce the amount of ballast needed over soft ground by increasing the bearing capacity of the subsoil. These types of grids also have a number of possible applications in slope stabilization, including soil strength reinforcement, soil drainage improvement, and retaining-wall construction.

\section{Rock-fill buttresses}

A simple method to increase slope stability is to increase the weight of the material at the toe, which creates a counterforce that resists failure (fig. C5). A berm or buttress of earthfill can be easily dumped onto the toe of a slope. Broken rock or riprap instead of soil is preferable, however, because it has a greater frictional resistance to shear forces and is also free draining, which reduces the problem of impeding ground-water flow. 

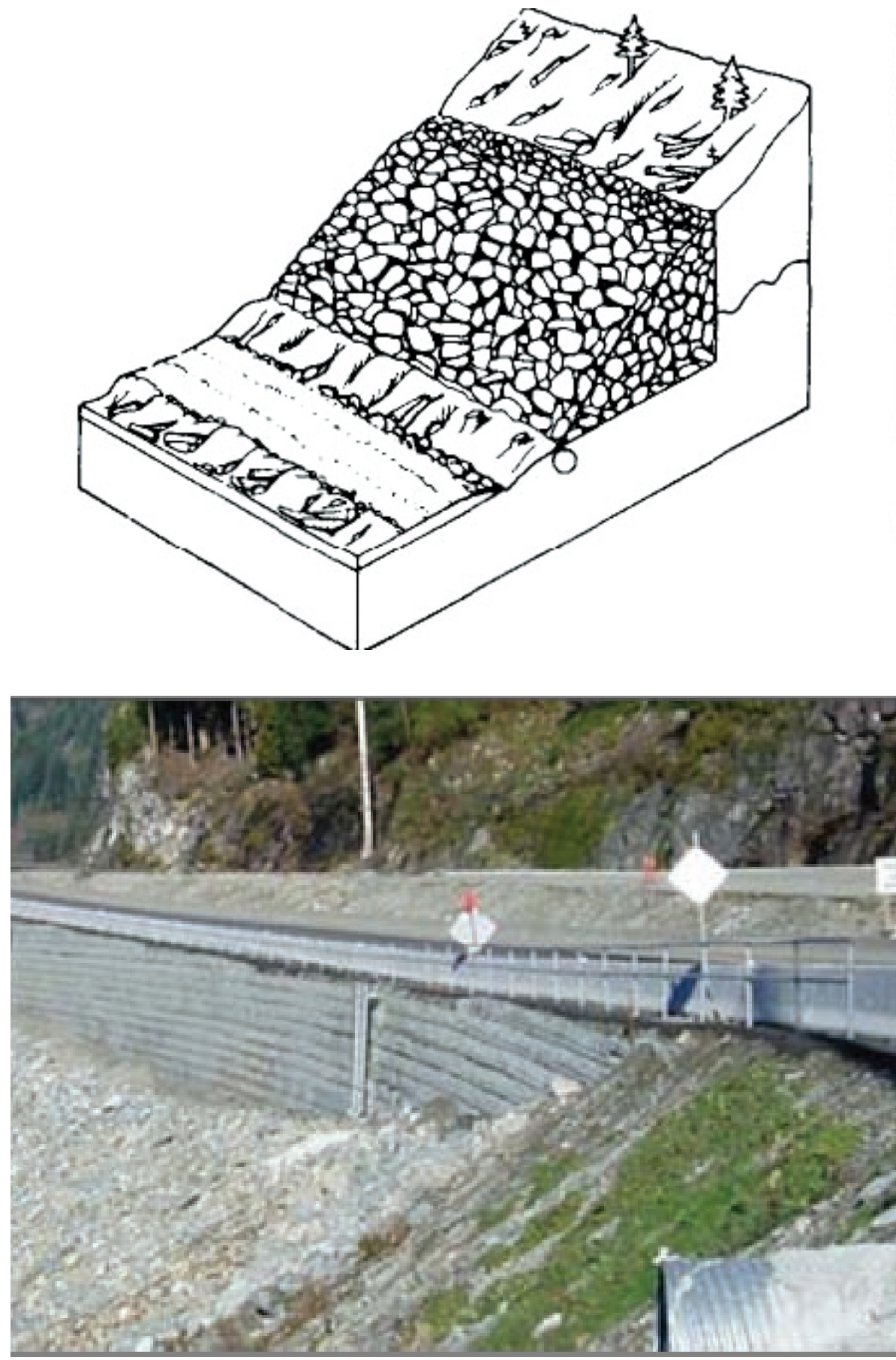

Figure C5. Schematic and photograph of a rockfill buttress in Canada. (Graphic is from Reference 11.) 


\section{Stream channel linings}

Channel linings are another way of stabilizing a stream or creek channel and the sides of the stream or creek. The lining is usually slush grouted with high-quality concrete, preferably reinforced by steel fiber mat to resist abrasion. Protruding boulders are set in the concrete to dissipate the energy of waterflow.

Channel linings can reduce the incidence and volume of debris flows (fig. C6). They are also effective in maintaining channel alignment upstream from a bridge and for protecting the abutments. Channel linings are most effective if applied over the entire reach of an unstable channel. Linings are usually much less costly than, for example, check dams, especially if a long reach is to be stabilized. Check dams are preferable, however, if the banks are very unstable because a dam can be keyed into the bank, providing toe support and thereby enhancing stability.
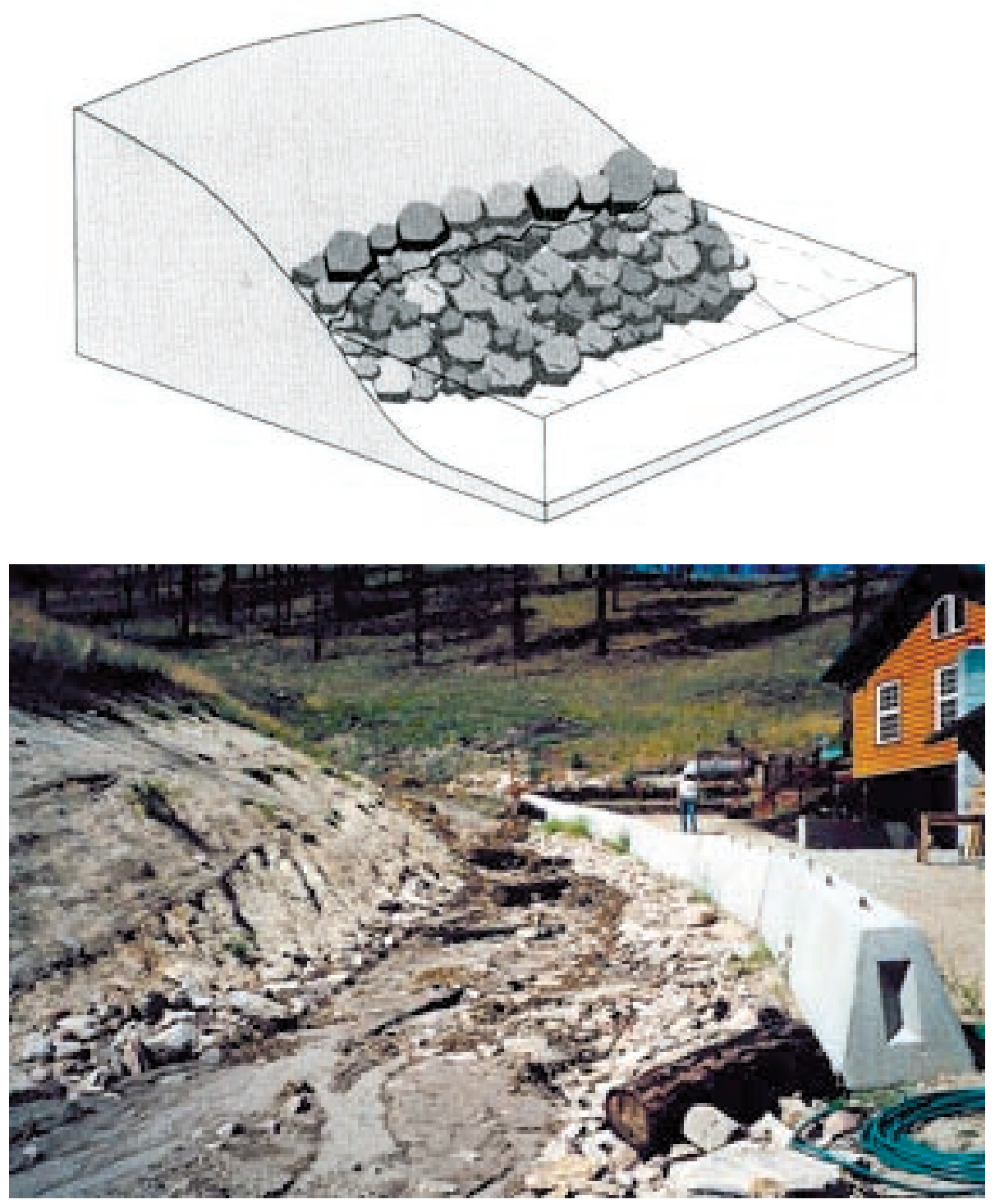

Figure C6. Example of creek channel lining using rock, Dickson Creek, Montana, USA. (Photograph and graphic, U.S. Department of Agriculture.) 


\section{Check Dams}

Check dams are small, sediment-storage dams built in the channels of steep gullies to stabilize the channel bed. They are commonly used in Europe and Japan to control channelized debris-flow frequency and volume. A less common use of check dams is to control raveling and shallow slides in the source area of debris slides. Check dams are expensive to construct and therefore are usually built only where important installations or wildlife habitat, such as a camp or unique spawning area, lie downslope. Channelized debris flows are associated with channel gradients over 25 degrees and obtain most of their volume by scouring the channel bed. Check dams serve three purposes when installed in the channels (following information quoted from Reference 11):

1. To mitigate the incidence of failure by reducing the channel gradient in the upper channel.

2. To reduce the volume of channel-stored material by preventing down cutting of the channel with subsequent gully sidewall destabilization and by providing toe support to the gully slopes.

3. To store debris-flow sediment, when installed in the lower part of the channel.

When installed on debris slides, the dams store raveled material, which eventually creates small terraces on the slide, reducing the surface slope. Check dams can be constructed of reinforced concrete or log cribs (figs. C7 and C8). Concrete mortared rock dams do not usually exceed $8 \mathrm{~m}$ in height, whereas log crib dams must not exceed $2 \mathrm{~m}$ ( 6 feet). The spacing of dams depends on channel gradient and dam height. For example, a 2-m-(6 foot) high dam in a 20-degree channel with 10-degree sloping channel infill will be spaced every $12 \mathrm{~m}$ (36 feet). Lateral stream erosion and scour by spillway water are the main drawbacks.

\section{To prevent check dam failure}

During construction, the concrete wingwalls and log crib ends must be tied securely into the canyon wall and streambed to withstand backfill pressures and lateral scour. Wingwalls should slope at about 70 percent and extend a minimum of 1-2 meters ( 3 to 6 feet) into the banks. The foundation of the dam should have a minimum width of one-third the total height of the dam and be deeper than any scour holes likely to develop.

Backfilling the dam, rather than allowing it to fill naturally, reduces the dynamic loading on the structure and results in a more stable design. The slope of the backfill should be less than one-half the channel gradient. Dams that have been back-filled usually will survive a debris flow. The backfill material will not be scoured during or after a torrent. 

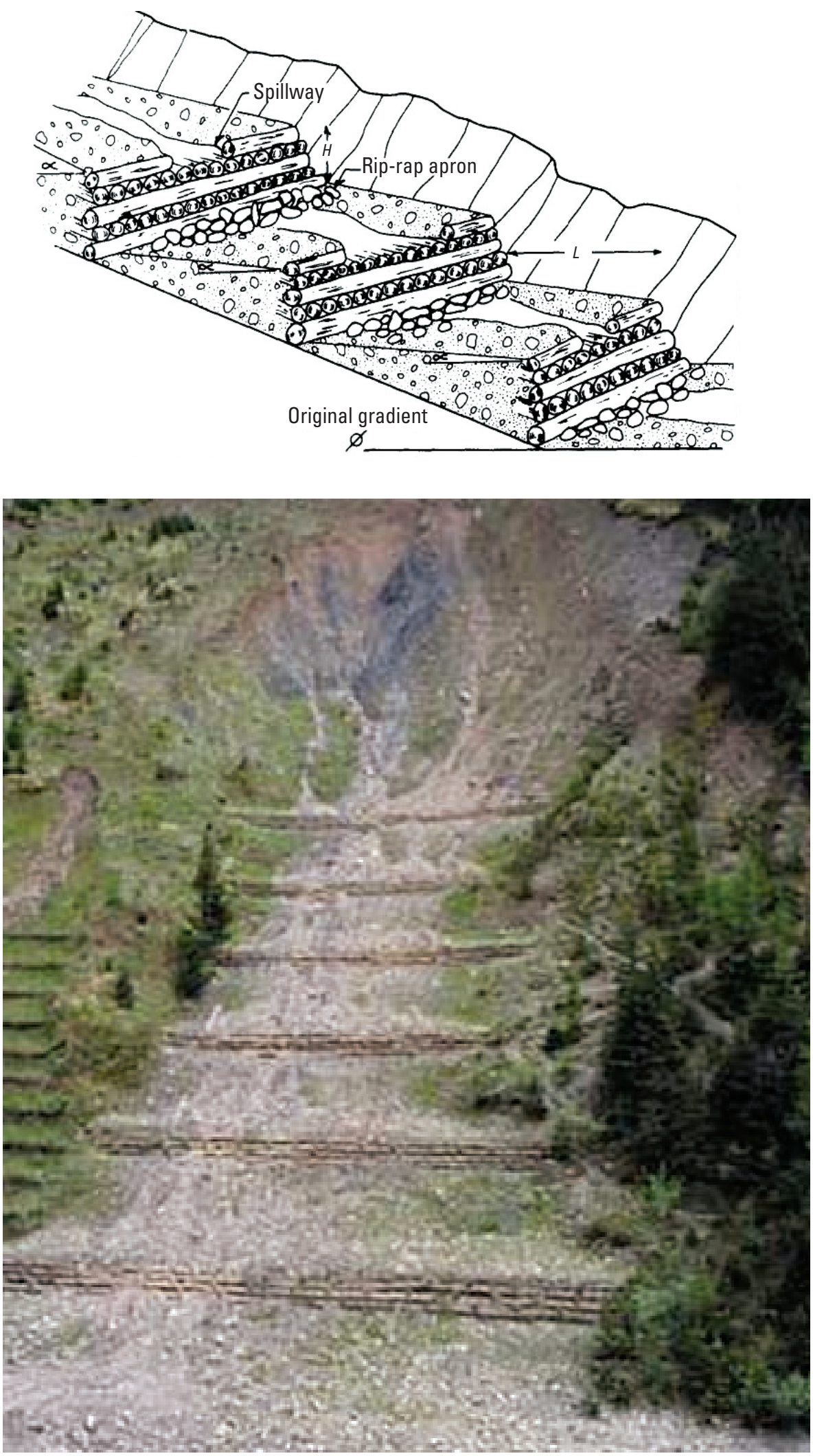

Figure C7. Schematic and photograph of a crib wall check dam, which is one kind of check dam. (Graphic from Reference 11, photograph taken in Trafoi, Italy, courtesy of "Erosion Control," Forester Communications, Santa Barbara, California, USA.) 


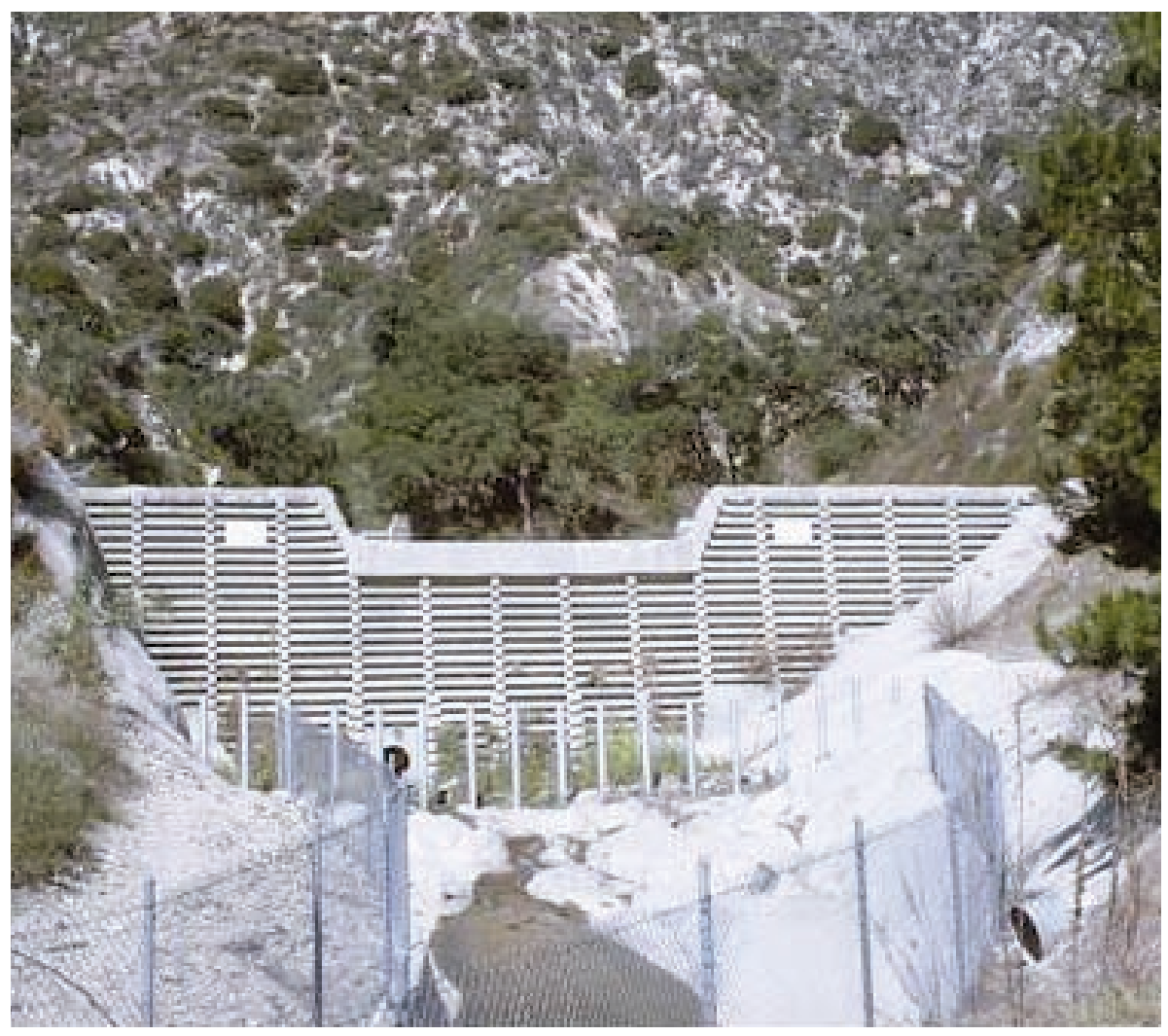

Figure C8. Upstream view of concrete crib-type check dam with low-flow center section in southern California, USA. (Photograph by Los Angeles County Flood Control District.) 


\section{Drainage Techniques}

Ground water probably is the most important single contributor to landslide initiation. Not surprisingly, therefore, adequate drainage of water is the most important element of a slope stabilization scheme, for both existing and potential landslides. Drainage is effective because it increases the stability of the soil and reduces the weight of the sliding mass. Drainage can be either surface or subsurface. Surface drainage measures require minimal design and costs and have substantial stability benefits. They are recommended on any potential or existing slide.

The two objectives of surface drainage are to prevent erosion of the face, reducing the potential for surface slumping, and to prevent infiltration of water into the soil, thereby reducing ground-water pressures. Subsurface drainage also is effective but can be relatively expensive. It is therefore essential that ground water be identified as a cause of the slide before subsurface methods are used. The various methods of drainage include the following:

\section{Site leveling}

Smoothing the topography of the slide surface can prevent surface water from ponding or connecting with the ground water. Any depressions on the slope that might retain standing water must be removed. Infilling and sealing large cracks in the soil surface by grading the soil mass are beneficial and prevent surface water from reaching the failure plane.

\section{Ditches and drains}

Surface drainage can be through either surface ditches or shallow subsurface drains (fig. C9). Surface drainage is especially important at the head of the slide, where a system of cutoff ditches that cross the headwall of the slide, and lateral drains to lead runoff around the edge of the slide are effective. Ditch gradient should be at least 2 percent, to ensure rapid flow away from the unstable area.

The simplest type of subsurface drain is the lateral trench constructed above an unstable slope. Drainage trenches are economical only for shallow soils overlying bedrock or hard impermeable till. The trenches should be excavated to the base of the shallow soil to intercept any ground-water flow along the failure plane. They are backfilled with coarse gravel to prevent sloughing of the ditch sidewalls. An improvement is to use drainpipe and then backfill the area with coarse gravel. 

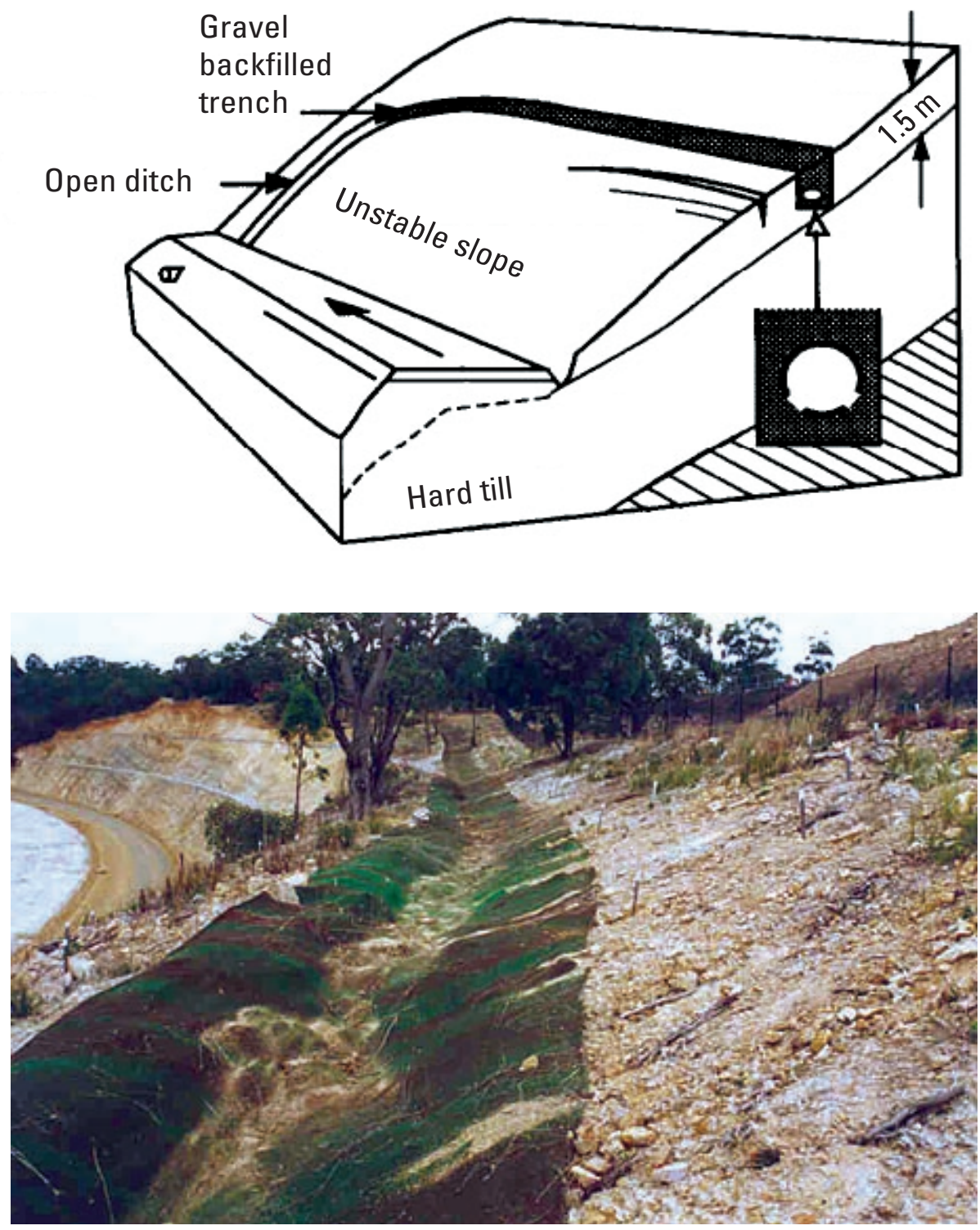

Figure C9. Schematic and photograph of a drain trench. (Graphic from Reference 11, photograph by Department of Transport, Energy and Infrastructure, South Australia.) 


\section{Drainpipes}

Horizontal drainpipe is a widely used device for landslide prevention in highway construction (fig. C10). It is most effective when installed during initial excavation. Because of the long lag times to lower ground-water tables, the drains are effective only if the pipe is carefully installed, the failure surface is intersected, and the pipe actually drains the soil. As most slopes have varying soil and hydraulic and geometric conditions, drainage systems must be individually designed. After drilling has been carried out to the desired depth and the casing installed, the latter is cleared of soil, and sections of slotted PVC drainpipe are covered with filter cloth, then pushed into the casing and coupled together. The casing is then withdrawn and screen is installed over the end of the drain. Drain holes must be thoroughly cleaned of drill cuttings and mud. Uncleaned holes may be only 25 percent effective.

In clay soils, the full change in ground-water tables can take up to 5 years, with 50 percent of the improvement taking place in the first year. Once water tables are lowered in clay soils, the change is fairly permanent; however, seasonal fluctuations can occur: rainfall will not alter the ground-water level in the slope provided the drains do not clog. In sandy soils, the ground-water table will lower within a few months but will also fluctuate with rainfall.
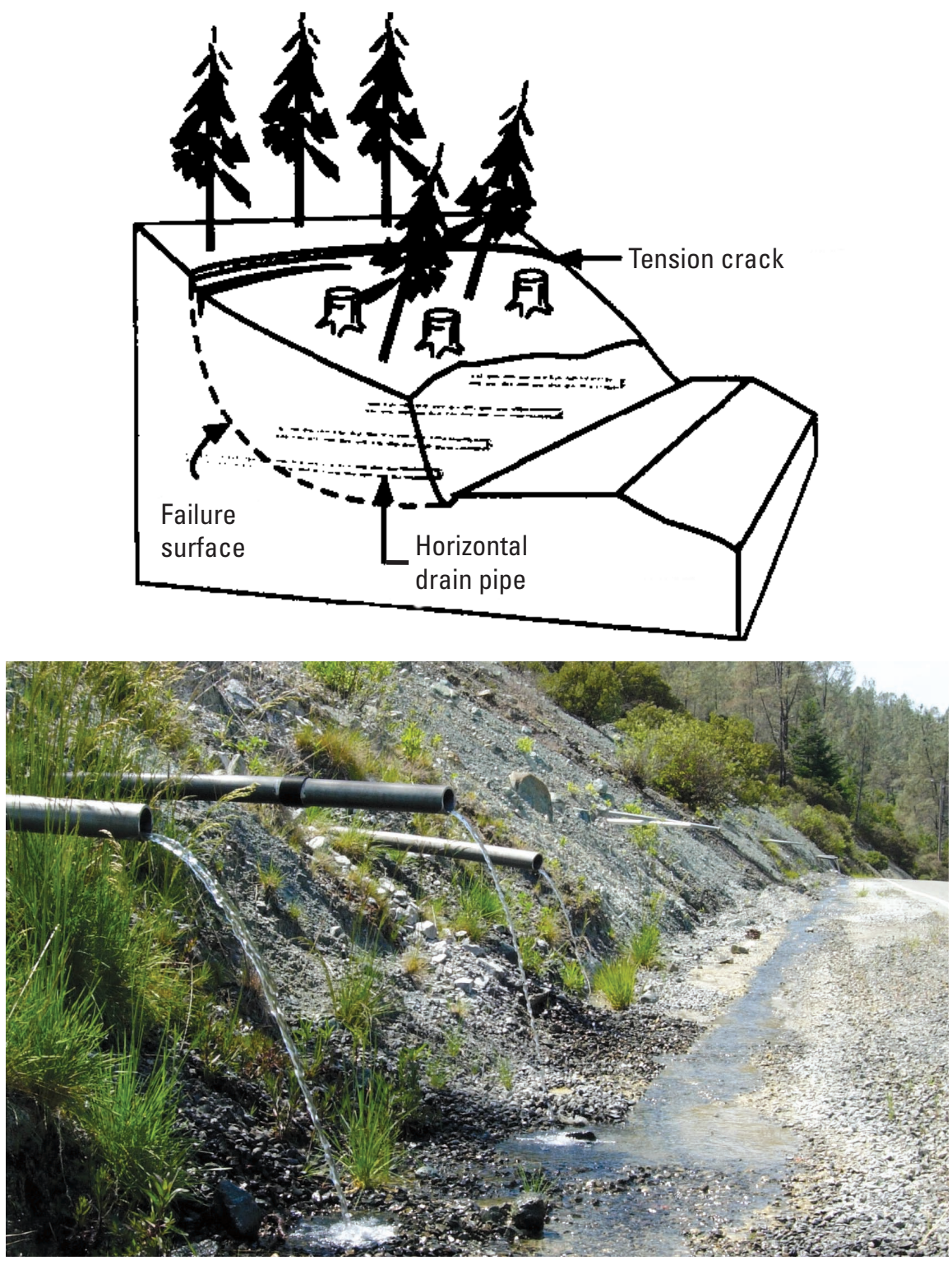

Figure C10. Schematic of drainpipes. (Schematic from Reference 11.) Photograph of drainpipes in a landslide in California, USA, by Andrew Alden. 


\section{Straw wattles and straw bales}

Straw wattles, also known as straw worms, bio-logs, straw noodles, or straw tubes, are manufactured cylinders of compressed, weed-free straw (wheat or rice), 20 to 30 centimeters ( 8 to 12 inches) in diameter and 7 to 9 meters (20 to 25 feet) long (fig. C11). They are encased in jute, nylon, or other photodegradable materials and have an average weight of 16 kilograms (35 pounds). They are installed in a shallow trench forming a continuous barrier along the contour (across the slope) to intercept water running down a slope. Straw wattles should be effective for a period of 1 to 2 years if they can be installed on slopes up to 70 percent; however, their effect diminishes greatly on slopes steeper than 50 percent. Soils can be shallow but not less than about 8 inches. Straw wattles increase infiltration, add roughness, reduce erosion, and add short-term protection on slopes where permanent vegetation will be established to provide long-term erosion control. Straw bales are easily obtainable in most areas of the world, are very portable, and have a modular-type application for slope erosion and drainage control (fig. C12).

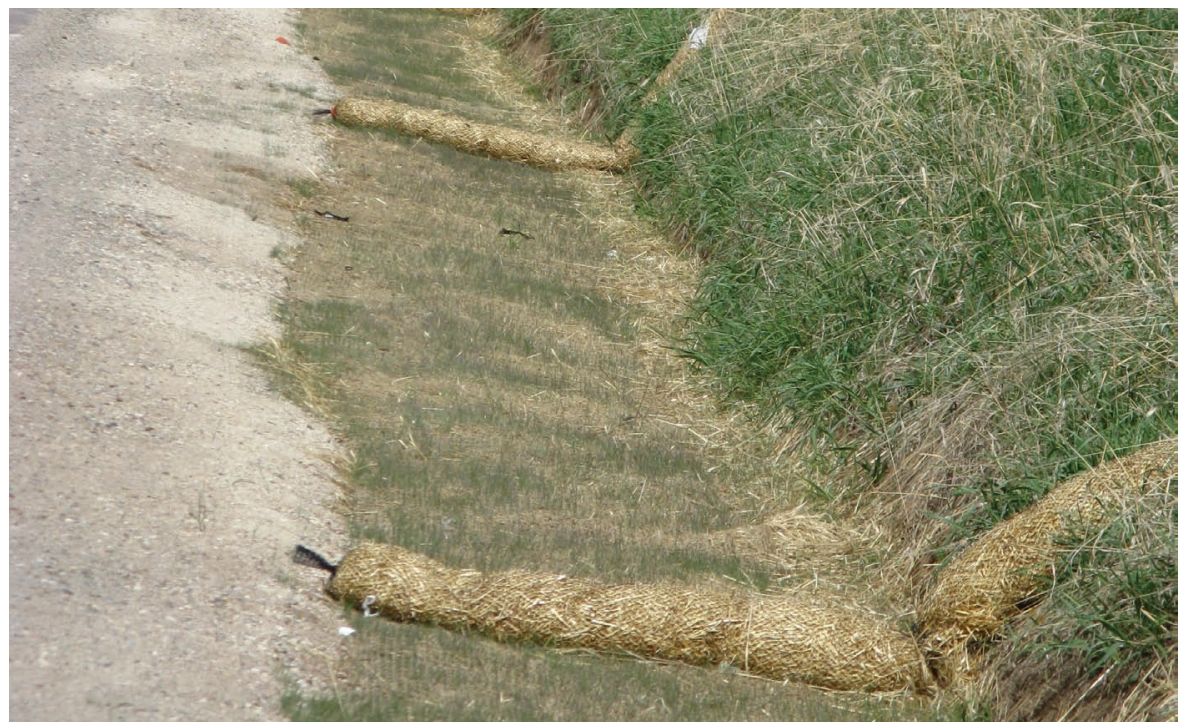

Figure C11. Straw wattles on the side of a road capture sediment and hold it onsite, enabling seeds to settle and germinate, aiding the revegetation process. (Photograph by Lynn Highland, U.S. Geological Survey.)

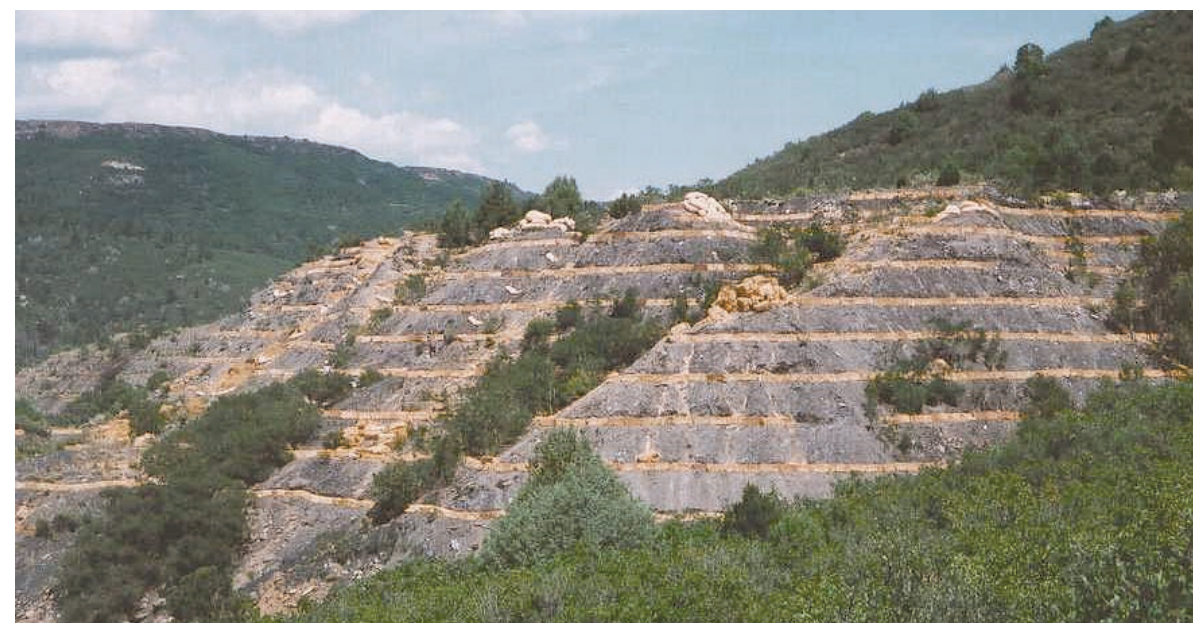

Figure C12. Straw bales have a similar application and are widely available. Individual bale size can be seen in the pile of bales, right center of photograph. (Photograph of slope in New Mexico, USA, New Mexico Department of Mining, Minerals, and Natural Resources.) 
Note: The advice of a civil engineer is needed for any walls higher than 3 meters ( 9 feet), or for those in complex foundation soils.

\section{Retaining Walls}

For all types of retaining walls, adequate drainage through the structure is essential because very high ground-water pressure can build up behind any retaining wall, leading to its failure. Drainage can be provided simply with a coarse backfill and foundation material.

\section{Timber crib}

Timber crib walls are box structures built of interlocking logs and backfilled with coarse aggregate (fig. C13). They work by intersecting the critical sliding surface, thus forcing the potential failure surface to a deeper, less critical depth. The structure must be able to withstand: (1) shearing, (2) overturning, and (3) sliding at the base. It must, therefore, be strongly built by burying to sufficient depth and extending beyond the critical failure plane. Crib walls are only effective where the volume of soil to be stabilized is relatively small. They are most efficient where a thin layer of unstable soil overlies a deeper, more stable layer of soil. Crib wall structures should have a volume equal to 10 to 15 percent of the volume of the soil to be stabilized. This relatively small volume provides little counterweight support at the toe; therefore, virtually the entire resistance to failure comes from the strength of the crib.
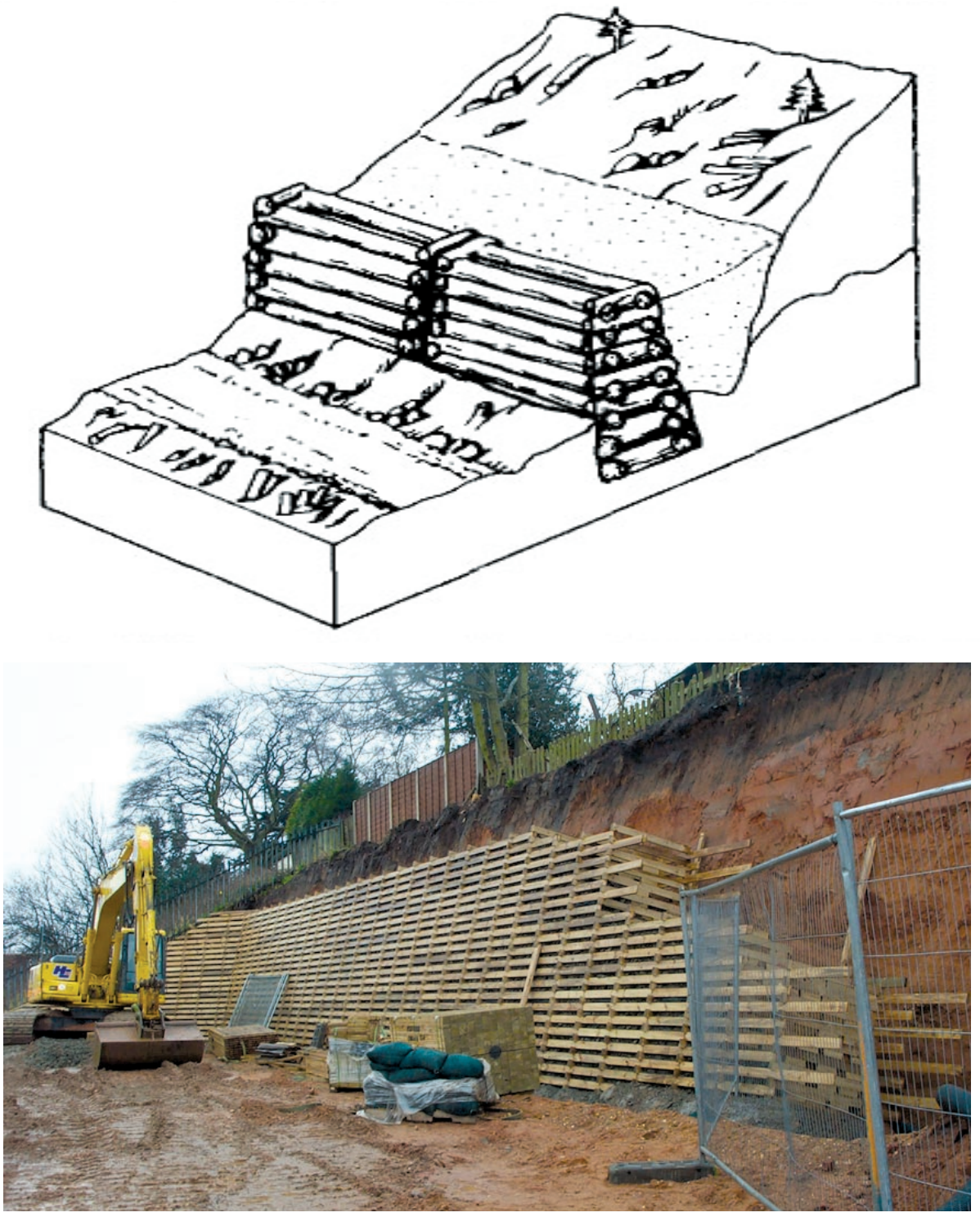

Figure C13. Schematic and photograph of a timber crib. (Schematic from Reference 11, photograph is courtesy of PHI Group, United Kingdom.) 


\section{Steel bin wall}

A steel bin wall is formed from corrugated galvanized steel components bolted together to form a box and then filled with earth (fig. C14). The stability of a gravity wall is due to the weight of the wall itself, perhaps aided by the weight of soil in front of the wall. The bulk of the weight is from the contained soil, not the steel, and this should be kept in mind when the foundation is prepared. Large walls must be individually engineered, with load and foundation requirements calculated. Structural and civil engineering design charts provide stringer (horizontal member) specifications and height-to-width ratios for typical loading conditions. The widths of walls vary from 2 to 5 meters ( 6 to 15 feet) and are one-half to three-fifths the height of the wall. To provide additional sliding resistance, the foot of the wall is usually 0.5 to 1.0 meter ( 1.5 foot to 3 feet) below grade, although the design should not rely on the additional toe support, as it can erode or be removed inadvertently. The factor of safety is improved if the wall is at a 1:6 slope. Fill material must be well drained and compacted, preferably in 20-centimeter ( 7.8 inches) lifts. Material behind the wall also should be well drained and moderately compacted.
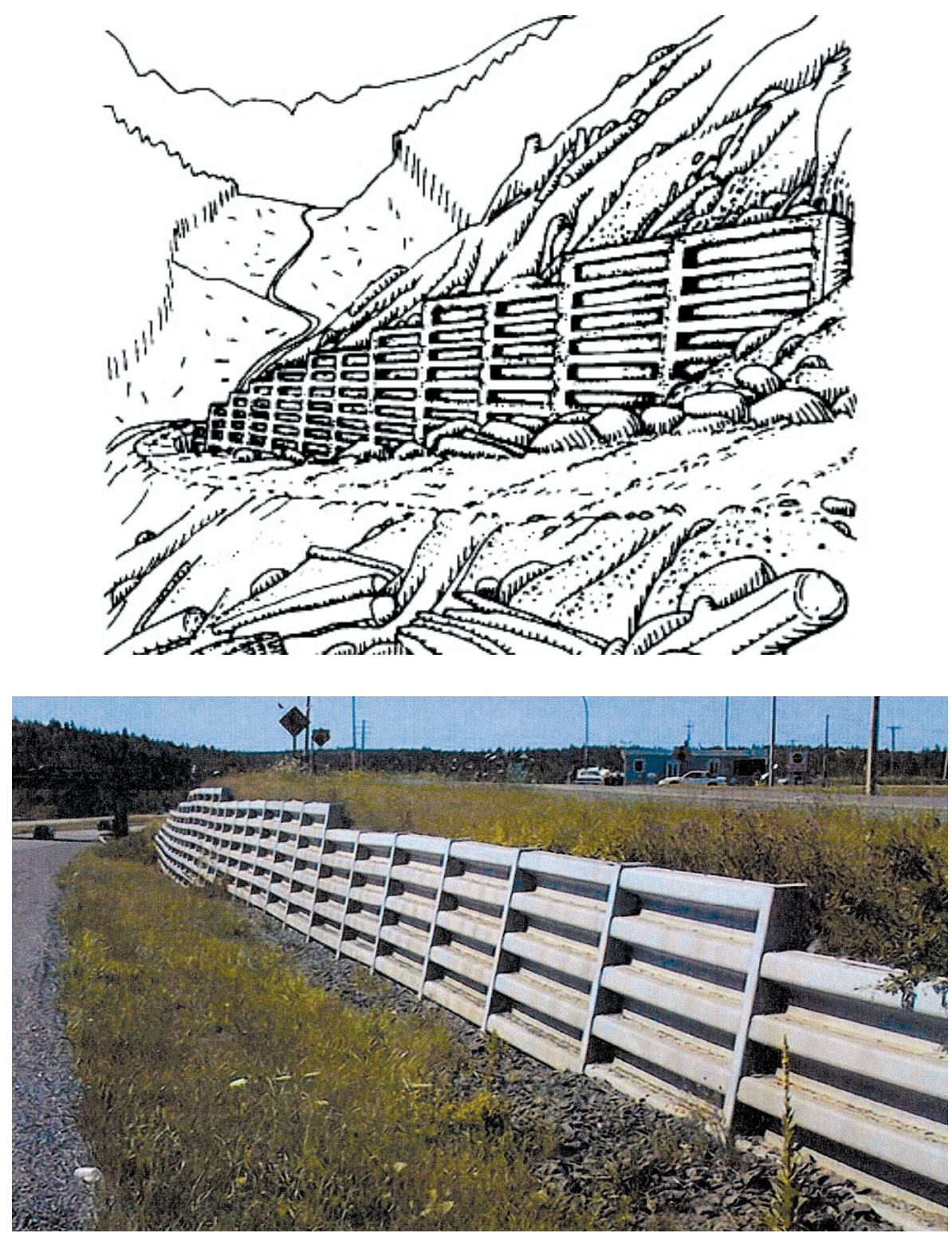

Figure C14. Schematic and photograph of a steel bin wall. (Schematic from Reference 11.) 
Reinforced earth wall

Reinforced Earth is a patented system for constructing fills at very steep to vertical angles without the use of supporting structures at the face of the fill (fig. C15). The system uses horizontal layers of flexible metal strips within the fill to form a composite earth-metal system with high strength.
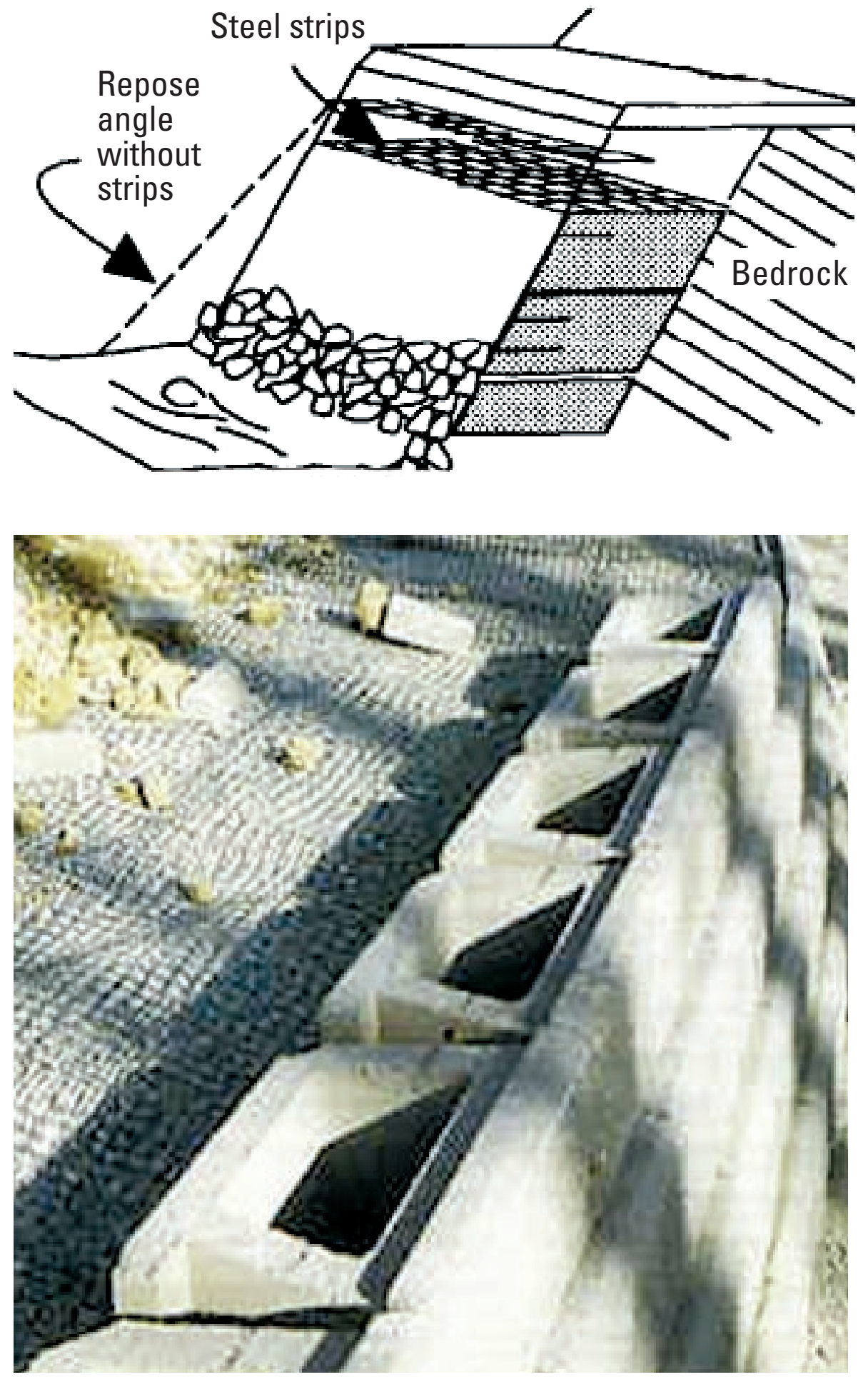

Figure C15. Schematic and photograph of a reinforced earth wall. (Schematic from Reference 11.) 


\section{Gabion walls}

Gabions are wire mesh, boxlike containers filled with cobble-sized rock that are 10 to 20 centimeters ( 4 to 8 inches) size (fig. C16). A gabion retaining wall can also be constructed from stacked gabions. Gabion walls usually are inexpensive and are simple and quick to construct. Due to their flexibility, they can withstand foundation movement, and they do not require elaborate foundation preparation. Because of their coarse fill, they are very permeable and thus provide excellent drainage.

Gabion walls work because the friction between the individual gabion rows is very high, as is the friction between the basal row and the soil underneath. When failure occurs, it is almost always in the foundation soil itself. Three-tiered walls up to 2.5 meters ( 8 feet) high can usually be constructed without consulting any detailed engineering analysis. Higher walls are very heavy by nature of their added bulk and need larger base foundations and possibly counterforts for bracing of the wall. (A counterfort is a buttress bonded to the rear of walls, designed to improve stability.) Gabion walls built on clay soils require counterforts, which can be constructed as gabion headers extending from the front of the wall to beyond the slip circle. The counterforts serve as both structural components and as drains.

Design charts are available for various combinations of hillslope angle and retaining-wall height.
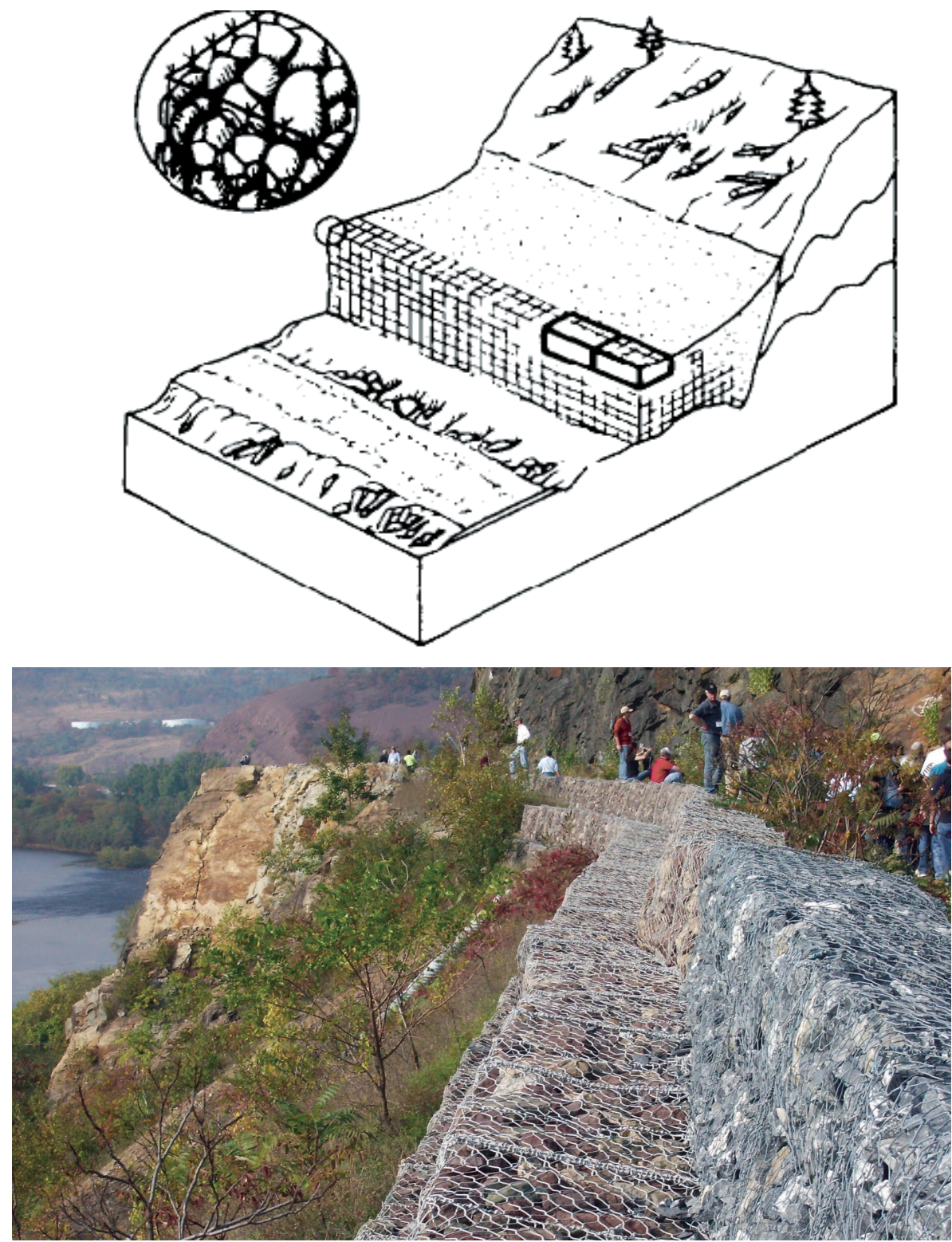

Figure C16. Schematic and photograph of a gabion wall along a highway. (Schematic from Reference 11.) (Photograph of gabions located in the Pocono Mountains, Pennsylvania, USA, by Lynn Highland, U.S. Geological Survey.) 
Piles

Large-diameter piles can be placed into the toe of a slope to form a closely spaced vertical pile wall (fig. C17). Pile walls are normally used as a preexcavation restraint system - the cut slope excavation takes place in front. Whereas large-diameter concrete pile and culvert pile walls have been used successfully on highways, wood or steel piles that are small in diameter have not. For most earth or rock movement, wood piles are not adequate to provide enough shearing resistance. They are suitable only where the volume of soil to be stabilized is small. On average, one wood pile is necessary for every 50 cubic meters ( 65.3 cubic yards) of soil, which is not sufficient for large stabilization projects. Too few piles can result in toppling and (or) breakage by the moving mass of soil, as well as by soil movement between the piles.

A major limitation when log piles are used is depth, as many failure surfaces lie below the height of the piles. Wood piles are the best for shallow soil failures over deeper stable soils. The piles should extend well below the potential failure surface and be firmly driven into firm subsoil. If the depth of placement is not sufficient to allow the piles to act as a cantilever system, then the piles must be tied back with an additional anchor system.

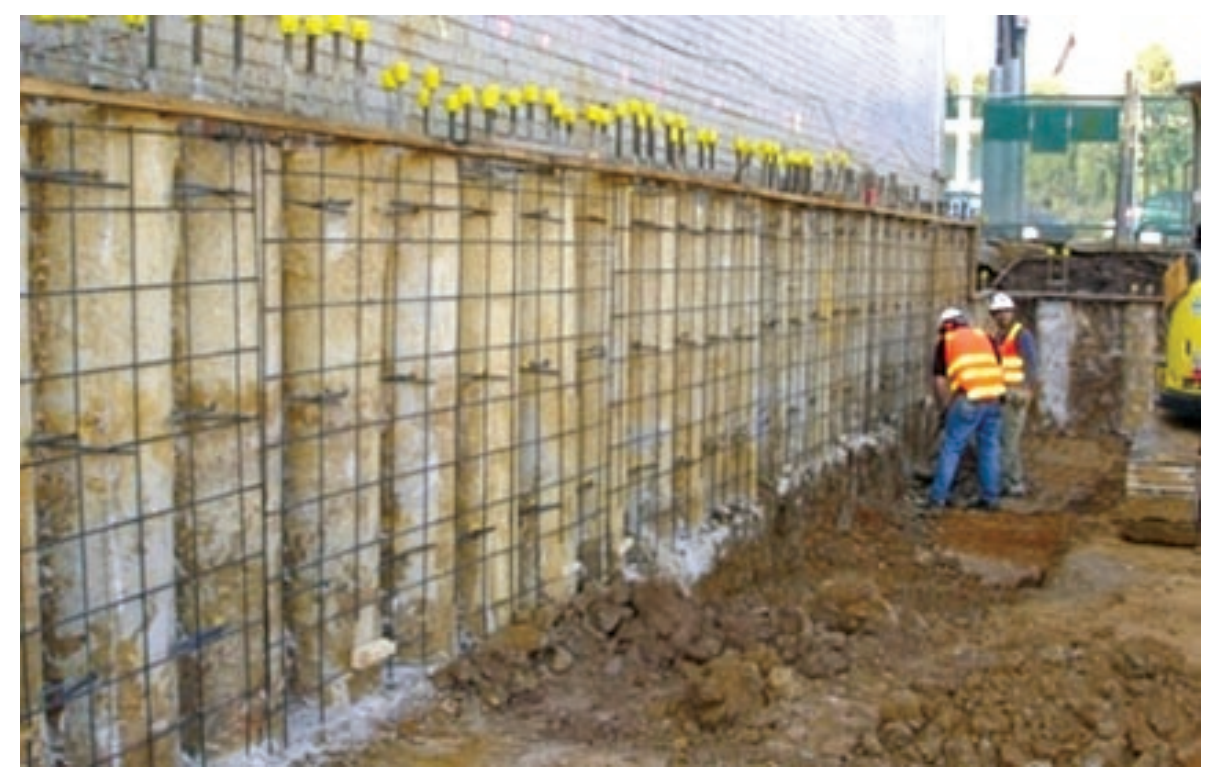

Figure C17. A concrete-filled pile wall. Reinforcing mesh has been hung over face of piles, ready for shotcrete spraying. Location is Brighton, Melbourne, Australia. (Photograph courtesy of Basement Construction Services, Victoria, Australia.) 


\section{Slope Stabilization Using Vegetation}

Seeding with grasses and legumes reduces surface erosion, which can under certain conditions lead to landslides. Planting with shrubs adds vegetative cover and stronger root systems, which in turn will enhance slope stability. If not controlled, surface erosion and small, shallow slope failures can lead to larger problems that cannot be controlled. Large-scale erosion requires applied engineering technology to correct and control. The terms "bioengineering" and "biotechnical slope protection" refer to the use of vegetation as slope protection to arrest and prevent slope failure and surface erosion. Bioengineering is discussed in detail in Section III of the handbook.

Planning is required for the successful implementation of a revegetation program. Before undertaking seeding, a person with local experience should be consulted for advice. Local knowledge based on successes and failures of projects is invaluable. Seed application should begin immediately following a disturbance, at a minimum of approximately 6 weeks before periods of drought or damaging frost.

A slope made as stable as possible before seeding will be of benefit in making the slope resistant to future erosion and failure. Controlling surface-water drainage, removing cut-bank overhangs, reducing slope angles, and benching all should be done before seeding begins.

There are two basic types of seeding: dry seeding and hydraulic, also known as hydroseeding:

Dry Seeding Dry seeding is done with rotary disk and air-blown seeders. These methods are less costly than hydraulic seeding but are limited to rough soil surfaces and gentler slopes. Rotary disk seeders spread seed and fertilizer by centrifugal force. The simplest seeder is the cyclone-type, hand-held seeder. Air-blown seeders use air to blow or shoot seed and fertilizer a distance of 5 to 8 meters (15 to 24 feet). Equipment can be adapted for motorized vehicles.

Hydraulic Seeding, or Hydroseeding This type of seeding is the application of seed in a water slurry that contains fertilizer, soil binder, and (or) mulch. The system requires a mixing tank with mechanical hydraulic agitation and volume pumping capacity. Hydraulic seeding is effective for seeding slopes 1:1 and steeper, where tacking of the seed to the slope is necessary.

\section{Types of seeds}

A combination of two to five species is the normal grass-legume mix used for erosion control. Suitability of seeds depends on soil type, climatic conditions, species compatibility, and species replacement. Local conditions will vary, and no universal type of grasses or legumes can be recommended. The types of vegetation can vary from locality to locality, and it is best to get advice from locals who are familiar with local growing conditions.

\section{Mulching}

Mulch is a nonliving material spread over the soil surface to provide protection from surface erosion by rain and retention of soil moisture. Various types of mulches will work-straw, grass fibers, wood fibers, seaweed, and paper products. 


\section{Biotechnical Slope Protection}

This type of slope protection is used to reduce the environmental consequences of landslide-mitigation measures. When used for landslide remediation or mitigation, conventional earth-retaining structures made of steel or concrete usually are not visually pleasing or environmentally friendly. These traditional "hard" remedial measures are increasingly being supplanted by vegetated composite soil/structure bodies that are environmentally more friendly. This process has come to be known as biotechnical slope protection. Common biotechnical systems include geonets anchored by soil nails that hold in place soil seeded with grass and geocells with seeded soils in the interstices.

Research has been done on using plants to stabilize soil to prevent excessive erosion and also to mitigate the effect of landslides. One of the most promising types of plants is Vetiver, a type of grass that works very well in many different environments, to stabilize slopes against erosion. See Appendix C for more information on this plant, its uses, and its geographical suitability.

Biotechnical slope protection consists of two elements: biotechnical stabilization and soil bioengineering stabilization, both of which entail the use of live materials-specifically, biotechnical vegetation stabilization uses mechanical elements (structures) in combination with biological elements (plants) to prevent and arrest slope failures and erosion. Mechanical and biological elements must function together in a complementary manner. Soil bioengineering stabilization, on the other hand, can be regarded as a specialized subset of biotechnical stabilization in which live plant parts, that is, roots, stems, and branches, serve as the main structural/ mechanical elements in the slope protection system. Biotechnical slope-protection systems blend into the landscape. They emphasize the use of natural, locally available materials, such as soil, rock, timber, and vegetation, in contrast to manufactured materials such as steel and concrete. The structural or mechanical components do not visually intrude upon the environment as much as conventional earth-retaining structures. Examples of biotechnical vegetation structures, which commonly incorporate vegetation into the structure itself, include log and timber cribs, gabion and rock-breast walls, welded wire walls, and reinforced earth. Internal, tensile reinforcements using the principles of bioengineering permit construction of oversteepened fill slopes to as much as $70^{\circ}$. A general guide to different bioengineering stabilization methods and more detailed information can be found in reference 30 .

As noted previously, soil bioengineering relies mainly on the use of native materials such as plant stems or branches, rocks, wood, or soil. Appropriate vegetation for bioengineering can be obtained from local sources of willow, alder, and other native, easily propagated varieties. In addition, soil bioengineering systems commonly are environmentally compatible during the construction process because they generally require minimal access for equipment and workers and cause relatively minor disturbance. With time, the bioengineering systems become visually nonintrusive and blend into the natural surroundings. This is a favorable attribute in environmentally sensitive areas such as parks, riparian areas, and scenic corridors where esthetic quality, wildlife habitat, and ecological restoration are important. As bioengineered structures that utilize tree species become older, they have the added benefit that they become more stable and eventually assist in the natural succession and long-term colonization of forest species. In most cases, native grasses, shrubs, and trees are used as the vegetation in bioengineering stabilization. Willow has been very successful in many parts of the world. In tropical and subtropical areas, Vetiver grass hedgerows (VGHR) for stabilization have become very popular because of

It is suggested that potential users consult the Vetiver grass Web site at: http://www.vetiver.org the fast growth and deep root penetration of this grass. However, if exotic species of plants or trees are introduced, there is a real danger that they will conflict with native plant life. 

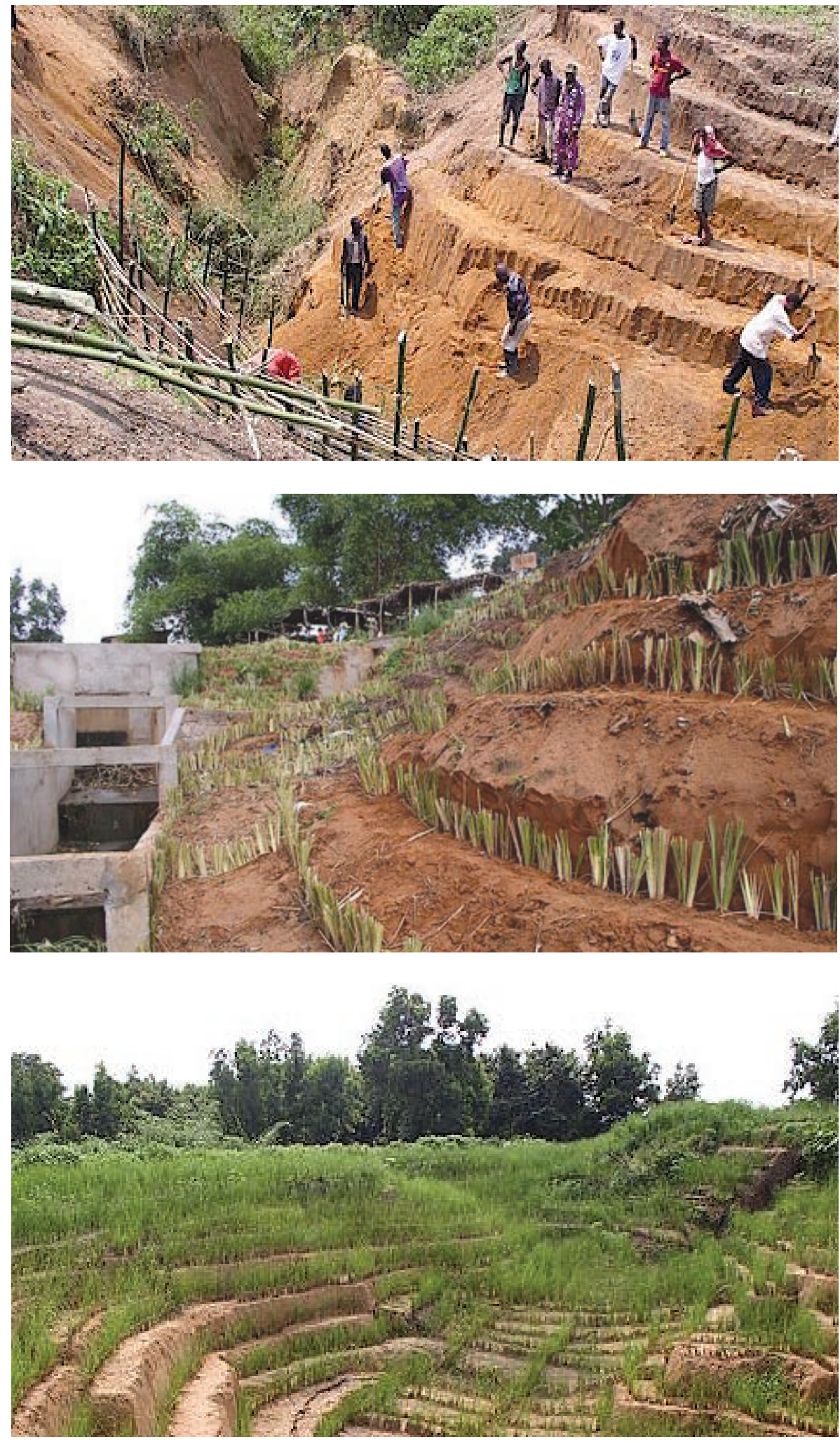

Figure C18. A Vetiver grass system is being used in the Democratic Republic of the Congo for gully control in urban areas and for highway stabilization. These gullies are a major problem in this area and other West African countries (top); the same slope now has improved drainage, and the slope has been planted in Vetiver grass (middle); this planting of Vetiver grass is about 3 months old (bottom). 
While detailed slope-stability assessments normally have been carried out by geotechnical engineers and engineering geologists, the organic interactions between vegetation, soil, and structures that must be evaluated in applying the technique of bioengineering stabilization are perhaps better understood by soil scientists, agriculturists, foresters, and hydrologists. Thus, the bioengineering approach to slope stabilization requires cooperation of geotechnical and plant-science disciplines working in parallel and in unison.

Publications are available that tell how effective it is in different regions of the world. A good beginner overview on Vetiver grass is the book, "Vetiver Grass: A Thin Green Line Against Erosion." The full reference for the book is in Reference 22. (See also reference 47.)

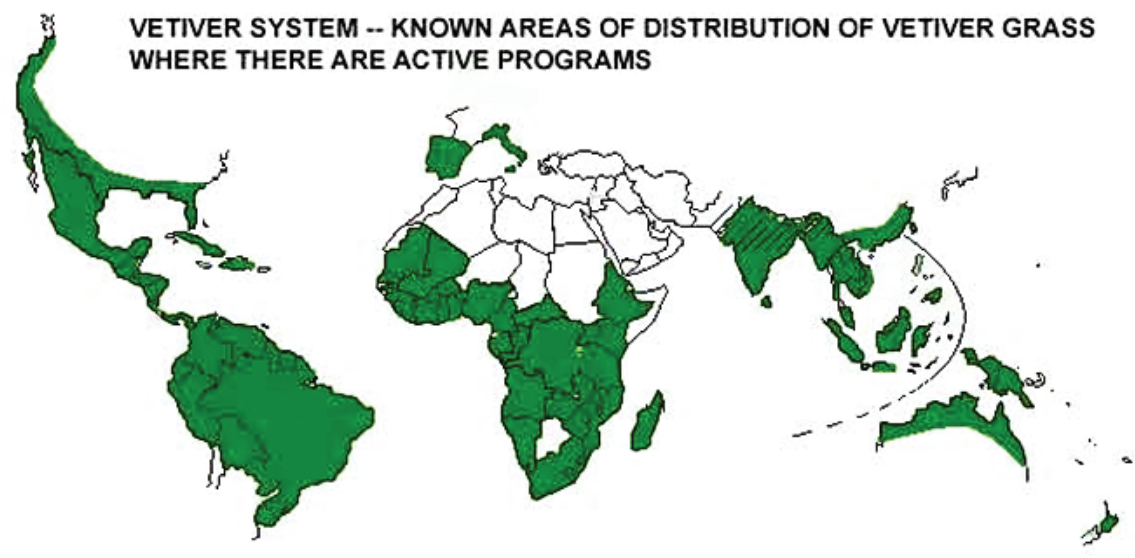

Figure C19. Worldwide distribution of active Vetiver grass programs. Graphic is from the Vetiver grass Web site (http://www.vetiver.org).

Additional Notes on Vetiver grass: For developing nations, soil erosion that encompasses, in its extreme form, landslides is one of the most damaging natural processes that must be dealt with. Little has been accomplished in dealing with erosion that can be widely applied, in inexpensive, long-lived, and appealing applications. Vetiver, a tropical grass, offers a practical and inexpensive way to prevent erosion. Planted in lines along the contours of sloping lands, Vetiver quickly forms narrow but very dense hedges. Its stiff foliage then blocks the passage soil and debris. This deeply rooted, persistent grass has restrained erodible soils for decades in Fiji, India, and some Caribbean nations. Figure C18 shows photographs of a Vetiver grass project in the Democratic Republic of the Congo and how it is used for stabilization for gullies and roads. The project is sponsored by various government agencies. These and additional photographs are on the Vetiver grass Web site, cited at the end of this section. 


\section{Part 2. Rock Slope Stabilization/Mitigation}

\section{Techniques}

Rockfall can range from a few fist-sized rocks to large cliff sections and boulders which, depending on size and shape, can roll, bounce, and careen down slopes, landing in areas at great distances from the fall lines. Recreation areas such as beaches near cliffs, parks, and open spaces are affected by rockfall, and people are frequently exposed to these hazards. People venturing too near the edges of cliffs and rocky slopes can add pressure to already weak overhangs and cause rockfalls to land on people below or sustain injuries themselves on these collapsing edges. Whether hiking, camping, walking, or working around cliffs or rock faces, people encounter the hazard many times without warning. A variety of engineering techniques can be implemented to help mitigate the effects of rockfalls, and some of these are discussed here. In some cases, more than one type of engineered solution is the best, and a combination of these remediation measures applied to one area of rockfall hazard is shown in figure $\mathrm{C} 20$.

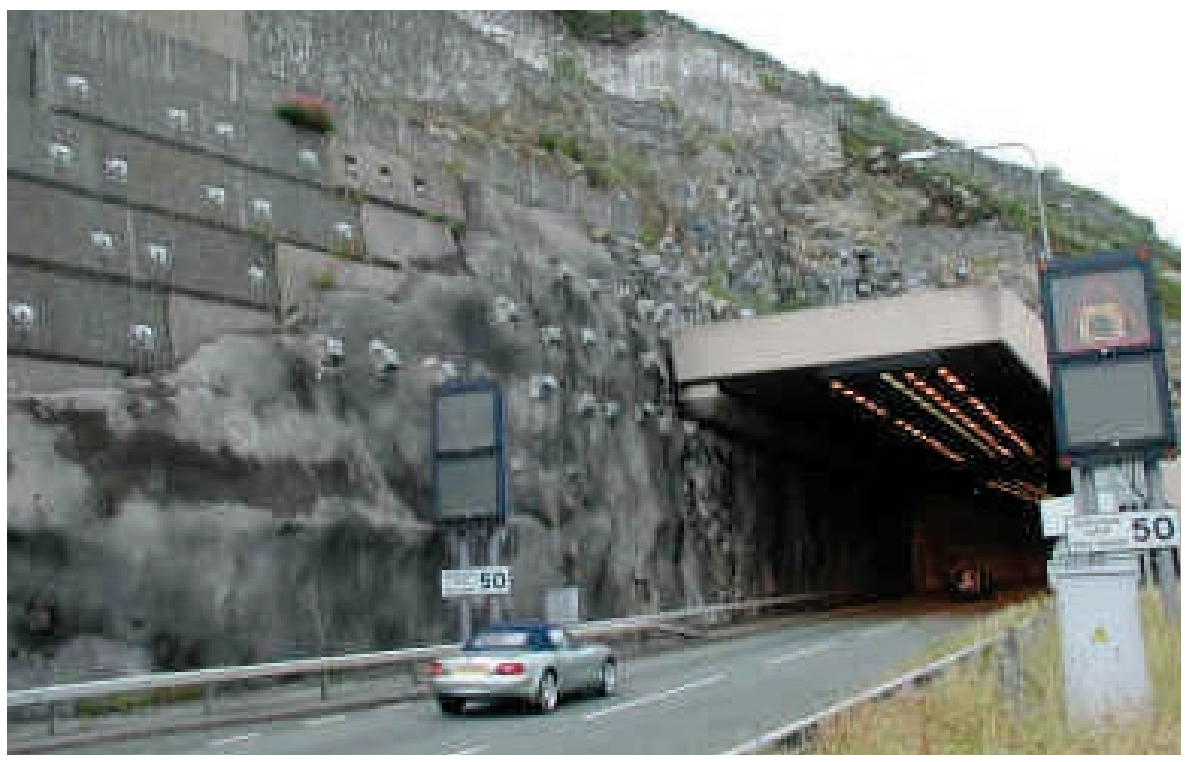

Figure C20. This photograph shows rockfall countermeasures that include mass concrete retaining walls, gabion walls (both wall types are at top of photograph), check fences, boulder treatment, and buttressing. (Photograph is the Pen-y-Clip tunnel on a highway in North Wales, United Kingdom. Photograph by Dave Giles, Engineering Geology Consultancy Group, University of Portsmouth, United Kingdom.) 


\section{Safe Catching Techniques}

\section{Catch Ditches}

Wide catch ditches are effective in containing rockfall, but the ditches must be designed with the cliff geometry taken into account, and it is best to consult a professional about specifications. The bottom of the catchment ditch should be covered with loose earth to prevent falling rock from bouncing or shattering into pieces or shards. If there is not enough space to construct as wide a ditch as is specified, then a combination of smaller ditches with a gabion or rock wall along their downhill edges can be used.

\section{Cable, Mesh, Fencing, and Rock Curtains}

Cable lashing and wire nets are simple, low-cost methods for protecting a road or path from rockfall. For large, unstable blocks, strands of metal cable are wrapped around the blocks and anchored to the slope. Where the rock is too fractured to be restrained by individual cables, cable nets are used. Wire mesh (closely spaced interwoven wires) can be used to prevent smaller rocks, less than 0.75 meter ( 2.4 feet) in size, from falling. (See figure C21 for a photograph of an example of wire mesh). The standard mesh is doubletwisted gabion wire mesh or a heavy gage metal chain link. The mesh is either loosely draped over a uniform rock face or bolted or otherwise firmly secured where the cliff face is irregular and the mesh cannot make close contact with the rock. Bolting the mesh to the rock face can prevent rock from becoming dislodged and provides overall stability of the slope or rock face. Wire mesh also is useful on steep soil cuts, especially beneath talus slopes.

Catch nets made of cable and wire mesh can be constructed to catch falling rock at the bottom of gullies and slopes. When suspended from an anchored cable, the mesh forms a flexible barrier to dissipate the energy of the falling rock and will usually stop boulders up to $1 \mathrm{~m}$ in diameter, if properly secured. Additionally, catch nets can be used in conjunction with roadside catch ditches.

Rock fences such as the ones shown in figure C22 are fairly easy to install and can restrain small rocks from falling onto roads but do not stop rocks that bounce out over the top of the fence barrier. Rock curtains, such as the one shown in figure $\mathrm{C} 23$, are more effective in directing rocks down to a catch ditch or other catching structure, preventing them from bouncing outward onto the highway or structures below.

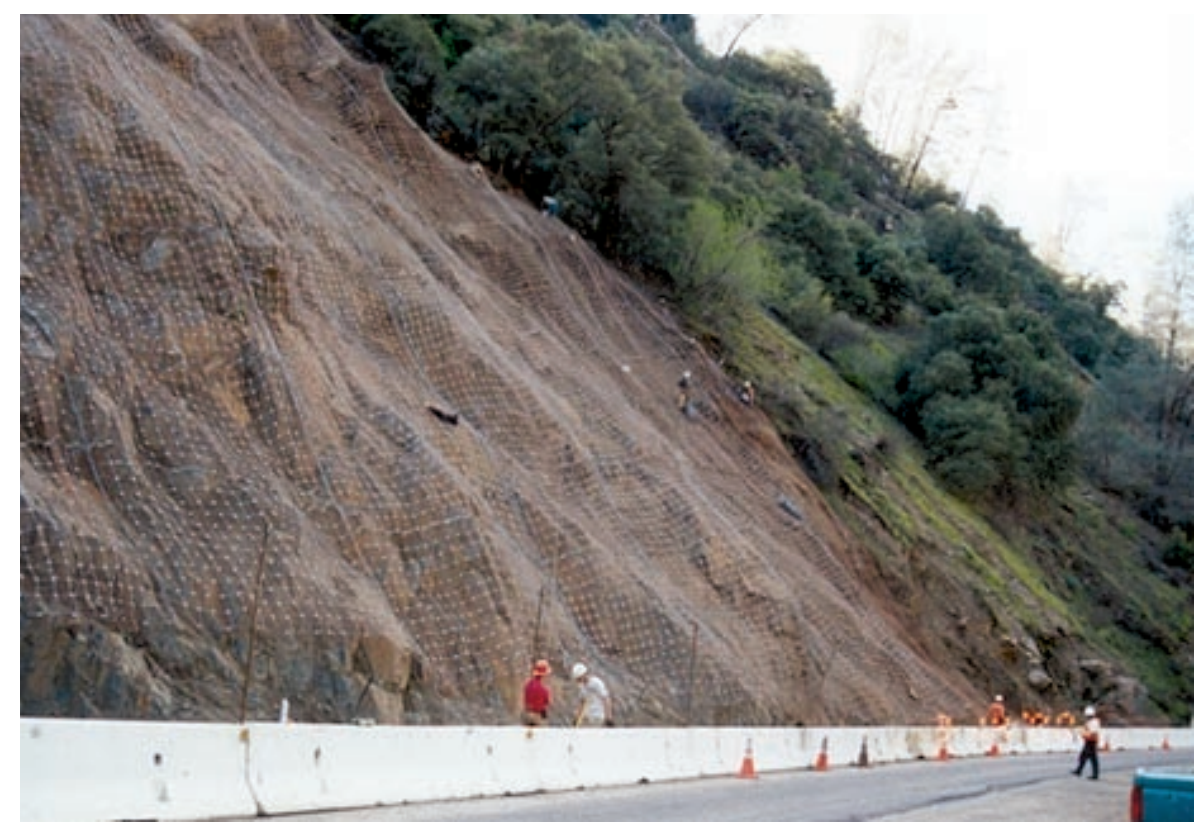

Figure C21. Example of wire mesh placed over a rocky slope to contain the rocks that may come down. 

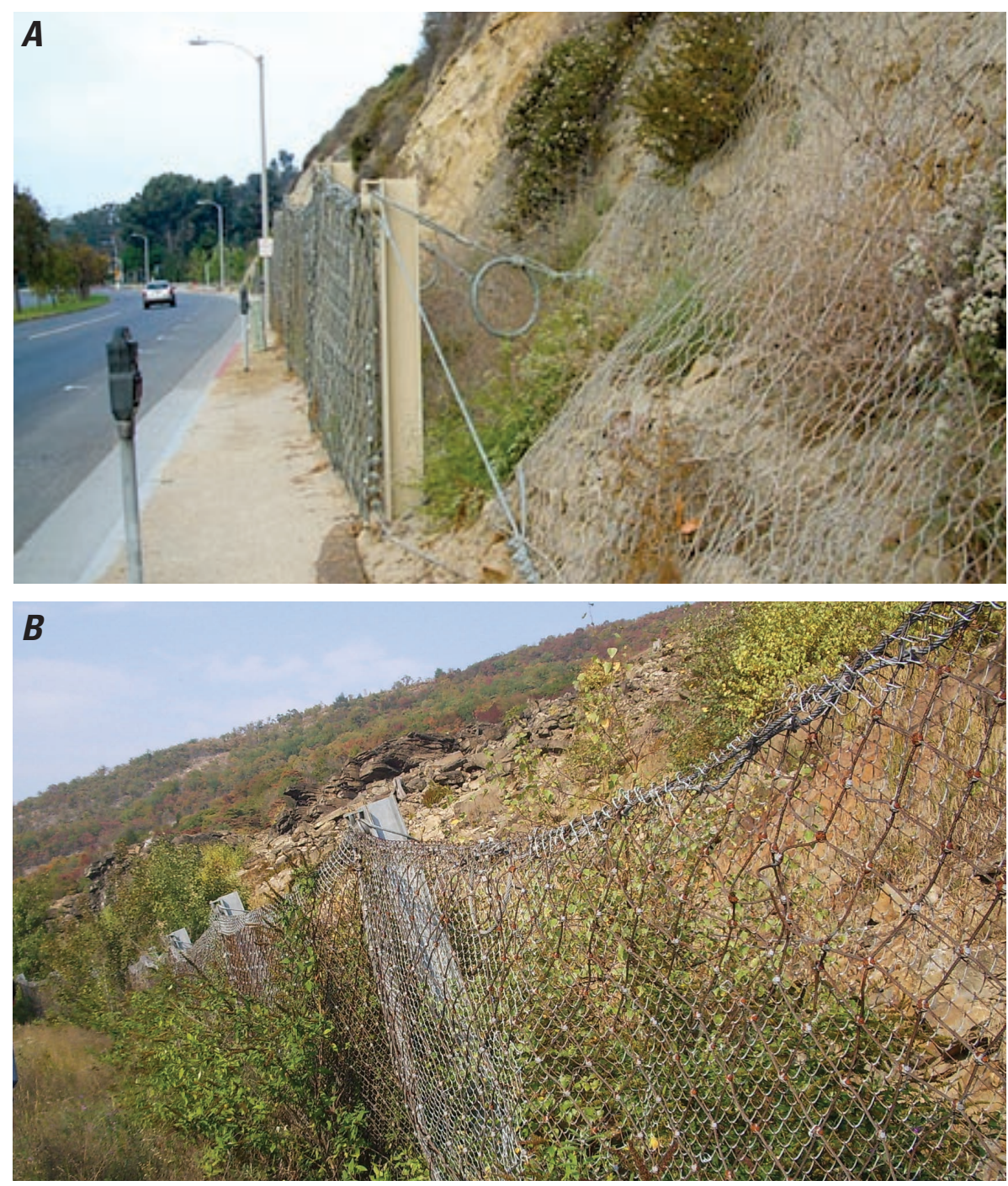

Figure C22. Protective rock barrier fencing along $(A)$ a dirt trail in Pennsylvania, USA, and $(B)$ a roadway in coastal California, USA. (Trail photograph, Lynn Highland, U.S. Geological Survey; roadway photograph from Federal Highway Administration, USA.)

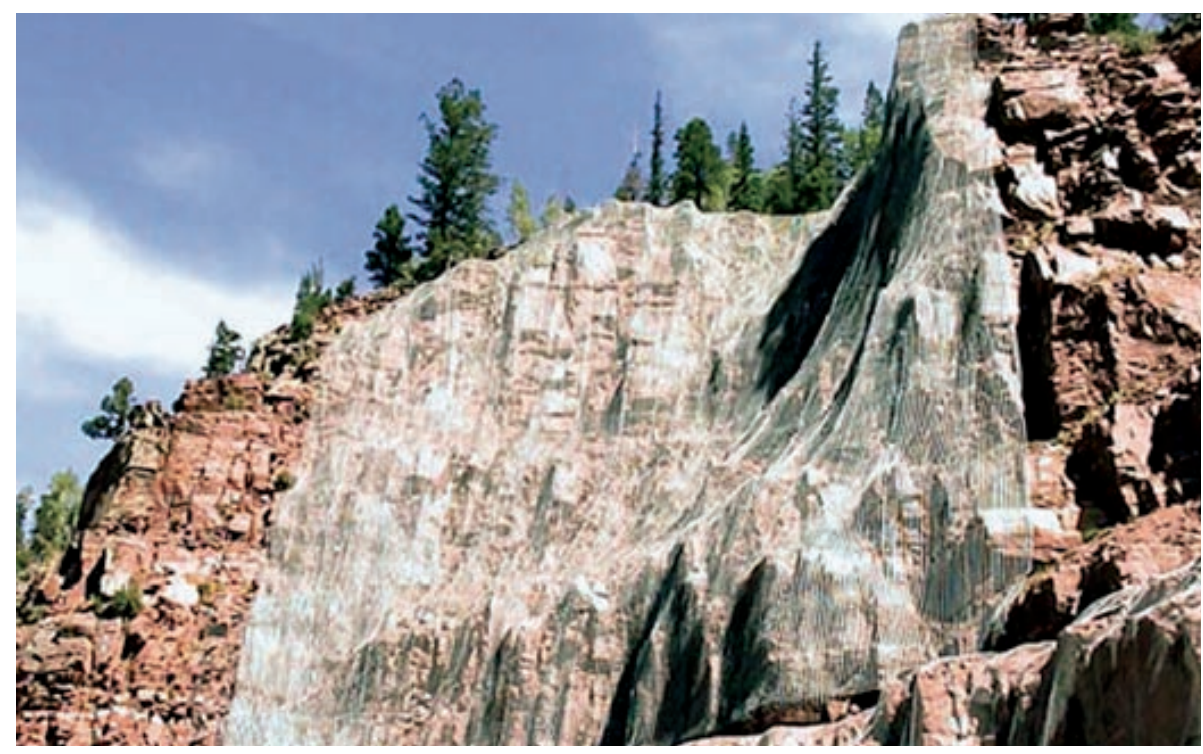

Figure C23. Example of a "rock curtain" that controls rockfalls in problem areas.

(Photograph by Doug Hansen, High Angle Technologies, Inc.) 


\section{Retaining Walls}

Retaining walls can work much like those described for soil slope-stabilization techniques in keeping rockfall debris out of an area. They are similar to rockfall fences but are in most cases more substantial and stronger. Retaining walls can be made out of steel, concrete, timbers, or other materials and must be anchored properly so as not to tip over during rockfalls.

\section{Rock Sheds/Shelters}

These are built over roads, railways, and sometimes structures to shield the area from rockfall and rock avalanches. Shed structures are either open ended or completely envelope the rockfall area in a concrete or steel (or other material) structure that will deflect rockfall away from the road, railway, or structure. Figures C24 through C27 show examples of rock sheds/shelters.

\section{Rock Ledge Reinforcement}

These are not commonly used because they work only for unique situations and must be carefully engineered and structurally strong.

Figure $\mathrm{C} 27$ is an example.

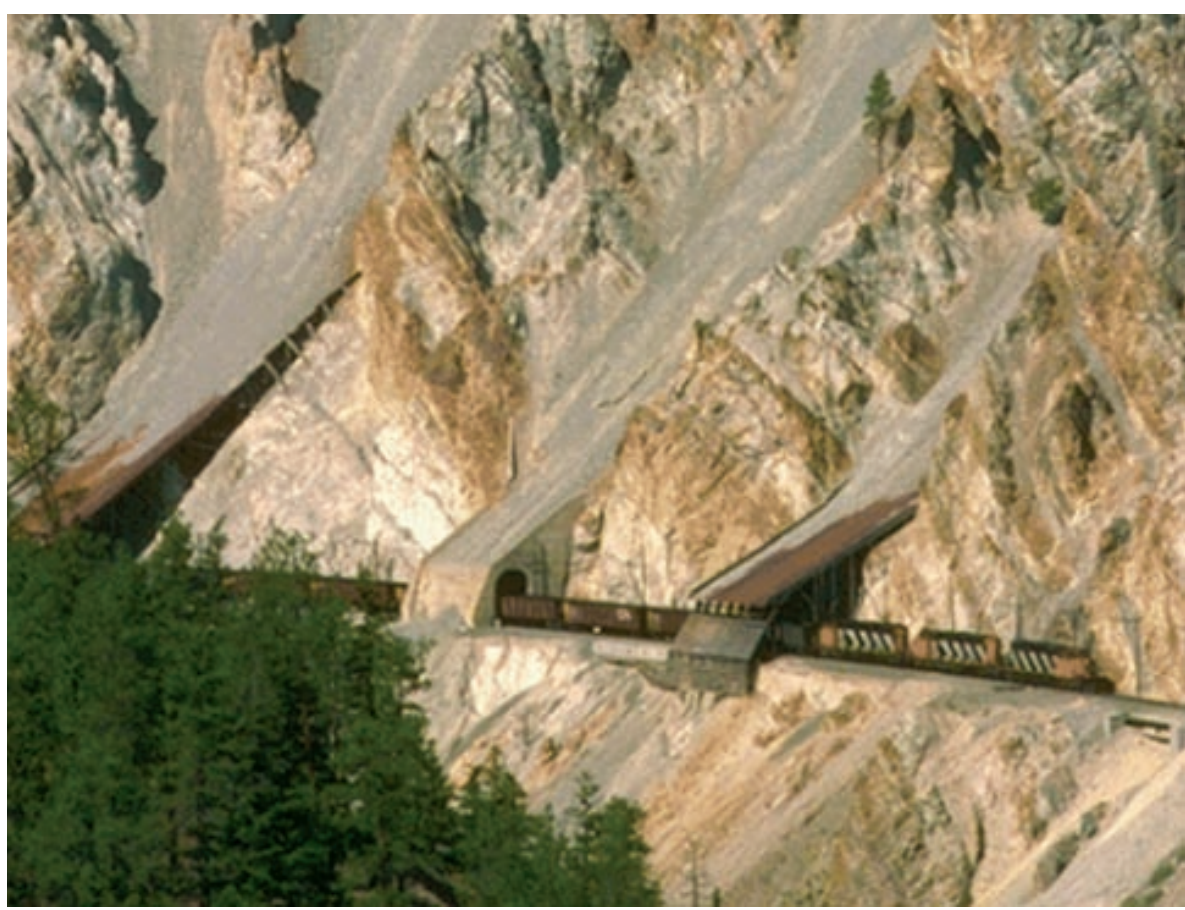

Figure C24. Pitquah rock sheds, British Columbia, Canada. These sheds enclose sections of railroad, protecting it from rockfall and rock avalanches. (Photograph by John Carter, www.trainet.org.) 


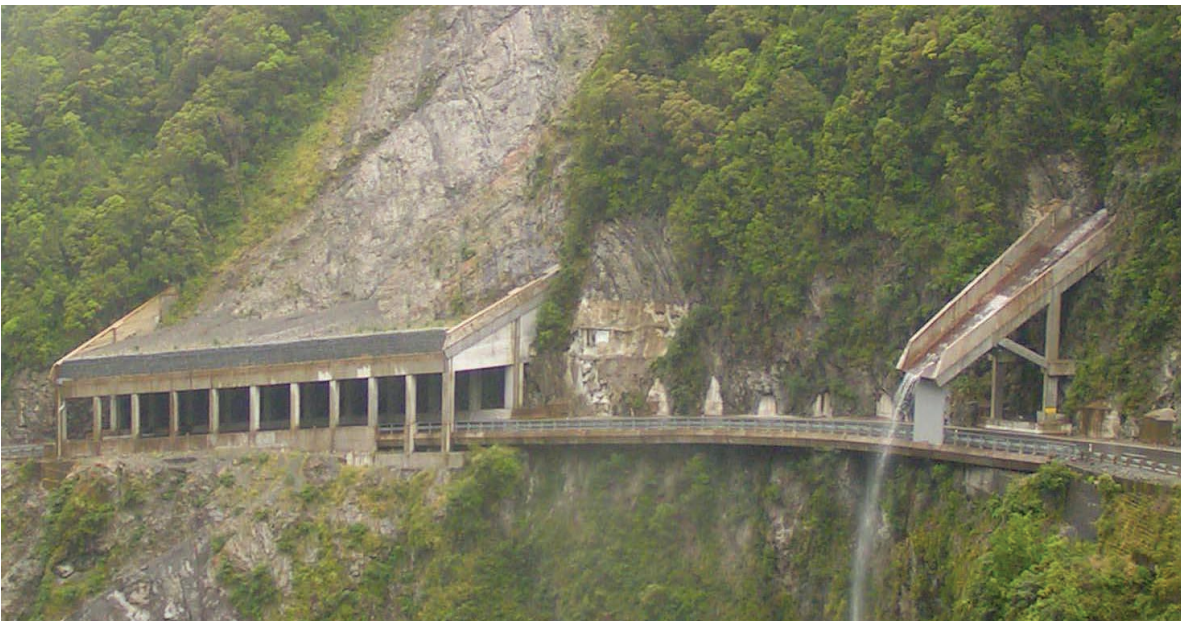

Figure C25. Example of an open rock shed in New Zealand (Photograph courtesy of Richard Wright, rock climber).

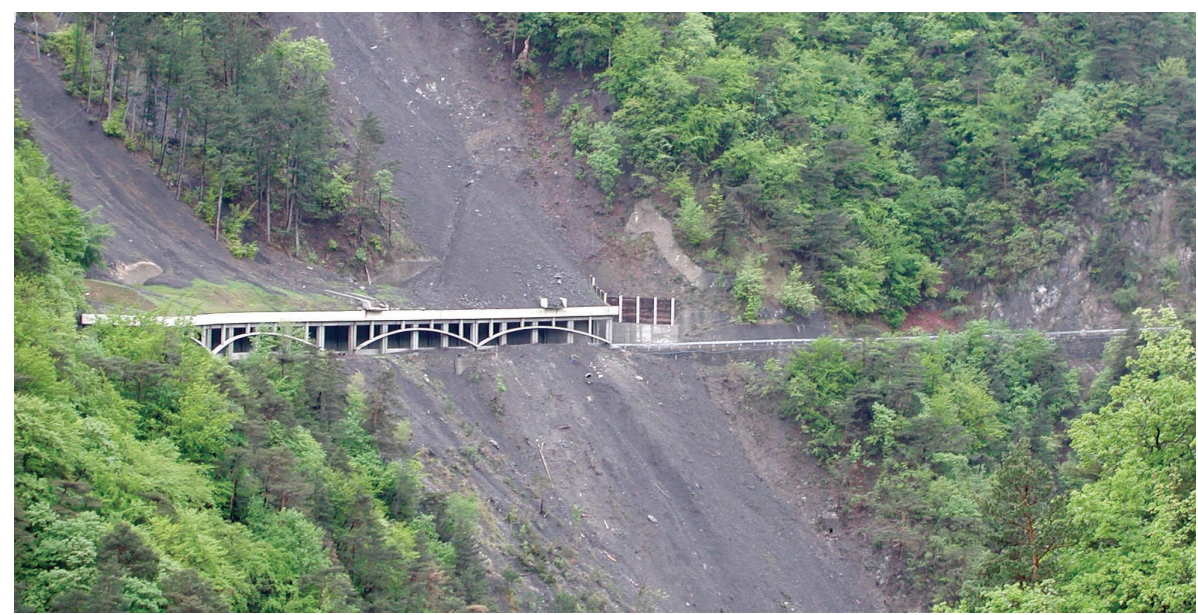

Figure C26. A rock avalanche shelter in the Montenyard area of France. The length of the shelter may be insufficient as a debris flow has damaged the road, shown to the right of the shelter. (Photograph by Dave Giles Engineering Geology Consultancy Group, University of Portsmouth, United Kingdom.)

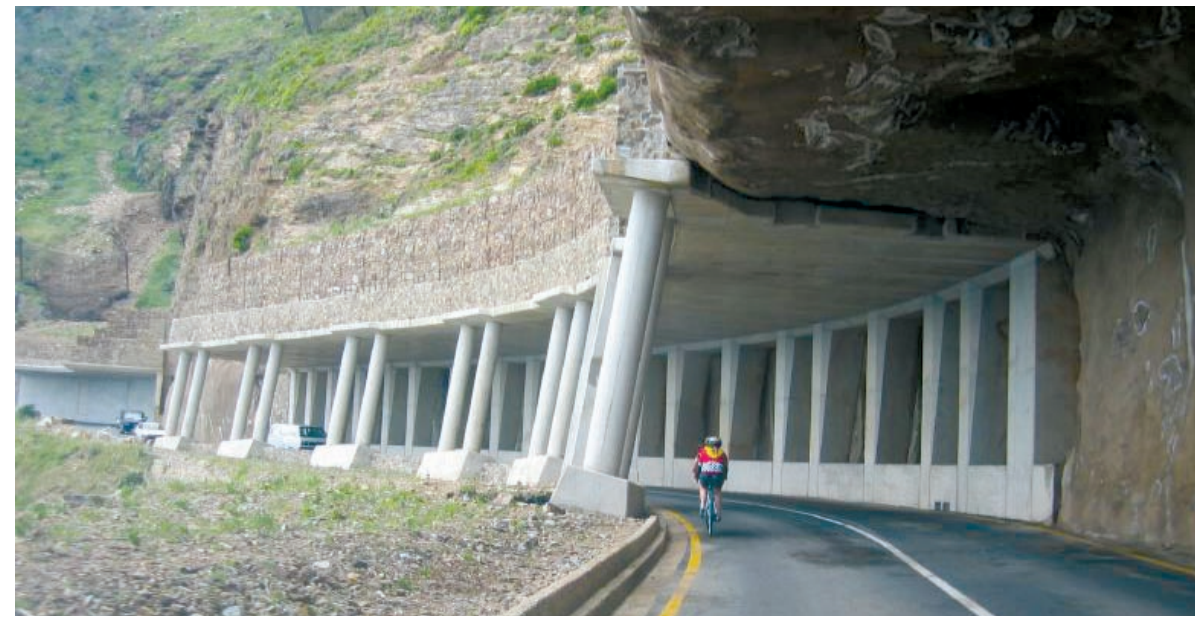

Figure C27. Example of a reinforced rock ledge, Chapmans Peak Drive, Cape Town, South Africa. Photograph attribution: http://commons.wikimedia.org/wiki Image:Chapmans_peak_dr.jpg. 


\section{Excavation of Rock}

\section{Benches}

Horizontal benches excavated into a rock face are among the most effective kinds of protection from rockfall. In addition to intercepting rockfall, benches reduce tensional forces in the surface rock and reduce surface erosion rates. They also reduce the rate of occurrence of rockfall. However, they have little or no effect on potential deep-seated rock failure.

Bench faces can be constructed steeper than the overall slope angle, as rocks that fall will likely remain on the benches (fig. C28). Vertical bench-face angles should be avoided, however, as tension cracks, dangerous overhangs, and excessive rockfall can result. The placing of bench faces should be stopped at the base of weaker rock layers, fractured rock zones, or water-bearing zones. A minimum width of $4 \mathrm{~m}$ is recommended for the benches, and all benches should have drainage ditches to divert water away from the slope.
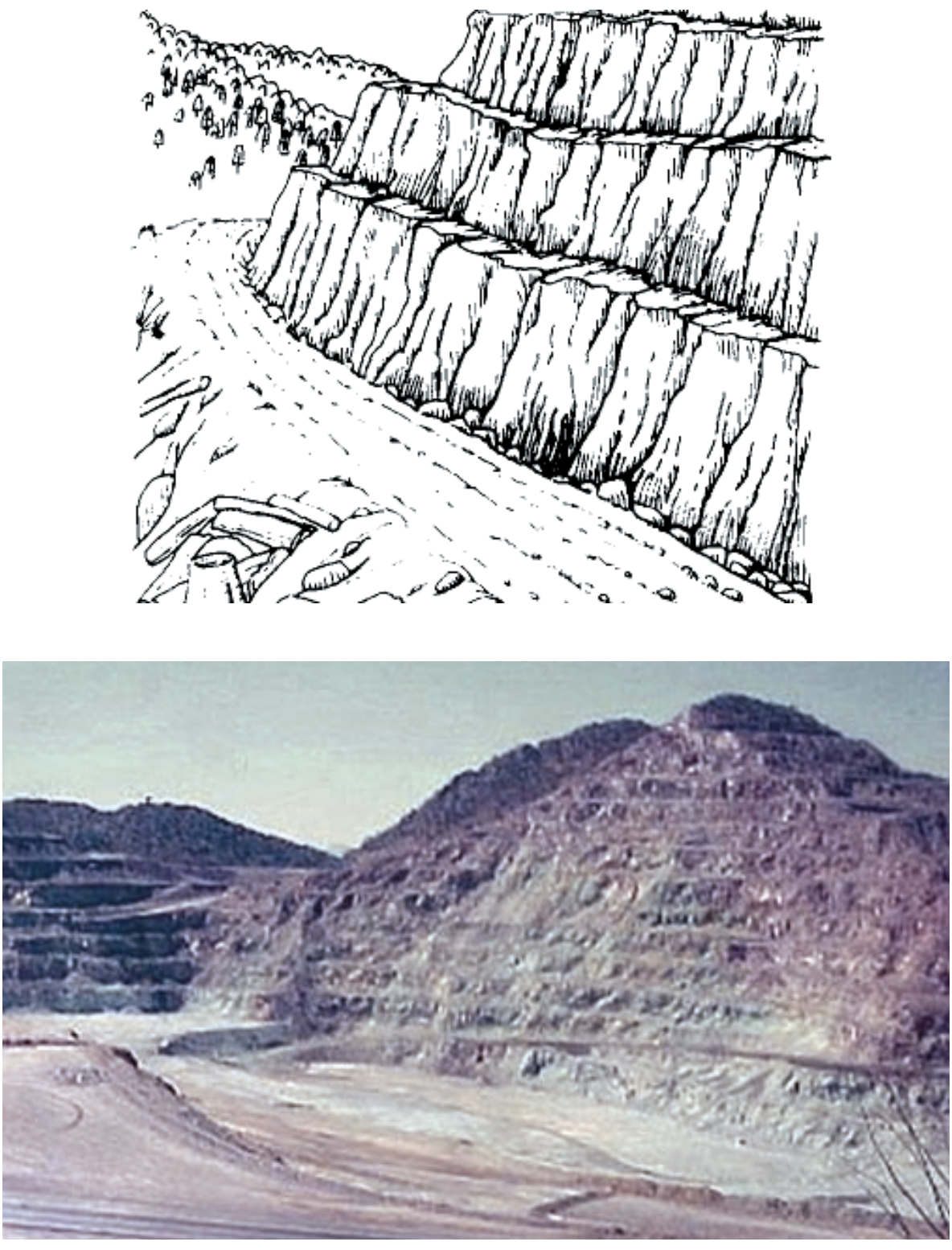

Figure C28. Schematic and photograph of rock benches. (Schematic from Reference 11, photograph of a mine in Tucson, Arizona, USA, by Steve Dutch, University of Wisconsin, USA.) 


\section{Scaling and Trimming}

Loose, unstable, and (or) overhanging blocks of rock, which may pose a danger to passing traffic and (or) pedestrians, can be removed by scaling or trimming. Scaling is the removal of loose blocks by the use of hand-held pry bars and small explosive charges. Trimming involves some drilling and light blasting by explosives, followed by scaling, to remove larger areas of overhanging or potentially dangerous rock. The necessity of scaling and trimming can be reduced with the use of controlled blasting, but blasting is not always feasible. Overhanging rock is either removed or trimmed back to a stable part of the face. Scaling operations are usually carried out by workers suspended by ropes or other means, using pry bars, jacks, and explosives. These operations can be time-consuming and expensive (sometimes dangerous) and on active slopes may need to be repeated every few years, or as needed. Scaling is highly skilled work and can be dangerous; scaling crews should be trained and the work performed by professionals.

Photographs C29 and C30 show rock scaling and trimming operations.

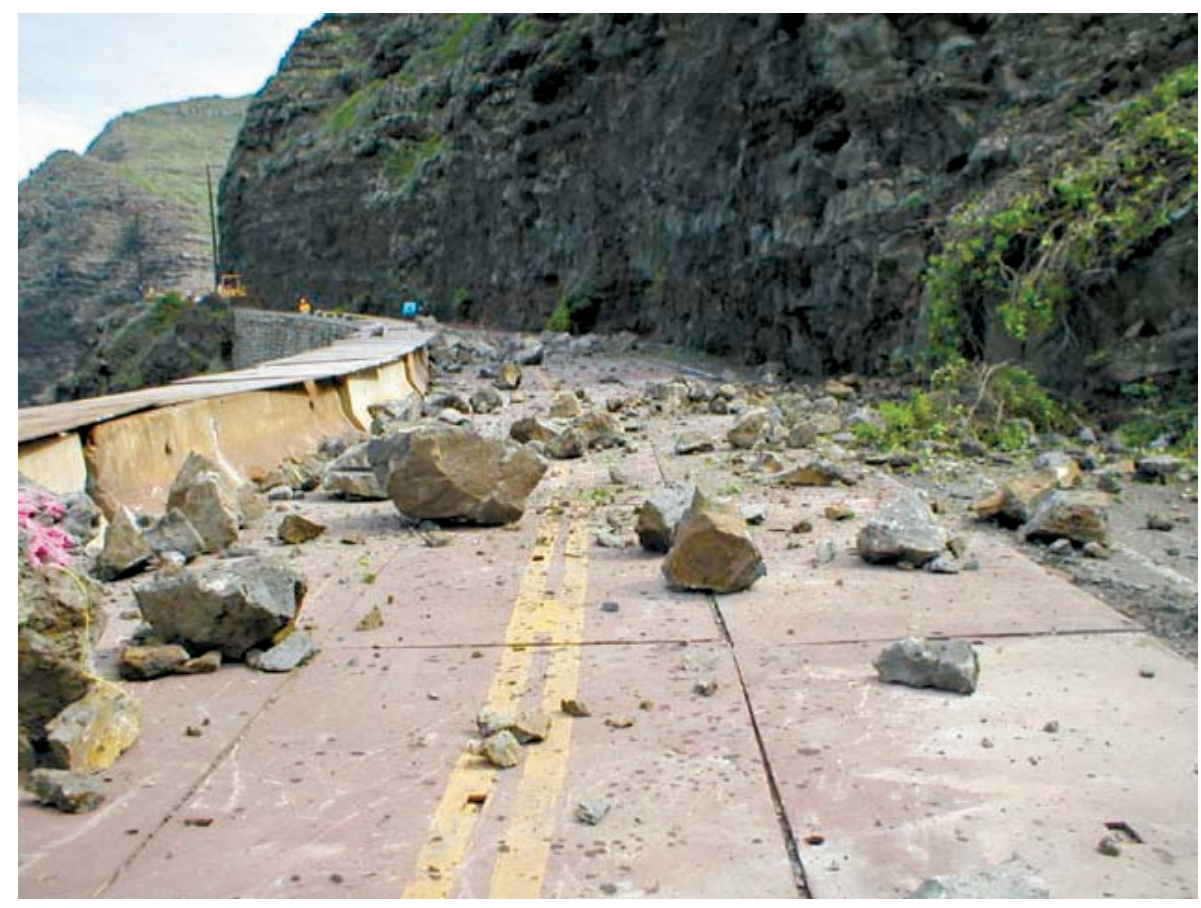

Figure C29. Rocks dislodged by scaling and blasting. (Photograph by Washington Department of Transportation, USA.) 


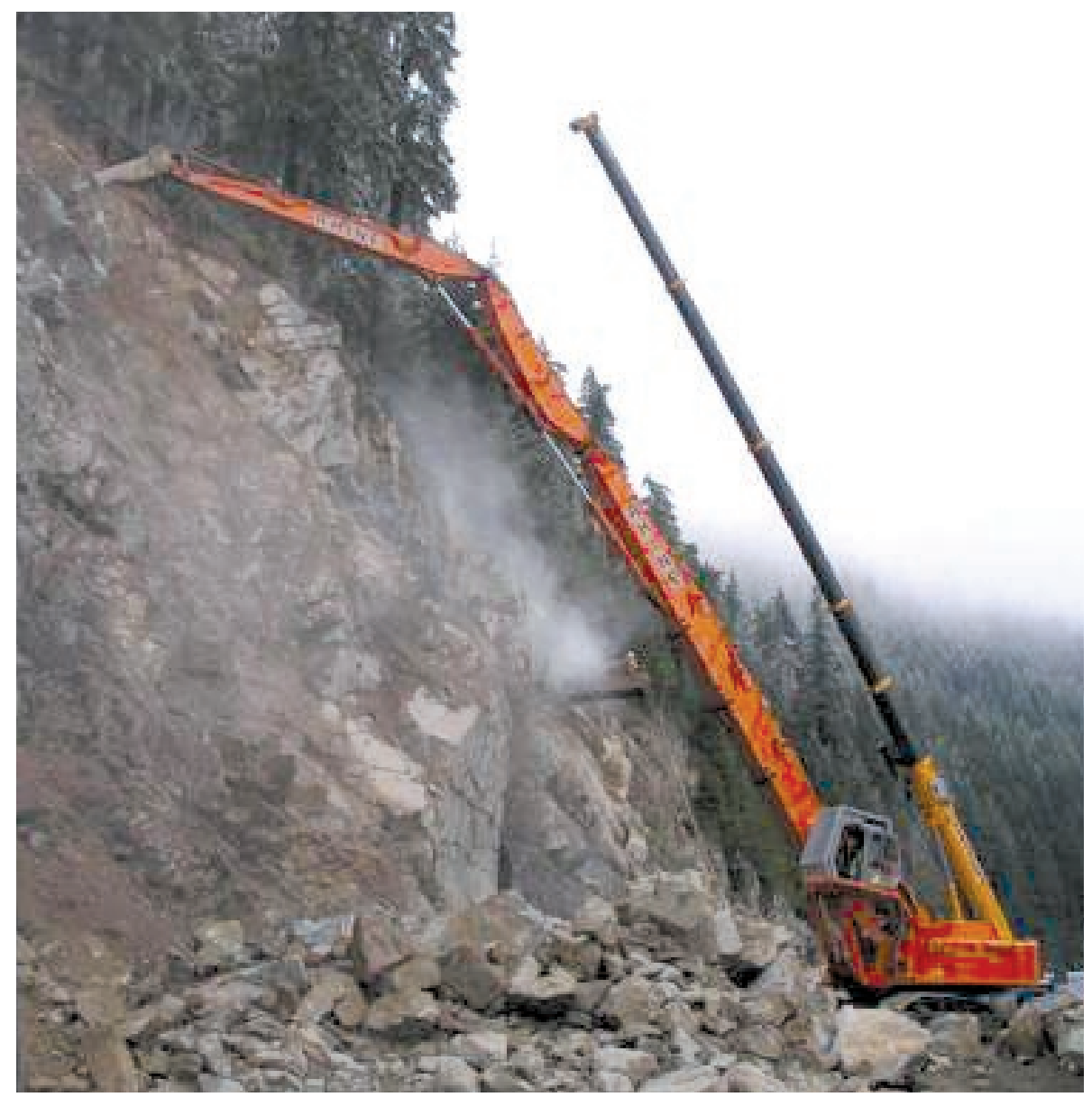

Figure C30. A hydraulic rock hammer in action, bringing down rock from the slope. This is an alternative to blasting rocks down. (Photograph by Washington Department of Transportation, USA.) 


\section{Reinforcing Potential Rockfall Areas}

\section{Shotcrete and Gunite}

Shotcrete and gunite are types of concrete that are applied by air jet directly onto the surface of an unstable rock face. Shotcrete is an all-inclusive term to describe the spraying of concrete or mortar either by a dry- or a wet-mix process. Gunite refers only to the dry-mix process in which the dry cementitious mixture is blown through a hose to the nozzle, where the water is injected immediately before application. This is a rapid and relatively uncomplicated method commonly used to provide surface reinforcement between blocks of rock and also to reduce weathering and surface scaling. Shotcrete contains aggregate up to $2 \mathrm{~cm}$ in size and is more commonly used than gunite, which has smaller aggregate. Both materials can be applied rapidly by air jet so that large areas can be covered in a short time. Figure C31 shows a shotcrete operation on the side of a highway.

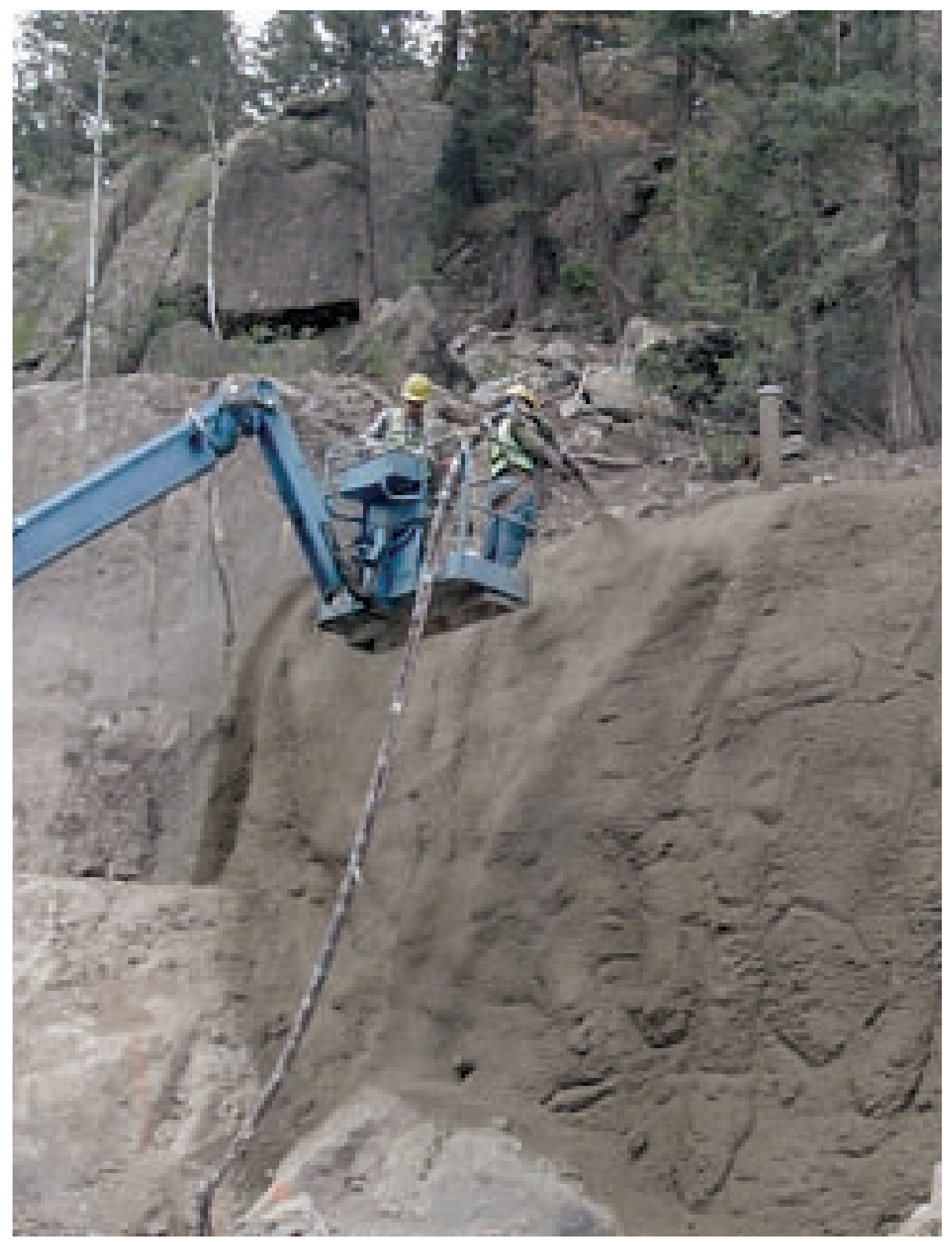

Figure C31. Shotcrete operation to stabilize rockfall area of Wolf Creek Pass in the Rocky Mountains of Colorado, USA. (Photograph by Colorado Department of Transportation.) 


\section{Anchors, Bolts, and Dowels}

These are tools composed of steel rods or cables that reinforce and tie together a rock face to improve its stability. Anchors are post-tensioned members used to support large blocks of rock, whereas bolts are shorter and support surface rock. Dowels are similar to bolts but are not post-tensioned. Reinforcing a rock slope with steel requires a specialist's knowledge of rock stability analysis, of grouting techniques, and of testing procedures. The determination of the orientation of the potential failure surfaces is crucial to a successful anchor system and requires a considerable amount of engineering experience. Figures $\mathrm{C} 32$ and $\mathrm{C} 33$ show rock bolts and rock bolt installation along a highway.

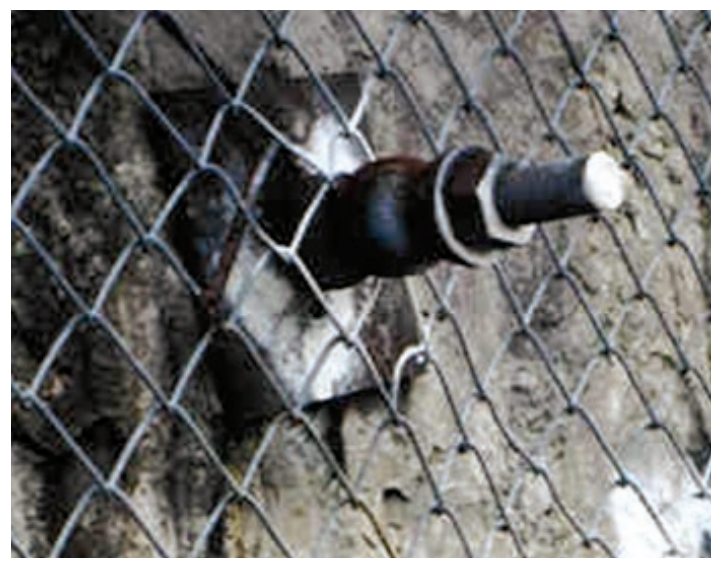

Figure C32. Closeup photograph of a rock anchor on a rock face, with mesh over the surface for more protection. The anchor is set in the rock about 5 meters ( 15 feet) deep.

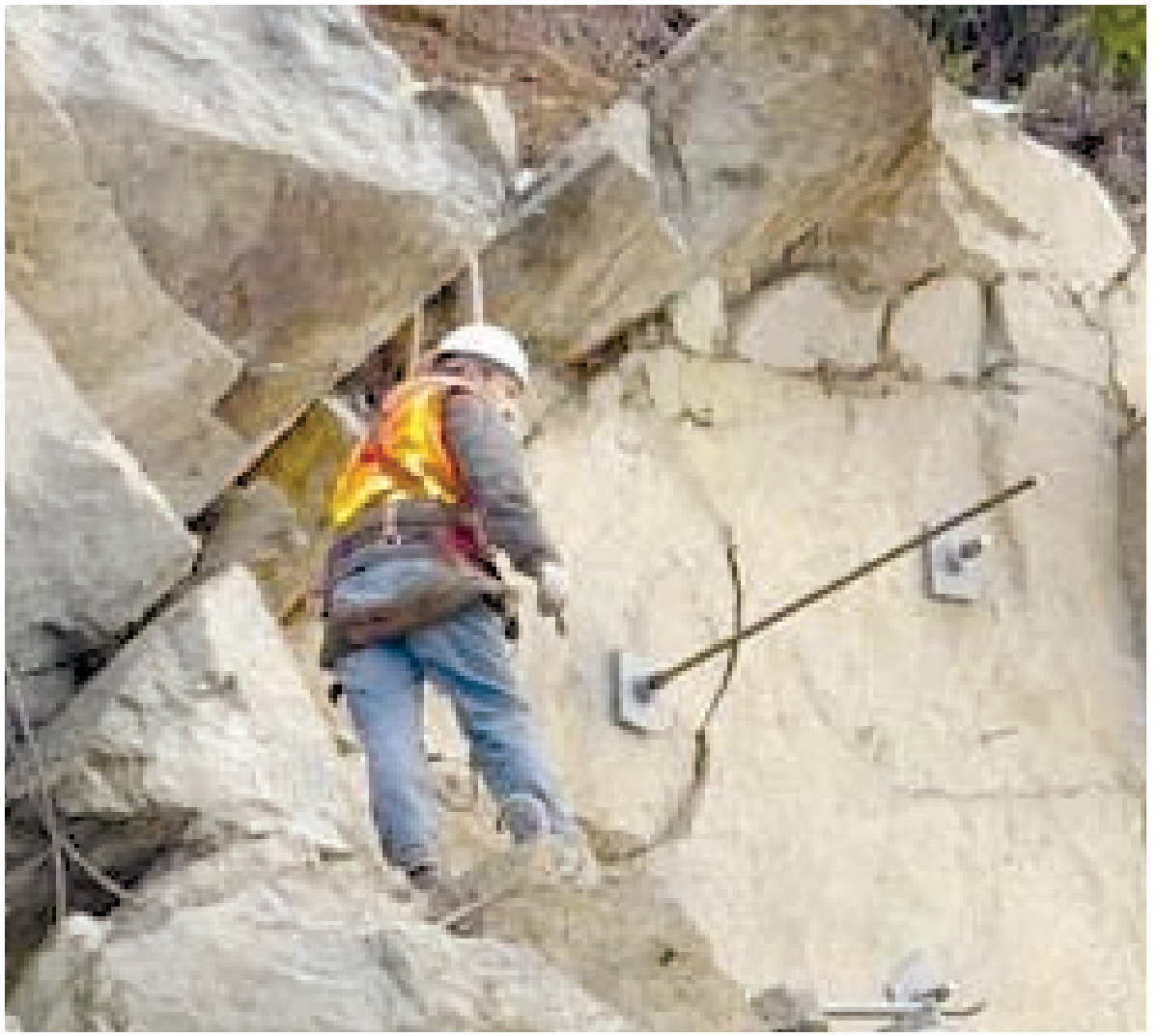

Figure C33. A rock bolting operation; notice broken-up (crumbling) nature of the rock. (Photograph by Washington Department of Transportation, USA.) 


\section{Part 3. Debris-Flow Mitigation}

This section describes some simple mitigation methods for debris-flow hazards for homeowners, businesses, and others. A short section on erosion and fire control is included since erosion, fire, and subsequent debris flows and flooding are interrelated hazards.

\section{Strengthening Slopes for Erosion/Debris Flows}

Erosion may cause the steepening and lengthening of gullies and cause the loosening of soil, plant debris, rocks, and boulders, which can intensify the effects of debris flows. Keeping an area free of excess fuel for fires can also help in the mitigation of debris flows, as burned slopes become more vulnerable to the effects of debris-flow initiation and erosion (fig. C34). Loss of vegetation that holds soil in place and physical and chemical changes to the soil that result from intense heat and burning by fires make this soil more prone to debris flows.

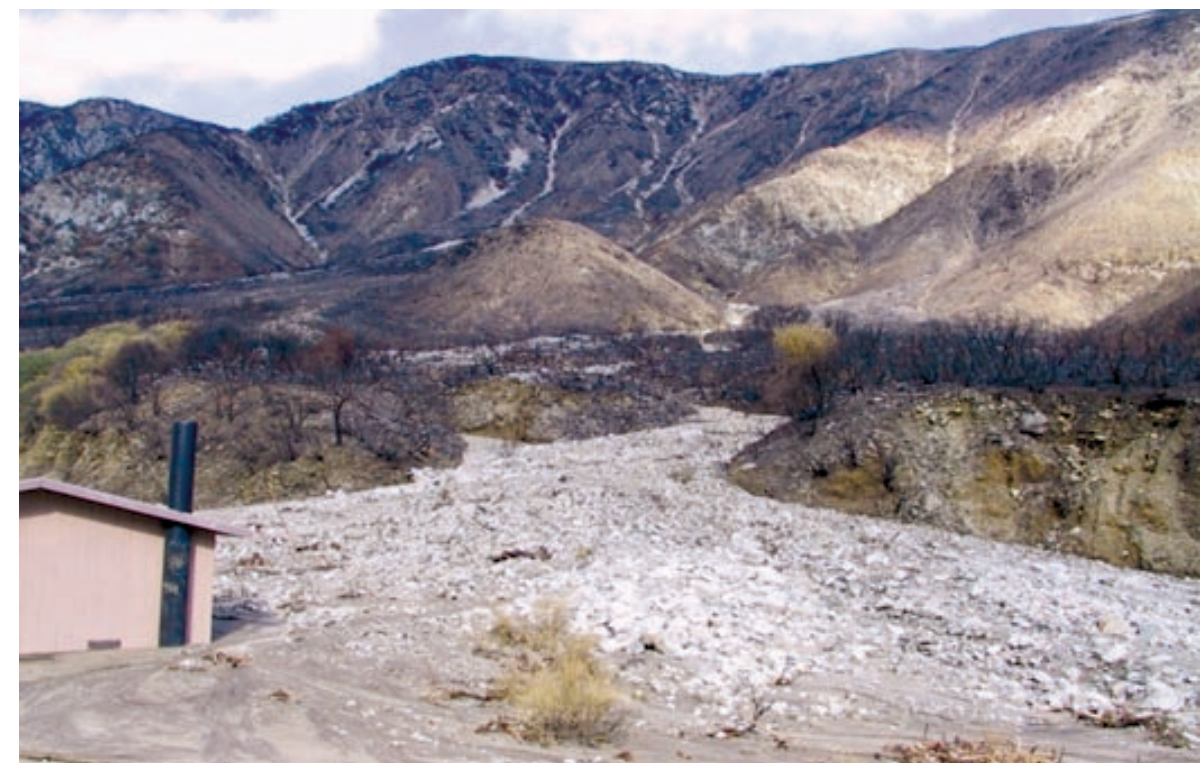

Figure C34. Wildfire-burned slopes and debris flow that occurred shortly after the fire at Lytle Creek, California, USA. (Photograph by Sue Cannon, U.S. Geological Survey.)

erosion The processes where the materials of the Earth's crust are loosened, dissolved, or worn away and then are moved from one place to another. Process includes actions of wind, rain, freeze-thaw, weathering, and physical abrasion. 


\section{Strengthening the soil to resist erosion}

Erosion is a process that must be taken into account when reinforcing an area, and some simple steps can be taken to lessen the effects of erosion. Erosion can sometimes lead to slope failures and drainage problems; trying to prevent it is something a homeowner can do, proactively, before bigger slope-failure problems are encountered. Straw or wood chips are effective in holding the soil in place. They have the further value of increasing the organic content of the soil. Place a covering of chips or straw about one-half centimeter (one-quarter inch) thick as slope and soil conditions indicate. Fertilizer may be added. Work the material into the top few centimeters (or inches) of the soil.

Woven burlap (a loosely woven, fibrous material of generally low cost) can be laid on the slope and tied down with stakes to prevent lifting by wind or water. Regular planting procedures can be followed before laying the burlap because the fabric will not interfere with establishing a growth on the slope. The burlap will decompose eventually but will remain long enough for vegetation to become well established.

\section{Proper planting of vegetation on slopes can prevent erosion}

Keep plants watered, but do not overwater. Replant barren areas or areas that have been burned. Make inspections during rains. Watch for gullying. Correct problems as soon as possible.

\section{Keeping slopes free from fuel for wildfires}

Burned slopes in debris-flow-prone areas can become hazardous as they increase the likelihood and intensity of debris flows when slopes become saturated by rainfall. Homeowners and businesses can act to keep properties free of excess fuel for wildfires, actions that may stop wildfires from spreading or burning large areas. Wildfires can denude slopes of vegetation and can change the soil chemistry, which may result in intensifying the hazard from debris flows. Piles of deadwood, dead vegetation, and other types of fuel that can accumulate on properties should be kept at a minimum to keep wildfires from starting or spreading. Many communities have local guidelines on controlling excess wildfire fuel and feature practical advice on the cleanup of property. Local municipalities can take community action to penalize unauthorized burning of trash, for example, through local ordinances. Lightningcaused wildfires are naturally occurring, but steps can be taken that preclude the spread of this type of wildfire through keeping available fuel at a minimum. For any necessary burning of farmland, for example, it is recommended that residents that live in areas of steep slopes be vigilant so a wildfire does not become uncontrolled and spread to other areas.

Note: It should be remembered that floods, earthflows, and debris flows (some of these known commonly as "mudslides") have many of the same characteristics and generally can be dealt with in similar manners. Floods, "mudslides," and debris flows sometimes accompany each other, but not always. 


\section{Structures for Mitigating Debris Flows}

\section{Debris-flow basins}

These catchment basins are commonly built at the base of slopes where debris flows are frequent (fig. C35). They are used especially in areas where the debris must be contained so that soil and debris are stopped from flowing into sensitive ocean or river shorelines areas or where there are structures at the base of the slope that are vulnerable to debris-flow damage. These basins will eventually fill with the debrisflow deposits and must be emptied periodically or they will overflow. Commonly, large pieces of equipment such as dump trucks and power shovels are needed to empty the debris and carry it away. However, small basins can be emptied manually. They should be designed to be able to contain the maximum flow volumes of an area to prevent overtopping during a flow event.

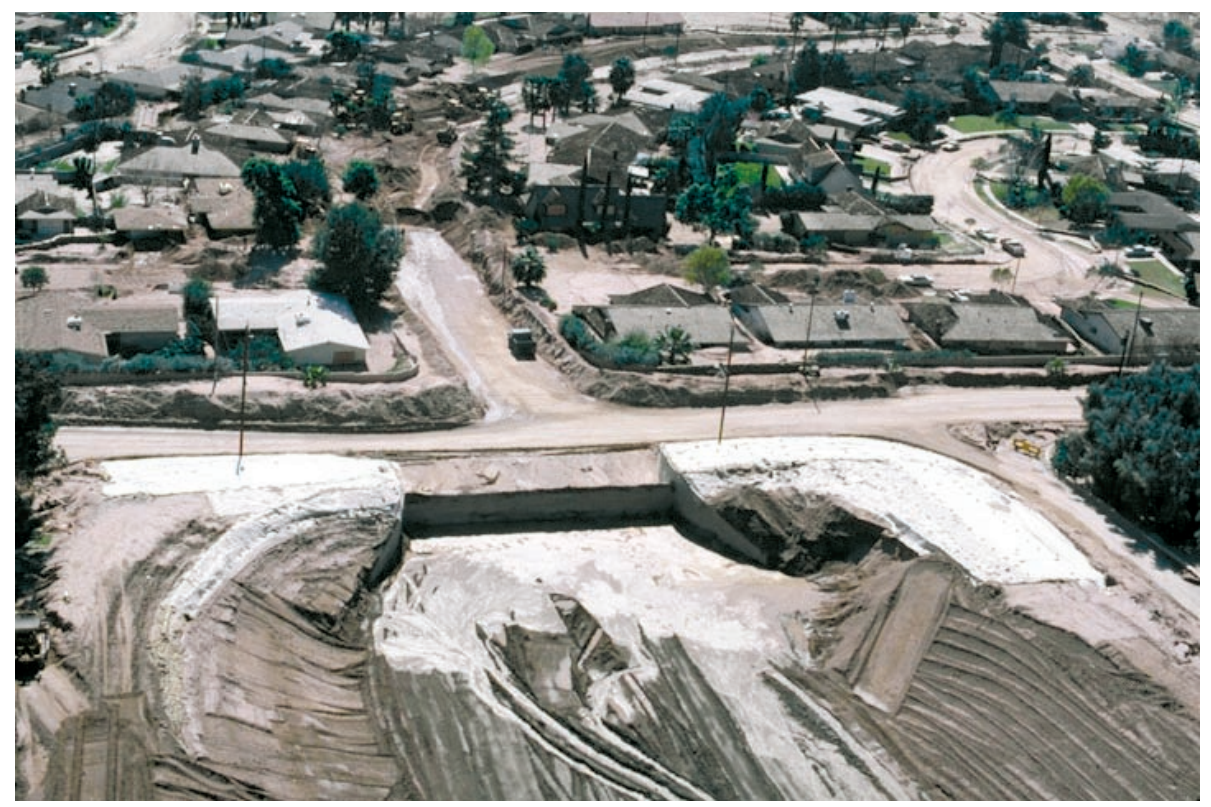

Figure C35. Aerial photograph of a debris-flow basin, constructed at the bottom of a slope in San Bernardino, California, USA. (Photograph by Doug Morton, U.S. Geological Survey.)

\section{Check dams}

See Appendix C, "Part 1. Earth Soil Slope Stabilization/Mitigation,” for an explanation of how check dams can also be used to reduce the hazards from debris flows. 


\section{Debris-flow retaining walls}

These are structures that can be built of various kinds of materials. They are designed to stop the progress of the debris fall, either by blocking the flow or diverting it around a vulnerable area. These structures should be carefully designed as any deflection of material may be unintentionally redirected into additional vulnerable areas (figs. C36 and C37).

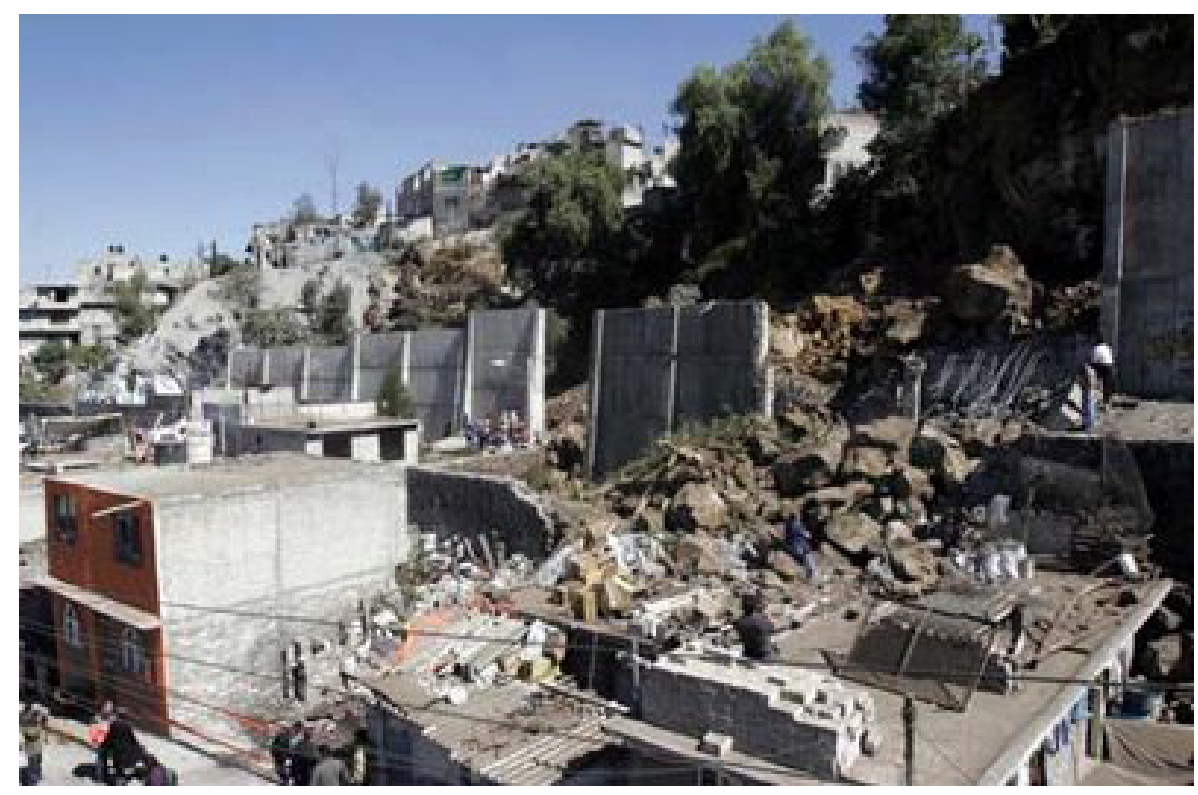

Figure C36. Caution is required in locating and constructing debris-flow retaining walls. This is a photograph of the partial failure of a retaining wall, caused by a landslide in Iztapalapa, a suburb of Mexico City, Mexico. The landslide slid onto a house at the toe of the slope, killing two people, and was triggered by heavy rains in the area. The house was below the 5 -meter-high ( 15 yards) wall, but the wall could not withstand the mass of rocks and soil. (Photograph by Chinagate/Xinhua.)

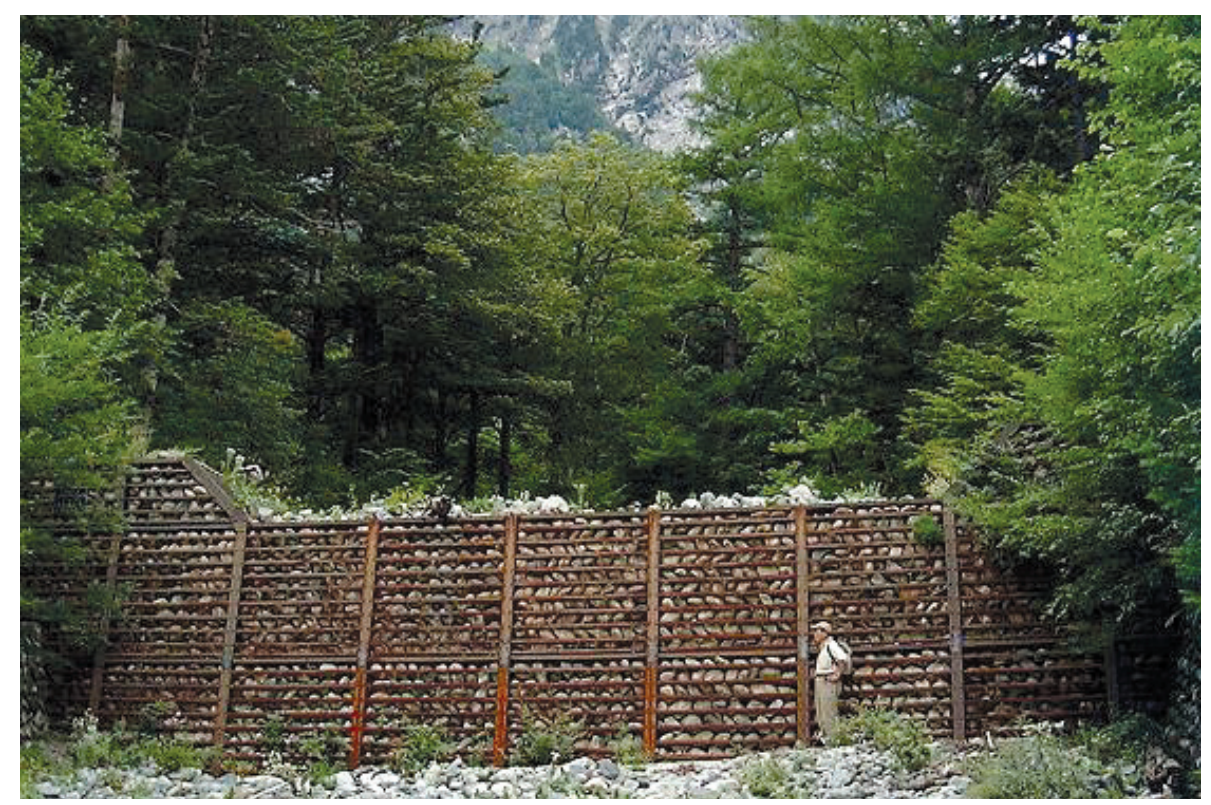

Figure C37. A debris-flow retaining wall in Kamikochi Basin, Japan. (Photograph courtesy of Goncalo Vieira.) 


\section{Debris-Flow Mitigation for the Homeowner}

This section provides some simple steps that a homeowner can take, or an emergency manager can recommend, to help individuals mitigate the effects of erosion, which in many cases may lead to debris flows and some landslides.

The following figures C38 through C52 show schematics of debris-flow mitigation techniques that may be helpful for protecting structures. The figures are modified from those found in Reference 20, a booklet published for Los Angeles, California, USA, homeowners by the Los Angeles County Department of Public Works, showing simple methodology for reducing hazards from floods, erosion, and debris flows.

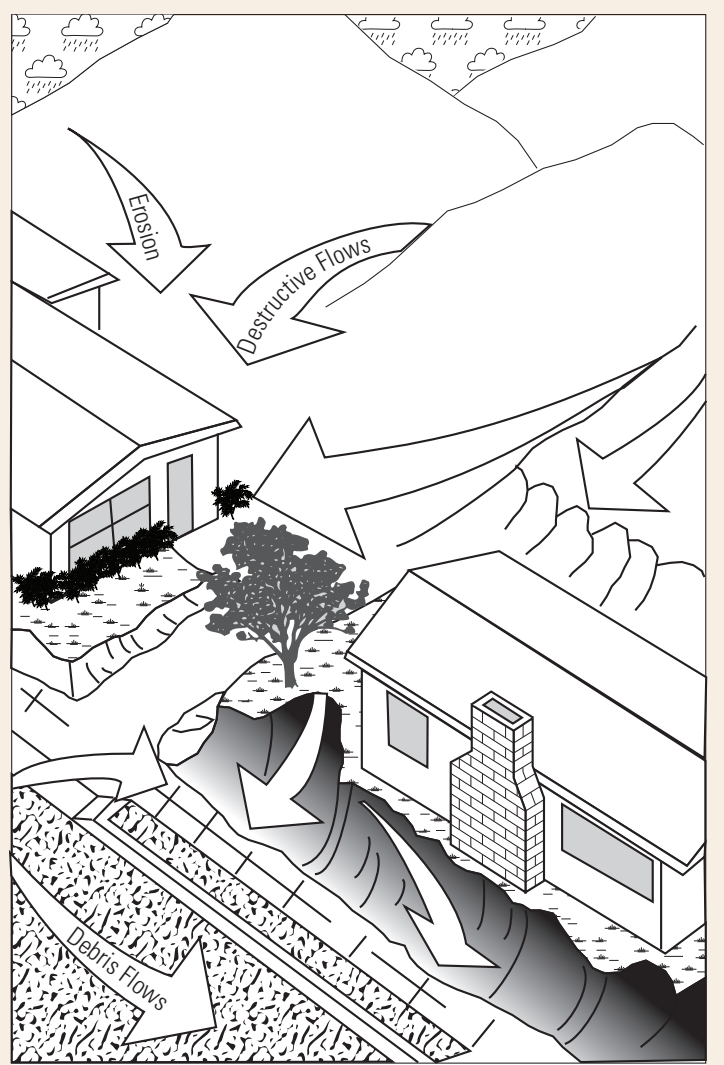

Figure C38. Schematic of an unprotected home, in the path of a debris flow and (or) "mudslide." Suggested methods to reduce the hazards from debris flows are shown in figure C39.

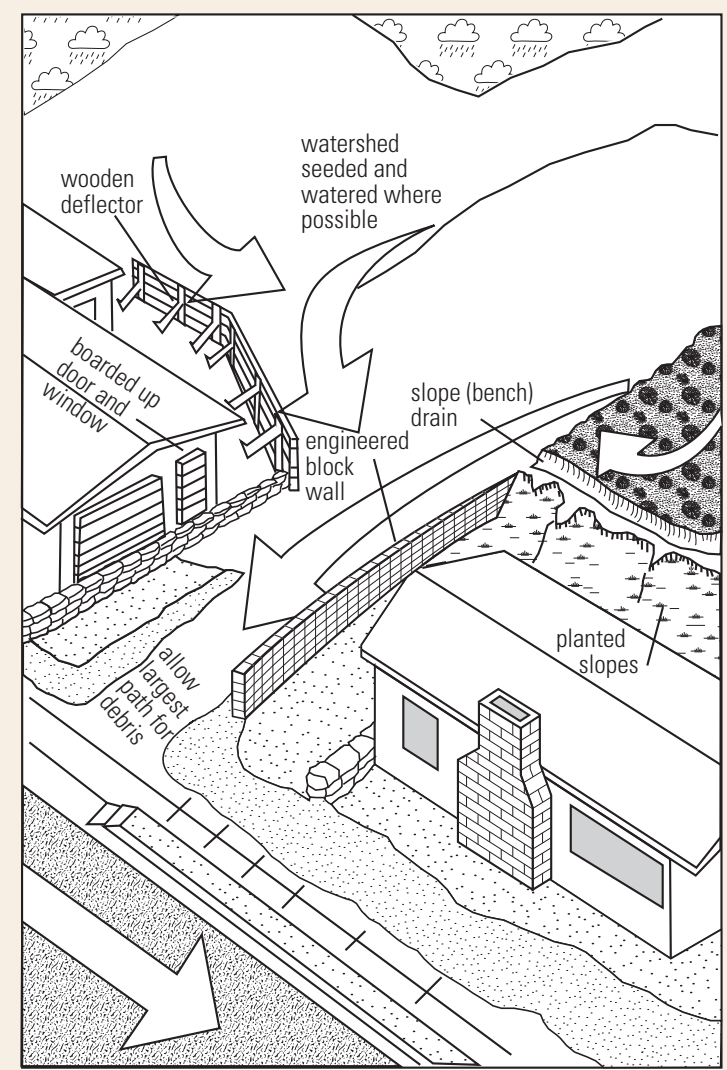

Figure C39. Schematic example of a house with protective structures in place. Shows construction of deflection walls and debris fences. Because of extreme force of impact associated with some debris flows, these and similar structures should be carefully engineered and constructed. 


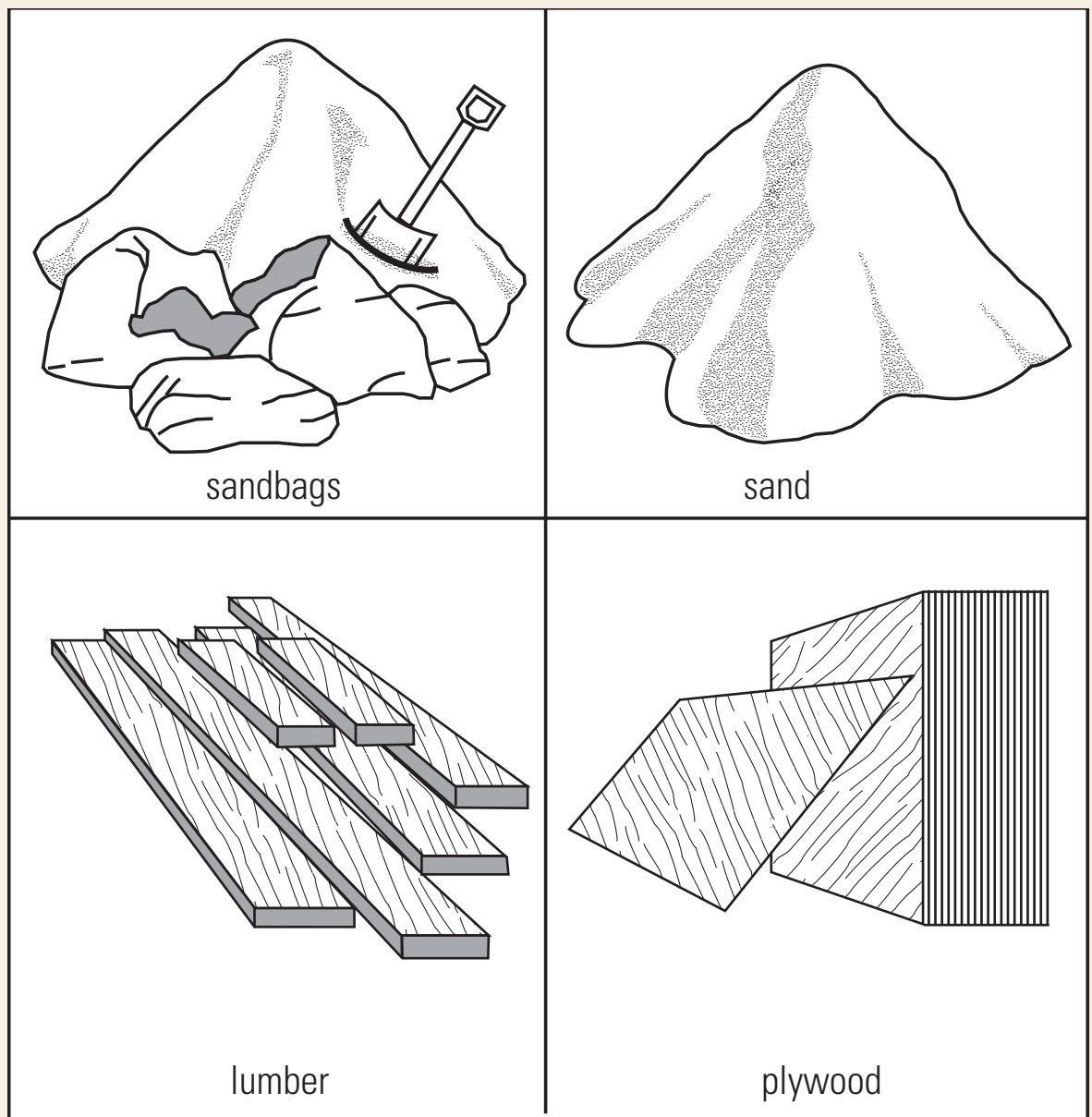

Figure C40. Schematic of typical materials, usually available in many regions of the world, for helping to reduce damage from flood/debris-flow events. 


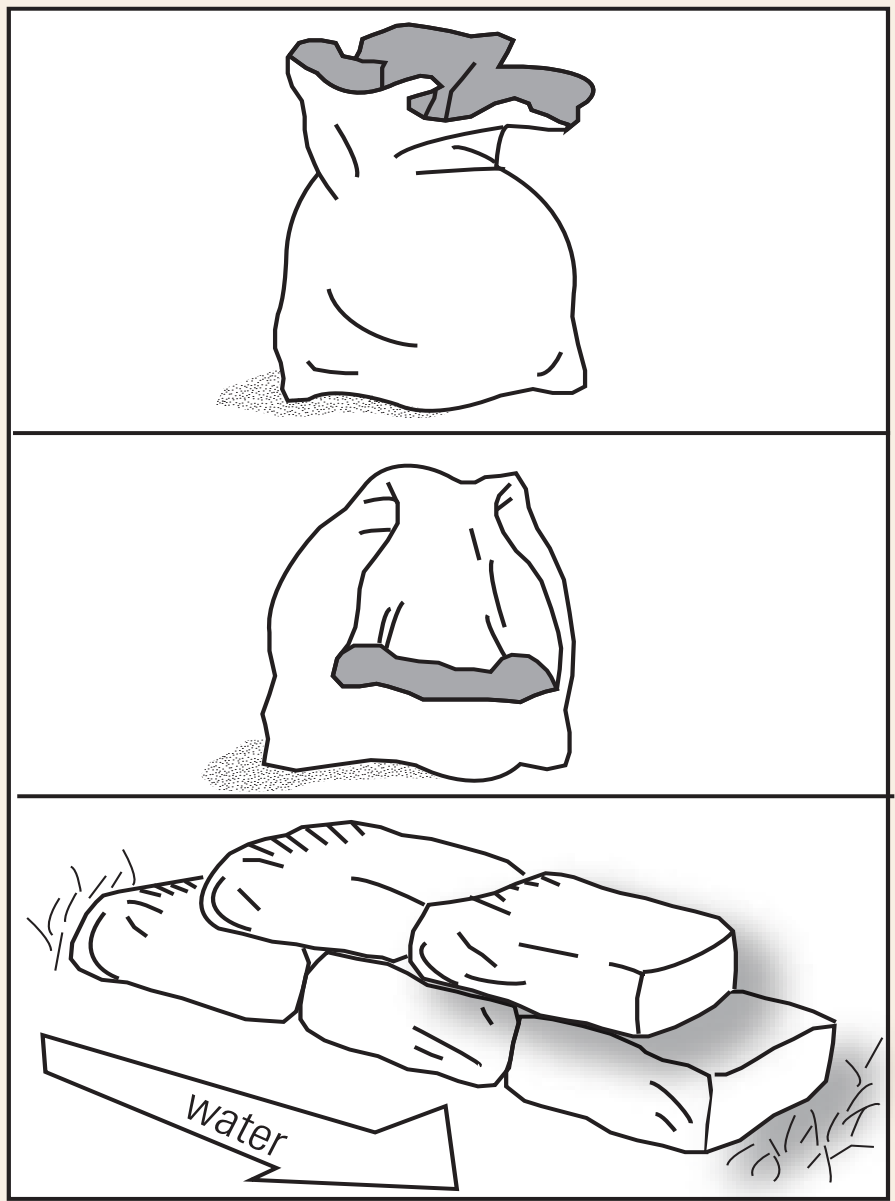

Figure C41. Sandbags are basically for low-flow protection of up to 0.6 meter (2 feet). Protection from higher flows requires a more permanent type of structure. It should be noted that sandbags will not seal out water.

Note: The ideal material for sandbags is sand, and bags should not be filled with wood chips, paper, trash, or other materials. Sand- and soil-filled burlap sandbags deteriorate when exposed for several months to continued wetting and drying. If bags are placed too early, they may not be effective when needed. 


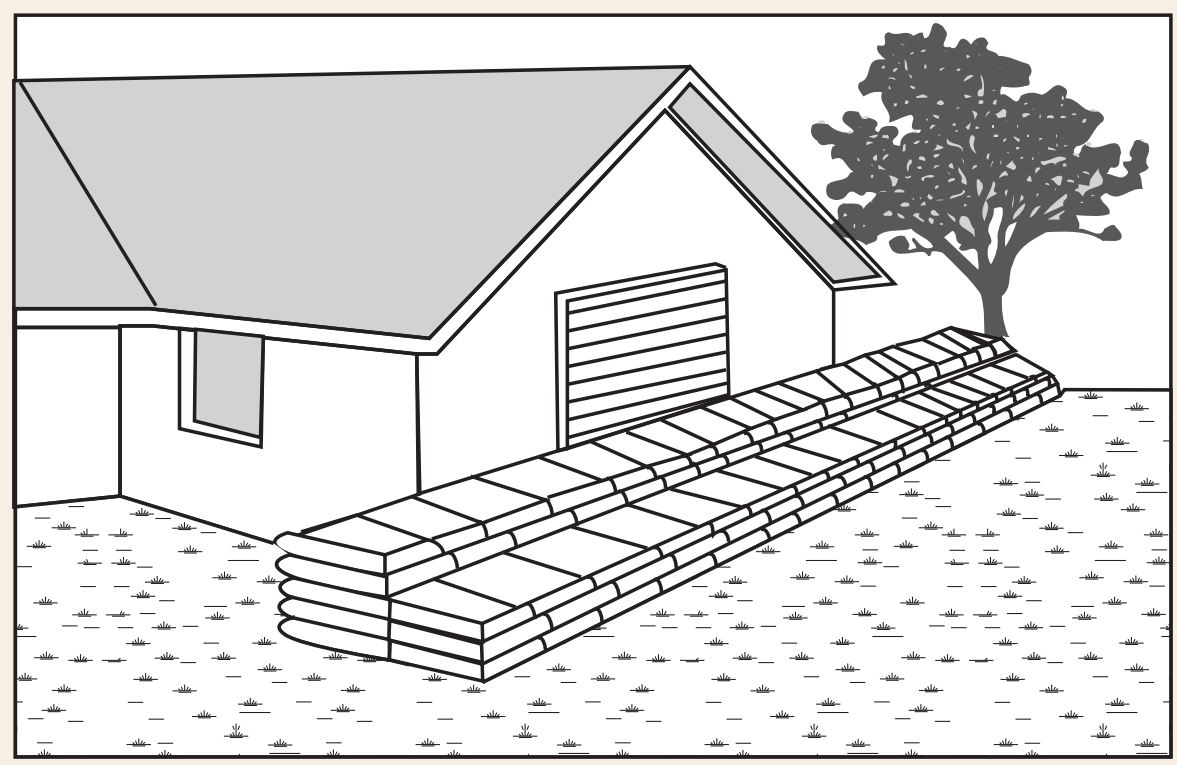

Figure C42. Schematic of a typical placement of sandbags for home protection (individual situations may vary in layout and orientation).

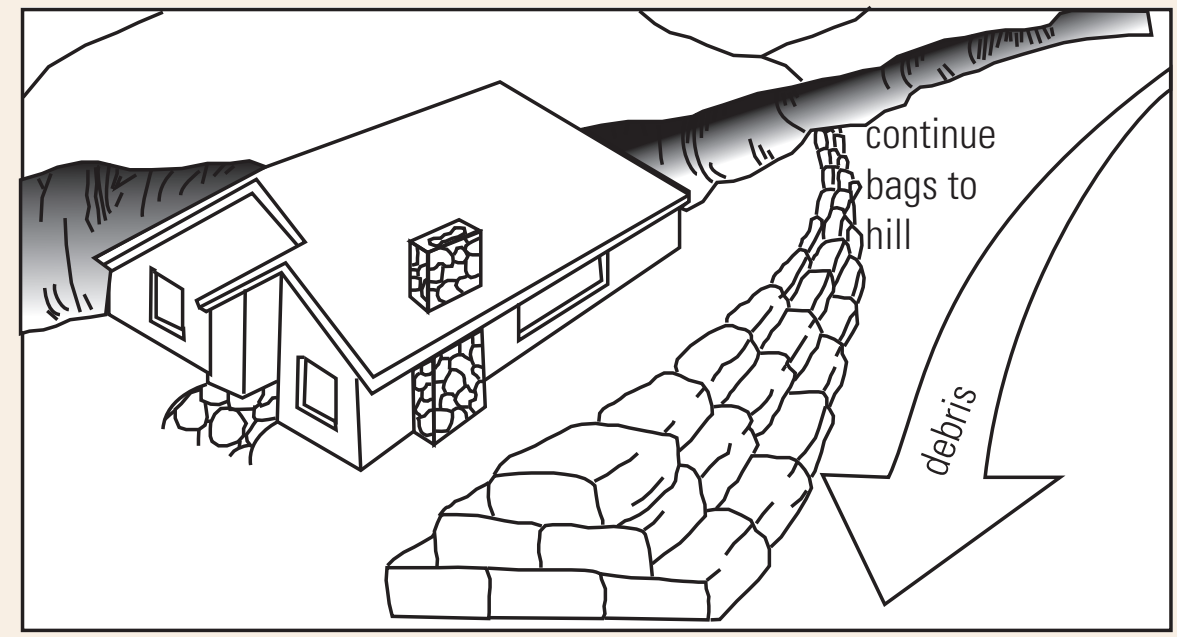

Figure C43. Sandbags help in directing debris away from buildings.

Caution: It is not advisable to use straw or bales of hay instead of sandbags. They do not perform as well as sandbags and may be washed away. 


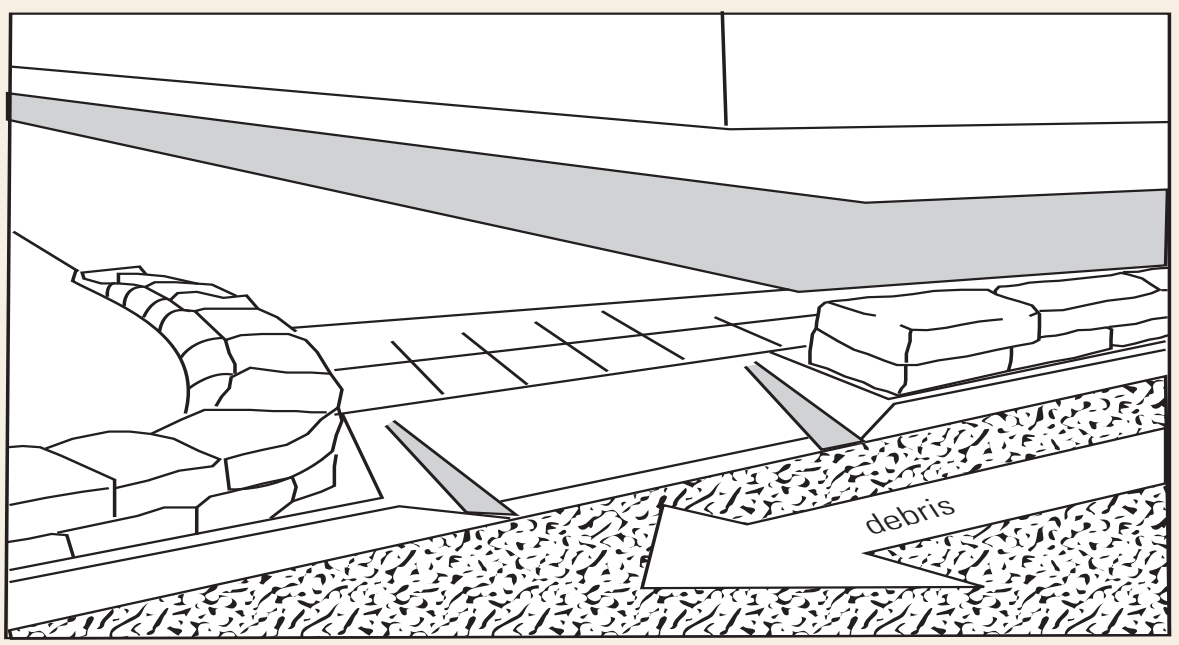

Figure C44. Controlling debris or stormflows in streets with sandbags.

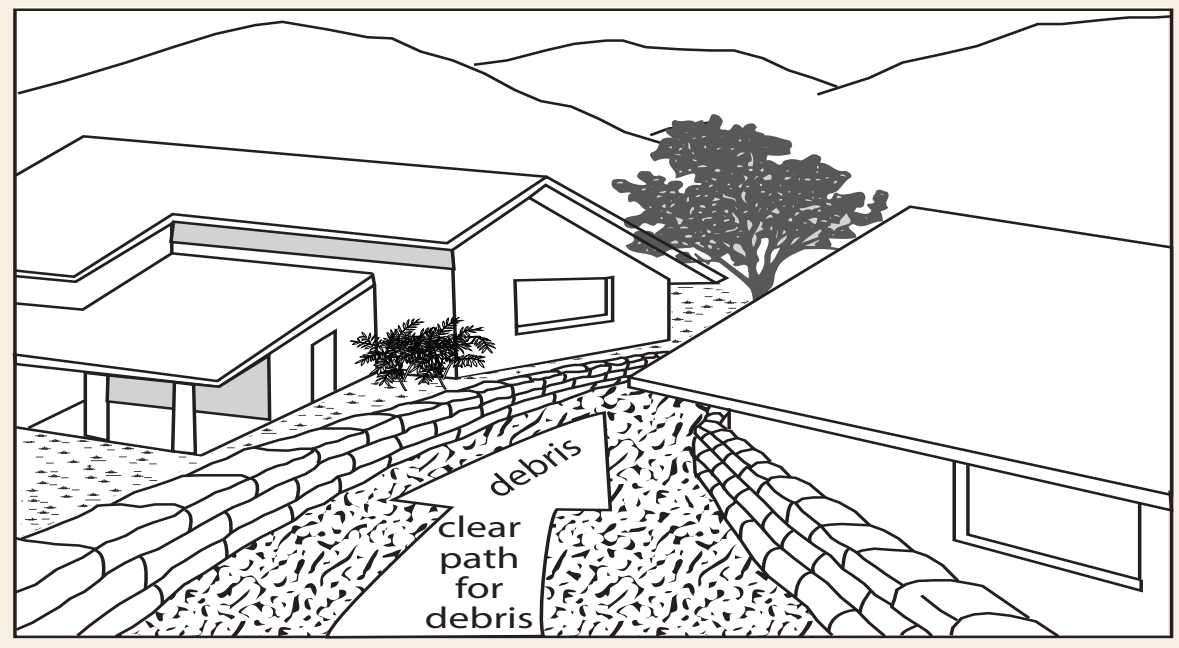

Figure C45. Directing flows between buildings by using sandbags. 


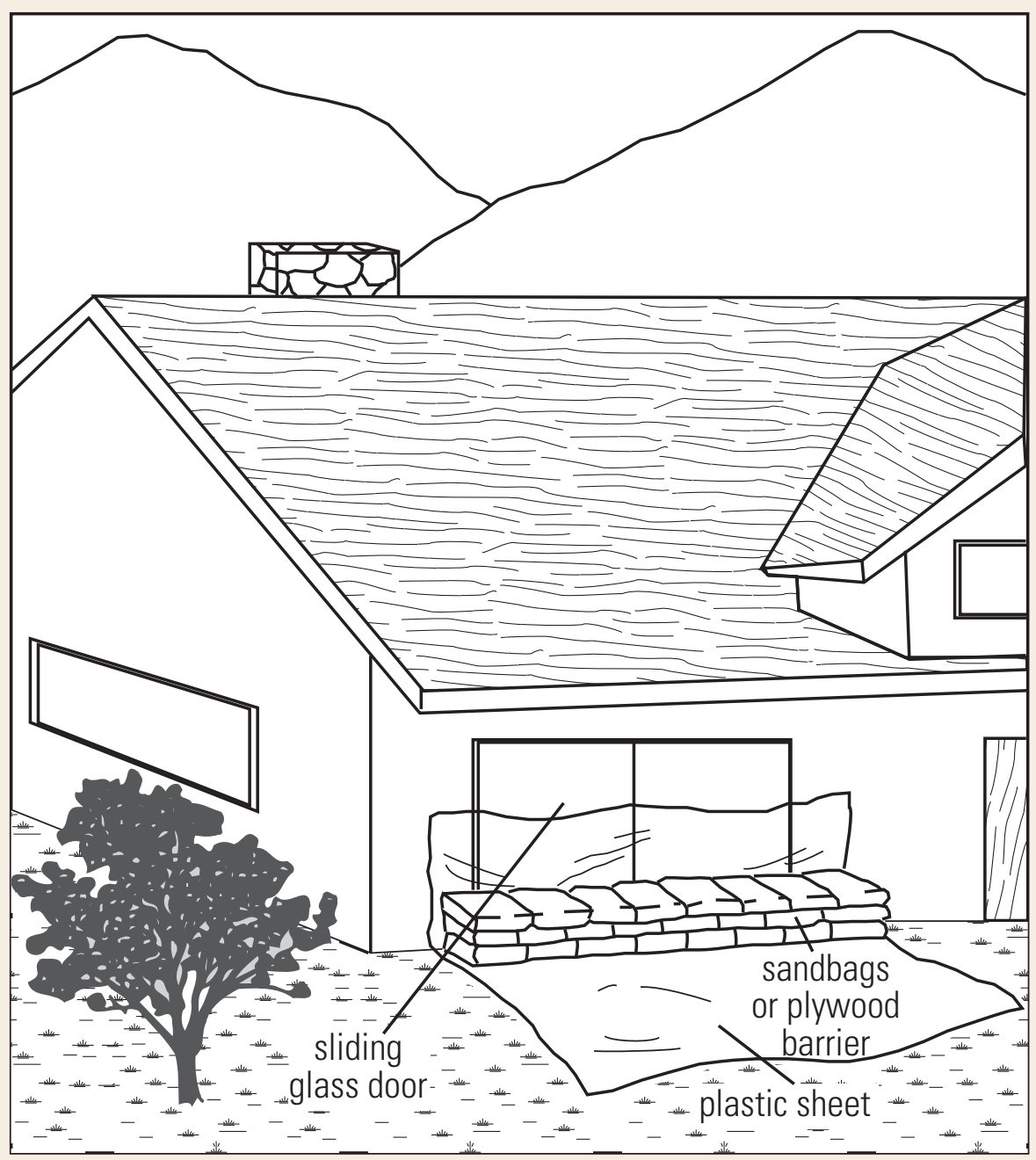

Figure C46. Sliding glass door sealing - Control of flows to prevent seeping into sliding glass door by using sandbags and plastic sheeting. 


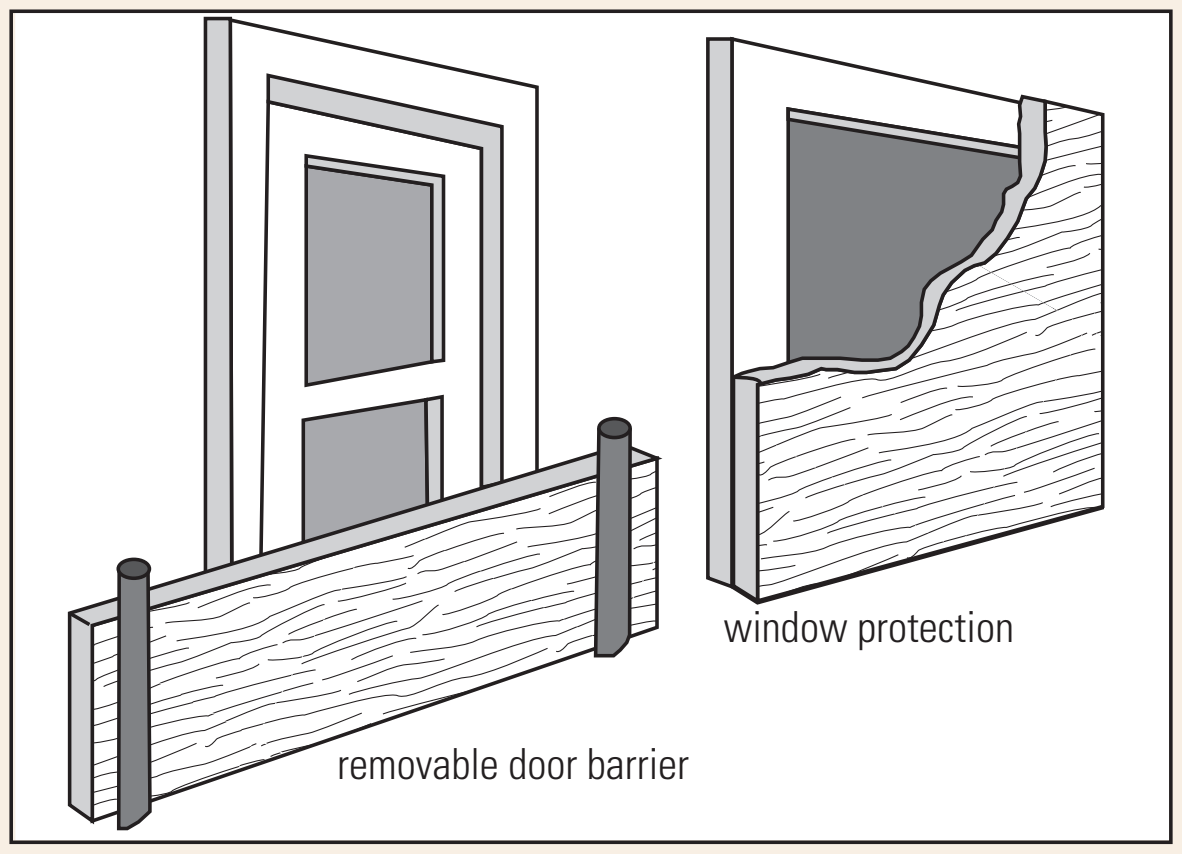

Figure C47. Typical window and door protection, using removable plywood.

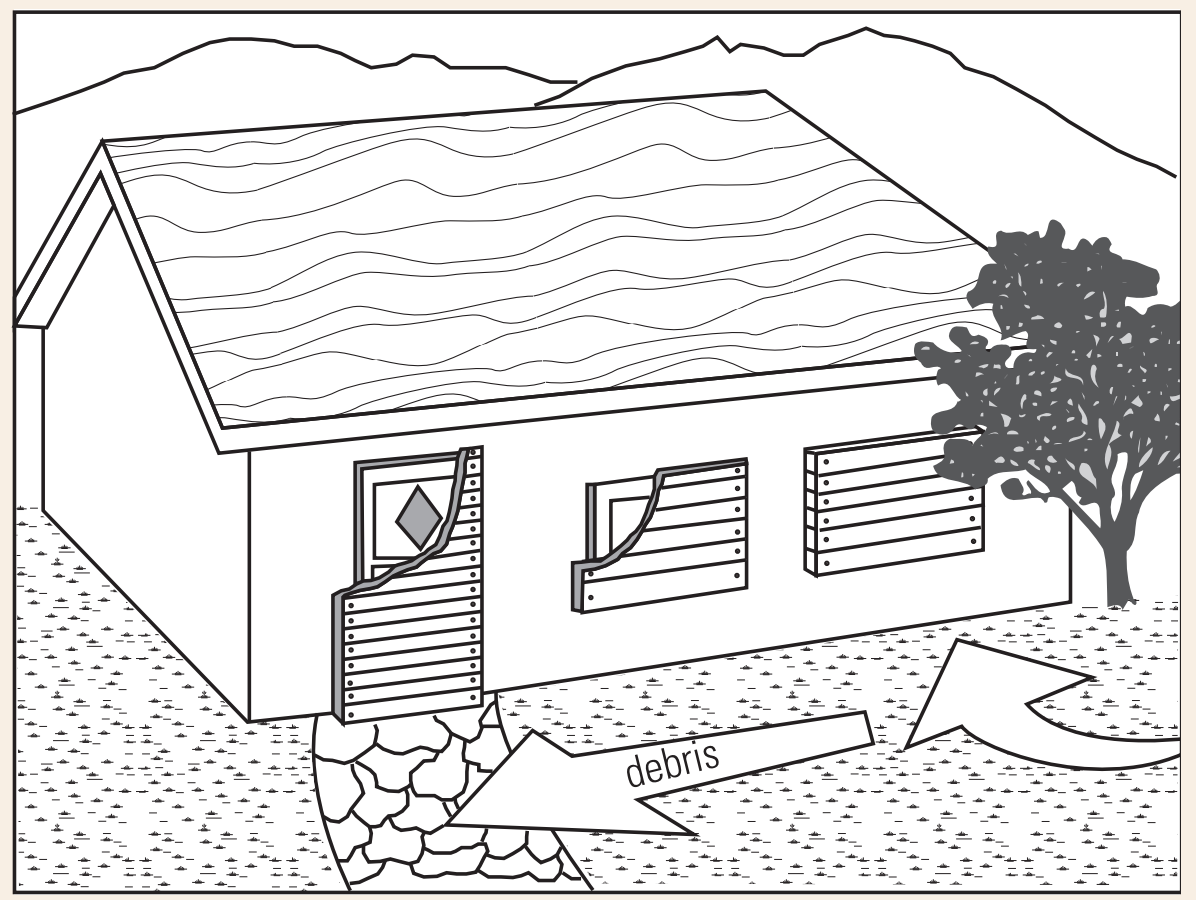

Figure C48. Nailing up plywood or lumber for window and door protection. 


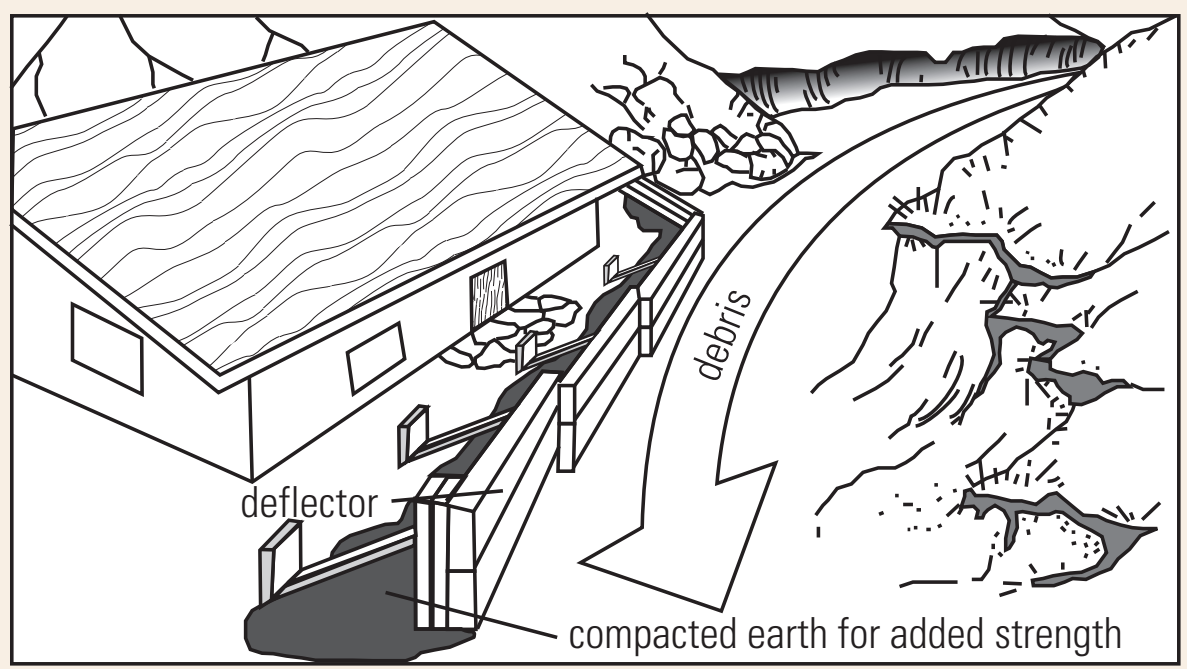

Figure C49. This is a timber deflector, which is more permanent than sandbags.

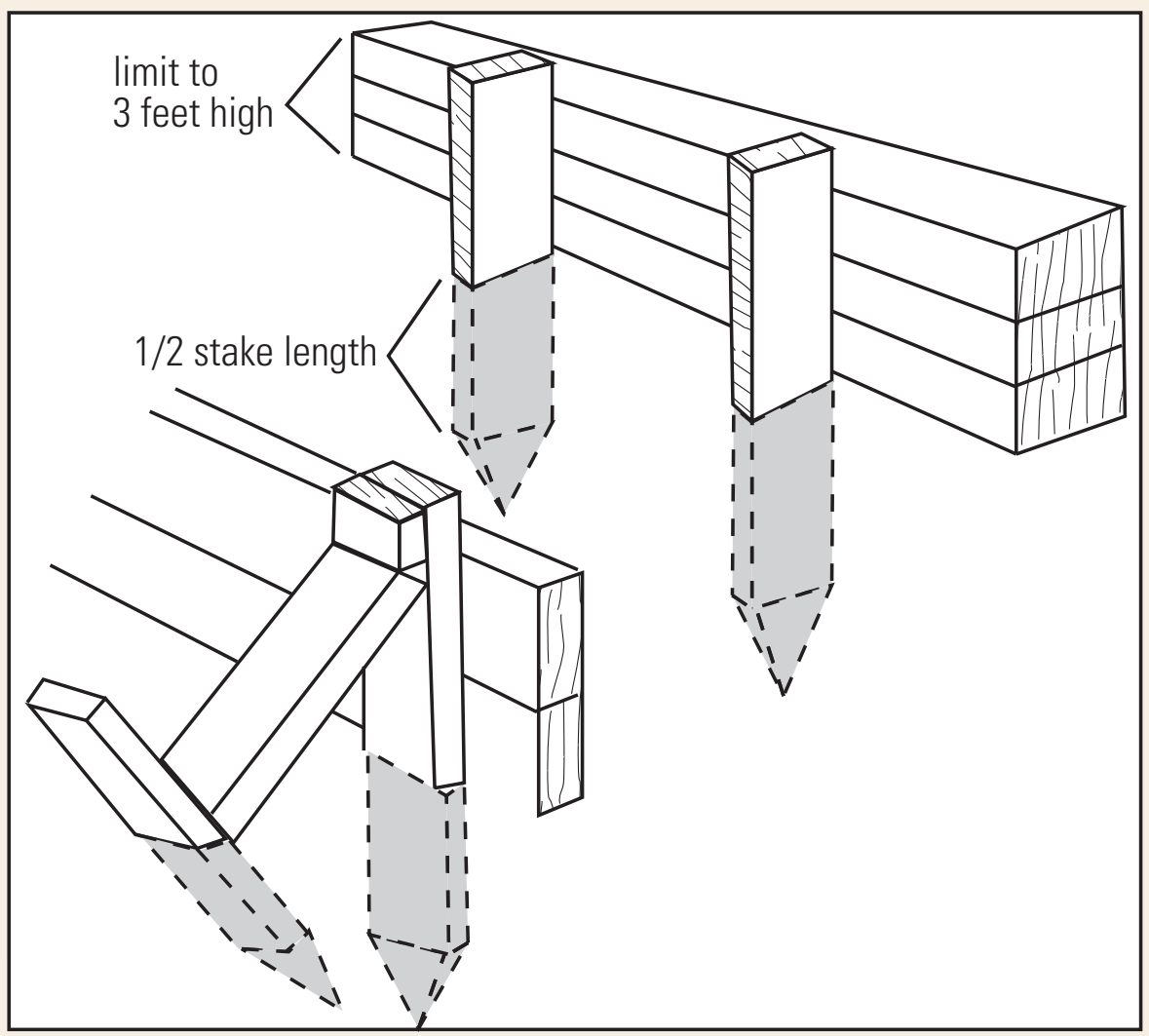

Figure C50. Closeup schematic of a timber deflector installation technique. 


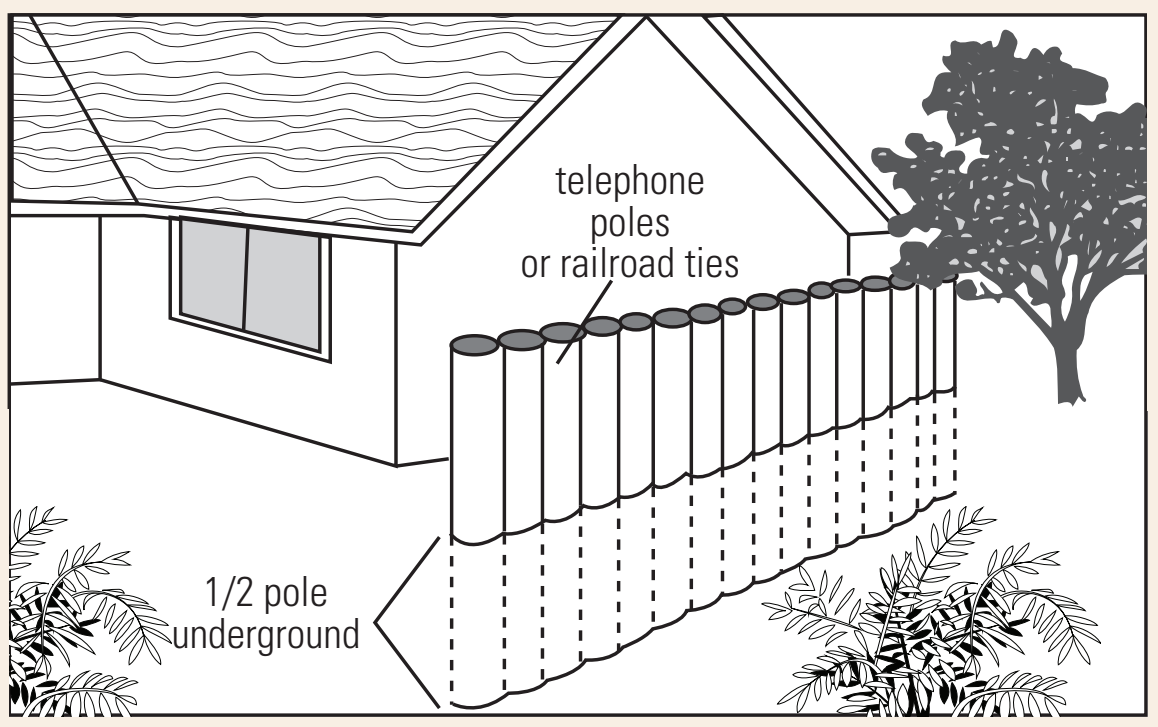

Figure C51. An alternative to timber deflectors-telephone pole sections or railroad tie barrier.

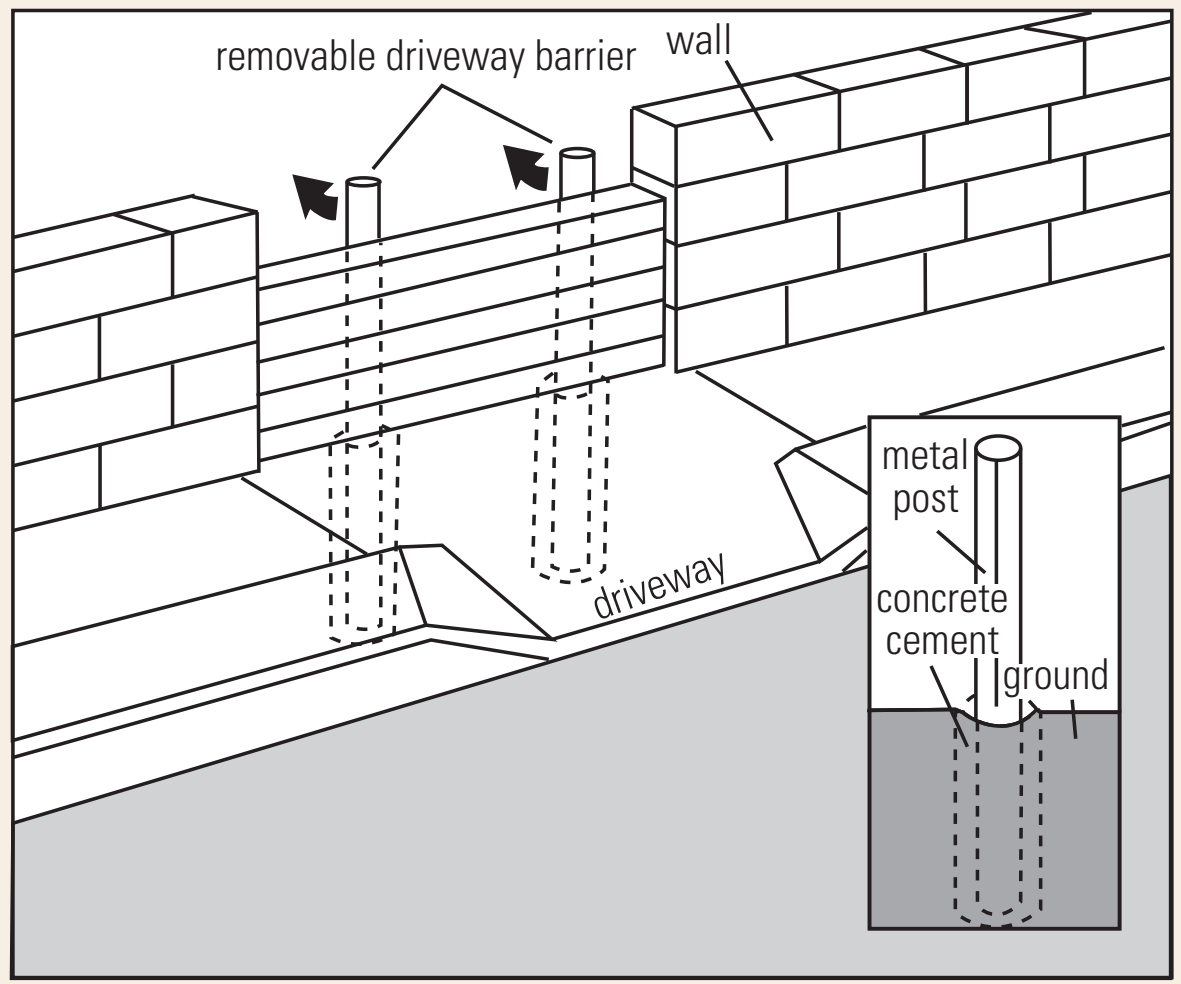

Figure C52. Removable driveway barrier. The metal posts can be removed and restored as needed, as they loosely fit into concrete casings in the ground 


\section{Basic Things to Remember Concerning Mitigation and Response to Debris-Flow and Other Landslide Hazards/Emergency Response}

Sandbags, tools, and sheets of plastic may be useful during heavy rains (the plastic can be used to protect and waterproof some items). Keep them available, where possible. Help others in the community that may not be able to reinforce their dwellings, such as the disabled or elderly. Educate children in mitigation techniques. Mitigation techniques are the most effective when used by as many members of a community as possible.

- If unusual cracks, settling, or earth slippage starts, it is recommended that people consult a municipal agent (such as an emergency manager) and (or) a qualified civil engineer or geologist as soon as possible.

- It is suggested that slopes or drainage areas not be altered without expert advice. It is always best to consult a professional or someone with experience in this type of work.

- Normal property drainage usually flows to the street or an approved drainage device. When landscaping, homeowners or others should avoid disrupting flow patterns created when the property was originally graded. Obstructions such as patios, sidewalks, and decks should not be placed in side swales unless an alternate method of drainage is provided.

- Post illustrations in the form of simple schematics in public places, to help people implement mitigation techniques.

- It is advisable to have an emergency response plan for evacuation and relocation of populations that are threatened by landslide hazards. It is generally best to make sure everyone is aware of these procedures. 


\section{Landslide Dam Mitigation}

As previously mentioned, the primary hazard from landslide dams is flooding that can occur when a landslide dam fails, or flooding that occurs when the dam is overtopped by the ongoing flow of water backing up behind the dam. The following measures can be implemented when communities are faced with potential hazards from landslide dams:

\section{Diversion of inflow water before it reaches the lake formed by the landslide dam}

This can be done by diverting water from the stream into upstream reservoirs or irrigation systems. Although usually only a temporary measure, diversion may slow the filling of the lake enough to allow the application of a more long-term solution.

\section{Temporary drainage from the impoundment by pumps or siphons}

The rising water level can be controlled temporarily by means of pumps or siphons, causing the water to flow over the low point of the dam. This is usually a short-term (less than 1 to 2 years) measure that provides time for more extensive, long-term solutions.

For more information and further reading:

References 11, 12, 13, 20, 25, 26, 39, 42, and 46 


\section{Construction of an erosion-resistant spillway}

The most common method of stabilizing a landslide dam is to construct an erosion-resistant open-channel spillway either across the dam or across an adjacent abutment. When the overtopping by water occurs, flow is controlled by the spillway in much the same way that emergency spillways are constructed on engineered dams to control water level. An additional advantage of this type of spillway is that it allows for the lowering of the water level behind the dam, which helps lessen the upstream flooding that landslide dams may cause.

Spillways are not always successful in preventing dam breaching and downstream flooding; they sometimes fail due to retrogressive erosion (erosion from the spillway outlet to its intake) caused by high-velocity outlet flow. To prevent erosion by minimizing flow velocity, the spillway should be wide and shallow. If possible, it should be lined with erosion-resistant materials (commonly riprap), especially at the outlet. Often, check dams are installed along steeper grades of the spillway to prevent erosion. Spillways that fail due to erosion may have been partially successful because they limit the total volume of the water behind the dam, thus reducing total discharge even if the dam breaches entirely.

Open-channel spillways across the landslide dam commonly are excavated by bulldozers; however, draglines, backhoes, explosives, and hand labor all have been used. Excavation can be dangerous in rough terrain, so an access road has to be constructed.

\section{Drainage tunnel through an abutment}

A long-term method of preventing overtopping and breaching of a landslide dam is construction of a diversion tunnel through an adjacent dam abutment. Because large landslide dams commonly occur in mountain canyons, they usually have bedrock abutments; thus rock-tunneling methods commonly are used. Figure C53 shows the Thistle, Utah, landslide in the United States, triggered by the El Niño conditions of 1983. Heavy rains the previous autumn and rapid snowmelt caused the massive failure. For further reading please see Reference 31.

The Thistle landslide also destroyed sections of both a major highway and a main line of a railroad track. After a tunnel was excavated through the mountain trains could continue to travel the route. The motorway (highway) was rerouted over a saddle, away from the landslide deposit (fig. 54).

The landslide will be left as it is, as it is too massive to remove. The landslide is still being monitored with instrumentatino by the State of Utah, and it has recently reactivated. Reactivation is another peril from landslide dams such as Thistle (fig. C55). 


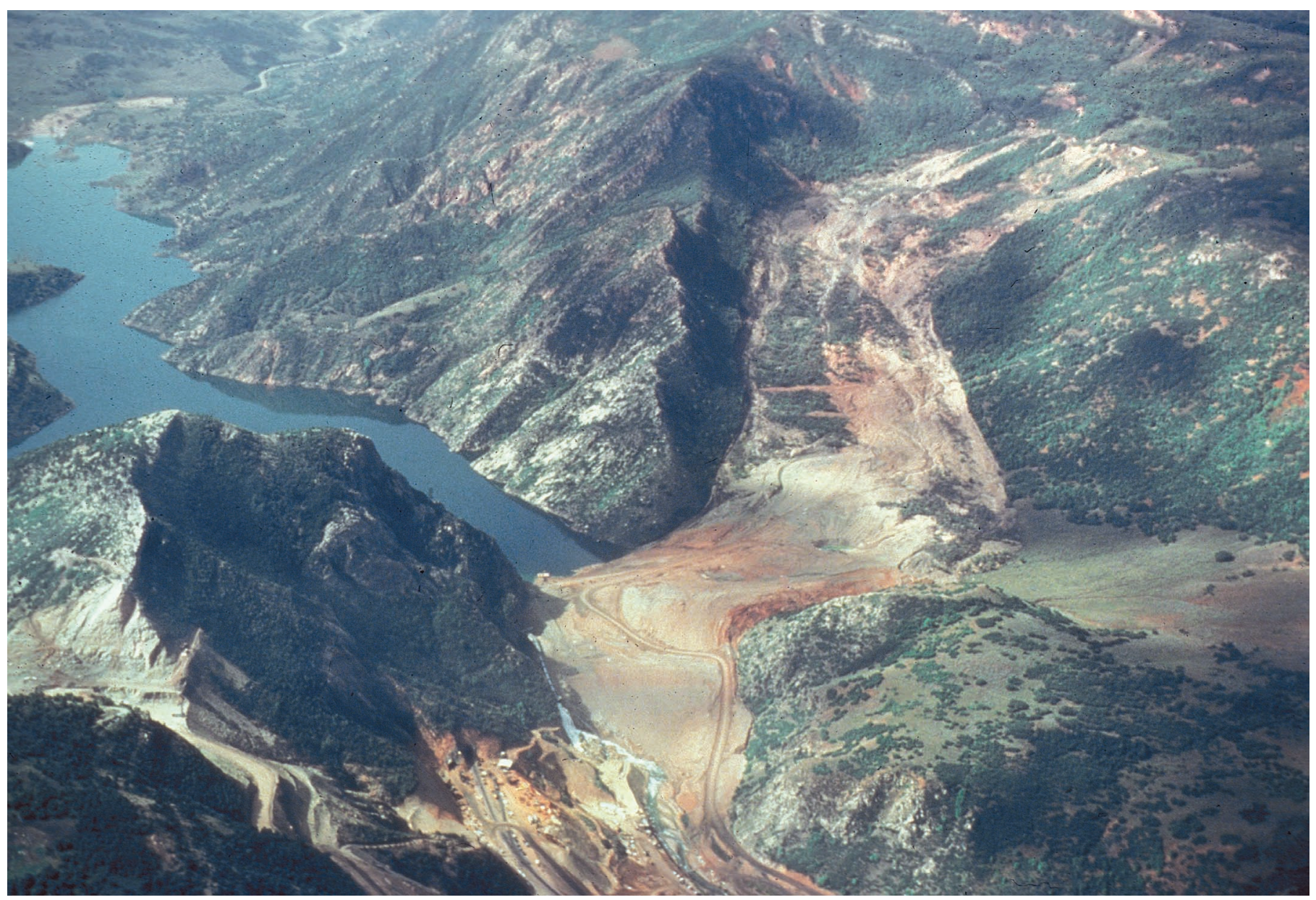

Figure C53. The Thistle landslide in Utah, USA, 1983. This landslide dammed a river, which formed a lake (called "Thistle Lake") behind the dam, flooding the town of Thistle. (Photograph by Robert L. Schuster, U.S. Geological Survey.) 


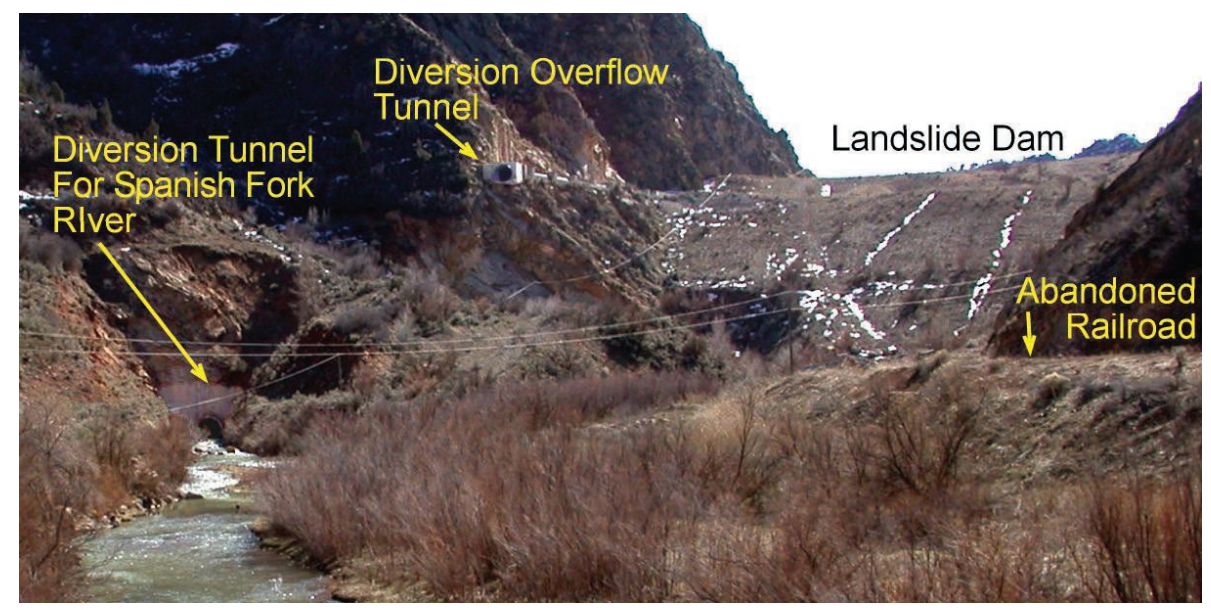

Figure C54. Closeup view of mitigation measures taken to reduce the impact of the Thistle landslide dam, showing the tunnel for the river, and the diversion overflow tunnel. (Photograph courtesy of the Utah Geological Survey).

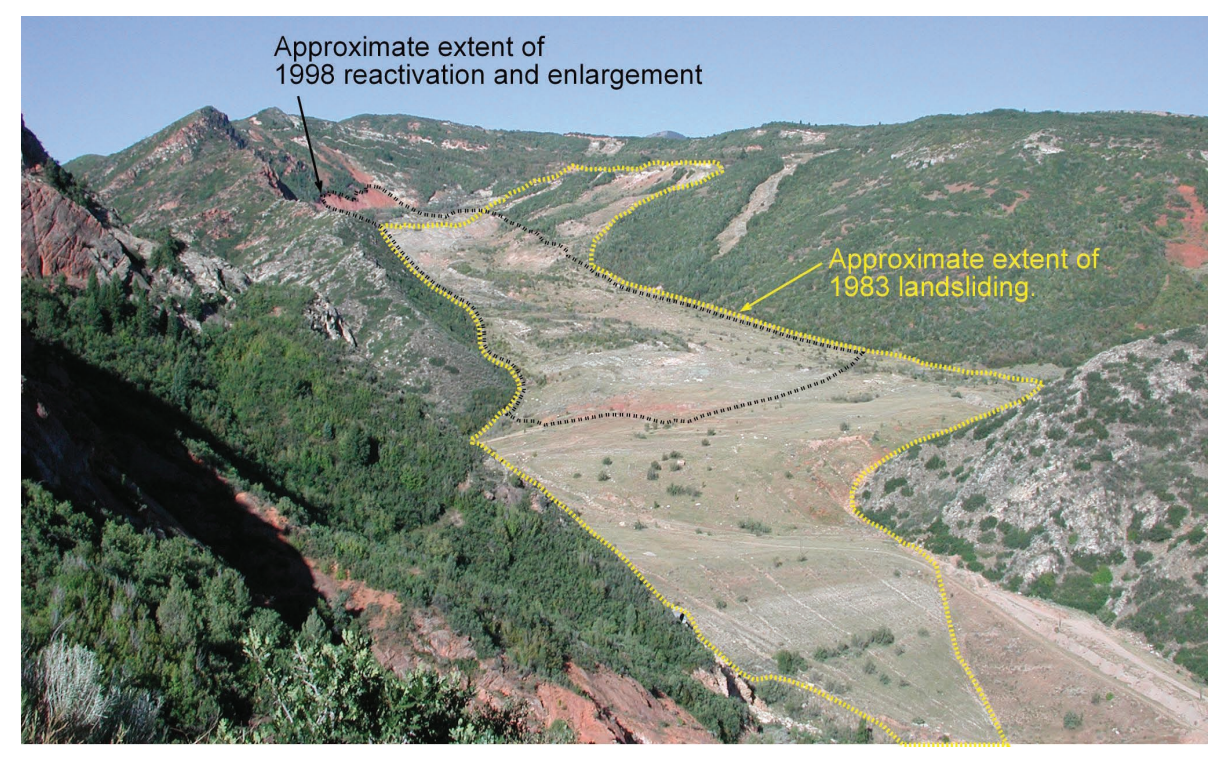

Figure C55. Photograph with annotations showing the reactivation and enlargement of the Thistle landslide dam. (Photograph courtesy of the Utah Geological Survey.) 


\section{Appendix D. \\ Sample Safety Information for Landslides/ \\ Debris Flows- \\ Suitable for Posting and (or) Distributing}

Adapt as needed to suit local conditions and (or) circumstances 


\section{What Can You Do If You Live Near Steep Hills?}

\section{Prior to Intense Storms:}

- Become familiar with the land around you. Learn whether debris flows have occurred in your area by contacting local officials, emergency management officials, State geological surveys or departments of natural resources, and university departments of geology. Slopes where debris flows have occurred in the past are likely to experience them in the future.

- Support your local government in efforts to develop and enforce land-use and building ordinances that regulate construction in areas susceptible to landslides and debris flows. Buildings should be located away from steep slopes, streams and rivers, intermittent-stream channels, and the mouths of mountain channels.

- Watch the patterns of stormwater drainage on slopes near your home and note especially the places where runoff water converges, increasing flow over soil-covered slopes. Watch the hillsides around your home for any signs of land movement, such as small landslides or debris flows or progressively tilting trees.

- Contact your local authorities to learn about the emergency-response and evacuation plans for your area and develop your own emergency plans for your family and business.

\section{During Intense Storms:}

- Stay alert and stay awake! Many debris-flow fatalities occur when people are sleeping. Listen to a radio for warnings of intense rainfall. Be aware that intense short bursts of rain may be particularly dangerous, especially after longer periods of heavy rainfall and damp weather.

- If you are in an area susceptible to landslides and debris flows, consider leaving if it is safe to do so. Remember that travel during an intense storm is hazardous.

- Listen for any unusual sounds that might indicate moving debris, such as trees cracking or boulders knocking together. A trickle of flowing or falling mud or debris may precede larger flows. If you are near a stream or channel, be alert for any sudden increase or decrease in water flow and for a change from clear to muddy water. Such changes may indicate debris-flow activity upstream, so be prepared to move quickly. Don't delay! Save yourself, not your belongings.

- Be especially alert when driving. Embankments along roadsides are particularly susceptible to landslides. Watch the road for collapsed pavement, mud, fallen rocks, and other indications of possible debris flows.

\section{What to do if you suspect imminent landslide danger:}

- Evacuate, if possible.

- Contact your local fire, police, or public works department.

- Inform affected neighbors.

\section{After landslides occur:}

- It is best to stay away from the slide area, as there may be danger of additional slides; however, this is not always possible or desirable.

- Check for injured and trapped persons near the slide area. Give first aid if trained, and call for help.

- Remember to help your neighbors who may require special assistance-infants, elderly people, and people with disabilities.

- Listen to a battery-operated radio or television for the latest emergency information.

- Remember that flooding may occur after a mudflow or a landslide.

- Check for damaged utility lines. Report any damage to the utility company.

- Check the building foundation, chimney, and surrounding land for damage.

- Replant damaged ground as soon as possible because erosion caused by loss of ground cover can lead to flash flooding.

- Seek the advice of geotechnical expert for evaluating landslide hazards or designing corrective techniques to reduce landslide risk. 


\section{Index}

A

acoustic imagery 47

alluvial fan 60

\section{B}

backcasting 129

backfill $78,83,86,90$

bedding surface/plane 60

bedrock 20, 22, 29, 46, 47, 60, 62, 70, 86,124

benches 53,104

borehole 47, 60

\section{C}

check dams $60,82,83,111,124$

colluvium 60

\section{D}

debris avalanche 20,21, 37

debris basin 60

debris flow 5, 12, 16-18, 20, 26, 30, 50, $60,61,83,103,109,112,113$

delta-front landsliding 60

differential 6, 8, 60, 62, 63, 73, 129

digital elevation model (DEM) 60, 70

drains $78,86,88,93$

drawdown 22, 60, 64

drilling 47, 66, 88, 105

\section{E}

earthflow 5, 22-25, 39

electronic distance meter (EDM) 60

emergency $1,35,49,50,113,122,124$, 128

epicenter 60

excavation $6,8,22,35,52,76,77,79$, 88,94

expansive soils 60

\section{$\mathbf{F}$}

factor of safety 60,91

field reconnaissance 46

fracture 60

\section{G}

geodesic/geodetic measurements 60

Geographic Information System (GIS) 60

geologic hazard 60

geologic map 60, 68

geomorphology 46, 60

geophysical studies 60

glossary 57, 60, 63

\section{H}

hydraulic $60,61,88,95,106$

hydraulic seeding 95

hydrology 60

I

InSAR 58, 70, 72

Instrumentation 47, 74

interstitial water 61

\section{L}

lahar $18-20,33,61$

landslide dam 32, 36, 53, 60, 123, 124, 126

landslide hazard map 61, 69

landslide inventory maps 61,68

landslide maps 52, 67

landslide risk map 61

landslide susceptibility map 61, 68

lateral spread 15

LiDAR 57, 73

liquefaction 14, 18, 32, 61

lithology 60, 61

loess 61

\section{M}

mapping 46, 49, 61, 66, 69, 73

mitigation $1,6,8,20,22,24,26,34$, $36,52-54,56-58,61,62,75,96$, $109,113,122,126$

monitoring 10, 18, 46, 47, 52, 58, 74

mudflow 61,128

mudslide 61,113

\section{$\mathbf{P}$}

perched ground water 61

pore water, 61

\section{$\mathbf{R}$}

reconnaissance geology/mapping 61

relief 61

remote sensing 73

retaining walls $6,10,12,24,25,44,52$, $53,90,99,112$

risk $5,26,48,58,61,70,76,128$

rockfall $5,7,49,50,53,79,99,100$, $102,104,107,129$

rock mechanics 61,76

rotational landslides 76

\section{S}

safety $1,36,48-50,60,91,127$

sag pond 61 sandbags 115-118, 120

sea cliff retreat 61

seepage 61

shear $6,10,16,22,24,26,61,80$

slurry $16,61,95$

soil mechanics 61

stress $24,60-62$

sturzstroms 62

subsidence $14,60,62$

surficial geology $26,46,62,70$

swelling soils $44,60,62$

\section{$\mathbf{T}$}

tensile stress 62

timber cribs 96

topple $5,8,9$

triggering mechanism 18

W

weathering $6,8,24,62,64,107,109$

wildfire 28,109

Z

zonation 58,62 
Publishing support provided by:

Denver Publishing Service Center

Manuscript approved for publication May 5, 2008

Edited by Mary Kidd

Designed and prepared by Margo VanAlstine with assistance from Carol Quesenberry

For more information concerning this publication, contact:

Team Chief Scientist, USGS Geologic Hazards

Box 25046, Mail Stop 966

Denver, CO 80225

(303)273-8579

Or visit the Geologic Hazards Team Web site at: http://geohazards.cr.usgs.gov/ 


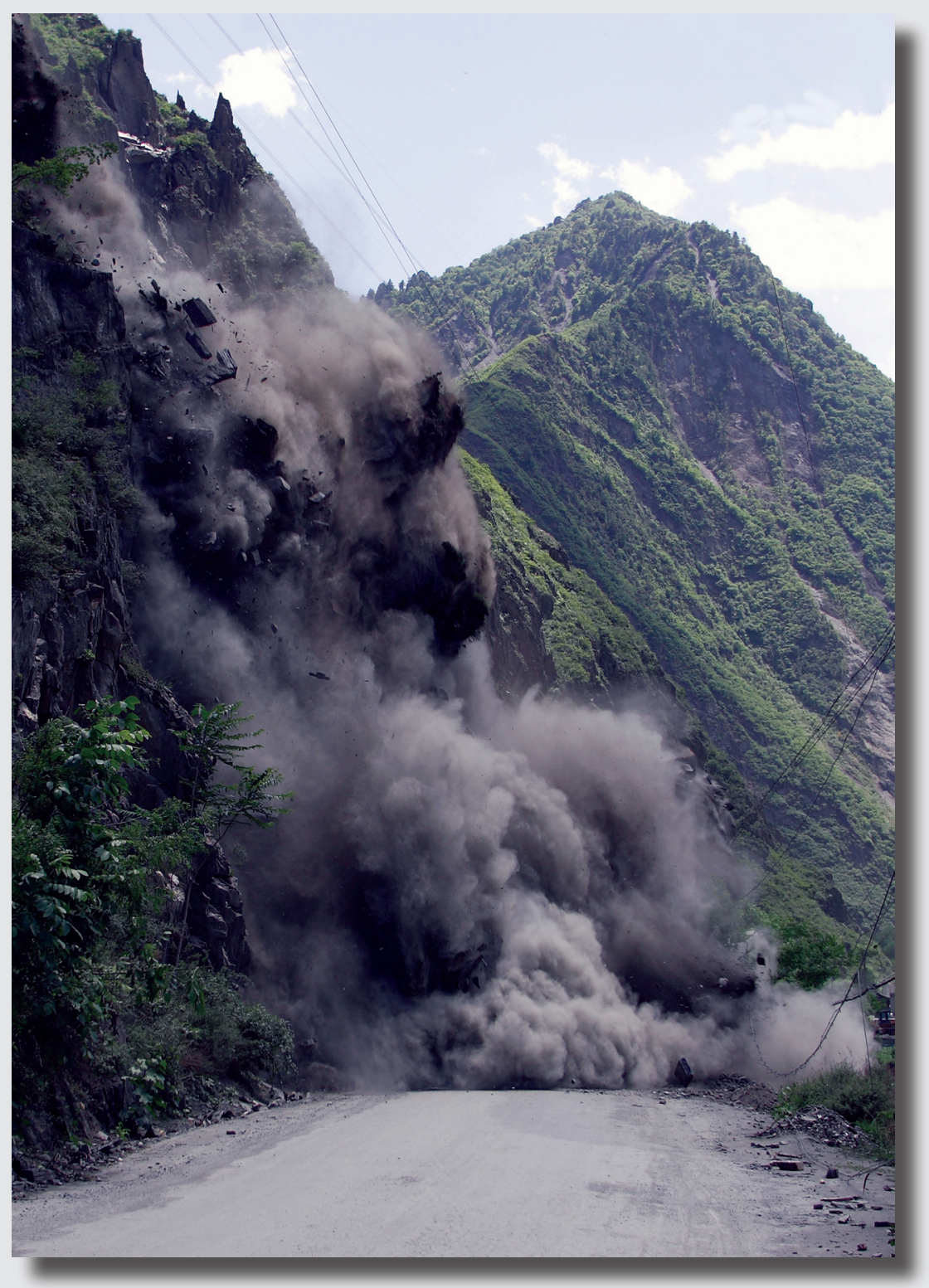

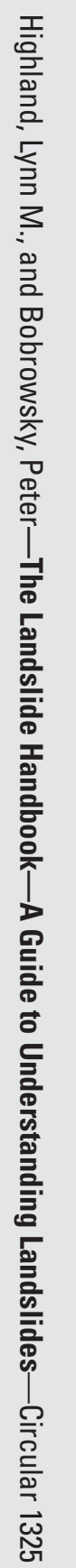

ISBN $978-141132226-4$

8 Printed on recycled paper

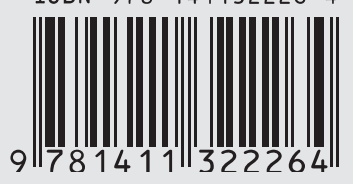

